Review

\title{
Bioalcohol Reforming: An Overview of the Recent Advances for the Enhancement of Catalyst Stability
}

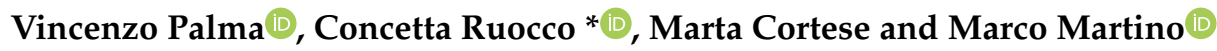 \\ Department of Industrial Engineering, University of Salerno, Via Giovanni Paolo II 132, \\ 84084 Fisciano (SA), Italy; vpalma@unisa.it (V.P.); mcortese@unisa.it (M.C.); mamartino@unisa.it (M.M.) \\ * Correspondence: cruocco@unisa.it; Tel.: +39-089-964027
}

Received: 13 May 2020; Accepted: 9 June 2020; Published: 12 June 2020

\begin{abstract}
The growing demand for energy production highlights the shortage of traditional resources and the related environmental issues. The adoption of bioalcohols (i.e., alcohols produced from biomass or biological routes) is progressively becoming an interesting approach that is used to restrict the consumption of fossil fuels. Bioethanol, biomethanol, bioglycerol, and other bioalcohols (propanol and butanol) represent attractive feedstocks for catalytic reforming and production of hydrogen, which is considered the fuel of the future. Different processes are already available, including steam reforming, oxidative reforming, dry reforming, and aqueous-phase reforming. Achieving the desired hydrogen selectivity is one of the main challenges, due to the occurrence of side reactions that cause coke formation and catalyst deactivation. The aims of this review are related to the critical identification of the formation of carbon roots and the deactivation of catalysts in bioalcohol reforming reactions. Furthermore, attention is focused on the strategies used to improve the durability and stability of the catalysts, with particular attention paid to the innovative formulations developed over the last 5 years.
\end{abstract}

Keywords: hydrogen; bioalcohol; reforming; coke; catalyst stability; active phase; support; promoter

\section{Summary}

1 Introduction

2 Bioethanol reforming

2.1 The influence of the active phase

2.2 The role of the support

2.3 The effect of the addition of promoters

3 (Oxidative) Biomethanol steam reforming

Pag. 2

3.1 The influence of the active phase
3.2 The role of the support

Pag. 3

Pag. 8

Pag. 12

Pag. 13

Pag. 19

Pag. 20

Pag. 25

3.3 The effect of the addition of promoters

Pag. 27

3.4 Unconventional reactor configuration, simulation, and theoretical studies

Pag. 32

3.5 Oxidative steam reforming of methanol

Pag. 36

Bioglycerol reforming

4.1 The influence of the active phase

4.2 The role of the support

4.3 The effect of the addition of promoters

Pag. 39

Pag. 42

Pag. 43

Other bioalcohol reforming

Pag. 46

Pag. 50

5.1 The influence of the active phase

Pag. 51

5.2 The role of the support

Pag. 53

5.3 The effect of the addition of promoters $\quad$ Pag. 54

6 Conclusions

Pag. 54 


\section{Introduction}

The search for clean technology approaches able to assure safe and sustainable energy production is increasingly gaining ground due to the heavy impacts of fossil fuels on the world economy (oil price fluctuation), global warming, and human health [1,2]. An effective solution proposed to reduce the consumption of conventional feedstocks involves the use of hydrogen as an energetic vector, which leads to no or very low carbon emissions, as well as the release of atmospheric pollutants [3]. Steam reforming of natural gas is the most widespread technology for hydrogen production, and applying the same technology to new-generation (biomass-derived) fuels could offer significant energy and environmental advantages [4]. Biomass is abundantly available in different forms. The use of biomass for energy generation results in a neutral carbon balance; only trace amounts of sulphur and heavy metals are present in biomass compared to fossil fuels, thus limiting the formation of harmful substances [5]. Among the available fuels produced from biomass, bioalcohols are emerging as competitive sources for hydrogen production via reforming [6-8]. Bioalcohols (i.e., alcohols generated from biomass or biological routes) can be produced from different feedstocks, including crops, agricultural and forestry waste, and food waste [9]. First-generation biofuels are produced from sugar, starch, oil-bearing crops, or animal fats. Bioethanol is mainly obtained via fermentation of sugar cane or starches, while butanol and propanol are formed as co-products via well-established technologies [10]. Wood, agricultural residues, forestry residues (cellulosic, hemicelluloses, or lignin), organic waste, food waste, and specific biomass crops are the feedstocks used for second-generation bioalcohols. Bioethanol and biobutanol can be produced via fermentation of lignocellulosic sugars via different microorganisms; for the latter, the process is more difficult and not commercialized yet (only pilot plants are available) [11]. Ethanol and butanol can also be derived from algae (third-generation bioalcohols) [12]. Bioglycerol is produced during biodiesel generation via transesterification of triglycerides, using vegetable oil as the feedstock [13]. In addition, glycerol can also be generated as a by-product, along with bioethanol (consuming up to $10 \%$ of the weight of the employed sugar) [14]. As an alternative to the conventional approaches for methanol production (which employ natural gas or coal as feedstocks), other routes are available, mainly involving biomass gasification [15] (including the conversion of municipal solid waste [16], animal waste, and agriculture wastes [17]) and $\mathrm{CO}_{2}$ hydrogenation [18].

Bioalcohol conversion (denoted as $\mathrm{X}$ ) to hydrogen can follow different routes, including steam reforming (Equation (1)), oxidative steam reforming (Equation (2)), dry reforming (Equation (3)), and aqueous-phase reforming (Equation (4)) [8]. Among these processes, according to the stoichiometry of the reaction, steam reforming gives the highest hydrogen yields. However, several side reactions may occur during reforming, which besides affecting the $\mathrm{H}_{2}$ selectivity, may also be responsible for carbon formation and catalyst deactivation. In this regard, the addition of oxygen via the oxidative process has been investigated as a viable route to mitigate carbon deposition $[19,20]$. The main pathways favoring coke formation during reforming include the Boudouard reaction, decomposition of carbon-containing intermediates (i.e., $\mathrm{CH}_{4}$ ), dehydration, and subsequent polymerization reactions [21]. The same intermediates participating in the main reactions, in fact, may also be involved in coking pathways, while the contribution of side reactions depends on the operating conditions and the nature of both the active metal and the selected support [22]. In particular, a high water content and oxygen co-feeding disadvantage carbon formation $[23,24]$, while the effect of the temperature on coke selectivity depends on the substrate, which influences the nature of the carbon formed and the effects of the coke gasification reactions $[25,26]$. In fact, it is clear that the product distribution and contributions of coke formation reactions also depend on the chosen molecule; it was found that the higher the number of the hydroxyl groups in a molecule, the lower the formation of $\mathrm{CH}_{4}$, while $\mathrm{CO}$ selectivity was enhanced. In addition, species with longer carbon chains promote the formation of carbonaceous deposits. In fact, the number of hydroxyl groups influences the oxygen content in the reaction intermediates, along with their contributions to dehydration reactions [27]. The characteristics of the coke formed (amorphous or filamentous, with possible whiskers) also change depending on the starting substrate and the acidic-basic properties of the catalyst [28]. In particular, alcohols were 
shown to be precursors of encapsulating coke, while $\mathrm{CO}$ and $\mathrm{CH}_{4}$ were responsible for the formation of filaments, whose contribution to catalyst deactivation was more pronounced [29].

$$
\begin{gathered}
\mathrm{C}_{n} \mathrm{H}_{2 n+1} \mathrm{OH}_{(g)}+x \mathrm{H}_{2} \mathrm{O}_{(g)} \leftrightarrow n \mathrm{CO}_{2(g)}+(x+n+1) \mathrm{H}_{2(g)} \\
\mathrm{C}_{n} \mathrm{H}_{2 n+1} \mathrm{OH}_{(g)}+(x-2 y) \mathrm{H}_{2} \mathrm{O}_{(g)}+y \mathrm{O}_{2(g)} \leftrightarrow n \mathrm{CO}_{2(g)}+(x+n-2 y+1) \mathrm{H}_{2(g)} \\
\mathrm{C}_{n} \mathrm{H}_{2 n+1} \mathrm{OH}_{(g)}+z \mathrm{CO}_{2(g)} \leftrightarrow(n+z) \mathrm{CO}_{(g)}+(n+1) \mathrm{H}_{2(g)} \\
C_{n} \mathrm{H}_{2 n+1} \mathrm{OH}_{(l)}+x \mathrm{H}_{2} \mathrm{O}_{(l)} \leftrightarrow n \mathrm{CO}_{2(g)}+(x+n+1) \mathrm{H}_{2(g)}
\end{gathered}
$$

The reforming of bioalcohols has attracted the attention of several scientists, who have proposed different approaches to modulate catalysts' selectivity and improve their durability, including the use of additives and promoters (i.e., alkaline or transition metals and acidic or basic oxides) [30-32], the choice of high surface area supports or perovskites [33,34] and core-shell catalysts [35], the development of innovative preparation methods allowing enhanced dispersion of active species and improved metal-support interactions [36,37], and the synthesis of solid solutions for the confinement of active metals particles [38]. The deposition of catalysts on structured carriers (i.e., foams and monoliths) with high thermal conductivity or on microchannel walls was also shown to prevent the deterioration of catalytic performance due to the reduction of hot and cold spots [39-41]. In addition, the use of fluidized bed reactors was proposed as an effective route to separate filamentous coke from catalyst particles [42].

The present review focuses on the most recent advances to improve the stability and durability of catalysts for the reforming processes of five alcohols (ethanol, methanol, glycerol, butanol, and propanol), presenting a critical analysis of the main carbon formation roots for each substrate. Particular attention is devoted to innovative formulations developed in the last 5 years, analysing the contributions of the active phase, the support, and eventual promoters to catalyst stability. novel reactor configurations developed to improve the performances of the considered reforming processes are also assessed.

This review article is divided into three main sections based on the alcohol used in the catalytic process: ethanol, methanol, and glycerol. Finally, a further section focusing on butanol and propanol reforming is presented. Each of the main sections is divided into paragraphs to highlight the effects of the active phases, supports, and promoters. At the end of every section, a summary table is provided to compare the catalytic performance in terms of carbon formation rates.

\section{Bioethanol Reforming}

During ethanol steam reforming (ESR), the main pathways responsible for coke formation are ethanol cracking, dehydration reactions to ethylene (Equation (5)) and subsequent polymerization (Equation (6)), and aldol condensation of acetone (Equation (7)), followed by dehydration and oligomerization of mesityl oxide, $\mathrm{CO}$ disproportion (Boudouard reaction, Equation (8)), and methane dehydrogenation (Equation (9)); ethane can also be formed and subsequently dehydrogenated [43-45].

$$
\begin{gathered}
\mathrm{C}_{2} \mathrm{H}_{5} \mathrm{OH} \rightarrow \mathrm{C}_{2} \mathrm{H}_{4}+\mathrm{H}_{2} \mathrm{O} \\
\mathrm{C}_{2} \mathrm{H}_{4} \rightarrow\left(\mathrm{C}_{2} \mathrm{H}_{4}\right)_{n} \rightarrow \mathrm{C} \\
2 \mathrm{C}_{2} \mathrm{H}_{5} \mathrm{OH} \leftrightarrow \mathrm{C}_{3} \mathrm{H}_{6} \mathrm{O}+\mathrm{CO}+3 \mathrm{H}_{2} \mathrm{O} \\
2 \mathrm{CO} \leftrightarrow \mathrm{CO}_{2}+\mathrm{C} \\
\mathrm{CH}_{4} \rightarrow \mathrm{C}+2 \mathrm{H}_{2}
\end{gathered}
$$

Based on the involved mechanism, different types of carbon can be formed (monoatomic adsorbed carbon, amorphous polymeric films, vermicular filaments, and graphitic crystalline platelets); while the monoatomic adsorbed carbon and polymeric coke are derived from the thermal decomposition of 
hydrocarbons, metallic sites are directly involved in the formation of filamentous and graphitic coke [46]. The crystallization of carbon coming from ethylene polymerization is favored at high temperatures, while carbide species mainly derivate from $\mathrm{CH}_{4}$ decomposition, which can polymerize and form amorphous carbon or carbon whiskers; finally, carbon growth during Boudouard reactions may involve island formation [47,48]. For several transition metals (e.g., $\mathrm{Ni}, \mathrm{Co}, \mathrm{Rh}, \mathrm{Ru}, \mathrm{Pd}, \mathrm{Pt}$ ) [49], discrete Fourier transform (DFT) calculations reveal that before C-C bond breaking, an intermediate $\mathrm{CH}-\mathrm{CO}$ bond is formed, which based on the reaction conditions and the nature of the metal surface can either dehydrogenate to form solid carbon or be hydrogenated to $\mathrm{CH}_{4}$ during the C-C rupture. For example, in the case of $\mathrm{Ni}$, it was shown that elevated temperatures favor intermediate decomposition over hydrogenation.

Ethanol reforming has been widely investigated under simulated bioethanol feeding (only containing water and ethanol); some studies were also performed with crude bioethanol feeding or a model mixture containing typical impurities (i.e., methanol, acetaldehyde, isopropyl alcohol, isobutyl alcohol, isoamyl alcohol). However, in the latter case, a faster catalyst deactivation was described. Glycerol and acetic acid are known as the major coke precursors; moreover, longer and heavier alcohols are not easily reformed but can be dehydrated to the corresponding olefins [50].

Liu et al. [51] described the mechanism of carbon formation on $\mathrm{Ni} / \mathrm{CeO}_{2}$ catalysts and the role of the hydroxyls groups in suppressing carbon formation (Figure 1). During ethanol steam reforming on the above catalysts, coke formation was mainly ascribed to the dehydrogenation of the surface methyl groups. $\mathrm{Ni}^{0}$, in fact, was the active phase leading to both the $\mathrm{C}-\mathrm{C}$ and $\mathrm{C}-\mathrm{H}$ cleavages of ethanol. In general, such methyl groups are not stable on the $\mathrm{Ni}(111)$ surfaces and are mostly dehydrogenated to surface carbon and hydrogen. However, in this study, surface carbon was formed through the generation of nickel carbides, which can also be originated from small amounts of ethoxy species decomposing on the $\mathrm{Ni}$ sites to form $\mathrm{Ni}_{3} \mathrm{C}$. Water can easily dissociate on the $\mathrm{Ni}-\mathrm{CeO}_{\mathrm{x}}$ to form hydroxyls groups, which together with the lattice oxygen on the surface, promote the oxidation of deposited carbon. However, the oxygen transfer from the ceria lattice to Ni particles is an endothermic reaction and only occurs above $470^{\circ} \mathrm{C}$. Thus, two competitive processes were described on the surface (carbon deposition and its oxidation by hydroxyls); the redox nature of the support as well as the Ni-ceria interactions are crucial to improve the oxygen transport and coke removal.
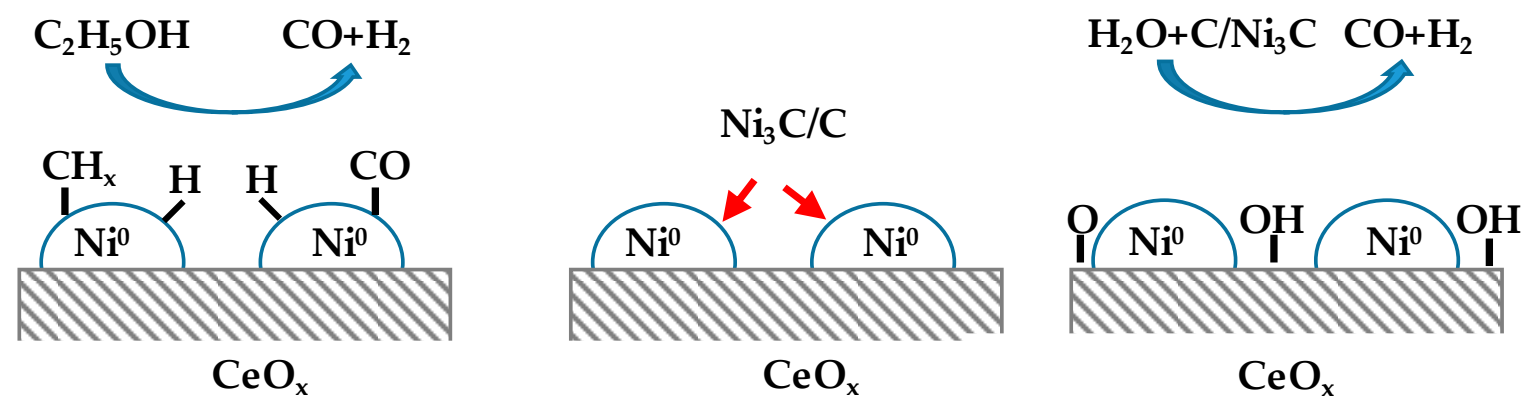

$$
\mathrm{CeO}_{x}
$$

Figure 1. Mechanism of coke formation and removal on a $\mathrm{Ni} / \mathrm{CeO}_{x}$ catalyst during ethanol steam reforming (ESR) [51].

The rate of ethylene formation throughout ESR is related to the support acidity and the amount of acidic sites on the catalysts' surfaces. Figure 2 displays the positive effects of acidic surface tailoring by the addition if $\mathrm{Ti}$ for a nanostructured $\mathrm{Ni}-\mathrm{Al}$ catalyst [52]. Ti doping resulted in an expansion of pore sizes, thus improving the mass transfer and the contact between catalytic sites and reactants; moreover, the redox properties of the $\mathrm{Ti}^{4+} / \mathrm{Ti}^{3+}$ couple strongly influenced the catalyst selectivity.

In fact, due to the titania effect on the surface basicity, the ethylene formed via ethanol dehydration was more stable and coke generated from the $\mathrm{C}_{2} \mathrm{H}_{4}$ by polymerization and carbonization was thermodynamically less favoured and easier to decompose compared to the Ni sample containing only alumina. 

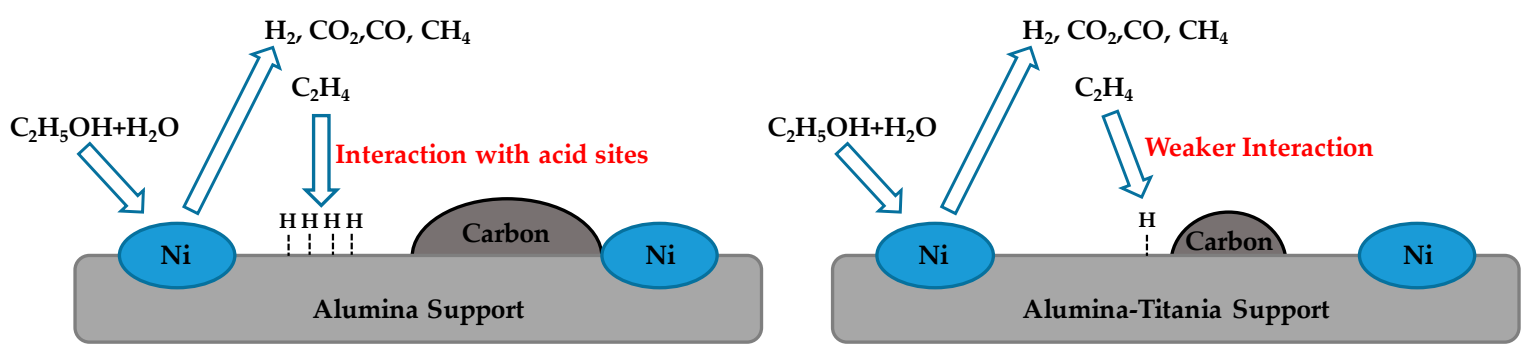

Figure 2. Mechanism of carbon formation of $\mathrm{Ni}-\mathrm{Al}$ and $\mathrm{Ni}-\mathrm{Al}-\mathrm{Ti}$ catalysts during ethanol steam reforming [52].

For alumina-based catalysts, the beneficial effects of support modification by the addition of $\mathrm{CeO}_{2}$ or $\mathrm{La}_{2} \mathrm{O}_{3}$ were shown, as well as for noble metals as active species (i.e., rhodium) [53]. The presence of low ceria loadings adds a Lewis acidity of medium strength to the $\mathrm{CeO}_{2}-\mathrm{Al}_{2} \mathrm{O}_{3}$ mixed oxide, while the reduced carbon deposition on this support is related to the oxygen storage capacity and mobility of the ceria. In fact, the reversible release of oxygen makes $\mathrm{O}_{x}$ (lattice oxygen) available on the oxide surface. Carbon monoxide adsorbs on the surface, reacting with $\mathrm{O}_{\mathrm{x}}$ and producing $\mathrm{CO}_{2}$. Moreover, the growth of carbon fibres is hindered by $\mathrm{CeO}_{2}$, which provides extra oxygen for gasification; solid carbon can react with oxygen lattices, further improving the yield to carbon oxides. Because $\mathrm{CO}$ is consumed to generate $\mathrm{CO}_{2}$, less carbon monoxide is available to be converted to coke via the Boudouard reaction. A different mechanism for the prevention of carbon build-up was reported for $\mathrm{La}_{2} \mathrm{O}_{3}$. In the presence of lantania, carbon dioxide is subtracted to the equilibrium via the formation of $\mathrm{La}_{2} \mathrm{O}_{2} \mathrm{CO}_{3}$, which can react with the carbon metal species in its vicinity and generate $\mathrm{CO}$.

The origin and nature of coke formed over $\mathrm{Ni} / \mathrm{La}_{2} \mathrm{O}_{3}-\alpha \mathrm{Al}_{2} \mathrm{O}_{3}$ catalysts via ethanol steam reforming were reported in a work by Montero et al. [22]. The spent catalysts were characterized by scanning electron microscopy (SEM) analysis, which allowed the morphology of the carbonaceous deposits to be determined (encapsulating, filamentous, and graphitic carbon). Acetaldehyde, ethylene, and non-reacted ethanol were identified as the main coke precursors responsible for the deposition of encapsulating coke via cracking and polymerization, while filamentous and partially graphitic coke were derived from $\mathrm{CH}_{4}$ and $\mathrm{CO}$ by decomposition and Boudouard reaction. As filamentous coke is located far from the metallic centers and is not able to cover the active sites (Figure 3), its influence on catalyst deactivation is reduced and the main impact on the catalyst activity loss comes from the encapsulation of active metal sites (in fact, the formation of filamentous coke caused a separation of metal nanoparticles from the support, without covering the active metal sites).

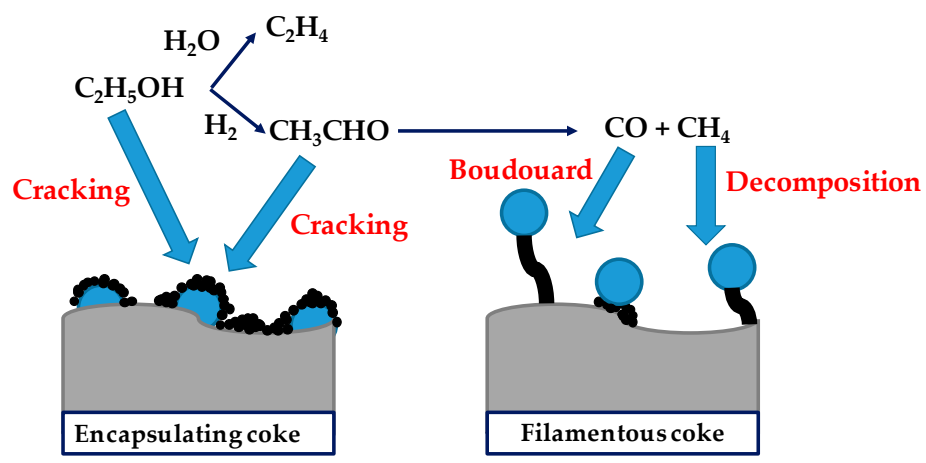

Figure 3. Mechanism and nature of coke formed over $\mathrm{Ni} / \mathrm{La}_{2} \mathrm{O}_{3}-\alpha \mathrm{Al}_{2} \mathrm{O}_{3}$ [22].

The first mechanism is predominant at high temperatures and with low space velocity, while the second one is favoured at intermediate contact times, at which methane and carbon monoxide concentrations reach a maximum; the increases of the temperature and steam-to-ethanol ratio enhance carbon gasification, reducing the concentration of coke precursors on the surface. 
For nickel core-shell-structured catalysts, it was found that during ESR reaction, the ethanol molecule is first dehydrogenated to acetaldehyde, which decomposes to $\mathrm{CH}_{4}$ and $\mathrm{CO}$, with a subsequent formation of carbon lumps. Conversely, if the ethanol dehydration occurs, ethylene is formed as an intermediate, which can easily polymerise into carbon nanotubes (CNT) [54].

Co@ $\mathrm{CoO}_{x}$ core-shell-structured catalysts exposed to mild oxidants (i.e., $\mathrm{H}_{2} \mathrm{O}$ and $\mathrm{CO}_{2}$ ) during ESR reaction suffer from stressing and collapse of the structure, with an oxidation of the $\mathrm{CoO}_{\mathrm{x}}$ core by means of the oxygen-free radical species which are, therefore, no longer available for the gasification of coke; for this system, carbon is mainly formed via dehydrogenation or condensation reactions [55]. Thus, sintering and formation of amorphous coke occurred. The promoting effect of ceria related to the $\mathrm{Ce}^{3+} / \mathrm{Ce}^{4+}$ redox cycle assured easier mobility of the active oxygen species, prevented re-oxidation of metallic Co particles, and at the same time allowed rapid consumption of carbonaceous species. For sol-gel alumina-supported cobalt catalysts, it was reported that the catalytic decomposition of ethylene on the Co sites was responsible for the formation of graphitic carbon, while amorphous coke was derived from the polymerization of carbon coming from methane decomposition. In addition, the influence of the $\mathrm{CoO} / \mathrm{Co}^{0}$ ratio on the carbon growth on the surfaces of the active sites was discussed. This ratio ruled the contribution of ethanol molecule activation and oxidation of adsorbed coke, with an optimal value of 1:3 selected to assure adequate activity and stability of the final catalyst [56].

Oxidative steam reforming of ethanol (OSRE) has also received considerable attention due to the role of gas-phase oxygen species, together with those components that are eventually presented as mobile lattice oxygen, in the oxidation of carbon deposited on the catalysts' surfaces $[57,58]$.

For Ni-Cu bimetallic catalysts derived from hydrotalcite-like compounds, the effect of oxygen co-feeding during ethanol steam reforming was investigated at $500{ }^{\circ} \mathrm{C}$ under a molar ratio of water/ethanol/oxygen equal to 6:1:0.3. As depicted in Figure 4, $\mathrm{O}_{2}$ addition mitigated the formation of filamentous-like coke deposits (which were observed under ESR conditions and caused the separation of metals nanoparticles from the support); oxygen promoted water production, limiting, the adsorption of hydrogen (thus hindering the reduction of $\mathrm{NiO}$ ) and $\mathrm{CO}$ or $\mathrm{CH}_{4}$ products on nickel active sites (which are converted to $\mathrm{CO}_{2}$ and $\mathrm{CO}$ ). Moreover, the dissolution of gasified carbon in nickel particles with further diffusion though the metal was mitigated, thus hampering the growth of filamentous coke [59].

ESR

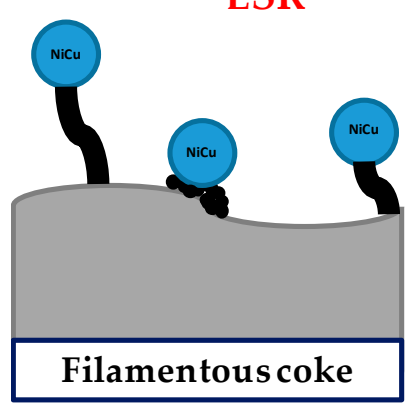

OSR

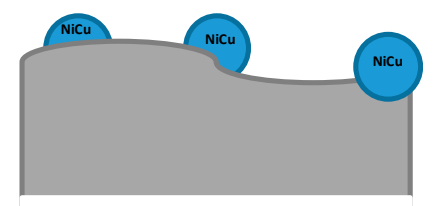

Figure 4. Effects of oxygen addition on carbon formation during ESR for Ni-Cu catalysts derived from hydrotalcite-like compounds [59].

The Pt-Ni/ $/ \mathrm{CeO}_{2}-\mathrm{SiO}_{2}$ catalysts, tested under a reacting stream of $\mathrm{C}_{2} \mathrm{H}_{5} \mathrm{OH} / \mathrm{H}_{2} \mathrm{O} / \mathrm{O}_{2}=1 / 4 / 0.5$ at $500{ }^{\circ} \mathrm{C}$, displayed better stability compared to the ESR measurements. The oxygen co-feeding improved coke gasification, thus resulting in diminished accumulation of carbon on the catalysts' surfaces; moreover, oxygen addition in the presence of the catalytic support having remarkable ionic conductivity encouraged the oxidation of carbon-containing species, without affecting the hydrogen production rate, which was almost the same for ESR and OSRE tests [60].

During stability tests in a fluidized bed reactor under OSRE conditions, the Pt-Ni/ $/ \mathrm{CeO}_{2}-\mathrm{SiO}_{2}$ catalyst displayed only partial deactivation, and after $300 \mathrm{~h}$ of time-on-stream (TOS), the system 
reached a new stationary condition with no more activity decay. When a plateau was observed in the gas product distribution, carbon deposition was measured at different time-on-stream values and no change in coke selectivity was observed. This phenomenon, depicted in Figure 5, can be explained by the fact that carbon deposition was not constant during the test. On the contrary, coke progressively accumulated on the most reactive catalytic sites (involved in both reforming reactions and carbon precursors generation). Therefore, the partial deactivation of the latter sites gradually reduced the carbon formation rate (CFR), and under stationary conditions the net rate of the carbon formation (i.e., the difference between coke formation and gasification) becomes equal to zero [61].

\section{COKE FORMATION}

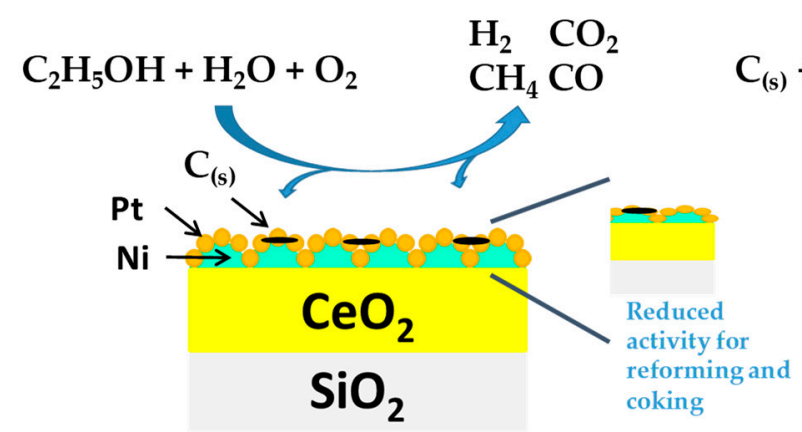

\section{COKE GASIFICATION}

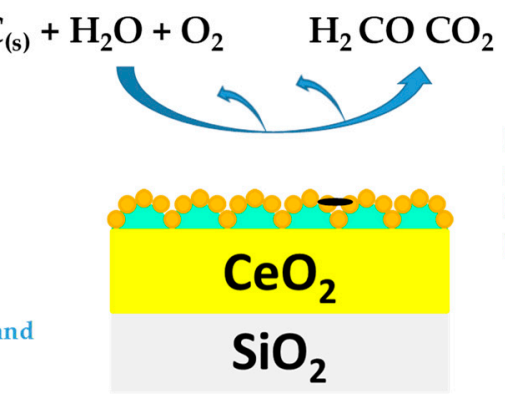

NET RATE OF

CARBON

FORMATION

EQUAL TO ZERO

Figure 5. Description of the partial activity loss observed for $\mathrm{Pt}-\mathrm{Ni} / \mathrm{CeO}_{2}-\mathrm{SiO}_{2}$ catalysts during oxidative steam reforming of ethanol (OSRE) at $500{ }^{\circ} \mathrm{C}$, where $\mathrm{C}_{2} \mathrm{H}_{5} \mathrm{OH} / \mathrm{H}_{2} \mathrm{O} / \mathrm{O}_{2}=1: 4: 0.5$ [61].

For ethanol dry reforming (EDR), the development of stable catalysts is a critical issue, especially when stoichiometric feeds are selected, implying that no excess of $\mathrm{CO}_{2}$ is available to remove carbon deposits; ethylene polymerization, Boudouard, and methane decomposition reactions are the main routes for carbon deposition and for the reaction of ethanol with carbon dioxide [62]. In the presence of supports with redox properties, the removal of coke accumulated through the above pathways is favoured. $\mathrm{CO}_{2}$, in fact, can re-fill the oxygen vacancy of the reduced support (i.e., ceria) to form $\mathrm{CO}$ and $\mathrm{O}$; this atomic oxygen can be transferred towards the metal surface or the metal-support interface, thus favouring the gasification of carbonaceous deposits [63].

Compared to gas-phase processes, aqueous-phase reforming of ethanol has rarely been investigated in the last five years. Aqueous-phase reforming of ethanol (APRE) is carried out at temperatures below $300^{\circ} \mathrm{C}$; such mild operative conditions minimize the contribution of undesirable decomposition reactions and tend to mitigate coking phenomena (carbon formation is thermodynamically unfavourable) $[64,65]$. Thus, only a few works provide information about the accumulation of solid carbon on the catalysts' surfaces. Zhao et al. [66] proposed a mechanism for carbon formation over $\mathrm{Ru}-\mathrm{Pt} / \mathrm{TiO}_{2}$ catalysts. Ethanol conversion via reforming passes through the cleavage of the $\mathrm{C}-\mathrm{C}$ bond and the metal particle size influences the $\mathrm{C} 1 / \mathrm{C} 2$ product ratio (larger particles assure a higher $\mathrm{C} 1 / \mathrm{C} 2$ ratio). The energy barriers for $\mathrm{C}-\mathrm{C}$ bond breaking are reduced on sites with low coordination at the corners and at step edges on metal surfaces. In fact, the most reactive sites (low coordination) can be strongly linked to the reaction intermediates $\left(\mathrm{CO}\right.$ and $\left.\mathrm{CH}_{\mathrm{x}}\right)$, with a consequent hard regeneration of the catalytic site. Carbon formation can also be linked to Boudouard reaction, methane decomposition, ethylene polymerization, and cracking of ethane; however, $\mathrm{CO}$ disproportion is more likely to occur. Despite the mechanism of APR of ethanol and the carbon formation pathways not being completely understood, for noble metals catalysts supported on titania, it was shown that the by-products selectivity decrease in the order of $\mathrm{Ru}>\mathrm{Rh}>\mathrm{Pt}>\operatorname{Ir}[64]$ and that the metal particle size strongly affects the formation of intermediate species acting as coke precursors [67].

Accordingly, in order to minimize the problem of carbon deposition, different strategies have been proposed in the literature, including the control of the metal particle sizes and the addition of a second 
metal or promoter able to change the electronic properties of the active species, as well as modify their interactions with the support [68-70]. In this section, the results of selected studies concerning steam reforming, oxidative steam reforming, dry reforming, and aqueous-phase reforming of ethanol are discussed. In the following paragraphs, bioethanol reforming with a focus on carbon formation will be discussed based on the nature of the active phase (Section 2.1), the chosen supports (Section 2.2), and the effects of promoters and additives (Section 2.3).

Ethanol reforming has been investigated with different noble and non-noble catalysts. Figure 6 groups the papers investigated in the present review based on the kind of active species selected.

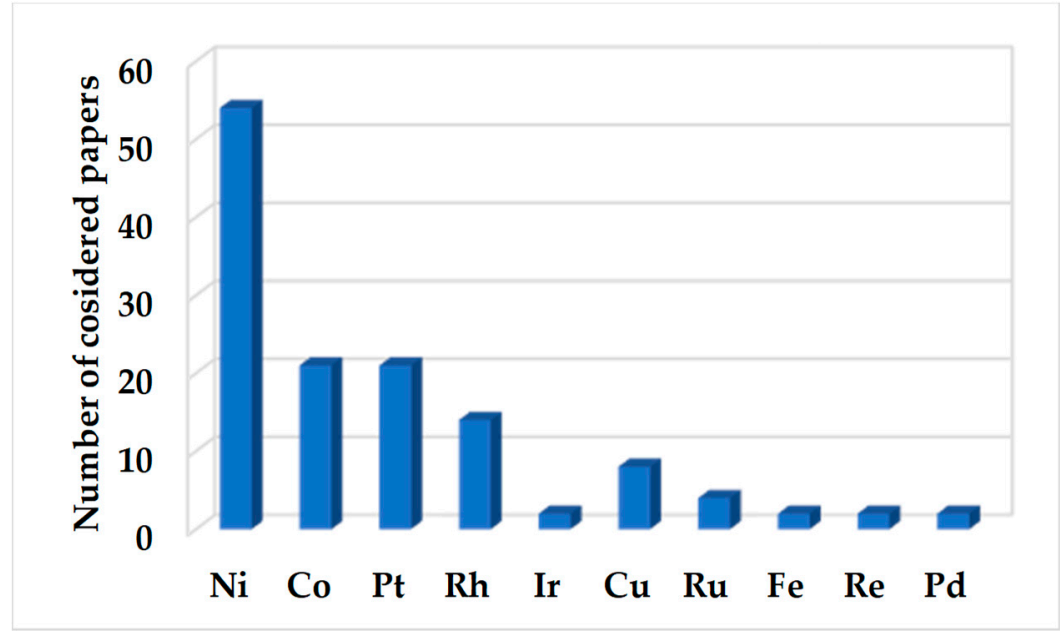

Figure 6. Number of considered papers as a function of the active phase analyzed for the ethanol reforming.

Nickel is the most widely selected metal for ethanol reforming, followed by cobalt. Moreover, among the noble metals, platinum and rhodium are most commonly selected.

\subsection{The Influence of the Active Phase}

In the following paragraph, the role of active species selection on catalyst stability for bioethanol reforming is discussed. In particular, various examples related to cobalt- and nickel-based catalysts are reported for the investigated processes, followed by the description of the performances of noble-metal-containing catalysts, as well as copper-based catalysts.

At $500{ }^{\circ} \mathrm{C}$ and under stoichiometric feeding conditions, $\mathrm{CH}_{4}$ decomposition and Boudouard reaction were shown to be responsible for the formation of filamentous coke over $\mathrm{Co}_{3} \mathrm{O}_{4} / \mathrm{CeO}_{2}$ catalysts during ESR [71]; carbon dissolves and subsequently precipitates on the rear of the metal, warding off the $\mathrm{Co}^{0}$ active sites from the support and leading to a loss of the $\mathrm{Co}^{0}$ active centers. However, by modulating the cobalt loading and particle dispersion, it is possible to vary the thickness of the filamentous coke, thus resulting in a good catalytic stability. In fact, active species dispersion and metal-support interactions are key factors affecting catalyst resistance towards deactivation. Thus, the improved stability of $\mathrm{Co} / \mathrm{CeO}_{2}$ catalysts during ESR at different temperatures $\left(400,600\right.$, and $\left.800{ }^{\circ} \mathrm{C}\right)$ under a steam-to-carbon ratio of 3 compared to $\mathrm{Ni}-, \mathrm{Fe}-$, and $\mathrm{Cu}$-based samples was ascribed to the strong metal-support interactions, which contributed to maintaining the Co species in an oxidized state; moreover, the gas-solid reactions between the hydrocarbon species adsorbed on the surface and the oxygen groups assured an easier gasification of such species, preventing their decomposition to coke [72]. For PtKCo/CeO $\mathrm{C}_{2}$ catalysts tested during oxidative steam reforming of ethanol, only a partial activity loss was observed and the reduced catalyst performance was ascribed to both carbon deposition and oxidation of cobalt metallic sites [73]. Carbon filaments were bonded to the support and contain cobalt particles at the top with the unblocked surface, not necessarily causing catalyst deactivation; 
thus, only a few metallic particles were encapsulated by carbon and no longer participated in the reaction. In addition, non-filamentous coke (formed as a result of condensation and graphitization of carbon-containing species chemisorbed on the catalysts' surfaces) only covered the external surface of the active particles, while the middle part was still accessible to the reactants. Pt addition had a negligible effect on carbon deposition. It was also shown that the oxygen from the feeding can oxidize the surface atoms of cobalt particles, with a rate that increases for small particle sizes (lower than $4 \mathrm{~nm}$ ).

The effect of the preparation method (mechanical mixing or sonication) on the stability performance of $\mathrm{Co}$ nanoparticles mixed with $\alpha-\mathrm{Al}_{2} \mathrm{O}_{3}$ was reported by Riani et al. [74]. Well-dispersed Co nanoparticles displaying a good interaction with alumina were observed in the sonicated sample, while for the mechanically mixed catalyst only aggregate nanoparticles were detected. The results of stability tests carried out at $500{ }^{\circ} \mathrm{C}$ and under a steam-to-ethanol ratio of 6 proved that Co aggregates produced long carbon nanotubes, which embedded the active particles, while the tendency to form graphitic carbon is very low for the nanoparticles interacting with alumina.

For NiCo-MgAl catalysts prepared by microwave- or sonication-assisted co-precipitation, it was found that the prereduction of the catalyst is crucial to assure proper acid-base properties of the material, which affected the catalyst stability during OSRE. For the unreduced sample, in fact, a high basicity was observed, which favored certain unwanted pathways (including acetone generation), along with the formation of coke precursors [58].

The preparation method was also shown to affect the durability of $\mathrm{Ni} / \mathrm{SiO}_{2}$ catalysts for ESR [75]. Compared to the impregnated samples and those prepared by deposition-precipitation, the catalysts synthetized via strong electrostatic adsorption displayed improved interactions between the active phase and the support, assuring good control of the Ni particle size, which helped reduce the carbon deposition at $600{ }^{\circ} \mathrm{C}$ under a $\mathrm{H}_{2} \mathrm{O} / \mathrm{C}_{2} \mathrm{H}_{5} \mathrm{OH}$ ratio of 9. The same authors demonstrated the benefits of using silica fibers instead of the commonly used porous $\mathrm{SiO}_{2}$. For porous catalysts, in fact, coke accumulates inside the pores and its gasification via the reaction with water is more difficult; conversely, carbon is deposited on the external surfaces of the fibers and its removal via gasification is easier.

The ultrasound-assisted synthesis of $\mathrm{Ni} / \mathrm{MgAl}_{2} \mathrm{O}_{4}$ catalysts allowed sufficiently dispersed $\mathrm{Ni}$ particles to be obtained, even at high Ni loading [70]; the limited surface acidity, mainly due to the presence of $\mathrm{Ni}$, promoted ethanol dehydration to ethylene, which for a $\mathrm{Ni}$ loading as high as $10 \%$ was further subjected to reforming, with very limited coking phenomena occurring.

$\mathrm{Ni} / \mathrm{Ce}_{0.9} \mathrm{Sm}_{0.1} \mathrm{O}_{2-\delta}$ nanowires were prepared via a simple two-step hydrothermal method followed by $\mathrm{Ni}$ deposited via wet impregnation. Such catalysts displayed high concentrations of oxygen vacancies on their surfaces and very low dimensions for $\mathrm{Ni}$ crystallites, assuring higher metallic surface areas compared to their analogue catalysts prepared from commercial doped ceria. Due to these improved properties, the $\mathrm{Ni} / \mathrm{Ce}_{0.9} \mathrm{Sm}_{0.1} \mathrm{O}_{2-\delta}$ sample displayed an exceptional stability with no loss of activity after $192 \mathrm{~h}$ of reaction at $550{ }^{\circ} \mathrm{C}$ under stoichiometric feeding conditions (no carbon deposits or filaments were detected for the spent catalyst) during ESR [76]. $\mathrm{Ni} / \mathrm{CeO}_{2}$ catalysts prepared via the sol-gel route displayed improved performance for APRE between 140 and $180^{\circ} \mathrm{C}$ with $10 \mathrm{wt} . \%$ ethanol in water stream compared to the same catalyst synthetized via the solution combustion method. During the reaction, $\mathrm{Ce}_{2} \mathrm{O}_{3}$ reduced $\mathrm{Ni}^{2+}$ to $\mathrm{Ni}^{0}$ and was itself oxidized to $\mathrm{CeO}_{2}$; the $\mathrm{Ni}$ sites can also be substituted for $\mathrm{Ce}$ in the $\mathrm{CeO}_{2}$ lattice, thus increasing oxygen mobility in the structure. The enhanced oxygen mobility of the catalyst prepared by sol-gel method resulted in an improved coking resistance [77].

For $\mathrm{Co} / \mathrm{CeO}_{2}$ catalysts, the use of nitrates as inorganic salt precursors was shown to increase acetaldehyde and ethylene selectivity, with severe carbon deposition [78]; conversely, the choice of cobalt acetyl acetonate strongly enhanced the catalyst stability during ESR at $450{ }^{\circ} \mathrm{C}$ under a steam-to-ethanol ratio of 10 , the organic ligands linked to the metal sites decreased the size of cobalt particles, improving their dispersion and assuring them a sort of imprinting effect, increasing the sites' accessibility to ethanol and water. Similarly, He et al. [36] prepared Ni/SBA-15 starting from two 
different nickel precursors (nitrate and citrate) and tested them for ethanol reforming at $500{ }^{\circ} \mathrm{C}$ and a $\mathrm{H}_{2} \mathrm{O} / \mathrm{C}_{2} \mathrm{H}_{5} \mathrm{OH}$ ratio of 3 . In the first case, $\mathrm{NiC}_{\mathrm{x}}$ species were detected, which were easily removed from catalysts' surfaces. On the contrary, the choice of Ni nitrate as a precursor led to the formation of carbon nanofibers (CNF) with a regular graphite structure, which covered the $\mathrm{Ni}$ active sites and were more difficult to remove. Similarly, $\mathrm{Pt}-\mathrm{Ni} / \mathrm{CeO}_{2}-\mathrm{SiO}_{2}$ was prepared by employing different cerium precursors (nitrate, ammonium nitrate, and acetyl acetonate) and tested at $500{ }^{\circ} \mathrm{C} \mathrm{C}_{2} \mathrm{H}_{5} \mathrm{OH} / \mathrm{H}_{2} \mathrm{O} / \mathrm{O}_{2}=1: 4: 0.5$. It was found that the organic precursor assured a templating effect on the ceria crystallites, protecting them and improving their dispersion; as a result, the carbon formation rate was reduced by half compared to the samples synthetized from inorganic precursors [37].

$\mathrm{Ni}$ catalysts prepared by using a smectite-derived material as the starting precursor compared to conventionally impregnated samples displayed reduced crystallite sizes of $\mathrm{Ni}$ and a consequent higher resistance towards carbon formation [79]. In fact, during synthesis, Ni species migrated in the smectite framework, and despite moving towards the surface during the reaction, a strong interaction with the framework was maintained, inhibiting sintering. Since this interaction limited the growth of particles, it was possible to reach considerable nickel contents (up to $35 \mathrm{wt} . \%$ ), thus resulting in high catalytic performance for ESR.

Noble-metal-based catalysts display lower coke formation and enhanced stability with time-on-stream testing compared to $\mathrm{Ni}$ or $\mathrm{Co}[80,81]$. For $\mathrm{Ir} / \mathrm{CeO}_{2}$ catalysts tested during ethanol dry reforming at $500{ }^{\circ} \mathrm{C}$ under $\mathrm{C}_{2} \mathrm{H}_{5} \mathrm{OH} / \mathrm{CO}_{2}$ ratio of 1:1 [82], a very low amount of amorphous carbon was detected, proving that the strong interaction between the Ir particles and the ceria support efficiently prevented the sintering of Ir metal particles, as well as coke formation. Moraes et al. [83] investigated the effect on carbon build-up of $\mathrm{Pt}$ addition to a $\mathrm{Ni} / \mathrm{CeO}_{2}$ nanocube catalyst for ethanol steam reforming at $300{ }^{\circ} \mathrm{C}$ and a steam-to-ethanol ratio of 3 . The formation of a catalytically inactive nickel carbide phase (solid solution on carbon in $\mathrm{Ni}$ ) was observed over the monometallic sample, which together with the accumulation of adsorbed acetates on the surface led to significant catalyst deactivation. A depicted in Figure 7, $\mathrm{Pt}$ inhibited the formation of $\mathrm{NiC}_{\mathrm{x}}$ species, enhancing the hydrogenation rate of carbonaceous species. Moreover, the noble metal is characterized by slower carbon diffusion kinetics; thus, a decrease of the carbon diffusion rate throughout the Ni lattice was assured by the platinum particles (Ni carburization during the reaction was mitigated by a discontinuous Pt surface outer shell) [84]. As a result, the CFR during $28 \mathrm{~h}$ of time-on-stream tests was one-fourth of the value recorded for the monometallic catalyst.

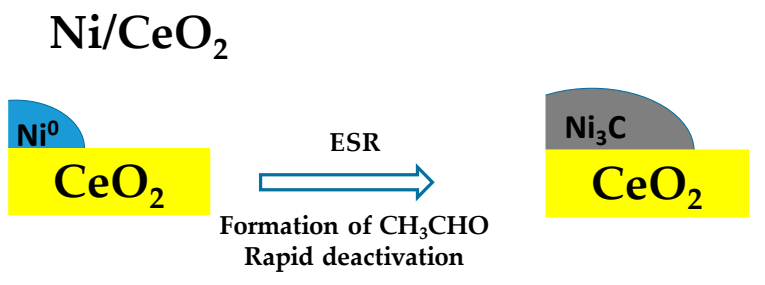

\section{$\mathrm{Pt}-\mathrm{Ni} / \mathrm{CeO}_{2}$}

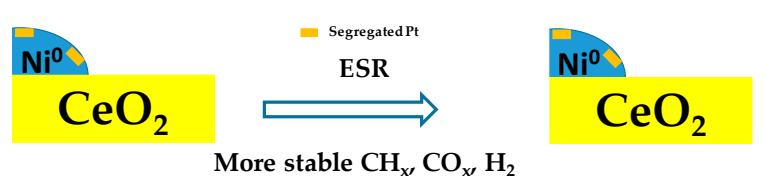

Figure 7. Effect of $\mathrm{Pt}$ addition on carbon formation for $\mathrm{Pt} / \mathrm{CeO}_{2}$ catalysts [84].

For noble-metal-based catalysts, due to the reduced solubility of carbon on the surface, it was shown that carbon nucleation is energetically unfavourable; the noble metal lattice is too large compared to graphene lattice, thus inhibiting its formation. As a consequence, the formation of superficial carbon 
instead of more structured deposits is promoted in the presence of supported noble metal catalysts (the solubility of carbon in the latter material is very low) [85].

Similar results were also reported by Palma et al. [86]. The addition of $\mathrm{Rh}$ to $\mathrm{Ni} / \mathrm{CeO}_{2}-\mathrm{La}_{2} \mathrm{O}_{3}$ samples enhanced the catalyst stability due to multiple effects, involving the reduced accumulation of acetate as well as the higher capacity for gasification of the methyl groups produced via decomposition of intermediates. In fact, acetates (derived from acetaldehyde dehydrogenation and subsequent oxidation) can be converted to $\mathrm{CH}_{\mathrm{x}}$ species or may accumulate on the surface of the Rh-free catalyst, leading to acetone formation and subsequent carbon deposition. As a result, the $\mathrm{Rh}-\mathrm{Ni}$ catalyst displayed almost no carbon formation for $24 \mathrm{~h}$ of reaction at $500{ }^{\circ} \mathrm{C}$ under a steam-to-ethanol ratio of 3 [87]. The excellent stability of $\mathrm{Rh}-\mathrm{Pt} / \mathrm{CeO}_{2}$ catalysts during ESR under stoichiometric feeding conditions at $700{ }^{\circ} \mathrm{C}$ was ascribed to the formation of a Rh-Pt alloy containing both $\mathrm{Rh}$ and Pt oxidized species, which also led to very small metal particles (almost $5 \mathrm{~nm}$ ). The control of the carbon accumulation was related to the availability of surface oxygen, which travels from the support, crossing the active metals and reaching the $\mathrm{CH}_{\mathrm{x}}$ coke precursors [85].

The basic properties of the $\mathrm{Rh}_{0.4} \mathrm{Pt}_{0.4} / \mathrm{CeO}_{2}$ catalyst assured stable performance during steam reforming of a bioethanol feed (having a steam-to-ethanol ratio of 3 and containing ethyl acetate $0.5 \mathrm{~mol} \%$, 1,1-diethoxyethane $0.2 \mathrm{~mol} \%$; trace constituents: propanol, 2-methyl-1-propanol, 3-methyl-1-butanol, and 2-methyl-1-butanol) at $700{ }^{\circ} \mathrm{C}$, where alcohol dehydration was disadvantaged, along with olefin production and further carbonaceous deposition on the catalysts' surfaces [88].

Due to the differing affinity for carbon deposit formation (different adsorption energies of the C-containing intermediate species were reported), $\mathrm{Pt} / \mathrm{Al}_{2} \mathrm{O}_{3}$ and $\mathrm{Rh} / \mathrm{Al}_{2} \mathrm{O}_{3}$ catalysts displayed dissimilar behaviour during steam reforming of crude bioethanol at $500{ }^{\circ} \mathrm{C}$ under a steam-to-ethanol ratio of 5 and with $1 \%$ impurities [89]. The carbon formation rate of the platinum-based catalyst was affected by the type of impurity selected and decreased in the order of IPA (Isopropyl alcohol) $>1$-propanol $>$ pure ethanol $>$ propanal $>$ propylamine $>$ acetone, while the $\mathrm{Rh} / \mathrm{Al}_{2} \mathrm{O}_{3}$ showed a higher durability, with a negligible trend related to the contaminants. A Pt-Co/CeO $-\mathrm{ZrO}_{2}-\mathrm{Al}_{2} \mathrm{O}_{3}$ catalyst was successfully employed for the steam reforming of a real bioethanol feed coming from the industry (having a steam-to-ethanol ratio of approximately 6 and also containing sulphur/phosphorous compounds); during stability measurements at $400{ }^{\circ} \mathrm{C}$, coke deposition did not occur [90].

In some cases, the addition of a second non-noble metal (i.e., $\mathrm{Co}$ or $\mathrm{Cu}$ ) had a mitigating effect in terms of carbon deposition [32,91]. The improved stability of Ni-Co/SBA-15 catalysts upon cobalt deposition was ascribed to the formation of a carbide phase (thermodynamically stable against decomposition to metallic $\mathrm{Co}$ and graphitic carbon), which assures a decrease in cobalt particle sizes [92]. Reduced $\mathrm{C}_{2} \mathrm{H}_{4}$ formation was observed during ESR for $\mathrm{NiCu}$ ex-hydrotalcite catalysts compared to the copper-free sample, which limited the deposition of graphitic carbon, as well as the formation of carbon filaments having small metallic particles at their growing tips.

For copper-nickel oxide catalysts [93], it was also reported that the metal-oxide interface facilitates the transformation of $\mathrm{CH}_{\mathrm{x}}$-adsorbed species resulting from acetaldehyde decomposition into methoxy-like adsorbed species, which are readily reformed to produce $\mathrm{H}_{2}$ instead of being decomposed to solid carbon.

Braga et al. [94] investigated the effect of $\mathrm{Co}$ addition to $\mathrm{Ni} / \mathrm{MgAl}_{2} \mathrm{O}_{4}$ on its stability during OSRE at $500{ }^{\circ} \mathrm{C}$ under $\mathrm{H}_{2} \mathrm{O} / \mathrm{EtOH} / \mathrm{O}_{2}=3: 1: 0.5$. Filamentous carbon was deposited on bimetallic Ni-Cu samples and the rate of carbon deposition increased for lower Co contents. The carbon gasification rate depends on the presence of surface oxygen for the oxidation of the ${ }^{*} \mathrm{C}$ species; the small dimension of cobalt particles (lower than $5 \mathrm{~nm}$ ) interacting with $\mathrm{Ni}$ enhanced the fraction of oxidized Co available to oxidize the carbon species on metal sites. Thus, cobalt deposition on $\mathrm{Ni} / \mathrm{MgAl}_{2} \mathrm{O}_{4}$ effectively mitigated coke accumulation, with the best results recorded for the $4 \mathrm{Co}-4 \mathrm{Ni}$ catalyst. 


\subsection{The Role of the Support}

The present paragraph describes the crucial role played by the catalytic support in preventing coking phenomena, mainly linked to its acidic and basic features, as well as its structural properties. Thus, the identification of the acidic and basic sites of the support is fundamental for the understanding of coke formation mechanisms.

For $\mathrm{Rh} / \mathrm{CeO}_{2}$ catalysts tested during ESR [95], $\mathrm{NH}_{3}$ temperature-programmed desorption (TPD) results indicate the presence of strong basic sites; however, a slightly acid behaviour was also observed. Different paths of ethanol molecule activation are observed based on the site features. Acidic sites favour dehydration reactions and ethylene formation, which is a well-known coke precursor; while the dehydrogenation pathway is promoted in basic sites, leading to the formation of $\mathrm{C}_{2} \mathrm{H}_{5} \mathrm{O}^{*}$ intermediates, which can decompose to $\mathrm{CH}_{\mathrm{x}}$ species and further be oxidized to $\mathrm{CO}$ and $\mathrm{CO}_{2}$.

$\mathrm{La}_{2} \mathrm{Ce}_{2-x} \mathrm{Ni}_{x} \mathrm{O}_{7-\delta}$ catalysts displayed very stable behaviour during oxidative steam reforming of ethanol. Ni incorporation into the pyrochlore structure, as well as the synergistic effect of nickel and cerium ions, induced the formation of $\mathrm{Ce}^{3+}$ ions, thus creating oxygen vacancies. This effect, together with the good dispersion of $\mathrm{Ni}$ particles and the presence of $\mathrm{NiO}$ as an impurity (sintered nickel oxides promote coke accumulation), mitigates coke deposition [96]. The same authors synthesized pyrochlore catalysts substituted by $\mathrm{Li}$ and $\mathrm{Ru}$ in $\mathrm{A}$ and $\mathrm{B}$ sites and supported them on $\mathrm{Al}_{2} \mathrm{O}_{3}$ or $\mathrm{La}_{2} \mathrm{Zr}_{2} \mathrm{O}_{7}$. Substitution of $\mathrm{La}^{3+}$ by $\mathrm{Li}^{+}$metal cations modified the relative compositions of active metal ions $\mathrm{Ru}^{\mathrm{n}+} / \mathrm{Ru}^{4+}$ and $\mathrm{Ce}^{4+} / \mathrm{Ce}^{3+}$, thus enhancing formation of vacancies and increasing the carbon oxidation rate. Moreover, during tests performed at $350^{\circ} \mathrm{C}$ under stoichiometric feeding conditions, disordered carbonaceous and ordered graphitic species were formed over the alumina-supported catalyst, while no coke accumulation was observed for the $\mathrm{La}_{2} \mathrm{Zr}_{2} \mathrm{O}_{7}$-based sample. The basic properties of this support, in fact, suppressed ethylene formation and its successive polymerization [97].

For $\mathrm{Cu}$ catalysts supported on $\mathrm{CeO}_{2}, \mathrm{ZrO}_{2}$, and $\mathrm{CeO}_{2}-\mathrm{ZrO}_{2}$, and tested during ethanol dry reforming, it was found that the concentration of the oxygen vacancies decreased in the order of $\mathrm{Cu} / \mathrm{CeO}_{2}-\mathrm{ZrO}_{2}>\mathrm{Cu} / \mathrm{CeO}_{2}>\mathrm{Cu} / \mathrm{ZrO}_{2}$. Thus, coke formation was inhibited and its degree of graphitization reduced with the $\mathrm{Cu} / \mathrm{CeO}_{2}-\mathrm{ZrO}_{2}$ catalysts, which displayed the highest durability at $700{ }^{\circ} \mathrm{C}$ under a $\mathrm{C}_{2} \mathrm{H}_{5} \mathrm{OH} / \mathrm{CO}_{2}$ ratio of $1: 1$ [98]. $\mathrm{Cu} / \mathrm{Ce}_{0.8} \mathrm{Zr}_{0.2} \mathrm{O}_{2}$ catalysts displayed negligible deactivation during dry reforming of ethanol at $700{ }^{\circ} \mathrm{C}$ and a $\mathrm{C}_{2} \mathrm{H}_{5} \mathrm{OH} / \mathrm{CO}_{2}$ ratio of 1:1. In fact, the incorporation of $\mathrm{Cu}$ prevented the crystallite growth of the $\mathrm{Ce}-\mathrm{Zr}-\mathrm{O}$ solid solution, which may occur during preparation; thus, the mean crystallite size of the $\mathrm{CuCeZr}$ catalyst was approximately $3.1 \mathrm{~nm}$ (lower than the value of $5 \mathrm{~nm}$ reported for the pure ceria-zirconia support); smaller particles are reported to reduce the formation enthalpy of oxygen vacancies. As a result, coke accumulation and sintering were mitigated [99] and stable behaviour with complete ethanol conversion for $90 \mathrm{~h}$ of time-on-stream was recorded [100]. Dang et al. [101] investigated the dry reforming of an ethanol/glycerol mixture (4:1) over a Ni/CaCO 3 catalyst: $\mathrm{CaCO}_{3}$ reacted with the alcohols to yield $\mathrm{CO}, \mathrm{H}_{2}$, and $\mathrm{CaO}$, while $\mathrm{CO}_{2}$ allowed for $\mathrm{CaCO}_{3}$ to be regenerated. The presence of carbonates was beneficial for suppressing coke accumulation; the highly reactive carbonaceous species can interact with the $\mathrm{CO}_{2}$ coming from the carbonate decomposition and can be easily converted to carbon monoxide.

The metal particle size and the dispersion of the active phase are also affected by the structure of the support. Da Costa-Serra and Chica [102] studied ethanol steam reforming for two Co-based catalysts supported on structured manganese oxides (Birnessite and Todorokite). In the latter case, the special microporous structure of the support provided high-quality positions for the stabilization of the cobalt particles (i.e., the microporous structure assures a good interaction of the metal particles with the support) during the preparation, thus leading to smaller metal particles compared to the birnessite-based sample (6 vs. $12 \mathrm{~nm}$ ). As a result, carbon accumulated during a $24 \mathrm{~h}$ ESR test at $500{ }^{\circ} \mathrm{C}$ under a $\mathrm{H}_{2} \mathrm{O} / \mathrm{C}_{2} \mathrm{H}_{5} \mathrm{OH}$ ratio of 13 was almost one-half of the todorokite-supported Co catalyst. The superior stability of a Ni/KIT-6 catalyst (ordered silica) for ethanol dry reforming at $550{ }^{\circ} \mathrm{C}$ under a $\mathrm{C}_{2} \mathrm{H}_{5} \mathrm{OH} / \mathrm{CO}_{2}$ ratio of 1 compared to a nickel sample supported on mesoporous silica was ascribed to the stabilization of the Ni species via the formation of Si-O-Ni-O-Si bonds, with a consequent confinement 
within the pores of the ordered structure; such confinement resulted in a stronger metal-support interaction and smaller $\mathrm{Ni}$ particles compared to the $\mathrm{Ni} / \mathrm{SiO}_{2}$ catalyst, which enhanced the resistance towards coke formation [103]. By depositing a Pt-Ni/CeO $\mathrm{Catalyst}_{2}$ on high surface area mesoporous silica, a better dispersion of both metal and ceria particles was observed compared to the silica-free sample, thus enhancing the catalyst stability during ESR. The bimetallic catalysts were also prepared at different $\mathrm{CeO}_{2} / \mathrm{SiO}_{2}$ ratios $(0.25,0.30$, and 0.40), and the relationship between the CFR and average $\mathrm{Ni}$ crystallites calculated for the spent catalysts was investigated. The smallest crystallite size, which was linked to the minimum coke selectivity, was recorded for a ratio of $30 \%$ [60].

Catalyst deposition on specific structured carriers may also affect their stability performance for ethanol reforming. The enhanced mass transfer rate and the improved gas-solid contact of structured carriers (i.e., foams, honeycombs, and monoliths) are expected to increase the contribution of coke gasification reactions, with a consequent mitigation in the deactivation of the catalyst $[40,104]$. $\mathrm{Rh} / \mathrm{CeSiO}_{2}$ catalysts supported on a ceramic monolith were subjected to a water/ethanol mixture of 3.5 at $755{ }^{\circ} \mathrm{C}$, and no coke formation was observed during $96 \mathrm{~h}$ of operation [105]. Cobalt deposition on a $\mathrm{Y}_{2} \mathrm{O}_{3}$-doped $\mathrm{ZrO}_{2}$ monolith eliminated the generation of undesired by-products $\left(\mathrm{C}_{2} \mathrm{H}_{2}\right.$ and $\left.\mathrm{C}_{2} \mathrm{H}_{4} \mathrm{O}\right)$, whose formation in the presence of the corresponding powder material was responsible for carbon deposition. Moreover, the stability of such structured catalysts was enhanced by infiltrating La into the monolith structure [106]. For the steam reforming of a simulated bioethanol for (containing $1 \mathrm{~mol} \%$ of acetaldehyde, isopropyl alcohol, isobutyl alcohol, and isoamyl alcohol) over a Pt-Ni/CeO $-\mathrm{ZrO}_{2}$ catalyst supported on a $\mathrm{SiC}$ foam, it was observed that the binder employed during the deposition of the catalytic wash coat on the structured carrier may affect catalyst stability [107]. The choice of boehmite as a binder reduced the carbon formation rate during tests at $450{ }^{\circ} \mathrm{C}$ at a steam-to-ethanol ratio of 3 compared to both the corresponding powder sample and the structured carrier containing silica as a ligand. In the latter case, in fact, very fast deactivation was observed, which was described as follows: during reforming reactions, steam can attack silica-structured $\mathrm{Si}$ atoms, with consequent structural changes for silica. Thus, active species particles can be wrapped or buried within the structure, losing their activity.

\subsection{The Effect of the Addition of Promoters}

The addition of promoters is a common strategy to mitigate carbon deposition on the catalysts' surfaces during ethanol reforming, and in the following paragraph, the influence of various promoters (mainly alkali metals and rare earths elements) on catalyst stability for bioethanol reforming is discussed.

For $\mathrm{Co} / \mathrm{CeO}_{2}$ catalysts tested during ESR, it was reported that the Co particle size influences the type of carbonaceous deposits; large cobalt particles caused the formation of carbon filaments with encapsulated cobalt (carbon diffuses inside the crystallites, destroying them and the causing growth of nanofibers), while few atomic layers of carbon, mainly located at the boundary of the $\mathrm{Co}$ and $\mathrm{CeO}_{2}$ particles, were detected over small cobalt particles. The same authors found that the concentration of hydroxyls groups on the catalysts' surfaces (modulated on the basis of the steam-to-ethanol ratio) is crucial to changing coke selectivity. In this regard, a high concentration of $\mathrm{OH}$ species and $\mathrm{K}-\mathrm{O}$ sites was assured upon potassium addition. Potassium, in fact, is able to favor the conversion of coke precursors to $\mathrm{CH}_{\mathrm{x}}$ instead of fully dehydrogenated $\mathrm{C}=\mathrm{C}$ species (mainly graphitic whiskers and layers) [108]. Moreover, the formation of carbonaceous deposits was also prevented over $\mathrm{Co} / \mathrm{ZrO} 2$ catalysts promoted by potassium, mainly due to the decreased contribution of the CO disproportion reaction [109]. $\mathrm{La}_{2} \mathrm{O}_{3}$ promotion improved the active species dispersion and the metal-support interactions for $\mathrm{Co} / \mathrm{CeO}_{2}$ (and Ni/CeO${ }_{2}$ ) catalysts; the lower carbon formation was attributed to the formation of $\mathrm{La}_{2} \mathrm{O}_{2} \mathrm{CO}_{3}$ as an intermediate phase, which contributes to eliminating carbon deposits, leading to the formation of carbon monoxide [110]. Cerdà-Moreno et al. [111] investigated the effect of La addition as a promoter on the stability of CoZn hydrotalcites at $600^{\circ} \mathrm{C}$ for the steam reforming of a raw bioethanol stream containing several impurities (acetaldehyde, methanol, propanol, and $\mathrm{SO}_{2}$ ) and 
having a steam-to-ethanol ratio of 10; the improved performance of the lanthanum-containing catalyst is mainly related to the reduced $\mathrm{C}_{2} \mathrm{H}_{4}$ selectivity.

For Ni/SBA-15 catalysts, the introduction of $\mathrm{Mn}$ as a promoter and the subsequent change in the redox properties of the catalytic support favored the formation of a lower amount of coke lumps (carbon donuts surrounding Ni particles), with less activity loss during ESR compared to the Mn-free catalysts [54]. A similar reduction in the extent of deactivation and the same differences in the types of coke formed were observed by adding Mo to Ni/SBA-15 catalysts [112] and Mn to Co/SBA-15 catalysts [113].

The synthesis of a Ni-Ce-W oxide catalyst via reverse microemulsion allowed $\mathrm{W}$ and part of the $\mathrm{Ni}$ to be incorporated into the ceria lattice, while the remaining $\mathrm{Ni}$ formed highly-dispersed nano-NiO (almost $2 \mathrm{~nm}$ ) outside the Ni-W-Ce oxide structure. Due to the synergy between $\mathrm{Ni}$ and $\mathrm{W}$ inside the ceria lattice, an increase of the oxygen vacancies with respect to the $\mathrm{W}$-free sample was observed, which assured considerable resistance towards coke formation during ESR [114].

Compared to the ceria-free samples, $\mathrm{CeO}_{2}$-promoted Ni/SBA-15 catalysts displayed well-dispersed nickel particles confined in the mesoporous channels of SBA-15 [115]; the metal-support interactions led to a homogeneous distribution of $\mathrm{Ni}$ and $\mathrm{Ce}$ with a large $\mathrm{Ni}-\mathrm{CeO}_{2}$ interface, which contributed to controlling the size of Ni particles. Ni's ability to break $\mathrm{CO}$ bonds responsible for $\mathrm{CO}$ disproportion and carbon deposit formation was mitigated thanks to the strong electronic perturbation induced by ceria. In addition, the $\mathrm{OH}$ groups present on the ceria surface, together with those derived from steam, can easily react with methyl groups to generate $\mathrm{CO}, \mathrm{CO}_{2}$, and $\mathrm{H}_{2}$. The high oxygen mobility in the ceria lattice enhanced the carbon gasification rate and assured a lower rate of carbon deposition. Thus, ceria can effectively minimize sintering and coking over Ni/SBA- 15 catalysts during ethanol steam reforming at $700{ }^{\circ} \mathrm{C}$ and $\mathrm{H}_{2} \mathrm{O} / \mathrm{C}_{2} \mathrm{H} 5 \mathrm{OH}$ ratio of 4 , reducing the accumulated amount of coke deposited by almost $70 \%$.

In an attempt to improve the stability of NiMgAl catalysts, Du et al. [116] investigated the addition of various promoters, which modulated the electronic properties of the final catalyst. $\mathrm{NiCoMgAl}$ catalysts, compared to the Mn- or Zr-promoted samples, displayed higher durability, ascribable to the good metal dispersion and small metal size, which hindered carbon deposition and sintering (small particles of metals such as Ni have been found to block the mechanism of carbon filament growth and to decrease carbon accumulation). Conversely, an enhanced rate of carbon formation (mainly in a filamentous form) was observed for the $\mathrm{NiMnMgAl}$ and $\mathrm{NiZrMgAl}$ samples. Ce addition to $\mathrm{NiMgAl}$ reduced the dimensions of metal particles, while the presence of lanthanum increased the surface $\mathrm{Ni}$ content and the number of basic sites; in both cases, a reduced carbon formation rate was measured. Similarly, the benefits of supporting $\mathrm{LaNiO}_{3}$ catalysts on $\mathrm{CeSiO}_{2}$ were reported [117]. The presence of $\mathrm{SiO}_{2}$ blocked the sintering of ceria particles and the very low carbon formation rate recorded during ESR at $700{ }^{\circ} \mathrm{C}$, while a $\mathrm{H}_{2} \mathrm{O} / \mathrm{C}_{2} \mathrm{H}_{5} \mathrm{OH}$ ratio of 3 over the $\mathrm{LaNiO}_{3} / \mathrm{CeSiO}_{2}$ catalyst was ascribed to the metal-support interactions, which contributed to maintaining small dimensions for $\mathrm{Ni}$ crystallites. The size of metal particles, in fact, affects the nucleation rate of carbon; a critical ensemble size (ensemble of 6-7 atoms) was proposed, below which carbon formation does not occur. For these catalysts, it was also reported that after initial deactivation, new stability conditions were reached, despite the presence of carbon on the catalyst's surface. The initial loss of activity was observed when the rate of formation of $\mathrm{CH}_{x}$ species was higher than their rate of desorption to form $\mathrm{CH}_{4}$. Such species can be further dehydrogenated to $\mathrm{C}$ as well as $\mathrm{H}$, and the highly-reactive carbon species can both encapsulate metallic particles, leading to complete deactivation, or diffuse through the Ni crystallites and nucleate the growth of carbon filaments. In the latter case, the top surface is still in contact with the reacting mixture and the catalyst is able to maintain its activity for the ESR. Dan et al. [118] investigated the steam reforming of a fir wood crude bioethanol over $\mathrm{Ni} / \mathrm{Al}_{2} \mathrm{O}_{3}$ catalysts (containing methanol, acetic acid, higher alcohols, esters, aldehydes, organic acids, and dimethyl furan). However, the bioethanol displayed rapid deactivation during tests at $350{ }^{\circ} \mathrm{C}$, due to the deposition of graphitic carbon. A significant improvement in its durability was observed with the addition of rare earth 
oxides, with $\mathrm{La}_{2} \mathrm{O}_{3}$ decreasing the alumina surface acidity and $\mathrm{CeO}_{2}$ promoting water activation for the gasification of coke deposits. Thus, stable performance was recorded for $4 \mathrm{~h}$ at $350^{\circ} \mathrm{C}$.

Likewise, the incorporation of $\mathrm{Au}$ into Ni/SBA- 5 catalysts improved the dispersion of the $\mathrm{NiO}$ phase to form smaller nickel oxide particles. In addition, strengthened interactions between the SBA-15 support and $\mathrm{NiO}$ phase were assured, thus efficiently reducing the coke deposition on active sites [119].

Mondal et al. [120] described the performance of unpromoted and $\mathrm{Rh}$-promoted $\mathrm{Ni} / \mathrm{CeO}_{2}-\mathrm{ZrO}$ catalysts for oxidative steam reforming of a crude bioethanol stream (containing ethanol, butanediol, butandioic acid, acetic acid, and glycerol). Stability tests were performed at $600{ }^{\circ} \mathrm{C}$ and $\mathrm{EtOH} / \mathrm{H}_{2} \mathrm{O} / \mathrm{O}_{2}$ $=1: 13: 0.35$. The addition of Rh led to smaller dimensions for Ni crystallites, and despite both amorphous and rod-shaped filamentous carbon nanotubes being observed for the two spent catalysts, the $\mathrm{Rh}-\mathrm{Ni} / \mathrm{CeO}_{2}-\mathrm{ZrO}_{2}$ lessened the deposition of encapsulating amorphous coke, thus exhibiting a significantly lower deactivation rate.

The addition of $\mathrm{Ce}$ or $\mathrm{La}$ to $\mathrm{Ni} / \mathrm{Al}_{2} \mathrm{O}_{3}$ acted as a spacer, preventing $\mathrm{NiO}$ particles from aggregating, and hence increasing metal dispersion on the catalyst's surface; thus, improved stability was recorded for ethanol dry reforming. In particular, despite multiwalled carbon nanofibers being deposited on both the promoted and unpromoted catalysts, the stable performance of rare-earth-containing samples was related to the absence of encapsulated Ni particles located on the tip of the filamentous nanocarbon [121,122]. In addition, in the presence of $\mathrm{CO}_{2}$, the formation of the $\mathrm{La}_{2} \mathrm{O}_{2} \mathrm{CO}_{3}$ intermediate discussed above was enhanced, along with its ability to oxidize surface $\mathrm{C}_{\mathrm{x}} \mathrm{H}_{\mathrm{y}}$ species and to preserve active metal sites. Similar results were also reported for Ce-doped $\mathrm{Co} / \mathrm{Al}_{2} \mathrm{O}_{3}$ catalysts [123], La-doped $\mathrm{Co} / \mathrm{Al}_{2} \mathrm{O}_{3}$ [124], and La-doped $\mathrm{Cu} / \mathrm{Al}_{2} \mathrm{O}_{3}$ catalysts [125].

In some cases, the addition of a promoter did not lead to the desired performance improvement. For the $\mathrm{Ni} / \mathrm{CeO}_{2}$ catalyst, the addition of $\mathrm{K}$ caused faster deactivation due to the deposition of a very large amount of graphitic fibres, which were longer and thicker than those observed over the unpromoted catalyst; these graphitic fibres encapsulated the nickel crystallites, resulting in an activity loss [126]. For Pt-Ni catalysts, the addition of a third metal (K, Cs, or Rh) as a promoter was investigated, finding that caesium and rhodium are able to reduce the carbon formation rate during ESR at $450{ }^{\circ} \mathrm{C}$ and under stoichiometric feeding conditions, while in the presence of potassium, this addition was detrimental for catalyst stability [23].

Table 1 summarizes the stability performance of different catalysts proposed over the last 5 years for steam reforming, oxidative steam reforming, and dry reforming of ethanol. As discussed above, various parameters affect the catalyst durability and carbon formation rate, including the catalyst composition (active species, support, promoters) and operative conditions (temperature, feeding, and space velocity). A high ethanol concertation, low contact time, and high steam/ethanol ratio increase carbon accumulation on the catalyst's surface. Moreover, noble-metal-based catalysts displayed lower coke formation compared to Ni- or Co-based catalysts, with the addition of promoters lessen the coke selectivity. In fact, as can be seen from the data reported in Table 1, when ESR was performed over Irand Rh-based catalysts, the CFR was among the lowest reported in the present review. Very low carbon formation rates were also measured in the presence of $\mathrm{Pd}$, as well as for bimetallic Rh-Ni catalysts. Carbon formation rates range between $10^{-2}$ to $10^{-7}$; overall, during oxidative steam reforming of ethanol, reduced coke selectivity values were recorded compared to the steam reforming and dry reforming cases, due to the enhanced contribution of gasification reactions promoted by $\mathrm{O}_{2}$. In this regard, the highest stability was assured over the $\mathrm{Pt}-\mathrm{Ni} / \mathrm{CeO}_{2}-\mathrm{SiO}_{2}$ catalysts, as well as over Ru-based perovskites containing La as a promoter. During dry reforming, the extent of catalyst deactivation was enhanced due to the absence of water in the feed, which is crucial for the promotion of carbon gasification; thus, CFR, defined as the ratio between the mass of carbon, measured in g, and the product of the catalytic mass (measured in g), the mass of carbon feed during the test (in g) and the time on stream (in hours), was of the order of $10^{-3} \mathrm{~g}_{\text {coke }} \cdot \mathrm{g}_{\text {catalyst }}{ }^{-1} \cdot \mathrm{g}_{\text {carbon,fed }}{ }^{-1} \cdot \mathrm{h}^{-1}$. However, a strong improvement in catalyst stability was observed by selecting ceria and zirconia instead of alumina as the catalytic support. The results reported in Table 1 also show the effects of the catalyst preparation 
method and the salt precursor selection on the stability of the final catalyst during ethanol reforming. In particular, the lowest values for carbon formation rates were recorded for the catalysts prepared by sonication (which assured lower dimensions for metal crystallites and a better active species-support interaction) instead of impregnation; moreover, the choice of organic salts as precursors improved the dispersion of active species, thus resulting in a more stable catalyst.

Table 1. Carbon formation rates of various catalysts employed for steam reforming, oxidative steam reforming, and dry reforming of ethanol.

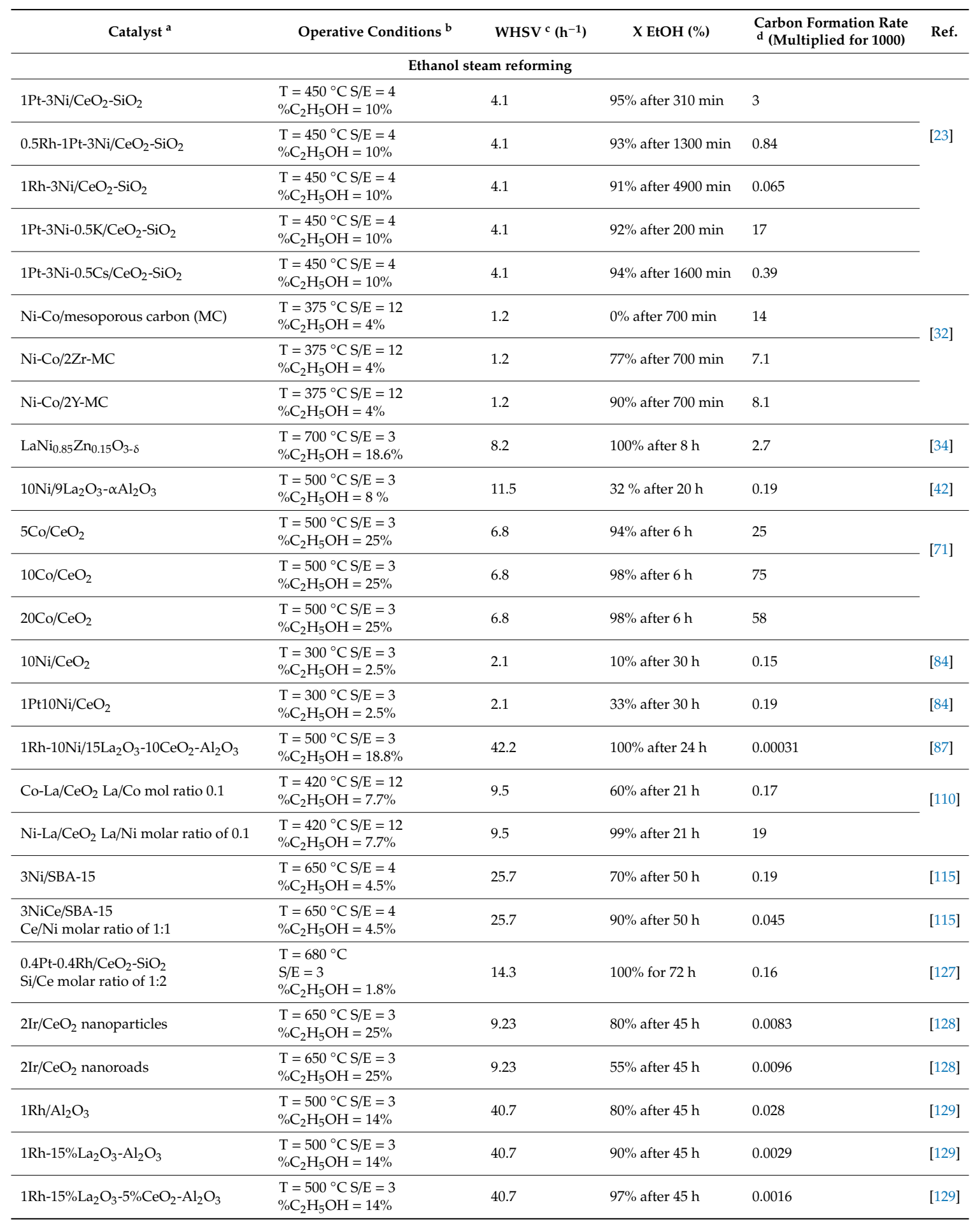


Table 1. Cont

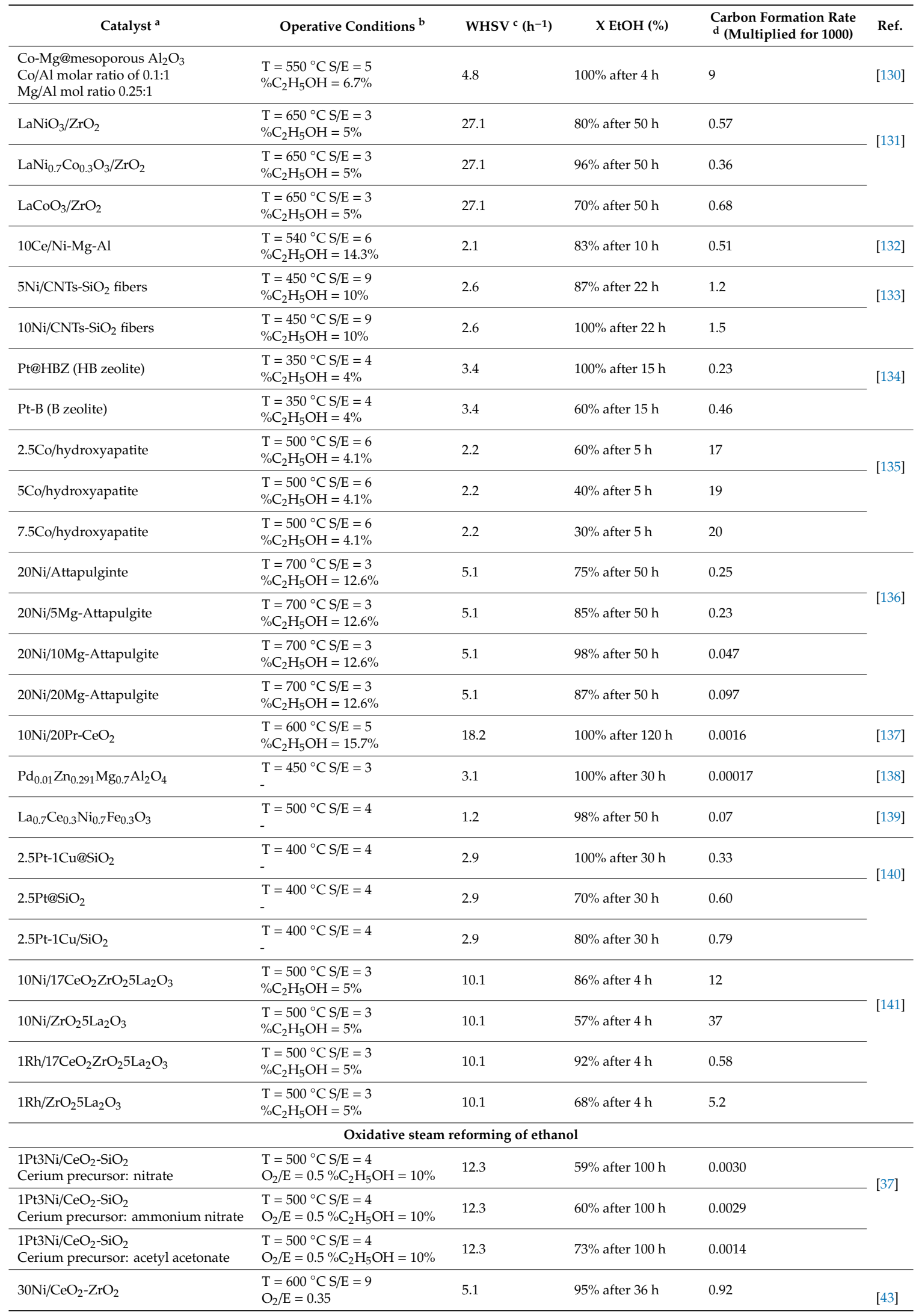


Table 1. Cont

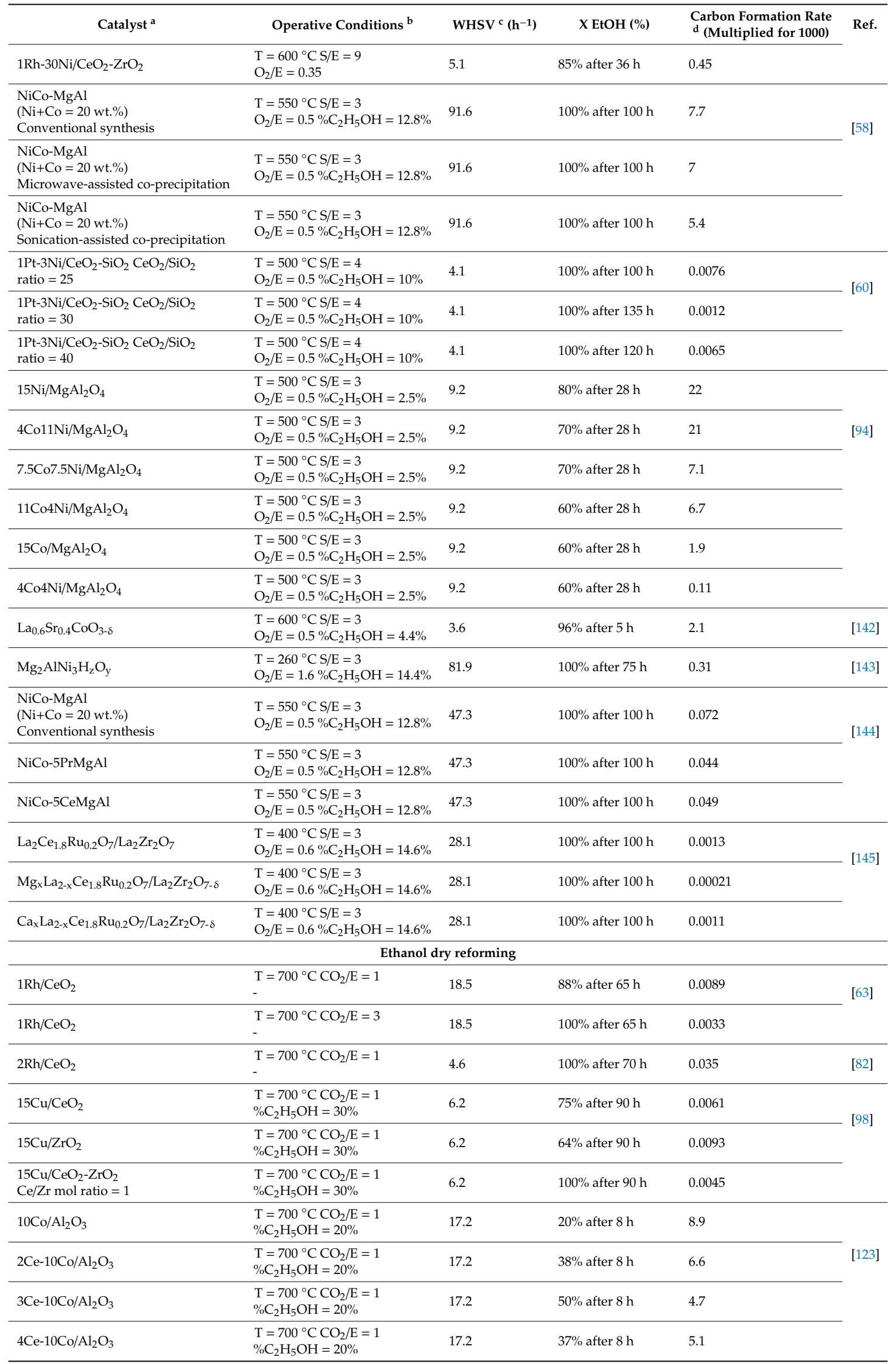


Table 1. Cont.

\begin{tabular}{|c|c|c|c|c|c|}
\hline Catalyst $^{\mathrm{a}}$ & Operative Conditions ${ }^{b}$ & WHSV $^{c}\left(h^{-1}\right)$ & X EtOH (\%) & $\begin{array}{l}\text { Carbon Formation Rate } \\
\text { d (Multiplied for 1000) }\end{array}$ & \multirow[t]{2}{*}{ Ref. } \\
\hline $5 \mathrm{Ce}-10 \mathrm{Co} / \mathrm{Al}_{2} \mathrm{O}_{3}$ & $\begin{array}{l}\mathrm{T}=700{ }^{\circ} \mathrm{CCO}_{2} / \mathrm{E}=1 \\
\% \mathrm{C}_{2} \mathrm{H}_{5} \mathrm{OH}=20 \%\end{array}$ & 17.2 & $34 \%$ after $8 \mathrm{~h}$ & 5.2 & \\
\hline $3 \mathrm{La} 10 \mathrm{Co} / \mathrm{Al}_{2} \mathrm{O}_{3}$ & $\begin{array}{l}\mathrm{T}=700^{\circ} \mathrm{CCO}_{2} / \mathrm{E}=1 \\
\% \mathrm{C}_{2} \mathrm{H}_{5} \mathrm{OH}=20 \%\end{array}$ & 17.2 & $30 \%$ after $72 \mathrm{~h}$ & 0.078 & [124] \\
\hline $10 \mathrm{Ni} / \mathrm{Al}_{2} \mathrm{O}_{3}$ calcined at $500^{\circ} \mathrm{C}$ & $\mathrm{T}=700{ }^{\circ} \mathrm{C} \mathrm{CO}_{2} / \mathrm{E}=3$ & 36.9 & $100 \%$ after $4 \mathrm{~h}$ & 5.5 & \multirow{3}{*}{ [147] } \\
\hline $10 \mathrm{Ni} / \mathrm{Al}_{2} \mathrm{O}_{3}$ calcined at $600^{\circ} \mathrm{C}$ & $\mathrm{T}=700{ }^{\circ} \mathrm{C} \mathrm{CO}_{2} / \mathrm{E}=3$ & 36.9 & $100 \%$ after $4 \mathrm{~h}$ & 6.7 & \\
\hline $10 \mathrm{Ni} / \mathrm{Al}_{2} \mathrm{O}_{3}$ calcined at $700^{\circ} \mathrm{C}$ & $\mathrm{T}=700{ }^{\circ} \mathrm{CCO}_{2} / \mathrm{E}=3$ & 36.9 & $100 \%$ after $4 h$ & 9.7 & \\
\hline
\end{tabular}

Note: ${ }^{a}$ The metal or oxides loadings are intended for the weight of the catalyst; ${ }^{b}$ all the tests were performed at atmospheric pressure; ${ }^{c}$ refers to the ethanol mass flow-rate; ${ }^{\mathrm{d}} \mathrm{g}_{\text {coke }} \cdot \mathrm{g}_{\text {catalyst }}{ }^{-1} \cdot \mathrm{g}_{\text {carbon,fed }}{ }^{-1} \cdot \mathrm{h}^{-1}$.

\section{Oxidative Biomethanol Steam Reforming}

Methanol is actually an attractive feedstock for reforming processes. It can be obtained from renewable and fossil sources [148], including biomass and $\mathrm{CO}_{2}$, thus offering a pathway to a sustainable carbon-neutral cycle [149]. It can be easily converted to hydrogen via the (oxy-) reforming processes, and the resulting gas mixture, without a water-gas shift unit [150], can be directly used in high-temperature proton exchange membrane fuel cells (Figure 8), or [151] after purification steps in low-temperature polymer electrolyte membrane (PEM) fuel cells [152].

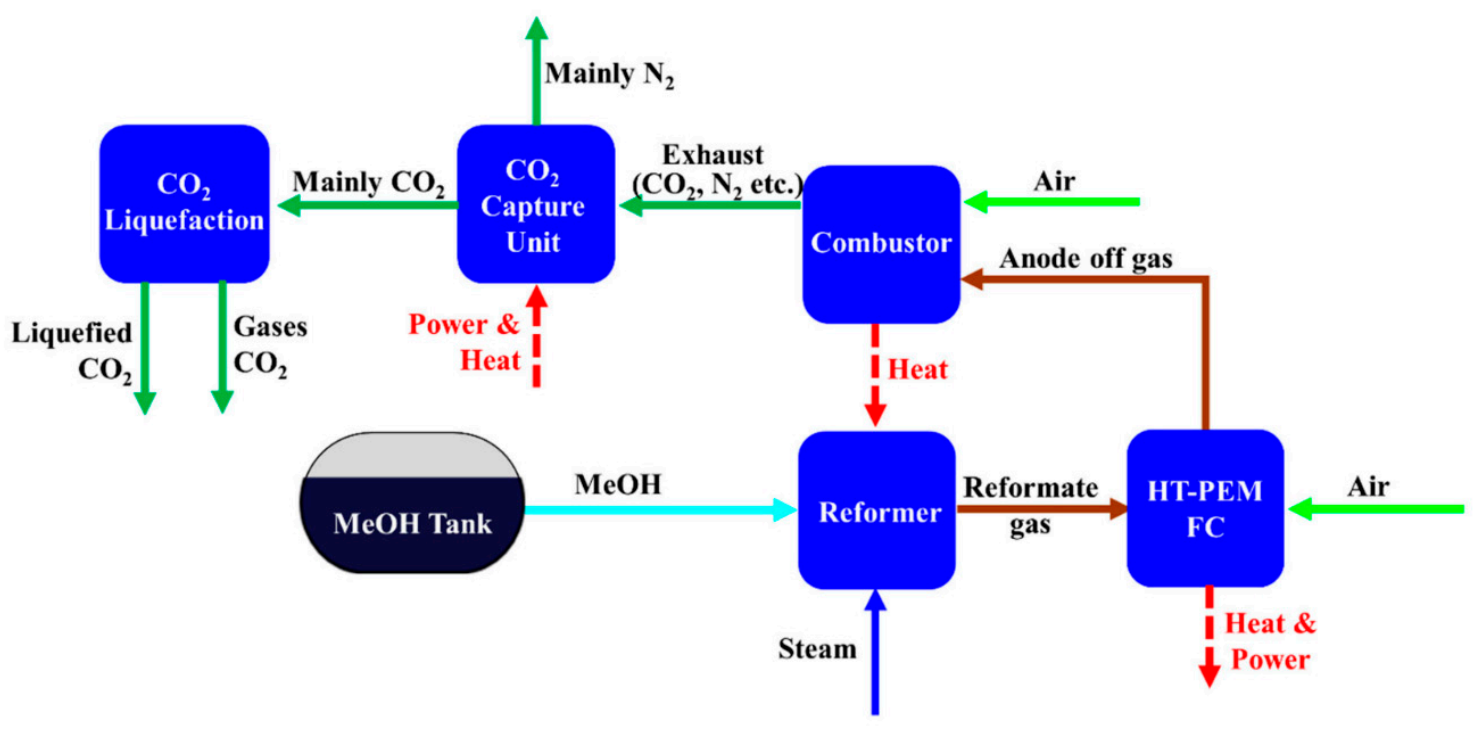

Figure 8. Block diagram of MSR-based system [150].

Many advantages were identified for using methanol for reforming processes. The molecule contains only one $\mathrm{C}$ atom, thus the absence of the $\mathrm{C}-\mathrm{C}$ bond prevents the formation of a series of by-products. During the reforming processes [153], its reforming temperatures are relatively low; moreover, its tendency to form coke is lessened due to the high H/C ratio [154]. Methanol steam reforming (MSR) can be described by the following chemical reactions [155]:

$$
\begin{gathered}
\mathrm{CH}_{3} \mathrm{OH}+\mathrm{H}_{2} \mathrm{O} \leftrightarrow \mathrm{CO}_{2}+3 \mathrm{H}_{2} \Delta H_{298 k}^{\circ}=+49.7 \mathrm{~kJ} \cdot \mathrm{mol}^{-1} \\
\mathrm{CO}+\mathrm{H}_{2} \mathrm{O} \leftrightarrow \mathrm{CO}_{2}+H_{2} \Delta H_{298 k}^{\circ}=-41.2 \mathrm{~kJ} \cdot \mathrm{mol}^{-1}
\end{gathered}
$$




$$
\mathrm{CH}_{3} \mathrm{OH} \leftrightarrow \mathrm{CO}+\mathrm{H}_{2} \Delta \mathrm{H}_{298 k}^{\circ}=+90.7 \mathrm{~kJ} \cdot \mathrm{mol}^{-1}
$$

The MSR reaction is endothermic and takes place with an increase in the number of moles; on the contrary, the water-gas shift reaction is exothermic and proceeds without a variation in the number of moles.

In this section, the results of selected studies published in the last five years on methanol (oxy-) steam reforming are reported. In the first paragraph, recent studies on the most-diffused active phases in MSR will be discussed. In the second section, comparative studies on the effects of the support will be reported. In the third section, the effects of promoters will be discussed, while theoretical and simulation studies, as well as non-conventional reactor configurations, will be reported in the fourth section. Finally, a selection of recent articles devoted to the oxidative steam reforming of methanol will be proposed. The paper distribution as a function of the active phase in the bibliographic survey reveals that copper is the preferred metal in methanol reforming; however, noble metals such as gold, platinum, and palladium are also used (Figure 9).

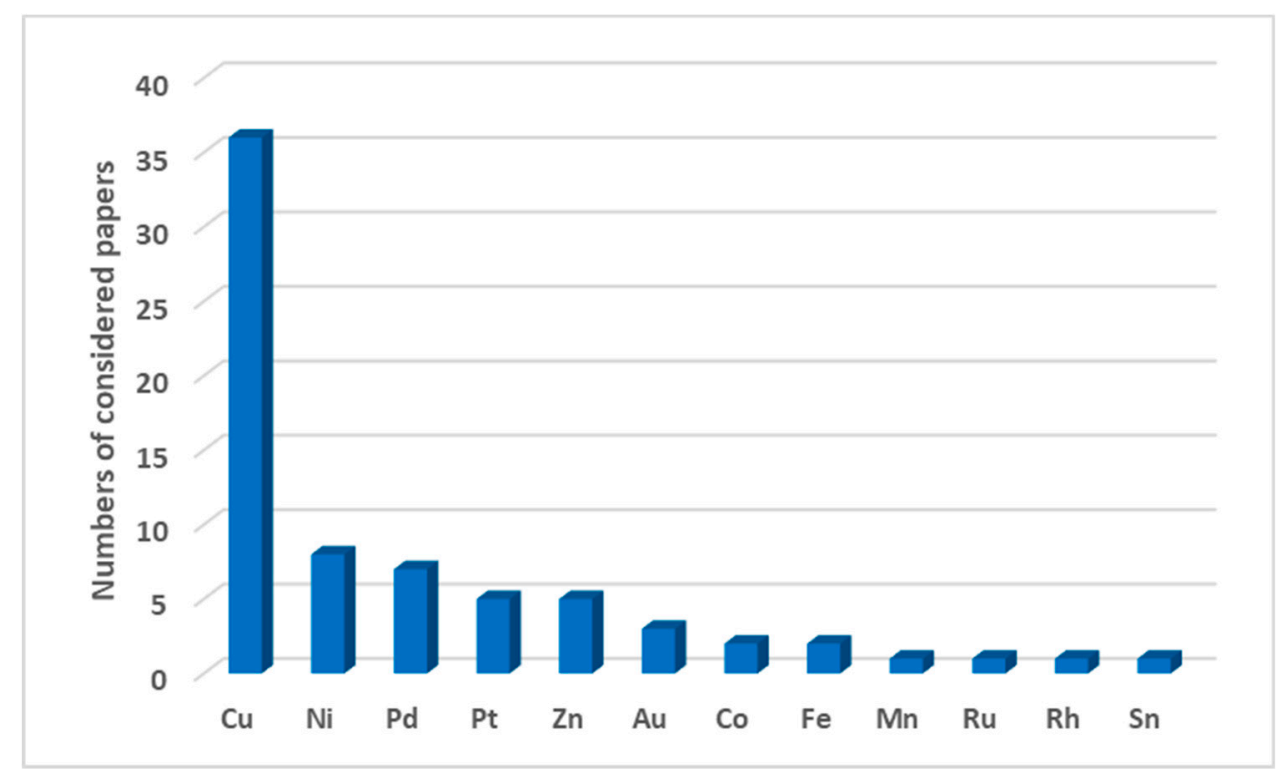

Figure 9. Number of considered papers as a function of the active phase analyzed for the methanol reforming.

\subsection{The Influence of the Active Phase}

As previously stated, in this section, the main results of a selection of articles on the effects of the active phase are reported. Most of them study copper-based catalysts, while only two cases are based on noble metal catalysts, palladium, or platinum.

Tonelli et al. investigated the stability of copper supported on ceria in MSR [156]. The ceria support was prepared by precipitation method with ammonium hydroxide from a solution of cerium (III) nitrate, while the catalyst was obtained by incipient wetness impregnation of the support with a copper (II) nitrate solution. The MSR tests were carried out on the catalyst, without reduction, at atmospheric pressure, at three temperatures $\left(260,280\right.$, and $\left.300^{\circ} \mathrm{C}\right)$, with a gaseous mixture of methanol, water, and nitrogen. The total flow rate was $82 \mathrm{~mL} \cdot \mathrm{min}^{-1}$, with a methanol molar percentage of $5 \%$ and a $\mathrm{H}_{2} \mathrm{O} / \mathrm{CH}_{3} \mathrm{OH}$ molar ratio equal to 1.2 , while the catalyst weight was $300 \mathrm{mg}$. The activity was evaluated under steady-state conditions during a time-on-stream of $60 \mathrm{~h}$ and under shutdown-start-up operation, under inert conditions. In all experiments, the initial methanol conversion was higher than $80 \%$ and the selectivity to hydrogen was $100 \%$; however, the activity decreased with the time-on-stream. In the case of steady-state conditions, the conversion losses were $76 \%$ at $300{ }^{\circ} \mathrm{C}, 78 \%$ at $280{ }^{\circ} \mathrm{C}$, and $67 \%$ at $260{ }^{\circ} \mathrm{C}$ after $3000 \mathrm{~min}$ in reaction, while the catalyst was regenerated by air treatment at $400{ }^{\circ} \mathrm{C}$. 
For the discontinuous mode, the initial conversion and conversion until 500 min were the same as that obtained under the continuous regime. Moreover, after the stop period, the activity was recovered and self-activation occurred. The X-ray photoelectron spectroscopy (XPS) spectra suggested that the deactivation was mainly attributed to the adsorption of carbonate or formate species, which can be desorbed under inert flow or air burning. The $\mathrm{Cu} 2 \mathrm{p}$ XPS spectra sample after reduction and after inert treatments showed a decreased $\mathrm{Cu}$ surface content, which could be due to the $\mathrm{Cu}$ migration out of the ceria lattice or to the redispersion of the $\mathrm{Cu}$ particles; moreover, an overreduction of ceria may have also occurred. The effect of $\mathrm{Cu}$ loading $(\mathrm{Cu}=7,10$, or 15 at $\%)$ on $\mathrm{Ce}_{\mathrm{X}} \mathrm{Zr}_{1-\mathrm{x}} \mathrm{O}_{2}(\mathrm{x}=0.4,0.5$, $0.6,0.7$, and 0.8 ) solid solutions was investigated by Das et al. [157]. The catalytic activity tests were performed in the temperature range of $200-330^{\circ} \mathrm{C}$, at atmospheric pressure, with a steam/methanol ratio of $1.1(\mathrm{~mol} / \mathrm{mol})$, using nitrogen $\left(23.5 \mathrm{~mL} \mathrm{~min}^{-1}\right)$ as the carrier and internal standard at a gas hourly space velocity $(\mathrm{GHsV})$ of $40,000 \mathrm{~h}^{-1}$. The results showed that the most-active catalysts had a $\mathrm{Ce} / \mathrm{Zr}$ ratio equal to 0.6 and $\mathrm{Cu}$ loading of 10 and 15 at $\%$; the MSR behaviour was found to be sensitive to the pretreatment, as evident in the case of the $10 \mathrm{at} \% \mathrm{Cu} / \mathrm{Ce}_{0.6} \mathrm{Zr}_{0.4} \mathrm{O}_{2}$ and $15 \mathrm{at} \% \mathrm{Cu} / \mathrm{Ce}_{0.6} \mathrm{Zr}_{0.4} \mathrm{O}_{2}$ catalysts, which perform better without pretreatment for the former and in the regenerated form for the latter. The time-on-stream activity tests showed a constant decrease of the $\mathrm{CH}_{3} \mathrm{OH}$ conversion over $50 \mathrm{~h}$ for both $10 \mathrm{at} \% \mathrm{Cu} / \mathrm{Ce}_{0.6} \mathrm{Zr}_{0.4} \mathrm{O}_{2}$ and 15 at $\% \mathrm{Cu} / \mathrm{Ce}_{0.6} \mathrm{Zr}_{0.4} \mathrm{O}_{2}$ catalysts; the XPS analysis showed that the surface atomic ratio of copper decreased from $5.9 \%$ before the activity tests to $1.4 \%$ after the activity test, demonstrating that the formation of reduced $\mathrm{Cu}$ is accompanied by sintering; moreover, carbon formation also occurred. These results suggested that the formation of large aggregates of copper covered with coke could be responsible for the loss in activity. After the regeneration, these aggregates break into a mixture of oxidized $\left(\mathrm{Cu}^{2+}\right)$ and reduced $\left(\mathrm{Cu}^{0}\right.$ and $\left.\mathrm{Cu}^{+}\right)$copper species and the catalysts recover the activity, suggesting a correlation between the activity and different proportions of copper components in the various forms of these catalysts. Deshmane et al. studied the effect of $\mathrm{Cu}$ loading $(\mathrm{Cu}=5-20 \mathrm{wt} . \%)$ on high surface area MCM-41 prepared by one-pot synthesis [158]. The Cu-MCM-41 catalysts were reduced before the catalytic activity tests with $4 \%$ hydrogen in argon at $550{ }^{\circ} \mathrm{C}$ for $5 \mathrm{~h}$. The tests were carried out at atmospheric pressure with a mixture $\mathrm{CH}_{3} \mathrm{OH} / \mathrm{H}_{2} \mathrm{O}$ (molar ratio $=1: 3)$ at a GHSV of $2838 \mathrm{~h}^{-1}$ in the temperature range of $200-350{ }^{\circ} \mathrm{C}$. The results showed that the methanol conversion increased with the increase of the $\mathrm{Cu}$ loading until $15 \mathrm{wt}$ \% for Cu-MCM-41, which showed $\approx 89 \%$ conversion, $100 \%$ hydrogen selectivity, and $0.8 \% \mathrm{CO}$ selectivity at $300{ }^{\circ} \mathrm{C}$. A further increase of copper loading was detrimental; methanol conversion decreased to about $77 \%$ when the $\mathrm{Cu}$ loading was $20 \mathrm{wt} . \%$. This result was attributed to the decrease in catalysts' surfaces area leading to a decrease in $\mathrm{Cu}$ dispersion. The time-on-stream test was carried out on 15wt.\% Cu-MCM-41 and 20wt.\% $\mathrm{Cu}-\mathrm{MCM}-41$, with the latter showing strong resistance to deactivation at $48 \mathrm{~h}$ of reaction, suggesting that the use of a high surface area MCM-41 support significantly enhanced the stability of Cu-based catalysts. The thermogravimetric analysis of the spent catalysts showed the presence of $\sim 1.3 \%$ and $\sim 2.1 \%$ carbon for $15 \%$ Cu-MCM-41 and 20\% Cu-MCM-41 catalysts, respectively. Xu et al. studied the effect of the preparation method on the catalytic activity of $\mathrm{Cu}$-based composite oxide catalysts for MSR [159]. Two catalyst were prepared, the first $\left(\mathrm{Cu}-\mathrm{ZnO}-\mathrm{Al}_{2} \mathrm{O}_{3}-\mathrm{ZrO}_{2}-\mathrm{Ga}_{2} \mathrm{O}_{3}\right.$ with $\mathrm{Cu} / \mathrm{Zn} / \mathrm{Al} / \mathrm{Zr} / \mathrm{Ga}=$ 14.9:30.9:3.9:10.8:1.9 mass ratio) by urea co-precipitation and active carbon co-nanocasting technique, and the other $\left(\mathrm{Cu}-\mathrm{ZnO}-\mathrm{Al}_{2} \mathrm{O}_{3}-\mathrm{ZrO}_{2}-\mathrm{Ga}_{2} \mathrm{O}_{3}\right.$ with $\mathrm{Cu} / \mathrm{Zn} / \mathrm{Al} / \mathrm{Zr} / \mathrm{Ga}=13.3: 28.2: 3.9: 10.0: 1.8$ mass ratio) by conventional co-precipitation method. The catalytic activity tests were performed at atmospheric pressure, with a methanol solution $\left(\mathrm{CH}_{3} \mathrm{OH} / \mathrm{H}_{2} \mathrm{O}=1: 1 \mathrm{molar}\right.$ ratio), a liquid flow rate of $0.03 \mathrm{~mL} \cdot \mathrm{min}^{-1}$, and a $\mathrm{F}_{\text {reactant }} \cdot \mathrm{W}_{\mathrm{cat}}{ }^{-1}=6000 \mathrm{~mL}^{*} \mathrm{~g}_{\mathrm{cat}}{ }^{-1} \mathrm{~h}^{-1}$. The results highlighted the better performance of the catalyst obtained with the active carbon co-nanocasting technique in terms of methanol conversion, hydrogen selectivity, and turnover frequency (TOF) values; moreover, no $\mathrm{CO}$ formation was reported. This trend was also confirmed in the stability tests carried out at $275^{\circ} \mathrm{C}$ for $70 \mathrm{~h}$, which showed a slight deactivation for the catalysts prepared with the active carbon co-nanocasting technique, while a continuous deactivation occurred in the other case. This result was attributed to the smaller $\mathrm{Cu}$ particle size distribution and higher metal-support interaction obtained with the active carbon co-nanocasting 
technique. Moreover, the temperature-programmed oxidation (TPO) profiles of this catalyst after the stability test showed a peak at $252^{\circ} \mathrm{C}$ and a shoulder at $451^{\circ} \mathrm{C}$, which were assigned to the deposition of amorphous carbon. The TPO of the catalysts obtained by conventional co-precipitation method after the stability test showed two peaks at 411 and $657^{\circ} \mathrm{C}$; the second one was attributed to the formation of graphitic coke, which is more stable and oxidizable only at high temperatures. Thattarathody and Sheintuch investigated the kinetic and dynamic behaviour of MSR on a $\mathrm{CuO} / \mathrm{ZnO} / \mathrm{Al}_{2} \mathrm{O}_{3}$ commercial catalyst at various steam-to-carbon ratios $(\mathrm{S} / \mathrm{C}=0,0.5,1)$, in a steady state and with temperature ramping conditions $\left(140-300{ }^{\circ} \mathrm{C}\right)$ [160]. High activity was observed above $200^{\circ} \mathrm{C}$; moreover, rate oscillation was observed under isothermal conditions at a steam-to-carbon ratio equal to 1 , as evident in the volumetric product compositions shown in Figure 10.
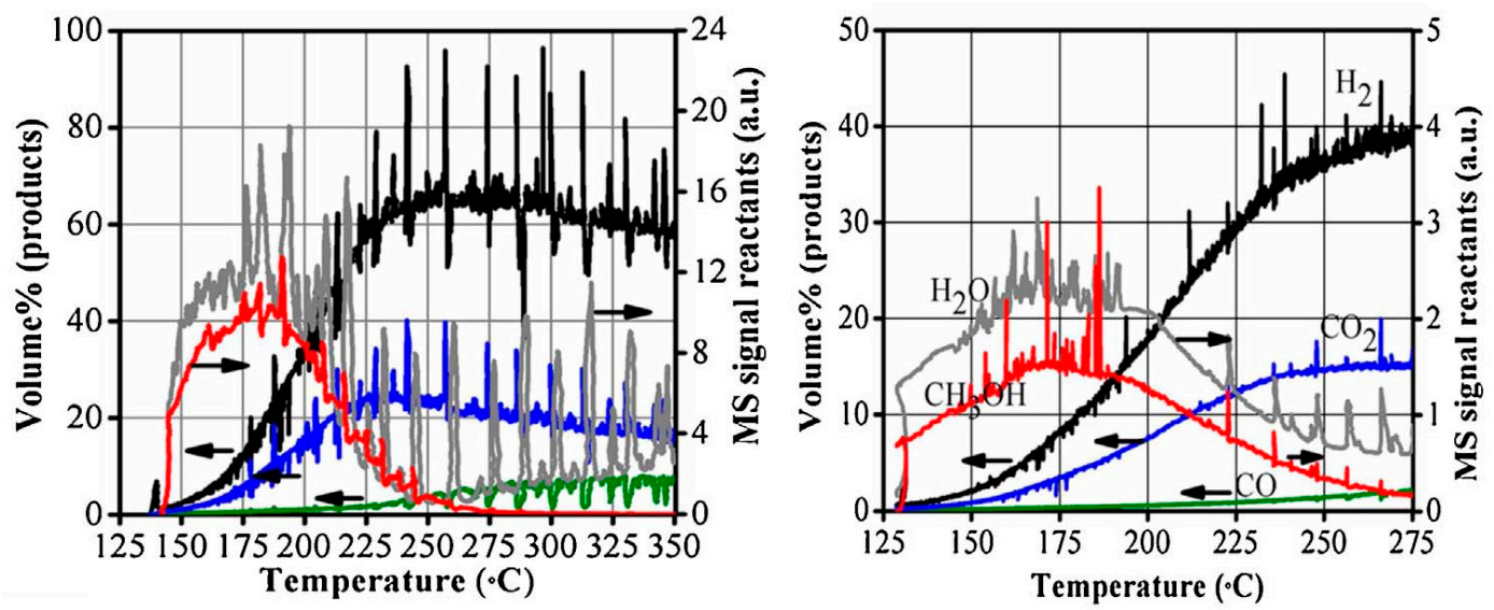

Figure 10. Comparison of product compositions during methanol steam reforming $(S / C=1)$ with an Ar flow of $10 \mathrm{~mL} / \mathrm{min}$ (left) and $50 \mathrm{~mL} / \mathrm{min}$ (right) [160].

After the tests, scanning TPO experiments were carried out to evaluate the amount of coke produced with the three different steam-to-carbon ratios $(0,0.5$, and 1.0), obtaining $0.0187,0.017$, and $0.018 \mathrm{~g}$ of carbon per $\mathrm{g}$ of catalyst, respectively. Bagherzadeh et al. studied the effect of the exposition of $\mathrm{CuO} / \mathrm{ZnO} / \mathrm{Al}_{2} \mathrm{O}_{3}$ catalysts prepared by hydrothermal and co-precipitation methods for glow-discharge plasma for $45 \mathrm{~min}$ at $1000 \mathrm{~V}$ in MSR [161]. The catalytic activity tests were carried out in the temperature range of $180-300{ }^{\circ} \mathrm{C}$, at a GHSV of $10,000 \mathrm{~cm}^{3} \cdot \mathrm{gcat}^{-1} \cdot \mathrm{h}^{-1}$; the volumetric flow rate of the argon carrier gas was set on $66.7 \mathrm{~cm}^{3} \cdot \mathrm{min}^{-1}$ and the $\mathrm{H}_{2} \mathrm{O} / \mathrm{CH}_{3} \mathrm{OH}$ molar ratio was approximately equal to 1.5. The characterization results demonstrated the benefits of coupling the co-precipitation method with glow-discharge plasma. X-ray diffraction (XRD) patterns highlighted the better dispersion of $\mathrm{CuO}$ (111) and another crystallite facet. Moreover, the SEM micrographs showed a more uniform distribution of isomorph particles, which had a smaller particles size and better surficial morphology, and the BET analysis demonstrated a higher specific surface area for the sample obtained by co-precipitation and following treatment with plasma. Accordingly, the results of the catalytic activity tests showed higher methanol conversion and better selectivity for the catalyst prepared by plasma-assisted co-precipitation method. For example, the methanol conversion and CO selectivity at $240{ }^{\circ} \mathrm{C}$ were $95 \%$ and $0.24 \%$, respectively; in addition, the time-on-stream test showed no significant deactivation over $900 \mathrm{~min}$ of reaction. Ajamein et al. studied the effect of fuel type (sorbitol, propylene glycol, glycerol, diethylene glycol, or ethylene glycol) in the preparation of $\mathrm{CuO} / \mathrm{ZnO} / \mathrm{Al}_{2} \mathrm{O}_{3}$ nanocatalysts obtained by microwave-enhanced combustion method for MSR [162]. The catalytic activity tests were carried out in the temperature range of $160-300{ }^{\circ} \mathrm{C}$, with a methanol/water ratio equal to 1.5. The results showed that the best performance was related to the use of ethylene glycol as fuel in the preparation of the catalyst. The characterization results demonstrated that sorbitol led to the formation of copper oxide species that were more crystalline in structure and assured a lower 
dispersion of crystallite active sites, especially the $\mathrm{Cu}(111)$ facet. The use of ethylene glycol resulted in a homogeneous morphology and narrow particles size distribution (the average surface particle size was about $265 \mathrm{~nm}$ ). The catalytic activity tests highlighted the better performance of the catalyst prepared with the assistance of ethylene glycol, which showed total methanol conversion at $260^{\circ} \mathrm{C}$, with a negligible $\mathrm{CO}$ selectivity. The stability tests of the catalysts obtained by sorbitol and propylene glycol showed total conversion during the first $600 \mathrm{~min}$ and a considerable drop over a further $800 \mathrm{~min}$. On the other hand, no deactivation occurred with the catalyst prepared by ethylene glycol. Among the polyol used, sorbitol had the highest polarity, facilitating the growth of $\mathrm{Zn}(002)$ crystals as the polar facet of zinc crystallites, improving the carbon monoxide formation. A comparative study on the use of different active metals supported on M-MCM-41 (M: Cu, Co, Ni, Pd, Zn, and $\mathrm{Sn}$ ), prepared by one-pot hydrothermal procedure, was proposed by Abrokwah et al. [163]. The activity tests were carried out under the same conditions previously reported [158], highlighting the best performance of the Cu-based catalyst, which showed methanol conversion of $68 \%$, hydrogen selectivity of $100 \%$, and CO selectivity of $6 \%$ at $250{ }^{\circ} \mathrm{C}$. On the other hand, PdMCM- 41 and Ni-MCM- 41 catalysts showed reduced activity for the water-gas shift reaction, resulting in higher $\mathrm{CO}$ selectivity. The stability tests were carried out at $300{ }^{\circ} \mathrm{C}$ for $40 \mathrm{~h}$; the $\mathrm{Cu}-\mathrm{MCM}-41$ catalyst displayed an initial increase in the conversion with time due to the unsteady state; thereafter, the conversion stabilized at $\approx 74 \%$ and no apparent deactivation occurred with a further $30 \mathrm{~h}$ of reaction. Except for Cu-MCM-41 and Co-MCM-41, all the other catalysts showed a decreasing trend for methanol conversion, which was attributed to coking and sintering. The thermogravimetric analysis differential scanning calorimeter (TGA-DSC) thermograms showed a nominal (absolute) $0.25 \%-0.96 \%$ coke formation between 400 and $570{ }^{\circ} \mathrm{C}$ that was attributed to the formation of amorphous and graphitic carbon. TPD studies on cobalt-manganese oxides demonstrated that the reaction paths of adsorbed methanol lead to decomposition to $\mathrm{CO}$ and $\mathrm{H}_{2}$, as well as formation of stable surface formates, which decompose at higher temperatures to $\mathrm{CO}_{2}$ and $\mathrm{H}_{2}$ [164]. Li et al. investigated the catalytic activity of $\mathrm{Mn}-, \mathrm{Fe}-, \mathrm{Co}-, \mathrm{Ni}^{-}, \mathrm{Cu}-$, and $\mathrm{Zn}$-based catalysts in the methanol, acetic acid, and acetone steam reforming [165]. The activity tests for MSR were performed with a steam-to-carbon ratio equal to 5 and a liquid hourly space velocity (LHSV) of $12.7 \mathrm{~h}^{-1}$ at atmospheric pressure, in the temperature range of $200-500{ }^{\circ} \mathrm{C}$. The results showed that $\mathrm{Mn}-, \mathrm{Fe}-$, and $\mathrm{Zn}$-based catalysts were not active in MSR due to the low ability to break the chemical bonds or to activate the steam. On the contrary, $\mathrm{Cu}$ - and Co-based catalysts were both active; however, Co promoted methanol decomposition, showing higher $\mathrm{CO}$ selectivity. The supported metals showed different catalytic behaviour with respect to the unsupported one; for example, in MSR, the unsupported $\mathrm{Cu}$ catalysts showed lower stability than the supported one, which rapidly deactivated (Figure 11).
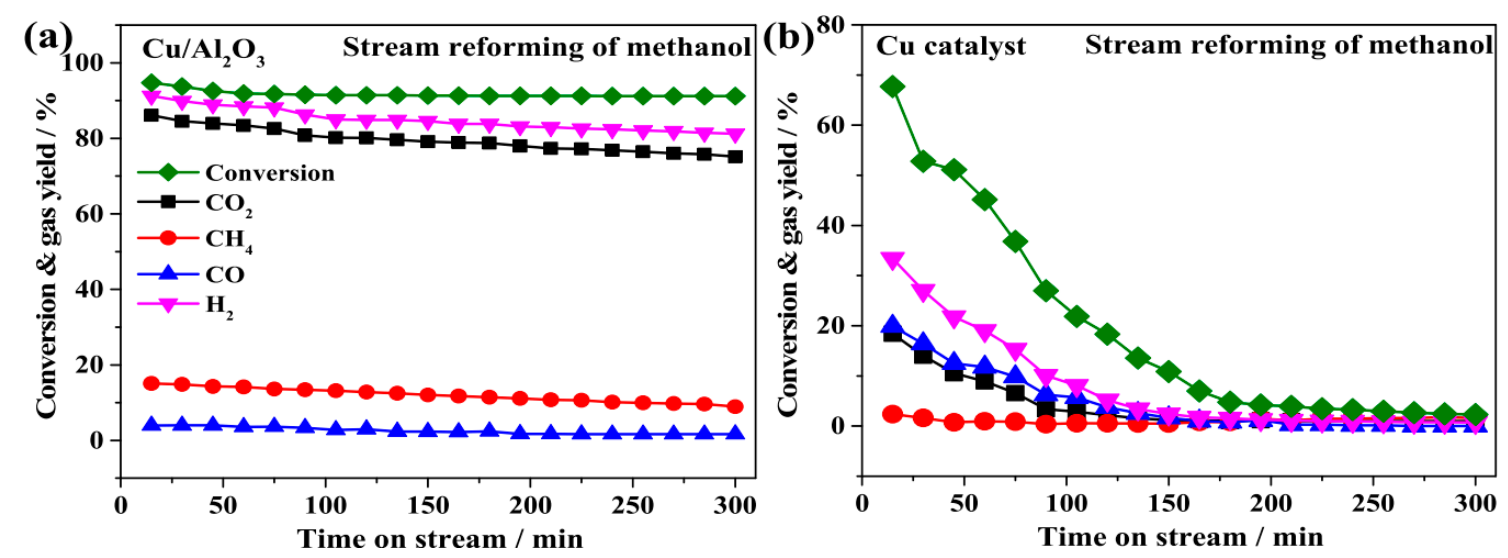

Figure 11. Time-on-stream tests (MSR) for $\mathrm{Cu} / \mathrm{Al}_{2} \mathrm{O}_{3}(\mathbf{a})$ and $\mathrm{Cu}(\mathbf{b})$ catalysts. Reaction conditions: $\mathrm{S} / \mathrm{C}=1.5 ; \mathrm{T}=500{ }^{\circ} \mathrm{C} ; \mathrm{LHSV}=12.7 \mathrm{~h}^{-1} ; \mathrm{P}=1 \mathrm{~atm}[165]$. 
It is worthwhile noting that the TPO profiles and the thermogravimetric analysis of the catalyst used in acetic acid and acetone steam reforming demonstrated the formation of a large amount of coke for all the catalysts. Conversely, carbon formation was really low in the case of MSR. Maiti et al. investigated the catalytic activity towards the MSR of a series of copper-ion-substituted $\mathrm{CuMAl}_{2} \mathrm{O}_{4}$ $(\mathrm{M}=\mathrm{Mg}, \mathrm{Mn}, \mathrm{Fe}$ and $\mathrm{Zn})$ spinels prepared via single-step solution combustion synthesis [166]. The catalytic activity tests were carried out in the temperature range of $200-330{ }^{\circ} \mathrm{C}$, under atmospheric pressure, with a steam/methanol ratio of 1.1 (molar basis), at a GHSV of $30,000 \mathrm{~h}^{-1}$. Among the studied catalysts, the $\mathrm{Cu}_{0.1} \mathrm{Fe}_{0.9} \mathrm{Al}_{2} \mathrm{O}_{4}$ was the most active, showing methanol conversion of $\approx 98 \%$ and $\mathrm{CO}$ selectivity of $\approx 5 \%$ at $300{ }^{\circ} \mathrm{C}$. On the other hand, the analogous impregnated catalyst, $10 \mathrm{at} \% \mathrm{CuO} / \mathrm{FeAl}_{2} \mathrm{O}_{4}$, showed less catalytic activity. The time-on-stream tests showed a decrease of the methanol conversion from $50 \%$ to $35 \%$ over $20 \mathrm{~h}$ of reaction at a temperature of $250{ }^{\circ} \mathrm{C}$. The evaluation of the XRD and high-resolution transmission electron microscopy (TEM) analysis showed the formation of a stable spinel phase containing substitutional copper ions, which stayed intact after $20 \mathrm{~h}$ of reaction. The decrease in the activity after the time-on-stream tests was attributed to the sintering of the catalyst, which also caused lowering of the copper surface concentration. $\mathrm{Cu}-\mathrm{Ni}-\mathrm{Al}$ spinel catalysts prepared by solid-phase method using copper hydroxide, nickel acetate, and pseudoboehmite as starting materials were studied by Qing et al. [167]. The results showed that $\mathrm{Cu}-\mathrm{Ni}-\mathrm{Al}$ spinels with molar ratios of 1:0.05:2 and 1:0.05:3 can be prepared at a calcination temperature ranging from 900 to $1100^{\circ} \mathrm{C}$; the spinel content increased with the calcination temperature. The catalytic performance was related to the calcination temperature of the catalyst, so the catalyst obtained at $1000^{\circ} \mathrm{C}$ showed the best catalytic performance. The stability tests carried out at $255^{\circ} \mathrm{C}$ and a weight hourly space velocity (WHSV) of $2.18 \mathrm{~h}^{-1}$ showed no significant deactivation after $300 \mathrm{~h}$; however, the diffractograms of the spent catalysts showed a shift of the peaks to high angles, confirming a gradual release of $\mathrm{Cu}$ during the reaction process. Luo et al. developed nano- $\mathrm{Ni}_{X} \mathrm{Mg}_{Y} \mathrm{O}$ solid-solution oxides prepared by impregnation, hydrothermal treatment, and co-precipitation as catalysts for MSR [168]. The catalytic activity tests were carried out under atmospheric pressure with a mixture of water and methanol (molar ratios of 1 or 3 ) and a GHSV of $92,000 \mathrm{~mL} \cdot \mathrm{g}_{\mathrm{cat}}{ }^{-1} \cdot \mathrm{h}^{-1}$ or $114,000 \mathrm{~mL} \cdot \mathrm{g}_{\mathrm{cat}}{ }^{-1} \cdot \mathrm{h}^{-1}$, at four different reaction temperatures $(400,500,600$, and $700{ }^{\circ} \mathrm{C}$ ). The best performance was obtained with the catalyst prepared by hydrothermal method, with methanol conversion of $97.4 \%$ and a hydrogen yield of $58.5 \%$, which was maintained for $20 \mathrm{~h}$ at a steam-to-carbon ratio of 3 . This superior catalytic activity was attributed to the nanoscale active phase and to the high micropore volume; moreover, the excellent anticarbon deposition capability was attributed to the formation of the solid solution, which was able to prevent the agglomeration of nickel particles, and to the high basicity of the magnesium oxide supports, which supplied oxygen from the adsorbed $\mathrm{CO}_{2}$ and $\mathrm{H}_{2} \mathrm{O}$ to burn off the amorphous carbon. Zeng et al. reported a study on the preparation and use of $\mathrm{Pd} / \mathrm{ZnO}$-based catalysts in MSR, which were synthesized by reduction with $\mathrm{NaHB}_{4}$ from Pd ions supported on a zeolitic imidazolate framework-8 (ZIF-8) [169]. The activity tests were carried out with various methanol/water molar ratios ranging from 1 to 6 , in the temperature range $250-380{ }^{\circ} \mathrm{C}$, with a flow rate from 0.01 to $0.2 \mathrm{~mL} \cdot \mathrm{min}^{-1}$. The activity of two catalysts that were synthesized by reduction and calcined at 400 and $450{ }^{\circ} \mathrm{C}$, respectively, was compared to that of two catalysts obtained by wet impregnation method and to that of a commercial $\mathrm{CuO} / \mathrm{ZnO} / \mathrm{Al}_{2} \mathrm{O}_{3}$ catalyst. The best performance in terms of methanol conversion $(97 \%), \mathrm{CO}_{2}$ selectivity $(86.3 \%)$, and stability after a time-on-stream test of $50 \mathrm{~h}$ was obtained with the catalyst prepared by reduction and calcined at $450{ }^{\circ} \mathrm{C}$. This result was attributed to the larger surface area, the evenly distributed PdZn alloy activity sites, and abundant oxygen vacancies. A reaction mechanism was also suggested, in which the PdZn surface stabilizes the intermediate methyl formate and could provide a benefit to the adsorption of hydrogenated O-anchored species, such as $\mathrm{HCOOH}, \mathrm{H}_{2} \mathrm{CO}$, and $\mathrm{CH}_{3} \mathrm{OH}$. Defects are able to alter the adsorption characteristics of these molecules, promoting dissociation; moreover, surface oxygen can enable water dissociation at low coverage, which is the key kinetic step in water splitting. Finally, the $\mathrm{CO}$ formation can be disfavored by the oxygen vacancies in the $\mathrm{ZnO}$ support. Claudio-Piedras et al. investigated the effect of the platinum precursor in Pt nanocatalysts supported 
on $\mathrm{CeO}_{2}$ nanorods in MSR [170]. The catalysts were prepared by impregnation with $\mathrm{Pt}\left(\mathrm{NH}_{3}\right)_{4}\left(\mathrm{NO}_{3}\right)_{2}$, $\left(\mathrm{CH}_{3}-\mathrm{COCHCO}-\mathrm{CH}_{3}\right)_{2} \mathrm{Pt}$, and $\mathrm{H}_{2} \mathrm{PtCl}_{6}{ }^{*} 6 \mathrm{H}_{2} \mathrm{O}$. The best performance was obtained with the catalysts prepared from the nitrate precursor, showing higher hydrogen yield and methanol conversion ascribable to the improved redox process, as well as to the better Pt dispersion on the surface of ceria, which promoted the water-gas shift (WGS) reaction at moderate temperatures. The time-on-stream tests highlighted the high stability of all the catalysts, with no significant deactivation observed after $24 \mathrm{~h}$ of reaction.

\subsection{The Role of the Support}

In this section, some studies on the effect of the support on the catalytic behaviour are reported, focusing on the preparation method, the effect of the precursors, and on the type of phase; in one article, a comparative study on the use of different supports is also discussed.

Barrios et al. prepared and tested two series of palladium catalysts in the MSR reaction, supported on $\mathrm{ZnO}-\mathrm{CeO}_{2}$ nanocomposites $(\mathrm{Zn} / \mathrm{Ce}=0.5,1$ or 2$)$ and obtained by co-precipitation using oxalate or carbonate precursors [171]. For comparison, a series of catalysts were prepared by impregnation of mixed oxides, obtained through the incorporation of $\mathrm{ZnO}$ onto ceria by incipient wetness impregnation with two nominal loadings ( $3.5 \mathrm{wt} . \%$ and $11 \mathrm{wt} . \%$ ), and by impregnation of ceria and $\mathrm{ZnO}$ with palladium acetate. The catalytic activity tests were carried out in the temperature range of $125-350{ }^{\circ} \mathrm{C}$, with a gas mixture of $\mathrm{CH}_{3} \mathrm{OH} / \mathrm{H}_{2} \mathrm{O}(1 / 1)$ diluted in $\mathrm{He}(16$ vol. $\%$ ) at a GHSV of $71,500 \mathrm{~cm}^{3} \mathrm{~h}^{-1} \mathrm{~g}^{-1}$ and a $\mathrm{W} / \mathrm{F}^{0} \mathrm{CH} 3 \mathrm{OH}$ ratio, defined as the catalytic mass normalized for the methanol volumetric flow rate of $174 \mathrm{~g} \cdot \mathrm{h} \cdot \mathrm{m}_{\mathrm{CH} 3 \mathrm{OH}^{-3}}$. XPS spectroscopy and the $\mathrm{CO}$ chemisorption experiments highlighted the formation of bulk and surface PdZn alloys in the ternary catalysts. The $2 \mathrm{wt} . \% \mathrm{Pd} / \mathrm{CeO}_{2}$ catalyst caused $\mathrm{CO}$ decomposition at $250{ }^{\circ} \mathrm{C}$ and reversed the water-gas shift at higher temperatures. The MSR occurred in all catalysts in which $\mathrm{ZnO}$ was present; however, the catalysts prepared by impregnation of the supports obtained by carbonate co-precipitation showed the highest $\mathrm{CO}_{2}$ selectivity due to the better dispersion of the $\mathrm{ZnO}$ phase. The time-on-stream tests carried out over $50 \mathrm{~h}$ of reaction showed that in the case of $\mathrm{Pd} / \mathrm{CeO}_{2}$, the methanol conversion $(80 \%)$ and the $\mathrm{CO}_{2}$ selectivity $(8 \%)$ remained constant after $18 \mathrm{~h}$ on stream. The $\mathrm{Pd} / \mathrm{ZnO}$ sample displayed a continuous decrease of methanol and water conversion; however, $\mathrm{CO}_{2}$ selectivity remained almost constant at $90 \%$. Both nanocomposite-supported $\mathrm{Pd}$ catalysts showed deactivation during the first $24-28 \mathrm{~h}$, followed by stabilized methanol conversions of $53 \%$ and $40 \%$ for the $\mathrm{Pd} / \mathrm{ZnO}-\mathrm{CeO}_{2}$ and $\mathrm{Pd} / \mathrm{ZnO} / \mathrm{CeO}_{2}$ samples, respectively, with selectivity of $80 \%$. The PdZn alloy formation seems to play a crucial role in preventing the methanol decomposition and in releasing hydrogen via inverse spillover, while the reforming reaction takes place mostly on the oxidized surface. Even though the nanocomposite-supported catalysts were less active and selective than the $\mathrm{Pd} / \mathrm{ZnO}$ catalysts, they showed much more stability, so that the $\mathrm{CeO}_{2}$ acted similarly to an "active dispersant of $\mathrm{ZnO}^{\prime}$. Ajamein et al. investigated the effect of the precursor type, ultrasound irradiation, and urea/nitrate ratio on the catalytic performance of $\mathrm{CuO} / \mathrm{ZnO} / \mathrm{Al}_{2} \mathrm{O}_{3}$ nanocatalysts prepared by ultrasound-assisted urea-nitrate combustion method in methanol steam reforming reaction [172]. The results showed that the use of boehmite precursor instead of aluminium nitrate reduces the crystallite size, increases the dispersion, and enhances the specific surface area of copper and zinc species. Comparing sonication and conventional mechanical mixing, the mixing of primary gel provided nanocatalysts with improved homogeneity. Moreover, the $\mathrm{CuO}$ and $\mathrm{ZnO}$ crystallite sizes and the specific surface areas increased with the urea/nitrate ratio. The best performance in the catalytic activity tests in term of methanol conversion and hydrogen yield were obtained with the catalyst prepared from boehmite with a urea/nitrate ratio equal to 1 obtained by ultrasound irradiation, due to the smaller crystallite sizes and to the highly dispersed particles. This catalyst was also subjected to a time-on-stream test at $240{ }^{\circ} \mathrm{C}$ for $1200 \mathrm{~min}$, with a $\mathrm{H}_{2} / \mathrm{CH}_{3} \mathrm{HO}$ ratio of 1.5 at a GHSV of $10,000 \mathrm{~cm}^{3} \mathrm{~g}^{-1} \mathrm{~h}^{-1}$, showing a decrease in methanol conversion from $100 \%$ to $90 \%$. Lin et al. reported the use of platinum atomically dispersed on $\alpha$-molybdenum carbide for low-temperature $\left(150-190^{\circ} \mathrm{C}\right)$ aqueous-phase methanol reforming, with an average TOF of 
18,046 moles of hydrogen per mole of platinum per hour [173]. The exceptional hydrogen production was attributed to the outstanding ability of $\alpha-\mathrm{MoC}$ to induce water dissociation, and to the synergy between platinum and $\alpha-\mathrm{MoC}$ in activating methanol with a $0.2 \mathrm{wt} . \% \mathrm{Pt} / \alpha-\mathrm{MoC}$ catalyst. DFT studies demonstrated that the $\alpha-\mathrm{MoC}$ support is able to provide highly active sites for water dissociation, with an activation energy of $0.56 \mathrm{eV}$, thus offering abundant surface hydroxyls and accelerating the methanol-reforming reaction at the interface between $\mathrm{Pt}_{1}$ and $\alpha$-MoC. Moreover, the geometry of the well-dispersed $\mathrm{Pt}_{1}$ maximizes the exposed active interface of $\mathrm{Pt}_{1} / \alpha-\mathrm{MoC}$ and increases the density of active sites for the reforming reaction. In a more recent study, Cai et al. investigated Zn-modified $\mathrm{Pt} / \mathrm{MoC}$ catalysts $(\mathrm{Zn}$ loading $=0-9.8 \%$ ) prepared by temperature-programmed reaction method in low-temperature methane steam reforming [174]. The activity tests were performed with $\mathrm{H}_{2} \mathrm{O}$ and $\mathrm{CH}_{3} \mathrm{OH}$ at a molar ratio of 3:1, in the temperature range of $120-200{ }^{\circ} \mathrm{C}$. The $\mathrm{Zn}$ doping favored the formation of $\alpha$-MoC1-x phase, enhancing the Pt dispersion and the interactions between $\alpha-\mathrm{MoC} 1-\mathrm{x}$ and $\mathrm{Pt}$ active sites. The $0.5 \mathrm{Zn}-\mathrm{Pt} / \mathrm{MoC}$ catalyst exhibited good performance in terms of hydrogen production, low $\mathrm{CO}$ selectivity, and good stability at $120^{\circ} \mathrm{C}$. However, at temperatures higher than $140^{\circ} \mathrm{C}$, the catalytic activity of this catalyst decreased during the initial stage of reaction, due to the sintering of Pt particles and to the change of $\alpha$-MoC1-x phase. A treatment with a 15 vol. $\% \mathrm{CH}_{4} / \mathrm{H}_{2}$ gas at $590{ }^{\circ} \mathrm{C}$ for $2 \mathrm{~h}$ was able to increase the catalytic activity of the spent $0.5 \mathrm{Zn}-\mathrm{Pt} / \mathrm{MoC}$ catalyst; however, the deactivation of the catalyst was inevitable. Liu et al. investigated the effects of supports in $\mathrm{Pt} / \mathrm{In}_{2} \mathrm{O}_{3} / \mathrm{MOx}$ catalysts $\left(\mathrm{MOx}=\gamma-\mathrm{Al}_{2} \mathrm{O}_{3}, \mathrm{MgO}, \mathrm{Fe}_{2} \mathrm{O}_{3}, \mathrm{La}_{2} \mathrm{O}_{3}\right.$, or $\mathrm{CeO}_{2}$ ) with Pt loading of $1 \mathrm{wt} . \%$ and $\mathrm{In}_{2} \mathrm{O}_{3}$ loading of $3 \mathrm{wt} . \%$ in MSR in the temperature range of $250-400{ }^{\circ} \mathrm{C}$ [175]. The catalytic activity tests were carried out in a flowing-type quartz tube (I.D. $=6.0 \mathrm{~mm}$ ), at a GHSV of between $12,870 \mathrm{~h}^{-1}$ and $38,610 \mathrm{~h}^{-1}$, with a steam-to-carbon ratio of between 0.6 to 1.8 . The activity tests showed that the prereduced $1 \mathrm{Pt} / 3 \mathrm{In}_{2} \mathrm{O}_{3} / \mathrm{CeO}_{2}$ catalyst exhibited the highest activity among the studied catalysts, with methanol conversion of $98.7 \%$, hydrogen selectivity of $100 \%$, and CO selectivity of $2.6 \%$ at $325{ }^{\circ} \mathrm{C}$, with a steam-to-carbon ratio of 1.4 and a GHSV of $12,870 \mathrm{~h}^{-1}$. These results were related to the active metal dispersion and enhanced redox properties associated with the strong interactions among $\mathrm{Pt}, \mathrm{In}_{2} \mathrm{O}_{3}$, and $\mathrm{CeO}_{2}$. Moreover, the $1 \mathrm{Pt} / 3 \mathrm{In}_{2} \mathrm{O}_{3} / \mathrm{CeO}_{2}$ catalyst showed good stability in the time-on-stream test over $32 \mathrm{~h}$. Díaz-Pérez et al. studied the $\mathrm{Cu}$-based catalysts supported on $\mathrm{SiO}_{2}, \mathrm{Al}_{2} \mathrm{O}_{3}-\mathrm{SiO}_{2}, \mathrm{TiO}_{2}$ rutile, and $\mathrm{TiO}_{2}$ anatase metal oxides for MSR [176]. The catalysts were prepared by wet impregnation with a loading of $20 \mathrm{wt} . \%$, while the activity tests were carried out with a steam-to-methanol ratio of 1:1.5. The results showed that on highly acidic supports such as $\mathrm{Al}_{2} \mathrm{O}_{3}-\mathrm{SiO}_{2}$, the methanol conversion decreased with the TOS due to carbon formation. On $\mathrm{TiO}_{2}$ anatase, the catalytic activity and stability was significantly lower than that on $\mathrm{TiO}_{2}$ rutile, probably due to the differences in adsorbate-surface binding on rutile and anatase. The catalyst supported on nanosized $\mathrm{SiO}_{2}$ showed the highest catalytic activity and selectivity. Time-on-stream tests were performed for over $80 \mathrm{~h}$ of reaction at low and high pressures, and no deactivation occurred; however, metal sintering was observed by means of HRTEM and XRD. The high activity and selectivity of $\mathrm{Cu} / \mathrm{SiO}_{2}$ was attributed to the low acid site concentration. Tahay et al. compared the performance of cubic and hexagonal phases of $\mathrm{ZnTiO}_{3}$ with $\mathrm{TiO}_{2}$ and $\mathrm{ZnO}$ as catalyst supports in MSR [177]. The $\mathrm{ZnTiO}_{3}$ phases were synthesized by sol-gel method, while copper was used as the active phase. The tests were carried out in the temperature range of $150-300{ }^{\circ} \mathrm{C}$ at a WHSV $1 \mathrm{~h}^{-1}$ under atmospheric pressure, with a mixture of $\mathrm{N}_{2} / \mathrm{H}_{2} \mathrm{O} /$ methanol at a ratio of 6:2:1. The results of the activity test showed that the $\mathrm{Cu} /$ cubic- $\mathrm{ZnTiO}_{3}$ catalyst exhibited high activity, high hydrogen selectivity. and low coke formation due to low-moderate acid sites in the cubic sample; moreover, the trend of methanol conversion at $300{ }^{\circ} \mathrm{C}$ is $\mathrm{Cu} /$ cubic- $\mathrm{ZnTiO}_{3}>\mathrm{Cu} / \mathrm{TiO}_{2}>\mathrm{Cu} /$ hexagonal- $\mathrm{ZnTiO}_{3}$. Time-on-stream tests showed a higher decrease of the methanol conversion of the $\mathrm{ZnTiO}_{3}$ hexagonal-based catalyst compared to the cubic-based one at $42 \mathrm{~h}$ of reaction. The thermogravimetric analysis revealed the presence of three weight losses: the first one between 25 and $200{ }^{\circ} \mathrm{C}$ was attributed to the water elimination, the second between 200 and $400{ }^{\circ} \mathrm{C}$ to the low-temperature oxidation of the copper, while the weight loss after $400{ }^{\circ} \mathrm{C}$ was attributed to the coke burning. The amount of deposited carbon in the case 
of $\mathrm{Cu} / \mathrm{cubic}-\mathrm{ZnTiO}_{3}$ was negligible; thus, the deactivation was only attributed to the $\mathrm{Cu}$ sintering process. The coke resistance of the $\mathrm{Cu} / \mathrm{cubic}-\mathrm{ZnTiO} \mathrm{O}_{3}$ catalyst could be related to the high $\mathrm{CO}_{2} / \mathrm{CO}$ ratio, which reduces the $\mathrm{CO}$ disproportionation on the catalysts' surfaces.

\subsection{The Effect of the Addition of Promoters}

In this section, a selection of recently published articles on the effect of promoters on the catalytic activity in MSR is reported. The sequence is settled based on the kind of promoter.

Talkhoncheh et al. studied the effect of the preparation method and the $\mathrm{CeO}_{2}$ promotion effect on $\mathrm{CuO} / \mathrm{ZnO} / \mathrm{Al}_{2} \mathrm{O}_{3} / \mathrm{ZrO}_{2}$-based nanocatalysts in the MSR reaction [178]. The catalysts were prepared by means of urea-nitrate combustion synthesis and homogeneous precipitation method; the catalytic activity tests were carried out at a temperature range of $200-300^{\circ} \mathrm{C}$ under atmospheric pressure at a GHSV of $10,000 \mathrm{~cm}^{3} \mathrm{~g}_{\mathrm{cat}}{ }^{-1} \mathrm{~h}^{-1}$, feeding a mixture of $\mathrm{H}_{2} \mathrm{O} / \mathrm{MeOH}$ with a ratio equal to 1.5. The XRD analysis and FESEM images showed that the homogeneous precipitation method and the $\mathrm{CeO}_{2}$ addition improves the dispersion, decreases the particle size, decreases the relative crystallinity of $\mathrm{CuO}$ and $\mathrm{ZnO}$ species, and enhances the surface homogeneity. The activity tests showed that the catalyst obtained by homogeneous precipitation method was more active in terms of high methanol conversion and low $\mathrm{CO}$ selectivity. Moreover, the $\mathrm{CeO}_{2}$ addition decreased the $\mathrm{CO}$ selectivity and reduced the methanol conversion. The stability test carried out on the ceria-promoted catalyst prepared by urea precipitation method showed no deactivation after $1200 \mathrm{~min}$ of time-on-stream. In fact, $\mathrm{CeO}_{2}$ was able to oxidize the carbon deposited on the nanocatalyst's surface. Taghizadeh et al. investigated the activity of cerium-promoted copper-based catalysts synthesized via conventional and surfactant-assisted impregnation methods using KIT-6 as support in MSR [179]. The activity tests were carried out at atmospheric pressure, with a methanol-to-water molar ratio of $\frac{1}{2}$ and at a WHSV of $2 \mathrm{~h}^{-1}$. The results demonstrated that the incorporation of cerium oxide improved the performance of the $\mathrm{Cu} / \mathrm{KIT}$-6-based catalysts due to the higher dispersion and to the smaller size of $\mathrm{Cu}$ particles; moreover, the surfactant-assisted impregnation enhanced the physiochemical properties of the resulting Ce-promoted catalysts. The catalyst prepared with this method showed methanol conversion of $\approx 92 \%$, hydrogen selectivity of $99 \%$, and negligible CO selectivity $(0.9 \%)$ at $300{ }^{\circ} \mathrm{C}$. These results were attributed to the presence of the CTAB surfactant, which hindered the metal species migration during the drying and decreased the sintering during the calcination. The time-on-stream tests highlighted the stability of the Ce-promoted catalysts, with no significant deactivation observed over $24 \mathrm{~h}$ of reaction time. Phongboonchoo et al. investigated the catalytic activities of $\mathrm{Ce}-\mathrm{Mg}$-promoted $\mathrm{Cu} / \mathrm{Al}_{2} \mathrm{O}_{3}$ catalysts prepared by co-precipitation in MSR [180]. The activity tests were carried out with a methanol/steam ratio of $1.5,1.75$, or 2 , diluted in He at a temperature range of $200-300{ }^{\circ} \mathrm{C}$. The results showed that the methanol conversion and hydrogen yield were higher with the monopromoted catalysts $\left(\mathrm{Cu}_{0.3} \mathrm{Mg}_{0.3} / \mathrm{Al}_{2} \mathrm{O}_{3}\right.$ and $\left.\mathrm{Cu}_{0.3} \mathrm{Ce}_{0.3} / \mathrm{Al}_{2} \mathrm{O}_{3}\right)$ than those without a promoter, probably due to the higher dispersion of copper species and to the strong interaction between copper and ceria, which lessened the catalyst reduction. Moreover, the performance of the bipromoter catalyst showed higher methanol conversion, higher hydrogen yield, and lower CO selectivity than the monopromoted catalyst. The increase in the catalytic activity was attributed to the formation of smaller $\mathrm{Cu}$ crystallites, improved copper dispersion, and lower reduction temperature. The effect of the steam-to-carbon ratio was also investigated, demonstrating that a lower $\mathrm{CO}$ selectivity was obtained with a ratio of 2. Moreover, in order to optimize the reaction conditions, a theoretical study was also performed via a face-centered central composite design response surface model (FCCCD-RSM). The analysis was carried out on four main factors (temperature, steam-to-carbon ratio, $\mathrm{Cu}$ weight percentage, and magnesium weight fraction: $\mathrm{Mg} /(\mathrm{Ce}+\mathrm{Mg}))$ by building a matrix and varying each factor within the level of the other factors. The results were analyzed using the Design-Expert 7.0 software package (Stat Ease Inc., Minneapolis, MN, USA), using analysis of variance and the percentage contribution of each factor to the responses. At a $95 \%$ confidence interval, the optimal operating region for maximal methanol conversion (100\%) and hydrogen yield in the range of $28.9-29.4 \%$, as well as CO 
selectivity of $0.16-0.18 \%$, provided a copper level of $46-50 \mathrm{wt} . \%$, a $\mathrm{Mg} /(\mathrm{Ce}+\mathrm{Mg})$ yield of $16.2-18.0 \mathrm{wt} . \%$, a temperature of $245-250^{\circ} \mathrm{C}$, and a steam-to-carbon ratio of 1.74-1.80 (Figure 12).
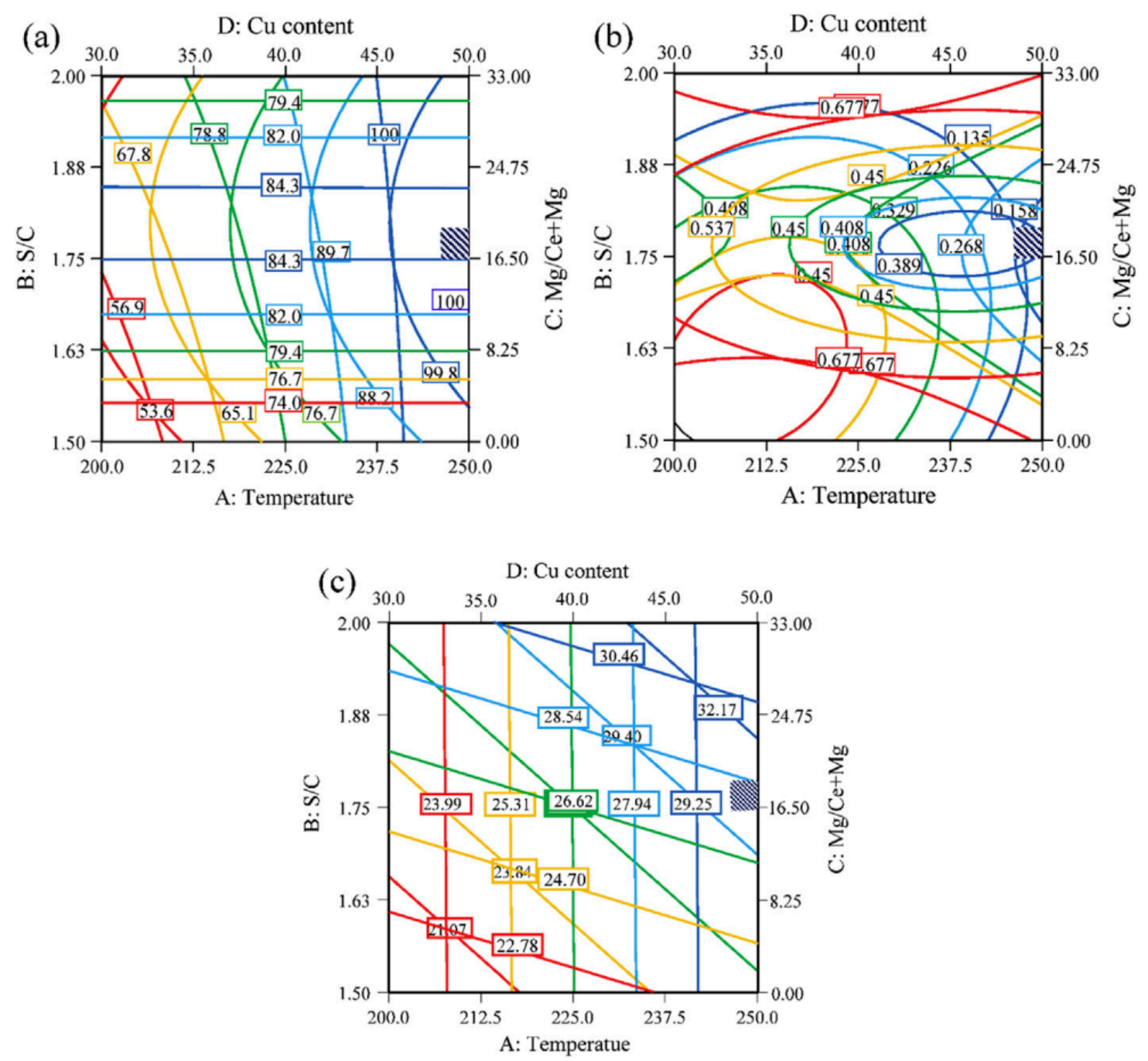

Figure 12. Contour plots for the optimal conditions for the methanol conversion (a); CO selectivity (b); $\mathrm{H}_{2}$ yield (c) [180].

These results were compared to the catalytic activity of $\mathrm{Cu}_{0.5} \mathrm{Ce}_{0.25} \mathrm{Mg}_{0.05} / \mathrm{Al}_{2} \mathrm{O}_{3}$ in a time-on-stream test of $72 \mathrm{~h}$ under the optimal operating parameters, showing complete methanol conversion and a $\mathrm{CO}$ selectivity of $0.14-0.16 \%$ with a hydrogen yield of $24-25 \%$; furthermore, no deactivation occurred.

Hou et al. proposed $\mathrm{Cu}-\mathrm{Al}$ spinel oxide as a sustained release catalyst for MSR, in which the surface modification of the spinel was performed with $\mathrm{MgO}$ [181]. The $\mathrm{Cu}-\mathrm{Al}$ spinel with a $\mathrm{Cu} / \mathrm{Al}$ atomic ratio equal to 1:3 was prepared by solid-phase method, where $\mathrm{MgO}$ was loaded by incipient wetness impregnation (loading $=0.9,1.7,3.6$, and $9.5 \%$ ); a reference catalyst $9.5 \% \mathrm{Mg} / \mathrm{Al}_{2} \mathrm{O}_{3}$ was also prepared . The catalytic tests were carried out with a methanol-to-water molar ratio of 0.46 , the methanol WHSV was $0.98 \mathrm{~h}^{-1}$, and the reaction temperature was $255^{\circ} \mathrm{C}$. The characterization results showed that the $\mathrm{MgO}$ strongly interacts with the $\mathrm{Cu}-\mathrm{Al}$ spinel by changing the surface microstructure. $\mathrm{Mg}^{2+}$ cations were incorporated into the spinel structure, substituting a portion of $\mathrm{Cu}^{2+}$ in the lattice. The doped catalysts showed a higher reduction temperature, lower copper releasing rate, and smaller copper particle size. The addition of suitable amounts of magnesium oxide to the $\mathrm{Cu}-\mathrm{Al}$ catalyst enhanced the catalytic activity and stability; the best performance was obtained with $1.7 \% \mathrm{Mg} / \mathrm{CuAl}$. 
The evaluation of coke formation on the spent catalysts demonstrated a correlation with the amount of the $\mathrm{MgO}$ loading. In the $\mathrm{CO}_{2}$-TPD profiles, two oxidation peaks were found; the peak at $150-300{ }^{\circ} \mathrm{C}$ was attributed to the decomposition of formate, while the peak at $300-500{ }^{\circ} \mathrm{C}$ was attributed to the decomposition of carbonate. For the catalysts with low loading ( $\leq 1.7 \mathrm{wt} . \%)$, the low temperature peak was dominant; on the contrary, for the catalyst with high loading $(9.5 \mathrm{wt} . \%)$, the high temperature peak was dominant. A correlation between the catalytic activity and the high temperature desorption peak was also found; thus, the lower activity of the catalysts with $\mathrm{MgO}$ loading higher than $1.7 \%$ was attributed to a coverage effect. The active copper was blocked by the dynamic formation of carbon deposits during the catalytic reaction. Moreover, lower $\mathrm{Cu}$ release rates were observed with the increase of $\mathrm{MgO}$ loadings and the $\mathrm{Cu}$ released was not able to sustain the catalytic activity; thus, fast deactivation was found for the $9.5 \% \mathrm{Mg} / \mathrm{CuAl}$ catalyst. Liu et al. investigated the use of $\mathrm{CuOZnOxGa} 2 \mathrm{O}_{3}-\mathrm{Al}_{2} \mathrm{O}_{3}$ and $\mathrm{CuOZnOxGa} \mathrm{O}_{3}-\mathrm{ZrO}_{2}$ catalysts (Ga wt.\% $=0-12.4$ ) prepared by sol-gel method in the MSR reaction [182]. The catalytic activity tests were performed at 250 and $275{ }^{\circ} \mathrm{C}$ at a GHSV of 2,200 $\mathrm{h}^{-1}$, with a mixture $\mathrm{CH}_{3} \mathrm{OH} / \mathrm{H}_{2} \mathrm{O} / \mathrm{N}_{2}$ in a 1:1:1.3 molar ratio. The characterization results showed that the addition of alumina and zirconia increased the specific surface area and modified the reduction temperature of the $\mathrm{CuOZnOGa}_{2} \mathrm{O}_{3}$ catalytic system. Zirconia promotion provided the highest reducibility and best performance in MSR for both studied temperatures. The introduction of $\mathrm{Ga}_{2} \mathrm{O}_{3}$ enhanced the hydrogen production rate but did not improve the stability of the CuZn system. The $\mathrm{CuZn}_{3} \mathrm{Ga}_{2} \mathrm{O}_{3} \mathrm{ZrO}_{2}$ catalysts showed higher stability. The hydrogen production rate at $275{ }^{\circ} \mathrm{C}$ after $44 \mathrm{~h}$ was $312 \mathrm{mLg}_{\mathrm{cat}}{ }^{-1} \mathrm{~min}^{-1}$, with methanol conversion of $75 \%$. The TPO and TG mass spectrometry analyses demonstrated the presence of negligible amounts of carbon deposits below $250{ }^{\circ} \mathrm{C}$. Mohtashami and Taghizadeh studied $\mathrm{ZrO}_{2}$-promoted $\mathrm{Cu}-\mathrm{ZnO} / \mathrm{MCM}-41$ catalysts prepared by sol-gel impregnation and modified impregnation methods in the MSR reaction [183]. The modified impregnation method consisted of treating the MCM-41 support with acetic acid for $5 \mathrm{~h}$ at room temperature before drying and calcining. The catalytic tests were performed in the temperature range of $280-320^{\circ} \mathrm{C}$; at a WHSV of $1.08,1.62$, or $2.16 \mathrm{~h}^{-1}$; and with a methanol-to-water molar ratio of 1:2. The inclusion of $2 \% \mathrm{ZrO}_{2}$ to the $\mathrm{Cu}-\mathrm{ZnO} / \mathrm{MCM}-41$ catalyst increased the methanol conversion from 90.6 to $94.0 \%$ at $300{ }^{\circ} \mathrm{C}$. The promoted catalyst prepared through the modified impregnation method showed the best performance, with methanol conversion of $97.8 \%$, a hydrogen selectivity of $99.0 \%$, CO selectivity of $0.4 \%$, and also good stability. Reduced deactivation was observed within $81 \mathrm{~h}$ in the time-on-stream test. The evaluation of the amount of coke deposited on the catalyst's surface after the time-on-stream tests by thermogravimetric analysis showed a significant reduction of the coke formation in the zirconia-promoted catalysts. This performance was attributed to the positive effect of the acetic acid pretreatment on the support, which modified the MCM-41 surface through the generation of oxyl groups, which were able to prevent metal particle aggregation, decrease the metal particles size, and improve the dispersion and reduction behaviours of the $\mathrm{CuO}$ particles. Lu et al. investigated the effect of the lanthanum addition and the effect of nickel loading on different supported Ni-based catalysts [184]. The catalysts were prepared by co-precipitation wetness impregnation method; the activity tests were carried out at a GHSV of $10,920 \mathrm{~h}^{-1}$, at atmospheric pressure, with a mixture of $\mathrm{MeOH} / \mathrm{H}_{2} \mathrm{O}$ (molar ratio = 3:1). The results demonstrated that the catalytic performance at low temperature for Ni-based catalysts can be enhanced by the addition of lanthanum, due to the formation of smaller and highly-dispersed $\mathrm{NiO}$ particles. The characterization results showed that lanthanum species are able to interact with nickel oxide and aluminum oxide to generate La-Ni or La-Ni-Al mixed oxides. The comparative study on the use of different supports showed that a weak interaction occurred between $\mathrm{SiO}_{2}$ and $\mathrm{NiO}$ species, while with $\mathrm{Al}_{2} \mathrm{O}_{3}$, the $\mathrm{NiAl}_{2} \mathrm{O}_{4}$ spinel and separated $\mathrm{NiO}$ particles located on the outer surface were formed. The use of the $\mathrm{MgO}$ support generated the $\mathrm{NiO}-\mathrm{MgO}$ solid solution, which decreased the amount of active nickel species. Azhena et al. studied the effect of $\mathrm{Cu}$ promotion in $\mathrm{Pd} / \mathrm{ZrO}_{2}$-based catalysts, along with the influence of the zirconia structure, in low-temperature MSR [185]. The catalysts were prepared by wet impregnation and the catalytic activity tests were carried out at atmospheric pressure with a steam-to-methanol ratio of 1.5 , a contact 
time $\mathrm{W}_{\mathrm{cat}} / \mathrm{F}_{\mathrm{CH} 3 \mathrm{OH}}{ }^{0}=83 \mathrm{Kg}_{\mathrm{cat}} \cdot \mathrm{mol}^{-1} \mathrm{~s}^{-1}$, and in the temperature range of $180-260{ }^{\circ} \mathrm{C}$. The results showed that the use of monoclinic zirconia provides benefits both in terms of activity and selectivity; at the same time, the selectivity is also improved by the addition of $\mathrm{Cu}$. These improvements were attributed to the enhanced dispersion of the metal phase on monoclinic zirconia and to the strong interaction between $\mathrm{Pd}$ and $\mathrm{Cu}$. Liu et al. studied the catalytic behaviour of $1 \mathrm{wt} . \% \mathrm{Pt} / \mathrm{xIn}_{2} \mathrm{O}_{3} / \mathrm{Al}_{2} \mathrm{O}_{3}$ catalysts ( $x=0-45 \mathrm{wt} . \%$ ) prepared by incipient wetness impregnation in the MSR reaction [186]. The catalytic activity tests were carried out under atmospheric pressure in the temperature range of $200-500{ }^{\circ} \mathrm{C}$. The optimal performance was obtained with a reacting mixture of $\mathrm{H}_{2} \mathrm{O} / \mathrm{CH}_{3} \mathrm{OH}$ (mole ratio = 1.4; flow rate $=1.2 \mathrm{~cm}^{3} \mathrm{~h}^{-1}$ ) diluted in $\mathrm{N}_{2}$ (flow rate $=30 \mathrm{~cm}^{3 \cdot} \mathrm{min}^{-1}$ ), at a GHSV of $14,040 \mathrm{~h}^{-1}$ and at $350^{\circ} \mathrm{C}$, with $\mathrm{In}_{2} \mathrm{O}_{3}$ loading of $30 \mathrm{wt} . \%$. Under these conditions, the $1 \mathrm{Pt} / 30 \mathrm{In}_{2} \mathrm{O}_{3} / \mathrm{Al}_{2} \mathrm{O}_{3}$ catalyst exhibited complete methanol conversion, high hydrogen selectivity $(99.6 \%)$, and low CO selectivity $(3.2 \%)$. The high activity was related to the intimate contact of $\mathrm{Pt}$ with partly reduced $\operatorname{In}_{2} \mathrm{O}_{3}$, which was hypothesized to be the active site of the reforming reaction. The performance of the $1 \mathrm{Pt} / 30 \mathrm{In}_{2} \mathrm{O}_{3} / \mathrm{Al}_{2} \mathrm{O}_{3}$ catalyst was also compared to that of the $1 \mathrm{Pt} / 30 \mathrm{ZnO} / \mathrm{Al}_{2} \mathrm{O}_{3}$ catalyst in a time-on-stream test of $17 \mathrm{~h}$; the higher activity and stability of $1 \mathrm{Pt} / 30 \mathrm{In}_{2} \mathrm{O}_{3} / \mathrm{Al}_{2} \mathrm{O}_{3}$ was attributed to the enhanced dispersion of metallic Pt, and to the synergistic effect and strong interaction between $\mathrm{Pt}$ and $\operatorname{In}_{2} \mathrm{O}_{3}$, which facilitated the water activation, thus promoting the methanol reforming. Martinelli et al. investigated the effect of the sodium doping on supported Pt-based catalysts in methanol steam reforming [187]. The support was yttria-stabilized zirconia YSZ $(\mathrm{Y} / \mathrm{Z}=0.11)$ prepared by co-precipitation, while the catalysts were obtained by sequential incipient wet impregnation with a platinum salt precursor (Pt loading $2 \mathrm{wt} . \%$ ) and sodium nitrate (Na loading $0.25,0.5,1$, or $2.5 \mathrm{wt} . \%$ ). The catalytic activity tests were carried out in a steady state under a feed stream containing $2.9 \% \mathrm{CH}_{3} \mathrm{OH}, 26.1 \% \mathrm{H}_{2} \mathrm{O}, 29.9 \% \mathrm{H}_{2}$, and $4.3 \% \mathrm{~N}_{2}$ (balance He) at atmospheric pressure, at a GHSV of $381,000 \mathrm{~h}^{-1}$, in the temperature range of $275-350^{\circ} \mathrm{C}$. The catalysts were activated in hydrogen $\left(100 \mathrm{~cm}^{3} \cdot \mathrm{min}^{-1}\right)$ at $350{ }^{\circ} \mathrm{C}$ for $1 \mathrm{~h}\left(\right.$ ramp rate $\left.=4{ }^{\circ} \mathrm{C} \cdot \mathrm{min}^{-1}\right)$. The results showed that with a $2.5 \mathrm{wt} . \%$ of $\mathrm{Na}$ loading, the $\mathrm{CO}_{2}$ selectivity was higher than $90 \%$; the product distribution was attributed to different reaction pathways for methanol decomposition. Methanol decarbonylation was favored in the absence of sodium, while formate decarboxylation was promoted in the presence of $2.5 \mathrm{wt} . \%$ of $\mathrm{Na}$ (Figure 13). These conclusions were supported from the observed weakening of the $\mathrm{C}-\mathrm{H}$ bond of formate in in situ diffuse reflectance infrared Fourier transform spectroscopy (DRIFT) studies and kinetic isotope effect experiments. The formate exhibited a $v(\mathrm{CH})$ stretching band at a low wavenumber, consistent with $\mathrm{C}-\mathrm{H}$ bond weakening, thus favoring the dehydrogenation that is directly related to the decarboxylation. The hypothesis is that formate is similar to an intermediate; moreover, $\mathrm{Na}$ is able to favor the dehydrogenation and the selectivity can be tuned between decarbonylation and decarboxylation based on the Na dopant level.
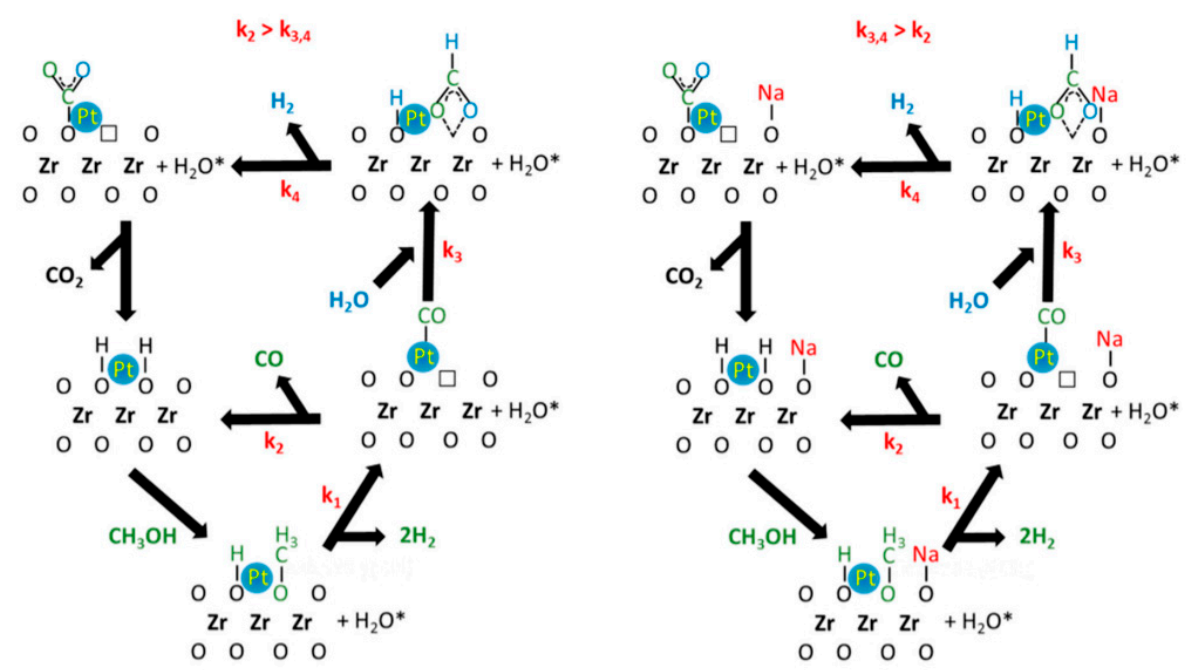

Figure 13. Proposed MSR pathway on undoped Pt/YSZ (right) and Na-doped Pt/YSZ (left) [187]. 
Zhang et al. investigated the activity of Au-based catalysts supported on modified montmorillonites in MSR [188]. The tests were carried out at atmospheric pressure, in the temperature range of $250-500{ }^{\circ} \mathrm{C}$, with a $\mathrm{CH}_{3} \mathrm{OH} / \mathrm{H}_{2} \mathrm{O}$ molar ratio of 1 . Among the catalysts examined, Au-Ti-Ce/Na-bentonite showed the best performance, with a methanol conversion of $72 \%$ and a hydrogen selectivity of $99 \%$ at $350{ }^{\circ} \mathrm{C}$. This result was attributed to the formation of the Au-Ce-Ti solid solution into the interlayer space of the bentonite, leading to a high surface area, small Au particle size, and a large average pore volume and diameter. The time-on-stream test showed no significant deactivation during $120 \mathrm{~h}$ of reaction (Figure 14).

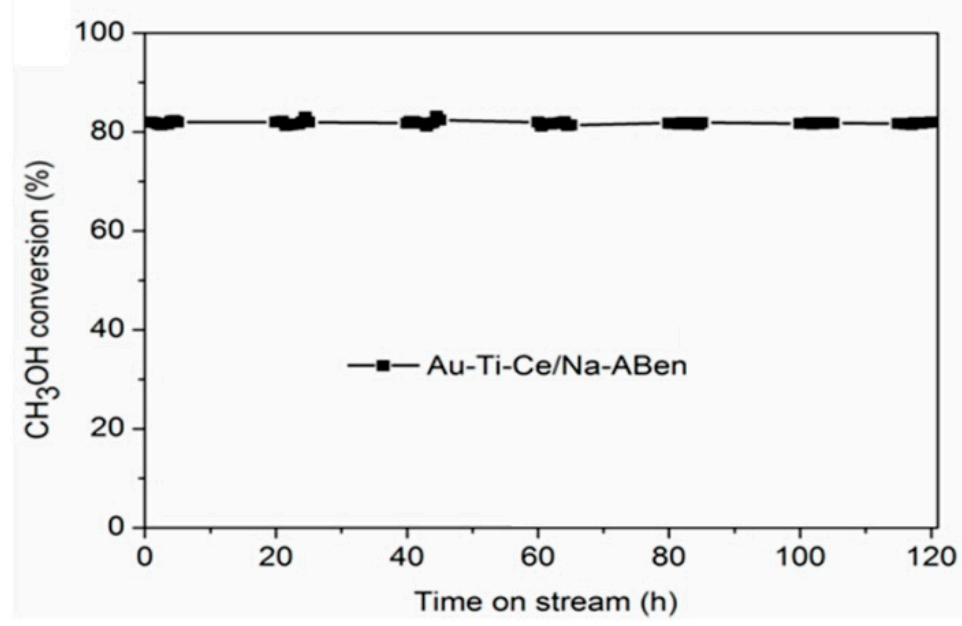

Figure 14. Time-on-stream test. $\mathrm{T}=400{ }^{\circ} \mathrm{C}, \mathrm{CH}_{3} \mathrm{OH} / \mathrm{H}_{2} \mathrm{O}=1,0.175 \mathrm{~mL} \cdot \mathrm{h}^{-1}[188]$.

Lytkina et al. studied the influence of the composition and structure of metal-oxide-stabilized zirconia support $\left(\mathrm{M}_{X} \mathrm{Zr}_{1-\mathrm{X}} \mathrm{O}_{2-\delta}, \mathrm{M}=\mathrm{Y}, \mathrm{La}, \mathrm{Ce}\right)$ prepared by co-precipitation method in bimetallic $\mathrm{Cu}-\mathrm{Ni}$ and Ru-Rh catalysts for MSR [189]. The activity tests were carried out at atmospheric pressure in the temperature range of $200-400{ }^{\circ} \mathrm{C}$, with a mixture of methanol and water with a molar ratio of $1 / 1$, at a GHSV of $172 \mathrm{~h}^{-1}$. In this study, a bifunctional mechanism for MSR over the $\mathrm{ZrO}_{2}$-based catalysts was proposed, in which methanol conversion proceeds on the metal atoms, while the support provides the active sites for the water activation. In cerium-doped catalysts, the fraction of trivalent cerium cations decreases with the increase of cerium amount; thus, the lower catalytic activity for the catalysts with higher cerium loading can be ascribed to the interaction of defects, clustering, or sintering. The lanthanum-doped catalysts showed higher activity than the yttrium ones; however, the selectivity was lower. The Ru-Rh-based catalysts displayed higher activity in both the MSR and the methanol decomposition reaction, which caused a drop in the selectivity. The best performance was obtained with the $\mathrm{Ni}_{0.2}-\mathrm{Cu}_{0.8} / \mathrm{Ce}_{0.1} \mathrm{Zr}_{0.9} \mathrm{O}_{2-\delta}$ catalyst in terms of the hydrogen yield, selectivity, and stability. Lu et al. studied $\mathrm{CuZnAlO}_{X}$ catalysts prepared by co-precipitation method and boron-modified/CuZnAlO catalysts with various boron loadings $(0.28 \%, 0.38 \%, 0.73 \%, 0.89 \%$, or $4.10 \%)$ prepared by impregnation method in MSR [190]. The catalytic tests were performed at atmospheric pressure, at a GHSV of $9000 \mathrm{~mL} \cdot \mathrm{g}^{-1} \cdot \mathrm{h}^{-1}$, in the temperature range $160-310^{\circ} \mathrm{C}$, with a $\mathrm{H}_{2} \mathrm{O} / \mathrm{CH}_{3} \mathrm{OH}$ molar ratio of 3 . The characterization results showed that the introduction of boron affected the $\mathrm{Cu}$ dispersion and reducibility. The best performance was obtained with a boron loading of $0.38 \%$; the methanol conversion reached $93 \%$ due to the presence of higher specific surface area, lower reduction temperature, and strong interactions between the boron and copper species, which suppressed the $\mathrm{Cu}$ particle migration. Time-on-stream tests showed no deactivation of this catalyst over a period of $102 \mathrm{~h}$ of reaction, except for a negligible change for the $0.38 \mathrm{~B} / \mathrm{CuZnAlO}$. Maiti et al. compared the catalytic activity behaviour of sol-gel-synthesized nanostructured $\mathrm{Cu}_{x} \mathrm{Fe}_{1-\mathrm{x}} \mathrm{Al}_{2} \mathrm{O}_{4}(0.3 \leq \mathrm{x} \leq 0.8$; where $\mathrm{n}=30$, $40,50,60,70$, and 80 ) hercynites with the corresponding catalysts prepared by solution combustion synthesis in MSR [191]. The activity tests were performed at atmospheric pressure, in the temperature 
range $200-300^{\circ} \mathrm{C}$, at a GHSV of $30,000 \mathrm{~h}^{-1}$, with a gas stream molar ratio for methanol/water/nitrogen of 1:1.1:8.4. The catalysts prepared by sol-gel method were more active than those prepared by solution combustion synthesis; moreover, $\mathrm{Cu}$ doping enhanced the catalytic activity towards methane steam reforming. The $\mathrm{Cu}_{0.8} \mathrm{Fe}_{0.2} \mathrm{Al}_{2} \mathrm{O}_{4}$ catalyst showed a methanol conversion of $\sim 80 \%$ and low $\mathrm{CO}$ selectivity of $2 \%$, even after $50 \mathrm{~h}$ of time-on-stream testing; this behaviour was explained as the result of a partial breakdown of the spinel lattice during the reforming reaction, with the formation of $\mathrm{CuO}$ followed by reduction to metallic copper, leading to a stable ratio between reduced and oxidized copper $\left(\mathrm{Cu}^{0}, \mathrm{Cu}^{+}\right) / \mathrm{Cu}^{2+}$. XPS studies showed the presence of adventitious carbon; however, the difference in the $\mathrm{C} 1 \mathrm{~s}$ signal from the fresh to the aged samples indicated a moderate carbon accumulation, also demonstrating that the carbon accumulation was not severe. Song et al. studied the effects of $\mathrm{ZnO}$ content on the performance of $\mathrm{Zn}_{\mathrm{y}} \mathrm{Ce}_{1} \mathrm{Zr}_{9} \mathrm{O}_{\mathrm{x}}(\mathrm{y}=0,0.5,1,5)$ in MSR [192]. The catalysts were prepared by using conductive carbon black $\mathrm{T} 100$ as a hard template; the catalytic tests were conducted at atmospheric pressure, in the temperature range of $200-500{ }^{\circ} \mathrm{C}$, at a steam-to-carbon of 1.4 , at a GHSV of $5151 \mathrm{~h}^{-1}$. The best performance was obtained with the $\mathrm{Zn}_{1} \mathrm{Ce}_{1} \mathrm{Zr}_{9} \mathrm{O}_{\mathrm{x}}$ catalyst, which showed full methanol conversion and an improved hydrogen production rate of $0.31 \mathrm{~mol} \cdot \mathrm{h}^{-1} \mathrm{~g}_{\mathrm{cat}}{ }^{-1}$ at $400{ }^{\circ} \mathrm{C}$. Moreover, the stability tests, which were carried out for $24 \mathrm{~h}$, showed no deactivation and a CO selectivity below $8 \%$. The characterization results revealed the formation of a solid solution with the incorporation of $\mathrm{Zn}^{2+}$ into the $\mathrm{Ce}_{1} \mathrm{Zr}_{9} \mathrm{O}_{\mathrm{x}}$ lattice, which modulated the $\mathrm{O}_{\text {Latt }} / \mathrm{O}_{\text {Ads }}$ surface ratio and generated a new $\mathrm{Zn}-\mathrm{O}-\mathrm{Zr}$ interfacial structure, increasing the $\mathrm{CO}_{2}$ selectivity. The $\mathrm{CO}_{2} / \mathrm{CO}$ intensity ratio in the desorption peaks observed during $\mathrm{CH}_{3} \mathrm{OH}$-TPD increased with the zinc molar ratio in the catalysts until $y=1\left(\mathrm{Zn}_{1} \mathrm{Ce}_{1} \mathrm{Zr}_{9} \mathrm{Ox}\right.$ catalyst $)$ and decreased from $\mathrm{y}=1$ to $\mathrm{y}=5$ ( $\mathrm{Zn}_{5} \mathrm{Ce}_{1} \mathrm{Zr}_{9} \mathrm{Ox}$ catalyst); thus, the highest abundance of lattice oxygen in the $\mathrm{Zn}_{1} \mathrm{Ce}_{1} \mathrm{Zr}_{9} \mathrm{Ox}$ catalyst suppressed the undesired $\mathrm{CO}$ formation.

\subsection{Unconventional Reactor Configuration, Simulation, and Theoretical Studies}

This section deals with recently published articles on the MSR, in which the reactor configuration, in addition to being innovative compared to the conventional one (such as membrane or structured reactors), assumes a dominant role in the catalytic activity. In addition, simulations and theoretical studies have also been included.

Mateos-Pedrero et al. studied the effect of the surface area and polarity ratio of the $\mathrm{ZnO}$ support on the catalytic activity of $\mathrm{CuO} / \mathrm{ZnO}$ in MSR [193]. The surface area of $\mathrm{ZnO}$ was tuned by changing of the calcination temperature, while the polarity ratio was modified by using different salt precursors. The supports were prepared by a modified hydrothermal method, using two different salt precursors, zinc acetate or zinc nitrate, and calcined at four different temperatures: 300, 350, 375 , and $400{ }^{\circ} \mathrm{C}$. The catalysts were prepared by impregnation of the support with copper nitrate at $\mathrm{pH}=6 \mathrm{using}$ ammonium hydroxide, with a metal loading of $15 \mathrm{wt} . \%$ and calcined at $360^{\circ} \mathrm{C}$. The results showed that the copper dispersion and surface area increased with the surface area of the support and that the reducibility of the copper species increased with the polarity ratio in the $\mathrm{ZnO}$ support. The activity tests showed a dependence from the surface area of the support, and therefore from the $\mathrm{Cu}$ dispersion; moreover, the selectivity increased with the polarity ratio. The best performance was obtained with the catalyst whose support was obtained from zinc acetate and was calcined at $375{ }^{\circ} \mathrm{C}$. This catalyst was tested in a Pd-membrane reactor in two different experiments to evaluate the methanol conversion and gas selectivity stability in one case, and to investigate the hydrogen recovery and hydrogen permeate purity under various operating conditions in the other case. The first set of experiments showed that it is possible to reach $97 \%$ of methanol conversion at $300{ }^{\circ} \mathrm{C}, 2.0 \mathrm{bar}$, and WHSV $=2.73 \mathrm{~h}^{-1}$, with good stability and selectivity. The second set of experiments showed that it is possible to achieve a hydrogen recovery rate of ca. $75 \%$ and a hydrogen permeate purity rate higher than $90 \%$ at $330{ }^{\circ} \mathrm{C}, 2.5 \mathrm{bar}$, and WHSV $=1.37 \mathrm{~h}^{-1}$. Kim et al. carried out process simulation and design, as well as economic analysis, to evaluate the technical and economic feasibility of MSR in a membrane reactor for ultrapure hydrogen production [194]. 
The simulation was performed with Aspen HYSYS ${ }^{\circledR}$; certain operating conditions were investigated, such as the effects of the hydrogen permeance $\left(1 \times 10^{-5}-6 \times 10^{-5} \mathrm{~mol} \cdot \mathrm{m}^{-2} \cdot \mathrm{s}^{-1} \cdot \mathrm{Pa}^{-1}\right), \mathrm{H}_{2} \mathrm{O}$ sweep gas flow rate $\left(1-20 \mathrm{kmol} \cdot \mathrm{h}^{-1}\right)$, and reaction temperature $(448-493 \mathrm{~K})$ in a conventional packed-bed reactor, using previously reported reaction kinetics. Improved performances regarding the methanol conversions and hydrogen yield were observed for all the studied cases in the membrane reactor configuration compared to the packed-bed configuration. Higher hydrogen permeance and $\mathrm{H}_{2} \mathrm{O}$ sweep gas flow rates were beneficial for methanol conversion, but no further improvement was obtained for $\mathrm{H}_{2} \mathrm{O}$ sweep gas flow rates over $10 \mathrm{kmol} \cdot \mathrm{h}^{-1}$. A unit hydrogen production cost was also calculated, showing a higher cost for the packed-bed reactor $\left(9.37 \$ \mathrm{~kg} \cdot \mathrm{H}_{2}{ }^{-1}\right)$ than for the membrane reactor $\left(7.24 \$ \mathrm{~kg} \cdot \mathrm{H}_{2}{ }^{-1}\right)$. Köpfle et al. studied the activation and the catalytic performance in MSR of two $\mathrm{Zr}$-containing intermetallic systems, $\mathrm{Cu}-\mathrm{Zr}$ and $\mathrm{Pd}-\mathrm{Zr}$ [195]. Metal mixtures of $\mathrm{Cu}$ and $\mathrm{Zr}$ were prepared with different stoichiometry ratios $(\mathrm{Cu} / \mathrm{Zr}=9: 2,2: 1,1: 2)$. Moreover, two $\mathrm{Pd}-\mathrm{Zr}$ systems were prepared by ALD/CVD (atomic layer deposition/chemical vapour deposition) of zirconium(IV)tert-butoxide on $\mathrm{Pd}$ and $\mathrm{Zr}$ foils ( $\mathrm{Pd} / \mathrm{Zr}$ ratio 2/1). The preparation of the corresponding $\mathrm{Cu}-\mathrm{Zr}$ intermetallic catalyst was carried out using the $\mathrm{Cu}$ foil. The transitions of the initial metal and intermetallic compound structures in the active and $\mathrm{CO}_{2}$-selective states were monitored in MSR by an inverse surface science and bulk model approach. The $\mathrm{CO}_{2}$ selectivity and the catalytic performance of the $\mathrm{Cu}$ - $\mathrm{Zr}$ system were promising due to the formation of a beneficial $\mathrm{Cu}-\mathrm{ZrO}_{2}$ interface. The two $\mathrm{Pd}-\mathrm{Zr}$ systems showed a low-temperature coking tendency, high water activation temperature, and low $\mathrm{CO}_{2}$ selectivity. Zhou et al. reported a benchmark study in which the performance of porous $\mathrm{Cu}-\mathrm{Al}$ fiber sintered felt, constructed using the solid-phase sintering method, was compared to that of $\mathrm{Cu}$ fiber sintered felt and $\mathrm{Al}$ fiber sintered felt. The fibers were impregnated with $\mathrm{Cu} / \mathrm{Zn} / \mathrm{Al} / \mathrm{Zr}$ catalysts and used in a cylindrical MSR microreactor [196]. The results showed that the $\mathrm{Cu}-\mathrm{Al}$ fiber based catalyst gave higher methanol conversion and hydrogen flow rates than the $\mathrm{Cu}$ - and Al-fiber-based catalysts. The rough-fiber-based catalyst showed a much higher methanol conversion and hydrogen flow rate than the smooth one. Moreover, the methanol conversion and hydrogen flow rate increased with the decrease of the $\mathrm{Cu}$ fiber weight and the increase of the $\mathrm{Al}$ fiber weight. The best performance in terms of hydrogen production was obtained with a three-layer $\mathrm{Cu}-\mathrm{Al}$ fiber with $80 \%$ porosity and a $1.12 \mathrm{~g} \mathrm{Cu}$ fiber/1.02 $\mathrm{g}$ Al fiber. The time-on-stream tests showed a significant deactivation of the catalysts after $32 \mathrm{~h}$ due to the coke formation. In further studies, a laser micromilling technique was reported for the fabrication of surface microchannels on porous copper-fiber-sintered felts [197]. The effects of the surface microchannel shape and catalyst loading on the activity in the MSR microreactor was investigated. The results showed that the rectangular shape provided a lower pressure drop, higher average velocity, and higher permeability compared to the stepped and polyline microchannels, as well as the highest methanol conversion and hydrogen flow rate. Furthermore, in the latter case, the deactivation of the catalyst observed during time-on-stream tests was attributed to the carbon deposition and catalyst loss. Tajrishi et al. studied the use of Cu/SBA-15-based nanocatalysts in a parallel-type microchannel reactor for MSR reaction [198]. SBA-15 was prepared by hydrothermal method, while the catalysts were prepared by wetness impregnation method. The catalytic activity tests were carried out at atmospheric pressure; the microchannel reactor walls were coated with the nanocatalysts and a mixture of methanol and distilled water was injected into the microreactor by a syringe pump at various flow rates $\left(1.8,2.4\right.$ and $\left.3 \mathrm{~mL} \cdot \mathrm{h}^{-1}\right)$ through a vaporizer at $150^{\circ} \mathrm{C}$. A series of reaction conditions was evaluated on the $5 \% \mathrm{Cu} / \mathrm{SBA}-15$ catalyst, such as the effects of the reaction temperature $(260,280,300$, 320 , and $\left.340^{\circ} \mathrm{C}\right)$, the WHSV $\left(32.76,43.68\right.$, and $\left.54.56 \mathrm{~h}^{-1}\right)$, and the steam-to-carbon molar ratio $(1,2$, and 3) on the methanol conversion; hydrogen yield; and $\mathrm{H}_{2}, \mathrm{CO}$, and $\mathrm{CO}_{2}$ selectivity. Moreover, the effects of promoters were investigated by performing a series of experiments at $300{ }^{\circ} \mathrm{C}$ at a weight GHSV of $43.68 \mathrm{~h}^{-1}$ and at a steam-to-carbon molar ratio of 2 on the following catalysts: $\mathrm{xCu} / \mathrm{SBA}-15$ $(\mathrm{x}=5,10$ and $15 \%), 10 \% \mathrm{Cu} / \mathrm{yZnO} / \mathrm{SBA}-15(\mathrm{y}=5,10$ and $15 \%), 10 \% \mathrm{Cu} / 5 \% \mathrm{ZnO} / 2 \% \mathrm{CeO}_{2} / \mathrm{SBA}-15$, $10 \% \mathrm{Cu} / 5 \% \mathrm{ZnO} / 2 \% \mathrm{ZrO}_{2} / \mathrm{SBA}-15$, and $10 \% \mathrm{Cu} / 5 \% \mathrm{ZnO} / 2 \% \mathrm{CeO}_{2} / 2 \% \mathrm{ZrO}_{2} / \mathrm{SBA}-15$. Specific surface area measurements and field emission SEM images demonstrated that the addition of $\mathrm{CeO}_{2}$ and $\mathrm{ZrO}_{2}$ to the 
$10 \% \mathrm{Cu} / 5 \% \mathrm{ZnO} / \mathrm{SBA}-15$ catalyst led to a reduction in the agglomeration of crystallites, thus increasing the specific surface area and lowering the pore diameter. The methanol conversion and hydrogen selectivity were improved by $\mathrm{ZrO}_{2}$ promotion, while $\mathrm{ZnO}$ and $\mathrm{CeO}_{2}$ promoters reduced the $\mathrm{CO}$ selectivity. Moreover, $\mathrm{CeO}_{2}$ and $\mathrm{ZrO}_{2}$ promoted the stability of the $\mathrm{Cu} / \mathrm{ZnO} / \mathrm{SBA}-15$-based catalysts, due to the better reducibility of $\mathrm{CuO}$ particles and less coke deposition. The $10 \% \mathrm{Cu} / 5 \% \mathrm{ZnO} / 2 \% \mathrm{CeO}_{2} / 2 \% \mathrm{ZrO}_{2} / \mathrm{SBA}-15$ catalyst showed the best performance, displaying optimal methanol conversion of $95.2 \%$, low $\mathrm{CO}$ selectivity of $1.4 \%$, high $\mathrm{H}_{2}$ yield of $90 \%$, and good stability in the time-on-stream test over $60 \mathrm{~h}$ of reaction at $300^{\circ} \mathrm{C}$, at a weight space hourly velocity of $43.68 \mathrm{~h}^{-1}$, and at a steam-to-carbon molar ratio of 2 , due to smaller size of the copper and zinc crystallites, higher copper dispersion, and greater specific surface area. Liu et al. studied copper foams with different types of hole arrays as catalyst supports for cylindrical laminated MSR microreactors [199]. The copper foams were fabricated by laser processing method; the catalytic formulation $(\mathrm{Cu} / \mathrm{Zn} / \mathrm{Al} / \mathrm{Zr})$ was loaded by impregnation, while macroscopic numerical analysis was used to analyse the reactant distribution on the foams. The optimal hole array distribution was obtained on the basis of the experimental results by varying the reactant flow rate, reaction temperature, and catalyst loading. The simulation results showed that the radial distribution uniformity was improved and the axial flow velocity was increased from the copper foams with hole arrays. The copper foams whose hole size decreased in the arrays from the center to the radial direction provided the best catalytic performance; by feeding a flow rate of $10 \mathrm{~mL} \cdot \mathrm{h}^{-1}$ at $300{ }^{\circ} \mathrm{C}$, the initial methanol conversion was $95 \%$ and the initial hydrogen production flow rate was $0.52 \mathrm{~mol} \cdot \mathrm{h}^{-1}$; after time-on-stream tests for $24 \mathrm{~h}$, the methanol conversion decreased to $70 \%$ and the hydrogen production flow rate decreased to $0.35 \mathrm{~mol} \cdot \mathrm{h}^{-1}$. Sarafraz et al. investigated the use of the $\mathrm{Cu}-\mathrm{SiO}_{2}$ porous catalyst coated on the internal wall of a microreactor with parallel micropassages in MSR [200]. The catalyst was prepared by coating with copper and silica nanoparticles, using convective flow boiling heat transfer followed by calcination. The catalytic activity tests were carried out in the temperature range of $250-400{ }^{\circ} \mathrm{C}$, with a reactant flow rate of $0.1-0.9 \mathrm{dm}^{3} \cdot \mathrm{min}^{-1}$, a catalyst loading of $0.25-1.25 \mathrm{~g}$, and at a heat flux of $500 \mathrm{~kW} \cdot \mathrm{m}^{-2}$. The highest methanol conversion was obtained at GHSV of $24,000 \mathrm{~mL} \cdot \mathrm{g}^{-1} \cdot \mathrm{h}^{-1}$, at a temperature of $500{ }^{\circ} \mathrm{C}$, and with a methanol-to-water molar ratio of 0.1. The increase in the GHSV of the reactants generated a decrease in the methanol conversion, which was attributed to the suppression of the reactant diffusion into the pores of the catalyst and to the decrease in the average film temperature of the reactor. Moreover, for the low methanol-to-water molar ratio the reaction was complete, requiring more thermal energy; therefore, greater heat flux was necessary to compensate for the temperature drop. Shanmugam et al. investigated the effect of supports $\left(\mathrm{CeO}_{2}, \mathrm{Al}_{2} \mathrm{O}_{3}\right.$, and $\left.\mathrm{ZrO}_{2}\right)$ and an $\mathrm{In}_{2} \mathrm{O}_{3}$ co-support in Pt-based catalysts for MSR in a microchannel reactor [201]. $\mathrm{CeO}_{2}, \mathrm{Al}_{2} \mathrm{O}_{3}$, and $\mathrm{ZrO}_{2}$ were prepared by sol-gel method, the co-support was obtained by impregnation with $\mathrm{In}_{2} \mathrm{O}_{3}$, while the catalysts were obtained by impregnation. Two microchannel platelets were coated with the catalysts and sealed face-to-face by laser welding with the inlet and outlet capillaries. The activity tests were carried out in a microchannel reactor at atmospheric pressure in the temperature range of $300-375^{\circ} \mathrm{C}$, with a flow rate for the water/methanol mixture of $30 \mathrm{~mL} / \mathrm{h}$ and a steam-to-carbon ratio of 1.4. Among the studied catalysts, the best performance was obtained with $15 \mathrm{Pt} / \mathrm{CeO}_{2}$, which exhibited complete methanol conversion, high hydrogen selectivity, and high $\mathrm{CO}$ formation $\left(7 \mathrm{vol} . \%\right.$ ) at $350^{\circ} \mathrm{C}$. The addition of $\mathrm{In}_{2} \mathrm{O}_{3}$ reduced the $\mathrm{CO}$ formation to $1.9 \mathrm{vol} . \%$ due to the enhanced dispersion of metallic Pt nanoparticles and to the boost given to the water activation, which reacted with methanol on the Pt surface, leading to the selective formation of $\mathrm{CO}_{2}$ and $\mathrm{H}_{2}$ and suppressing the $\mathrm{CO}$ formation. The time-on-stream tests showed only slight deactivation in $100 \mathrm{~h}$ under reaction conditions at WHSV of $88 \mathrm{~L} \cdot \mathrm{h}^{-1} \cdot \mathrm{g}^{-1}$. Zhuang et al. developed a multichannel microreactor with a bifurcation inlet manifold and rectangular outlet manifold for MSR, in which the commercial $\mathrm{CuO} / \mathrm{ZnO} / \mathrm{Al}_{2} \mathrm{O}_{3}$ catalyst was directly packed [202]. The catalytic tests were performed with a variable steam-to-carbon ratio (1.1-1.5), a variable WHSV $\left(0.4-6.7 \mathrm{~h}^{-1}\right)$ in the temperature range of $225-325^{\circ} \mathrm{C}$, with two catalyst particle sizes of 50-150 mesh and 150-200 mesh. A computation fluid dynamics (CFD) simulation was also performed to study the flow distribution in the multichannel reactor. The results 
showed that the methanol conversion was enhanced by increasing the steam-to-carbon ratio and the temperature, as well as by decreasing the WHSV and catalyst particle size. On the other hand, the $\mathrm{CO}$ concentration decreased with a growth in the steam-to-carbon ratio and the WHSV, as well as decreased with the decrease of the temperature and catalyst particle size. A time-on-stream test was also carried out for $36 \mathrm{~h}$, achieving a methanol conversion of $94.04 \%$ and a CO concentration of $1.05 \%$, with a steam-to-carbon ratio of 1.3 , a temperature of $275^{\circ} \mathrm{C}$, a WHSV of $0.67 \mathrm{~h}^{-1}$, and a catalyst particle size of 150-200 mesh. Zhu et al. reported a modelling and design study for a multitubular packed-bed reactor for MSR on a $\mathrm{Cu} / \mathrm{ZnO} / \mathrm{Al}_{2} \mathrm{O}_{3}$ catalyst [203]. A multitubular packed-bed reformer pseudo-homogenous model was developed based on Langmuir-Hinshelwood kinetics of the MSR process to investigate the impacts of operating conditions and geometric parameters on the performance. Moreover, pressure drop, heat, and mass transfer phenomena, as well as diffusion inside the catalyst particles, were also investigated. A comparative study was also performed to evaluate the performance of a current-current reactor with respect a co-current reactor.

The simulation results showed that a co-current heat exchanger provided a lower $\mathrm{CO}$ concentration and better heat transfer efficacy; moreover, the lower liquid fuel flow rate and higher thermal air inlet temperature gave higher residual methanol and $\mathrm{CO}$ concentrations (Figure 15). At a fixed catalyst loading, the increase in the tube numbers, the growth of the baffle plate number, and the decrease in the tube diameter increased both the methanol conversion and the $\mathrm{CO}$ concentration. Ke and Lin performed density functional theory computations and transition state theory analyses on the intrinsic mechanism of Ni-catalysed MSR by considering 54 elementary reaction steps [204]. The microkinetic model was obtained by combining the quantum chemical results with a continuous stirring tank reactor. The microkinetic simulations showed that $\mathrm{O}^{*}, \mathrm{CO}^{*}, \mathrm{OH}^{*}$, and $\mathrm{H}^{*}$ are the only surface species with non-negligible surface coverage. The main reaction pathway is described in Equations (13) and (14).

$$
\mathrm{CH}_{3} \mathrm{OH} \rightarrow \mathrm{CH}_{3} \mathrm{OH}^{*} \rightarrow \mathrm{CH}_{3} \mathrm{O}^{*} \rightarrow \mathrm{CH}_{2} \mathrm{O}^{*} \rightarrow \mathrm{CHO}^{*} \rightarrow \mathrm{CO}^{*} \rightarrow \mathrm{CO}_{2}^{*} \rightarrow \mathrm{CO}_{2}
$$

and the rate determining step is:

$$
\mathrm{CH}_{3} \mathrm{O}^{*} \rightarrow \mathrm{CH}_{2} \mathrm{O}^{*}+\mathrm{H}^{*}
$$
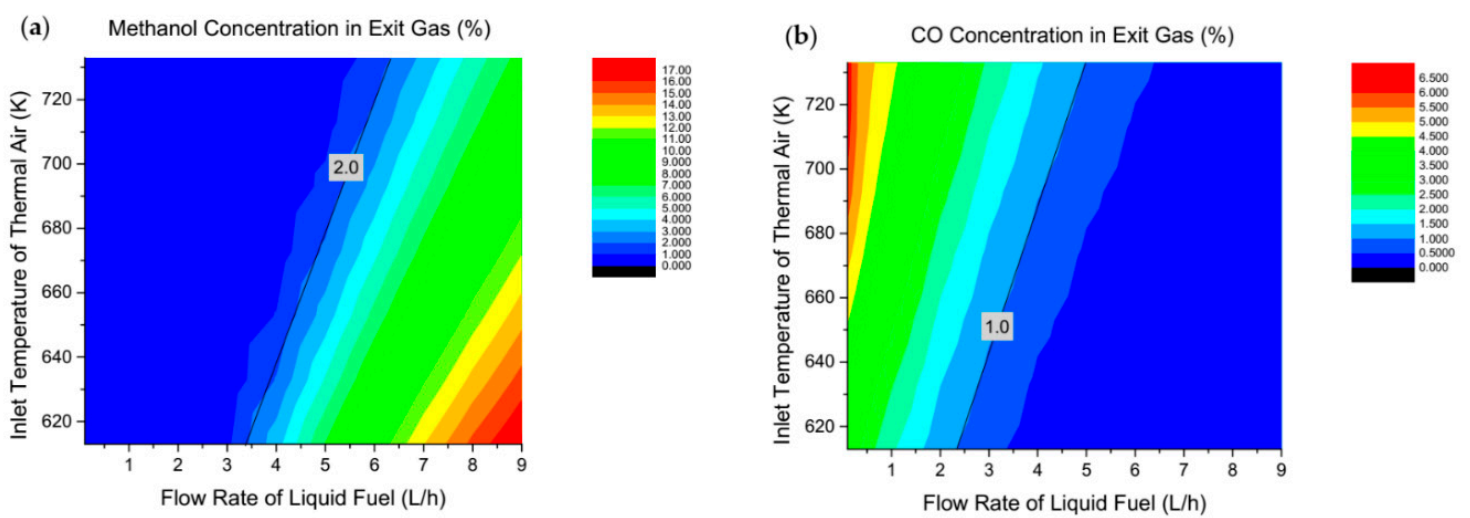

Figure 15. Profiles of the (a) methanol concentration and (b) CO concentration in the exit gas of the reformer with different inlet flow rates for the fuel mixture and inlet temperature of the thermal air [203].

Wang et al. studied a MSR rib microreactor heated by automobile exhaust [205]. The effect of the inlet exhaust and methanol-to-steam ratio on the performance of the reactor were numerically analyzed with a computational fluid dynamic study. The results showed that the methanol conversion increased with the inlet exhaust velocity and the inlet exhaust temperature; moreover, the axial temperature increased along the axis and decreased with the reactant inlet velocity. By fixing the inlet reactant velocity to $0.1 \mathrm{~m} / \mathrm{s}$ and the inlet temperature to $220^{\circ} \mathrm{C}$, the best performance was obtained with a water/methanol ratio of 1.3 , an exhaust inlet velocity of $1.1 \mathrm{~m} \cdot \mathrm{s}^{-1}$, and an exhaust inlet temperature of 
$500{ }^{\circ} \mathrm{C}$, obtaining methanol conversion of $99.4 \%$, hydrogen content of $69.9 \%$, and thermal efficiency of $28 \%$.

\subsection{Oxidative Steam Reforming of Methanol}

The OSRM is a combination of an exothermic reaction between $\mathrm{O}_{2}$ and methanol and the endothermic reaction of steam reforming. The exothermic reaction has frequently been assumed to be the partial oxidation (PO) of methanol [206]; however, more recently it was found that with the commercial $\mathrm{Cu} / \mathrm{ZnO} / \mathrm{Al}_{2} \mathrm{O}_{3}$ catalyst, the combustion of methanol is the main reaction between oxygen and methanol [207]. This process presents some advantages, such as the possibility to produce hydrogen with a very low concentration of $\mathrm{CO}$; moreover, it is suitable for power variation by varying the methanol/oxygen ratio [208]. A selection of articles on this topic follows below.

Pojanavaraphan et al. investigated the catalytic performance of a series of $\mathrm{Au} / \mathrm{CeO}_{2}-\mathrm{Fe}_{2} \mathrm{O}_{3}$ catalysts prepared by deposition-precipitation for the OSRM [209]. The catalysts were prepared with the aim of investigating the $\mathrm{Ce} /(\mathrm{Ce}+\mathrm{Fe})$ atomic ratio $(1,0.75,0.5,0.25,0)$, the gold loading $(1,3$, and $5 \mathrm{wt} . \%)$, and the calcination temperature $\left(200,300\right.$, and $\left.400{ }^{\circ} \mathrm{C}\right)$. The catalytic activity tests were carried out at a GHSV of $30,000 \mathrm{~mL} \mathrm{~g}$-cat $^{-1} \mathrm{~h}^{-1}$, in the temperature range of $200-400{ }^{\circ} \mathrm{C}$, at atmospheric pressure. A mixture of distilled water and methanol was continuously injected by a syringe into a vaporizer chamber at $150{ }^{\circ} \mathrm{C}$, at a rate of $1.5 \mathrm{~mL} \mathrm{~h}^{-1}$. The $\mathrm{H}_{2} \mathrm{O} / \mathrm{CH}_{3} \mathrm{OH}$ and $\mathrm{O}_{2} / \mathrm{CH}_{3} \mathrm{OH}$ molar ratios were varied from 1:1 to $4: 1$ and from 0 to 2.5 , respectively. The best performance was obtained with a gold loading of $3 \mathrm{wt} . \%$ and $\mathrm{Ce} /(\mathrm{Ce}+\mathrm{Fe})=0.25$ calcined at $300{ }^{\circ} \mathrm{C}$; this catalyst showed an optimal Au particle size; coexistence of the $\mathrm{CeO}_{2}-\mathrm{Fe}_{2} \mathrm{O}_{3}$ solid solution and free $\mathrm{F}_{2} \mathrm{O}_{3}$ phase; and strong interaction sites, such as $\mathrm{Au}-\mathrm{Au}, \mathrm{Au}^{0}$-free $\mathrm{Fe}^{3+}$, and $\mathrm{Ce}^{4+}-\mathrm{Fe}^{3+}$; which were indicated as the main factors for successfully improving the catalytic activity. The presence of high steam content negatively affected the formation of hydroxyl, carbonate, and formate species; the best reaction condition was $\mathrm{O}_{2} / \mathrm{H}_{2} \mathrm{O} / \mathrm{CH}_{3} \mathrm{OH}=0.6: 2: 1$. Stability tests were carried out, highlighting the effect of a pretreatment with $\mathrm{O}_{2}$ on the catalytic activity of the catalyst. The results showed that the activity of the unpretreated catalyst decreased in the methanol conversion from $95.7 \%$ to $91 \%$ and in the hydrogen yield from $85.87 \%$ to $82 \%$, while that of the pretreated catalyst followed the same trend, but with higher conversion and hydrogen yield. The TPO profile of the unpretreated spent catalyst showed two peaks attributed to the different types of coke formed, with a total coke percentage of $0.629 \mathrm{wt} . \%$. The pretreated catalyst showed the first oxidation peak at $84{ }^{\circ} \mathrm{C}$ with low intensity due to carbonaceous species, before being converted to the coke, revealing that the $\mathrm{O}_{2}$ pretreatment is able to reduce or retard the coke formation rate during the stability test via coke gasification; the coke percentage was only $0.053 \mathrm{wt} . \%$. These data demonstrated that the coke formation did not affected the stability of the pretreated catalyst, suggesting that the $\mathrm{O}_{2}$ pretreatment could reduce or retard the coke formation rate. Pérez-Hernández et al. investigated the effect of the bimetallic $\mathrm{Ni} / \mathrm{Cu}$ loading on $\mathrm{ZrO}_{2}$ support in the autothermal steam reforming of methanol (ASRM) for hydrogen production [210]. The support was prepared by sol-gel method while the catalysts were prepared by sequential impregnation to obtain three different total metallic loading values of $3 \mathrm{wt} . \%, 15 \mathrm{wt} . \%$, and $30 \mathrm{wt} . \%$, with a $\mathrm{Cu} / \mathrm{Ni}$ ratio equal to 4:1. TEM-EDX images highlighted the core-shell structure of the $\mathrm{Cu} / \mathrm{Ni}$ nanoparticles, but in the case of the $30 \mathrm{wt} . \% \mathrm{Ni} / \mathrm{Cu} / \mathrm{ZrO}_{2}$ sample the shell was constituted by the $\mathrm{Ni}-\mathrm{Cu}$ alloy. The activity tests showed that the methanol conversion increased with the $\mathrm{Ni} / \mathrm{Cu}$ loading, thus the highest conversion was obtained with the $30 \mathrm{wt} . \% \mathrm{Ni} / \mathrm{Cu} / \mathrm{ZrO}_{2}$ catalyst; however, the $15 \mathrm{wt} . \% \mathrm{Ni} / \mathrm{Cu} / \mathrm{ZrO}_{2}$ catalyst exhibited the highest hydrogen selectivity. A time-on-stream test was also performed on the $30 \mathrm{wt} . \% \mathrm{Ni} / \mathrm{Cu} / \mathrm{ZrO}_{2}$ catalyst, which exhibited stable performance during a $46 \mathrm{~h}$ time-on-stream test at $400{ }^{\circ} \mathrm{C}$, without apparent deactivation. Mierczynski et al. studied the performance of copper- and gold-doped copper catalysts supported on a multiwalled carbon nanotube (MWCNT) prepared by wet impregnation and deposition-precipitation methods in OSRM [211]. The tests were carried out at 200 and $300{ }^{\circ} \mathrm{C}$ on $100 \mathrm{mg}$ of catalyst and with a stream composition of $\mathrm{H}_{2} \mathrm{O} / \mathrm{CH}_{3} \mathrm{OH} / \mathrm{O}_{2}$ (molar ratio = 1:1:0.4), a GHSV of $26700 \mathrm{~h}^{-1}$, under atmospheric pressure, with a 
total flowrate of $31.5 \mathrm{~mL} \cdot \mathrm{min}^{-1}$ and methanol concentration of $6 \%$ (Argon was used as the diluent gas). The in situ XRD analysis showed the occurrence of $\mathrm{Au}-\mathrm{Cu}$ alloy in the bimetallic catalyst during the reduction process at $300{ }^{\circ} \mathrm{C}$. The highest activity and hydrogen yield were obtained with the $0.5 \% \mathrm{Au}-20 \% \mathrm{Cu} / \mathrm{MWCNT}$ bimetallic catalyst; the performance was related to the reducibility and to the highest total acidity of the catalytic system, which is able to stabilize the intermediate formed during the reaction. Jampa et al. investigated the use of $\mathrm{Cu}$-loaded mesoporous ceria and $\mathrm{Cu}$-loaded mesoporous ceria-zirconia catalysts synthesized by nanocasting process, using MCM- 48 as the template (\% of $\mathrm{Cu}$ loading varied from 1 to $12 \mathrm{wt} . \%$ in OSRM [212]. The catalytic activity tests were performed over a temperature range of $200-400{ }^{\circ} \mathrm{C}$ at atmospheric pressure, with a mixture of $\mathrm{H}_{2} \mathrm{O} / \mathrm{CH}_{3} \mathrm{OH}\left(1.5 \mathrm{~mL} \cdot \mathrm{h}^{-1}\right.$, molar ratio varied from $1: 1$ to $3: 1), \mathrm{He}\left(45 \mathrm{~mL} \cdot \mathrm{min}^{-1}\right)$, and oxygen $\left(45 \mathrm{~mL} \cdot \mathrm{min}^{-1}\right)$. The results showed that the best catalytic performance was obtained with $9 \mathrm{wt} . \% \mathrm{Cu}$ loading, which assured methanol conversion of $100 \%$ and hydrogen yield of $60 \%$; however, these results were obtained at $350{ }^{\circ} \mathrm{C}$ when mesoporous $\mathrm{CeO}_{2}$ was used as the support and at $300{ }^{\circ} \mathrm{C}$ when $\mathrm{CeO}_{2}-\mathrm{ZrO}_{2}$ was used as the support by feeding $\mathrm{O}_{2}$ at $5 \mathrm{~mL} \cdot \mathrm{min}^{-1}$ and a $\mathrm{H}_{2} \mathrm{O} / \mathrm{CH}_{3} \mathrm{OH}$ molar ratio of 2:1. The time-on-stream stability tests over $169 \mathrm{~h}$ of reaction resulted in a continuous decrease of the methanol conversion and hydrogen yields for both the $9 \% \mathrm{Cu} / \mathrm{CeO}_{2}$ and $9 \% \mathrm{Cu} / \mathrm{CeZrO}_{4}$. The TPO profiles of the spent catalyst $9 \% \mathrm{Cu} / \mathrm{CeO}_{2}$ showed two peaks at $207^{\circ} \mathrm{C}$ and $296^{\circ} \mathrm{C}$, whereas $9 \% \mathrm{Cu} / \mathrm{CeZrO}$ showed the oxidation peaks at 266 and $484^{\circ} \mathrm{C}$, indicating the presence of two different types of coke or carbonaceous species. The oxidation peaks at 207,266 , and $296^{\circ} \mathrm{C}$ were assigned to the poorly polymerized coke deposited on the catalyst particles, while the peak at $484^{\circ} \mathrm{C}$ was ascribed to highly polymerized coke deposited near the catalyst-support interface. Moreover, the significant decrease in the Branauer-Emmett-Teller (BET) specific surface area of the spent catalysts suggested that sintering had occurred. Based on these data, the deactivation was attributed to coke formation and agglomeration; however, the ceria/zirconia-based catalyst showed reduced CO selectivity. Thus, the main conclusion was that the addition of zirconium into the support improved the redox property, the thermal stability, and the oxygen storage capacity of the catalyst, resulting in a better performance in terms of $\mathrm{CO}$ oxidation reaction, and thus in a low $\mathrm{CO}$ level during autothermal steam reforming of methanol. Pu et al. investigated the $\mathrm{Cu} / \mathrm{ZnO}$-based catalysts promoted by $\mathrm{Sc}_{2} \mathrm{O}_{3}$ in ASRM [213]. The $\mathrm{Cu} / \mathrm{Sc}_{2} \mathrm{O}_{3}-\mathrm{ZnO}$ catalysts were prepared by the reverse precipitation method, with Cu metal loading of $15 \mathrm{wt} . \%$ and Sc/Zn molar ratios of 0, 0.03, 0.05, and 0.07. The catalytic activities were evaluated in the temperature range of $220-600{ }^{\circ} \mathrm{C}$ at atmospheric pressure, while an aqueous solution of methanol at a rate of $0.05 \mathrm{~mL} / \mathrm{min}$ was fed together with a mixed gas flow $\left(50 \mathrm{~mL} \cdot \mathrm{min}^{-1}\right.$ ) of $\mathrm{N}_{2}$ and $\mathrm{O}_{2}$. The characterization results showed that the Sc promotion assured a reduction of the particle size and an increase of the metal dispersion of $\mathrm{Cu}$. In addition, the Sc doping enhanced the interaction between the metal and support in the $\mathrm{ZnO}$ lattice, improving the metal dispersion and sintering resistance of the catalysts. The best performances in terms of catalytic activity and stability were obtained with the catalyst characterized by the Sc/ZnO molar ratio of $0.05 \mathrm{~mol} \cdot \mathrm{mol}^{-1}$. The decrease of the methanol conversion in the time-on-stream tests was attributed to sintering phenomena: in fact, coke formation was suggested by the performed analysis.

To summarize, the results shown in Table 2 highlight significant differences in the performance of the catalysts studied in the reviewed articles on the methanol reforming in terms of the carbon formation rate. The highest reported rate $\left(10^{-2} \mathrm{~g}_{\text {coke }} \cdot \mathrm{g}_{\text {catalyst }}{ }^{-1} \cdot \mathrm{g}_{\text {carbon,fed }}{ }^{-1} \cdot \mathrm{h}^{-1}\right)$ was for $\mathrm{Cu} / \mathrm{Al}_{2} \mathrm{O}_{3}$ [165], while the lowest one $\left(6.3 \cdot 10^{-7} \mathrm{~g}_{\text {coke }} \cdot \mathrm{g}_{\text {catalyst }}{ }^{-1} \cdot \mathrm{g}_{\text {carbon,fed }}{ }^{-1} \cdot \mathrm{h}^{-1}\right)$ was for $10 \% \mathrm{Cu}-10 \% \mathrm{Zn}-2 \% \mathrm{Zr} / \mathrm{MCM}-41$ [183]. Although in the two cases the reaction conditions were very different, both in terms of temperature and steam-to-carbon ratio $\left(500^{\circ} \mathrm{C}\right.$ and $\mathrm{S} / \mathrm{C}=1.5$ in the first case; $300^{\circ} \mathrm{C}$ and $\mathrm{S} / \mathrm{C}=2$ in the second case), the effect of the zirconium promoter seemed to play a major role. Zirconium, in fact, can stabilize the active species and decrease the growth of metal oxides during the synthesis process, thus allowing the size of the crystallites to be reduced and allowing a better dispersion of the active phases. On the other hand, the use of noble metals such as gold, as well as the addition of oxygen in the reforming reaction, does not seem to suppress the formation of coke; however, further studies are necessary. 
Table 2. Carbon formation rates for various catalysts employed for steam reforming and oxidative steam reforming of methanol.

\begin{tabular}{|c|c|c|c|c|c|c|}
\hline Catalyst $^{\text {a }}$ & Operative Conditions $^{b}$ & $\mathrm{~T}\left({ }^{\circ} \mathrm{C}\right)$ & WHSV $^{\mathrm{c}}\left(\mathrm{h}^{-1}\right)$ & X MeOH (\%) & $\begin{array}{l}\text { Carbon Formation Rate } \\
\text { (MULTIPLIED for 1000) }\end{array}$ & Ref. \\
\hline \multicolumn{7}{|c|}{ Methanol Steam Reforming } \\
\hline $15 \% \mathrm{Cu}-\mathrm{MCM}-41$ & $\mathrm{H}_{2} \mathrm{O} / \mathrm{CH}_{3} \mathrm{OH}=3 / 1$ & 250 & 1.0 & $\begin{array}{l}\approx 73 \\
\text { after } 48 \mathrm{~h}\end{array}$ & 0.015 & [158] \\
\hline $20 \% \mathrm{Cu}-\mathrm{MCM}-41$ & $\mathrm{H}_{2} \mathrm{O} / \mathrm{CH}_{3} \mathrm{OH}=3 / 1$ & 250 & 1.0 & $\begin{array}{l}\approx 60 \\
\text { after } 48 \mathrm{~h}\end{array}$ & 0.024 & [158] \\
\hline $\begin{array}{l}\mathrm{Cu}-\mathrm{ZnO}-\mathrm{Al}_{2} \mathrm{O}_{3}-\mathrm{ZrO}_{2}-\mathrm{Ga}_{2} \mathrm{O}_{3} \\
\mathrm{Cu} / \mathrm{Zn} / \mathrm{Al} / \mathrm{Zr} / \mathrm{Ga}= \\
14.9: 30.9: 3.9: 10.8: 1.9 \text { mass ratio }\end{array}$ & $\mathrm{H}_{2} \mathrm{O} / \mathrm{CH}_{3} \mathrm{OH}=1 / 1$ & 275 & 4.3 & $\begin{array}{l}\approx 85 \\
\text { after } 70 \mathrm{~h}\end{array}$ & 0.010 & [159] \\
\hline $\begin{array}{l}\mathrm{Cu}-\mathrm{ZnO}-\mathrm{Al}_{2} \mathrm{O}_{3}-\mathrm{ZrO}_{2}-\mathrm{Ga}_{2} \mathrm{O}_{3} \\
\mathrm{Cu} / \mathrm{Zn} / \mathrm{Al} / \mathrm{Zr} / \mathrm{Ga}= \\
13.3: 28.2: 3.9: 10.0: 1.8 \text { mass ratio }\end{array}$ & $\mathrm{H}_{2} \mathrm{O} / \mathrm{CH}_{3} \mathrm{OH}=1 / 1$ & 275 & 4.3 & $\begin{array}{l}\approx 70 \\
\text { after } 70 \mathrm{~h}\end{array}$ & 0.014 & [159] \\
\hline Pd-MCM-41 & $\mathrm{H}_{2} \mathrm{O} / \mathrm{CH}_{3} \mathrm{OH}=3 / 1$ & 300 & 1.0 & $\begin{array}{l}\approx 32 \\
\text { after } 40 \mathrm{~h}\end{array}$ & 0.041 & [163] \\
\hline Zn-MCM-41 & $\mathrm{H}_{2} \mathrm{O} / \mathrm{CH}_{3} \mathrm{OH}=3 / 1$ & 300 & 1.0 & $\begin{array}{l}\approx 5 \\
\text { after } 40 \mathrm{~h}\end{array}$ & 0.15 & [163] \\
\hline Ni-MCM-41 & $\mathrm{H}_{2} \mathrm{O} / \mathrm{CH}_{3} \mathrm{OH}=3 / 1$ & 300 & 1.0 & $\begin{array}{l}\approx 15 \\
\text { after } 40 \mathrm{~h}\end{array}$ & 0.16 & [163] \\
\hline Cu-MCM-41 & $\mathrm{H}_{2} \mathrm{O} / \mathrm{CH}_{3} \mathrm{OH}=3 / 1$ & 300 & 3.0 & $\begin{array}{l}\approx 75 \\
\text { after } 40 \mathrm{~h}\end{array}$ & 0.049 & [163] \\
\hline $\mathrm{Cu} / \mathrm{Al}_{2} \mathrm{O}_{3}$ & $\mathrm{H}_{2} \mathrm{O} / \mathrm{CH}_{3} \mathrm{OH}=3 / 2$ & 500 & 0.8 & $\begin{array}{l}\approx 91 \\
\text { after } 5 \mathrm{~h}\end{array}$ & 10 & [165] \\
\hline $\begin{array}{l}\text { NixMgyO } \\
\text { Impregnation }\end{array}$ & $\mathrm{H}_{2} \mathrm{O} / \mathrm{CH}_{3} \mathrm{OH}=1 / 1$ & 600 & 65.7 & $\begin{array}{l}51.4 \\
\text { after } 20 \mathrm{~h}\end{array}$ & 0.0079 & [168] \\
\hline $\begin{array}{l}\text { NixMgyO } \\
\text { Hydrothermal method }\end{array}$ & $\mathrm{H}_{2} \mathrm{O} / \mathrm{CH}_{3} \mathrm{OH}=1 / 1$ & 600 & 65.7 & $\begin{array}{l}58.3 \\
\text { after } 20 \mathrm{~h}\end{array}$ & 0.0030 & [168] \\
\hline $\begin{array}{l}\text { NixMgyO } \\
\text { Co-precipitation }\end{array}$ & $\mathrm{H}_{2} \mathrm{O} / \mathrm{CH}_{3} \mathrm{OH}=1 / 1$ & 600 & 65.7 & $\begin{array}{l}57.3 \\
\text { after } 20 \mathrm{~h}\end{array}$ & 0.085 & [168] \\
\hline $\mathrm{Cu} /$ cubic- $\mathrm{ZnTiO}{ }_{3}$ & $\mathrm{~N}_{2} / \mathrm{H}_{2} \mathrm{O} / \mathrm{CH}_{3} \mathrm{OH}=1 / 2 / 1$ & 250 & 1 & $\begin{array}{l}\approx 63 \\
\text { after } 42 \mathrm{~h}\end{array}$ & 1.1 & [177] \\
\hline $\mathrm{Cu} /$ hexagonal- $\mathrm{ZnTiO}_{3}$ & $\mathrm{~N}_{2} / \mathrm{H}_{2} \mathrm{O} / \mathrm{CH}_{3} \mathrm{OH}=1 / 2 / 1$ & 250 & 1 & $\begin{array}{l}\approx 5 \\
\text { after } 42 \mathrm{~h}\end{array}$ & 6.7 & [177] \\
\hline $10 \% \mathrm{Cu}-10 \% \mathrm{Zn} / \mathrm{MCM}-41$ & $\mathrm{H}_{2} \mathrm{O} / \mathrm{CH}_{3} \mathrm{OH}=2 / 1$ & 300 & 1.62 & $\begin{array}{l}\approx 75 \\
\text { after } 60 \mathrm{~h}\end{array}$ & 0.0011 & [183] \\
\hline $\begin{array}{l}10 \% \mathrm{Cu}-10 \% \mathrm{Zn}-2 \% \mathrm{Zr} / \mathrm{MCM}-41 \\
\text { Impregnated }\end{array}$ & $\mathrm{H}_{2} \mathrm{O} / \mathrm{CH}_{3} \mathrm{OH}=2 / 1$ & 300 & 1.62 & $\begin{array}{l}\approx 83 \\
\text { after } 60 \mathrm{~h}\end{array}$ & 0.00095 & [183] \\
\hline $\begin{array}{l}10 \% \mathrm{Cu}-10 \% \mathrm{Zn}-2 \% \mathrm{Zr} / \mathrm{MCM}-41 \\
\text { Sol-gel method }\end{array}$ & $\mathrm{H}_{2} \mathrm{O} / \mathrm{CH}_{3} \mathrm{OH}=2 / 1$ & 300 & 1.62 & $\begin{array}{l}90.2 \\
\text { after } 60 \mathrm{~h}\end{array}$ & 0.00079 & [183] \\
\hline $\begin{array}{l}10 \% \mathrm{Cu}-10 \% \mathrm{Zn}-2 \% \mathrm{Zr} / \mathrm{MCM}-41 \\
\text { MCM- } 41 \text { pretreated with acetic acid }\end{array}$ & $\mathrm{H}_{2} \mathrm{O} / \mathrm{CH}_{3} \mathrm{OH}=2 / 1$ & 300 & 1.62 & $\begin{array}{l}92.8 \\
\text { after } 60 \mathrm{~h}\end{array}$ & 0.00063 & [183] \\
\hline $10 \% \mathrm{Cu} / \mathrm{SBA}-15$ & $\mathrm{H}_{2} \mathrm{O} / \mathrm{CH}_{3} \mathrm{OH}=2 / 1$ & 300 & 43.7 & $\begin{array}{l}\approx 64 \\
\text { after } 60 \mathrm{~h}\end{array}$ & 0.0031 & [198] \\
\hline $10 \% \mathrm{Cu} / 5 \% \mathrm{ZnO} / \mathrm{SBA}-15$ & $\mathrm{H}_{2} \mathrm{O} / \mathrm{CH}_{3} \mathrm{OH}=2 / 1$ & 300 & 43.7 & $\begin{array}{l}\approx 74 \\
\text { after } 60 \mathrm{~h}\end{array}$ & 0.0025 & [198] \\
\hline $10 \% \mathrm{Cu} / 5 \% \mathrm{ZnO} / 2 \% \mathrm{CeO}_{2} / \mathrm{SBA}-15$ & $\mathrm{H}_{2} \mathrm{O} / \mathrm{CH}_{3} \mathrm{OH}=2 / 1$ & 300 & 43.7 & $\begin{array}{l}\approx 85 \\
\text { after } 60 \mathrm{~h}\end{array}$ & 0.0013 & [198] \\
\hline $10 \% \mathrm{Cu} / 5 \% \mathrm{ZnO} / 2 \% \mathrm{ZrO}_{2} / \mathrm{SBA}-15$ & $\mathrm{H}_{2} \mathrm{O} / \mathrm{CH}_{3} \mathrm{OH}=2 / 1$ & 300 & 43.7 & $\begin{array}{l}\approx 84 \\
\text { after } 60 \mathrm{~h}\end{array}$ & 0.0031 & [198] \\
\hline $10 \% \mathrm{Cu} / 5 \% \mathrm{ZnO} / 2 \% \mathrm{CeO}_{2} / 2 \% \mathrm{ZrO}_{2} / \mathrm{SBA}-15$ & $\mathrm{H}_{2} \mathrm{O} / \mathrm{CH}_{3} \mathrm{OH}=2 / 1$ & 300 & 43.7 & $\begin{array}{l}\approx 86 \\
\text { after } 60 \mathrm{~h}\end{array}$ & 0.0031 & [198] \\
\hline \multicolumn{7}{|c|}{ Oxidative Steam Reforming of Methanol } \\
\hline $\begin{array}{l}\mathrm{xAu} / \mathrm{CeO}_{2}-\mathrm{Fe}_{2} \mathrm{O}_{3} \\
\mathrm{x}=3 \mathrm{wt} . \% \\
\mathrm{Ce} /(\mathrm{Ce}+\mathrm{Fe})=0.25 .\end{array}$ & $\mathrm{O}_{2} / \mathrm{H}_{2} \mathrm{O} / \mathrm{CH}_{3} \mathrm{OH}=0.6 / 2 / 1$ & 350 & 11.9 & $\begin{array}{l}91 \\
\text { after } 12 \mathrm{~h}\end{array}$ & 0.098 & [209] \\
\hline $\begin{array}{l}x \mathrm{xuu} / \mathrm{CeO}_{2}-\mathrm{Fe}_{2} \mathrm{O}_{3} \\
\mathrm{x}=3 w \mathrm{wt} . \% \\
\mathrm{Ce} /(\mathrm{Ce}+\mathrm{Fe})=0.25 .\end{array}$ & $\begin{array}{l}\mathrm{O}_{2} / \mathrm{H}_{2} \mathrm{O} / \mathrm{CH}_{3} \mathrm{OH}=0.6 / 2 / 1 \\
\mathrm{O}_{2} \text { pretreatment }\end{array}$ & 350 & 11.9 & $\begin{array}{l}92 \\
\text { after } 12 \mathrm{~h}\end{array}$ & 0.0082 & [209] \\
\hline 9 wt. $\% \mathrm{Cu} / \mathrm{CeO}_{2}$ & $\begin{array}{l}\mathrm{H}_{2} \mathrm{O} / \mathrm{CH}_{3} \mathrm{OH}=2 / 1 \\
\mathrm{O}_{2}=5 \mathrm{~mL} \cdot \mathrm{min}^{-1}\end{array}$ & 350 & 0.9 & $\begin{array}{l}65 \\
\text { after } 2.8 \mathrm{~h}\end{array}$ & 0.0042 & [212] \\
\hline 9 wt. $\% \mathrm{Cu} / \mathrm{CeZrO}_{4}$ & $\begin{array}{l}\mathrm{H}_{2} \mathrm{O} / \mathrm{CH}_{3} \mathrm{OH}=2 / 1 \\
\mathrm{O}_{2}=5 \mathrm{~mL} \cdot \mathrm{min}^{-1}\end{array}$ & 300 & 0.9 & $\begin{array}{l}65 \\
\text { after } 2.8 \mathrm{~h}\end{array}$ & 0.0032 & [212] \\
\hline
\end{tabular}

Note: ${ }^{a}$ The metal or oxide loadings are intended for the weight of the catalyst; ${ }^{\mathrm{b}}$ all the tests were performed at atmospheric pressure; ${ }^{c}$ refers to the methanol mass flow rate; ${ }^{\mathrm{d}} \mathrm{g}_{\text {coke }} \cdot \mathrm{g}_{\text {catalyst }}{ }^{-1} \cdot \mathrm{g}_{\text {carbon,fed }}{ }^{-1} \cdot \mathrm{h}^{-1}$. 


\section{Bioglycerol Reforming}

An extensive research study concerning the applications of bioglycerol as the main by-product of biodiesel production processes ( 10\% by weight) [214] was carried out in recent years. Indeed, with the constant growth of the biofuel market and approximately 36 million tons of biodiesel having been produced [215], the supply of bioglycerol exceeds the global demand $\left(\sim 3 \cdot 10^{6}\right.$ ton produced by 2020, with a demand below $\sim 5 \cdot 10^{5}$ ton/year) [216]. The consequent drop in bioglycerol prices and the difficulties in the disposal of the produced surplus constitute a threat for the biodiesel production process, which is already fails to be competitive in terms of price $[215,217,218]$.

Crude glycerol (i.e., glycerol derived from the biodiesel production process) is a highly viscous liquid characterized by a dark color, which includes variable quantities of soap, catalyst, alcohol, monoglycerides, diglycerides, polymer, water, unreacted triacylglycerols, and biodiesel; glycerol concentrations are in the range of 40-85\%, depending on the efficiency of the biodiesel production process. Due to the presence of such impurities, it is not possible to use crude glycerol in most typical applications (e.g., cosmetics, food, alkyd resins, tobacco, pharmaceutical, polyurethane [217]), which are depicted in Figure 16.

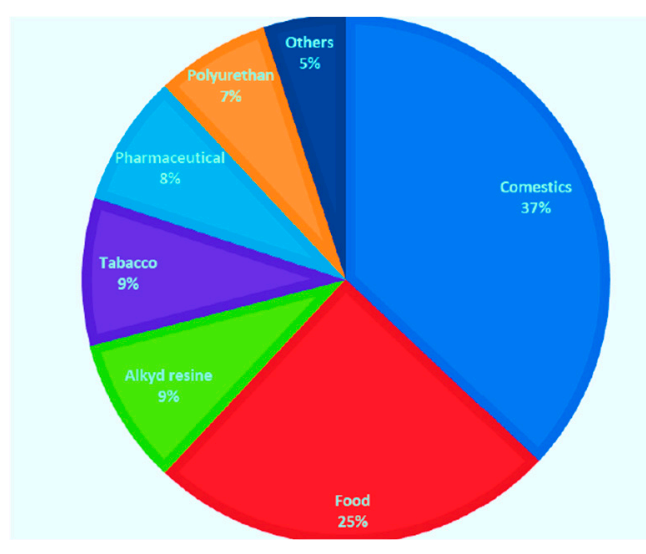

Figure 16. Crude glycerol's most typical applications [217].

Moreover, crude glycerol purification through distillation is an expensive process and most biodiesel plants use this feedstock for direct burning process; however, in this way, the recovery efficiency is low due to the combustion difficulties caused by the high viscosity and the formation of highly toxic substances (e.g., acrolein and aldehyde). Hence, the employment of surplus-produced crude glycerol to obtain other value-added chemicals could represent the best route in view of improving the biodiesel industry's economic feasibility [215,219].

An interesting pathway for crude glycerol revalorization is to use it as a renewable biomass source for $\mathrm{H}_{2}$ production; thereby, hydrogen, as a promising fuel for moving vehicles and providing power and heat for industries, would be produced, involving less energy consumption in comparison with the traditional routes for its obtainment (water electrolysis and thermochemical processes) [219]. Hydrogen can be produced by glycerol via several processes, including steam reforming, partial oxidation, autothermal reforming, aqueous-phase reforming, dry reforming, and photocatalytic reforming. Among them, steam reforming has drawn major attention. In fact, since the steam reforming of methane is presently the most widely-used process in the industry to obtain hydrogen, the adoption of glycerol would not require many changes in the already existent systems [218,220]. However, glycerol steam reforming (GSR) is an endothermic catalytic process that requires large energy consumption and suffers from catalyst deactivation caused by coke formation. Additionally, the other routes for $\mathrm{H}_{2}$ generation from glycerol are characterized by several disadvantages. The autothermal reforming (the process in which the partial oxidation is coupled with steam reforming) leads to a lower energy consumption compared to the SR. In fact, the steam reforming step absorbs the energy produced by 
the PO reaction; however, as a drawback, the presence of several hotspots caused by the heat produced during the PO can result in negative effects on the catalyst activity. The liquid-phase reaction (APR) operating at pressures of 30-80 bar and temperatures of $200-250{ }^{\circ} \mathrm{C}$, reduces the amount of necessary heat, especially due to the liquid form of the reactant, which does not require energy for vaporization; however, this process usually requires more time compared to the SR and requires noble metals to be adopted as catalysts (generally Pt), increasing costs. Glycerol dry reforming (GDR) appears to be an attractive path for $\mathrm{H}_{2}$ production, as it is a carbon capture and recycling (CCR) approach; indeed, with the adoption of this process, $\mathrm{CO}_{2}$ would be converted and recycled back into fuels and added value chemicals. Regardless, the major obstacles in the application of this technology concern the sintering of catalysts particles and the coke accumulation on the catalysts' surfaces, which are even higher compared to other reforming processes. A novel route could be represented by the photocatalytic reforming of glycerol, in which $\mathrm{H}_{2}$ would be produced under ambient conditions, in the presence of an appropriate catalyst and solar light $[62,219,220]$.

Catalysts activity and stability are essential aspects in the transformation of glycerol into hydrogen through reforming reactions, as they allow the activation energy to be lowered, improving the kinetics of the involved chemical reactions, thus reducing the energy requirements and the correspondent costs [219]. In recent years, an extensive effort has been made towards improving the activity of catalysts. Studies have been performed on both noble and non-noble metals, different kinds of supports, and the influence of promoters. Moreover, intensified investigations on the selective removal of reaction products have also been performed in order to avoid the thermodynamic limitations (glycerol conversion and hydrogen yield) of the process [218]. Since the positive results gained have been in terms of catalyst activity, the main critical issue in glycerol reforming reactions remains the stability of the employed catalysts.

Catalyst stability, the fundamental challenge in the industrial development of glycerol reforming processes, is mainly compromised by metal sintering and coke deposits. Coke formation in glycerol reforming reactions is a truly complex aspect, since a multitude of carbon sources may be responsible for coke deposits, thus making it difficult to define the catalyst deactivation pathway [221]. Numerous side reactions involved in glycerol conversion lead to the formation of coke, such as the Boudouard reaction (Equation (8)), olefin polymerization (Equation (6)), glycerol dehydration, and rearrangement and condensation reactions [222]. Papageridis et al. [223], having gained a deepened understanding of carbon deposition, suggested that atomic carbon or $\mathrm{C}_{\mathrm{y}} \mathrm{H}_{1-\mathrm{y}}$ species $\left(\mathrm{C}_{\alpha}\right.$ species $)$ are generated by dissociative chemisorption of the hydrocarbon on the catalysts surface. Thus, the production of an amorphous film $\left(C_{\beta}\right)$ by dehydropolymerization occurred, which can subsequently lead to the formation of graphitic carbon. Otherwise, these carbon atoms may also be dissolved and diffused through the metal to active growth areas, resulting in the precipitation of amorphous vermicular carbon $\left(C_{\gamma}\right)$ or whiskers (Figure 17). Moreover, under harsh and protracted reaction conditions, the amorphous carbon can also be converted into graphitic form $\left(C_{\delta}\right)$ [223]. An accurate analysis of the nature of the formed coke is a powerful tool in the improvement of catalyst stability, as the total amount of generated coke has less impact in catalytic deactivation in comparison to the degree of graphitization of the deposits [224,225]. Temperature-programmed oxidation tests (TPO) performed in numerous research studies have pointed out the easier oxidation of amorphous carbon ( $\mathrm{T}$ below $550{ }^{\circ} \mathrm{C}$ ) compared to filamentous and graphitic carbon deposits, such as carbon nanofibers or carbon nanotubes (T over $600^{\circ} \mathrm{C}$ ) [33,226].

The extent of coke deposition in glycerol reforming reactions is mainly dependent on the nature of the active phase, the extent of dispersion, and the chemical characteristics of the supports or promoters.

Glycerol reforming has been investigated for various metals and the below chart summarizes the papers considered in this review, dividing them on the basis of the active phase analyzed during the study. As it is possible to see from the graph (Figure 18), in recent years, due to their good catalytic activity, low cost, and ease of availability, Ni-based catalysts have drawn major attention among the 
other active phases. Regarding the active phase, the most investigated materials have been $\mathrm{Ni}-, \mathrm{Co}-$, Rh-, Pt-, and Ru-based catalysts; attention has also been given to $\mathrm{Ir}, \mathrm{Cu}$, and Pd catalysts.
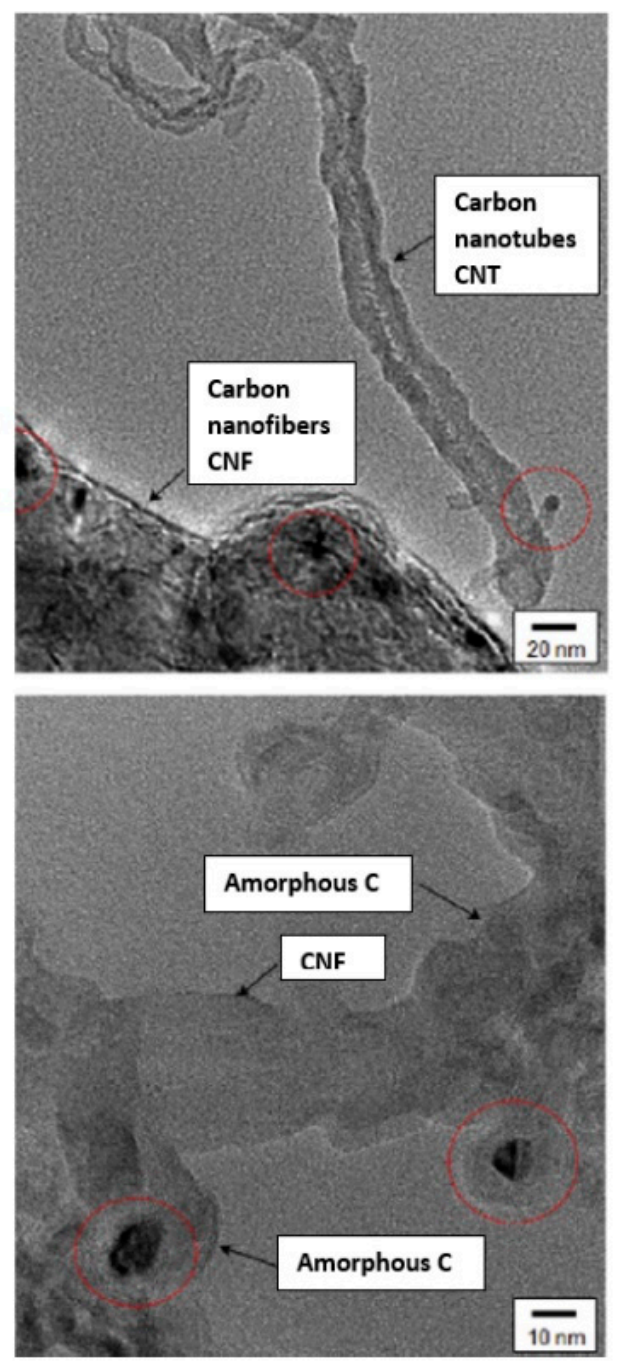

Figure 17. TEM images of amorphous and graphitic carbon formed during glycerol reforming.

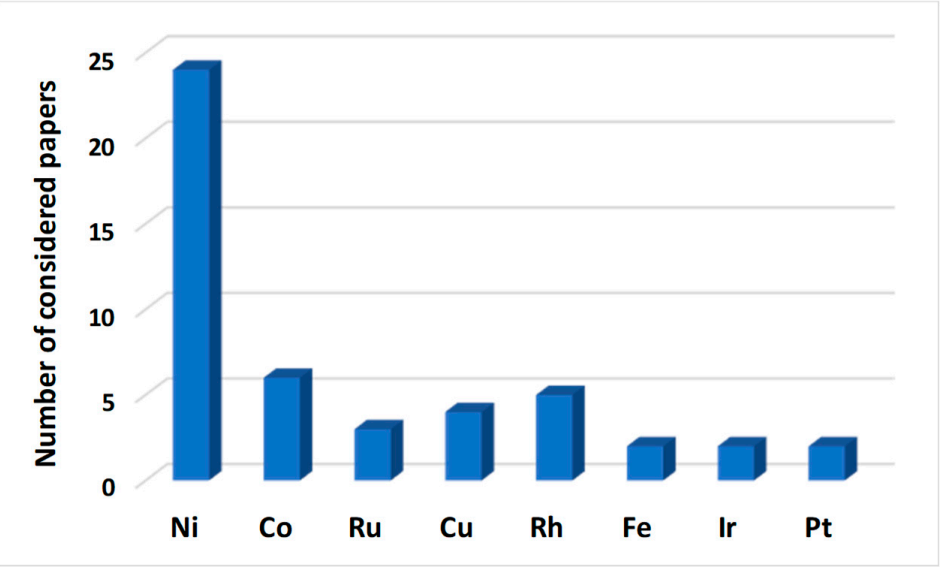

Figure 18. Number of considered papers as a function of the active phases analyzed for glycerol reforming. 


\subsection{The Influence of the Active Phase}

In the following paragraph, selected papers highlighting the roles of active species on catalyst stability for glycerol reforming are discussed.

As anticipated above, nickel is widely used, mainly due to its low cost and satisfactory activity; in addition, $\mathrm{Ni}$ has been found to promote the water-gas shift reaction, leading to an increase of $\mathrm{H}_{2}$ production [215]. Papageridis et al. [223] made a comparison between Ni-, Co-, and $\mathrm{Cu} / \gamma$-alumina-supported catalysts for the steam reforming of glycerol, observing the higher ability of the $\mathrm{Ni} / \mathrm{Al}$ sample to convert glycerol compared to $\mathrm{Co} / \mathrm{Al}$ and $\mathrm{Cu} / \mathrm{Al}$ catalysts. On the other hand, the Ni-based catalyst showed worse stability, characterized by a drastic drop in activity within the first $7 \mathrm{~h}$. $\mathrm{Rh}, \mathrm{Ru}, \mathrm{Pt}$, and Ir have been tested in GSR by Sensei et al. by preparing precious metal nanocatalysts over the promoted $\mathrm{Al}_{2} \mathrm{O}_{3}$ with $\mathrm{MgO}$. In the stability test performed at $600{ }^{\circ} \mathrm{C}$ (GHSV $=35,000 \mathrm{~mL} \mathrm{~g}^{-1} \mathrm{~h}^{-1}$ and $\mathrm{H}_{2} \mathrm{O}: \mathrm{C}_{3} \mathrm{H}_{8} \mathrm{O}_{3}=9$ ), Rh showed a glycerol conversion of $\sim 98 \%$ almost constantly over $20 \mathrm{~h}$, while the other metals were characterized by a drastic decrease in the conversion within the first $5 \mathrm{~h}$. Moreover, from the TPO analysis of $\mathrm{Rh} / \mathrm{MgAl}_{2} \mathrm{O}_{4}$, two oxidation peaks were detected, corresponding to the formation of amorphous and graphitic carbon, whereas for $\mathrm{Ru}, \mathrm{Pt}$, and Ir, only the presence of graphitic carbon has been evaluated [226]. Rh-alumina catalyst stability was also studied in GSR by Silva et al. [227]. A decrease in the glycerol conversion from $99 \%$ to $92 \%$ was achieved after $13 \mathrm{~h}$ of time-on-stream testing. Moreover, the characterization of the spent catalyst carried out by Raman spectroscopy, SEM/EDS, and TPO showed the presence of amorphous carbon species. According to the results of the TPO analysis, the authors regenerated the catalyst in air at $500^{\circ} \mathrm{C}$, obtaining a complete recovery of the catalytic performance. Montmorillonite (MMT)-supported nickel nanoparticle (Ni/MMT) catalysts were prepared by Jiang et al. In order to optimize the $\mathrm{Ni}$ loading and the calcination temperature in GSR. Stability tests were performed on the three catalysts containing 20\% Ni (Ni/MMT molar ratio 1:1) and calcination was performed at different temperatures (1Ni-1MMT-800, 1Ni-1MMT-700, and 1Ni-1MMT-600, calcined at 800, 700, and $600{ }^{\circ} \mathrm{C}$, respectively). The 1Ni-1MMT-700 catalyst showed the best stability among all the tested catalysts, probably due to the better dispersion of the metal obtained with the calcination at $700{ }^{\circ} \mathrm{C}$. Furthermore, comparing the stability of $1 \mathrm{Ni}-1 \mathrm{MMT}-700$ and $1 \mathrm{Ni}-1 \mathrm{Al}-700$ under $30 \mathrm{~h}$ of TOS, a rapid deactivation of the alumina-based catalyst was found. This result, coupled with the characterization of the spent catalysts, pointed out the different reaction pathways for the two catalysts; indeed, with $\mathrm{Al}_{2} \mathrm{O}_{3}$ acid, dehydration reactions that lead to coke precursors are more prevalent than dehydrogenation reactions [228]. Ni behavior in the steam reforming of glycerol has also been studied over a novel fly-ash-based catalyst. In the stability evaluation, which was performed at $550{ }^{\circ} \mathrm{C}$ with a steam/glycerol ratio of 10 and three different space periods of $3 \mathrm{~h}$ for time-on-stream testing, glycerol conversions higher than $90 \%$ were obtained [229]. Mono- and bimetallic Ni-based catalysts (Ni-Co, Ni-Cu, and Ni-Zn) supported on attapulgite were submitted in a GSR stability investigation at $600{ }^{\circ} \mathrm{C}$, with a steam/glycerol ratio of 9 and GHSV of $9619 \mathrm{~h}^{-1}$. After $30 \mathrm{~h}$ of time-on-stream testing, among all the catalysts, Ni-Zn/ATP exhibited the best performance, with glycerol conversion and $\mathrm{H}_{2}$ selectivity remaining almost stable over the time period [230]. Carrero et al. [231] evaluated the performance of bimetallic Ni-(Cu, Co, Cr)/SBA-15-supported catalysts; the addition of the second metal favored the dispersion of the Ni phase and the metal-support interactions, thus leading to better performances in GSR, particularly for th2e Ni-Cr/SBA-15 catalyst. This catalyst also showed a lower amount of deposited coke compared with the other bimetallic catalysts and a relatively good stability within $60 \mathrm{~h}$ at $600{ }^{\circ} \mathrm{C}$. Bimetallic $(\mathrm{Co}, \mathrm{Cu}$, and $\mathrm{Fe})-\mathrm{Ni} / \mathrm{CNTs}$ catalysts were analyzed in low-temperature GSR $\left(375^{\circ} \mathrm{C}\right)$ tests; a glycerol conversion of $\sim 91 \%$ was achieved for $\mathrm{Co}-\mathrm{Ni} / \mathrm{CNTs}$, which was also characterized by a lower amount of deposited coke $\left(0.05 \mathrm{mg}_{\mathrm{C}} \cdot \mathrm{mg}_{\mathrm{cat}}{ }^{-1}\right)$. Moreover, the thermogravimetric analysis performed on $\mathrm{Co}-\mathrm{Ni} / \mathrm{CNTs}$ revealed a shift of the coke peak to lower temperatures, pointing out that the Co addition may have increased the formation of amorphous carbon [232]. The influence of the active phase on the stability of the catalysts and the nature and extent of coke deposits was also analyzed in relation to the dry reforming of glycerol (GDR) by Tavanarad et al. [233], who in 2018 prepared and proved various 
$\mathrm{Ni} / \gamma$-alumina catalysts by varying the Ni loading from 5 to $20 \mathrm{wt} . \%$. The first activity screening on the Ni content showed that the best performances were obtained with a content of nickel of $15 \mathrm{wt} . \%$, while a Ni loading of $20 \mathrm{wt} . \%$ resulted in worse nickel dispersion and bigger crystalline structures. The $15 \mathrm{Ni} / \gamma-\mathrm{Al}_{2} \mathrm{O}_{3}$ was subsequently tested at $700{ }^{\circ} \mathrm{C}$ under $20 \mathrm{~h}$ of time-on-stream; a drastic drop in the catalyst activity was observed in the first $5 \mathrm{~h}$, followed by an almost constant glycerol conversion of $\sim 55 \%$ for the next $15 \mathrm{~h}$. TPO and SEM analyses of the catalyst after the stability test evidenced the presence of whisker-type carbonaceous species on its surface. A comparison between the stability of catalysts with different metals as the active phase and the same support specie was investigated by Bac et al. [234] via 72-h time-on-stream stability tests at $750{ }^{\circ} \mathrm{C}$, carried out on $\mathrm{Rh}, \mathrm{Ni}$, and $\mathrm{Co}$ supported on $\mathrm{Al}_{2} \mathrm{O}_{3}-\mathrm{ZrO}_{2}-\mathrm{TiO}_{2}$ (AZT) catalysts. Better performances were obtained for $\mathrm{Rh} / \mathrm{AZT}$ and $\mathrm{Ni} / \mathrm{AZT}$. Indeed, for both catalysts the $\mathrm{CO}_{2}$ conversion was above $91 \%$ of the thermodynamic limit, characterized by decreases of only $13 \%$ and $8 \%$, respectively. The stability of Rh/AZT was attributed to the lack of sintering and carbon deposits, while Ni/AZT exhibited the ability to post-gasify surface carbon species that were deposited on the catalyst during the first few hours. Moreover, the Co/ATZ catalyst showed a drastic drop in $\mathrm{CO}_{2}$ conversion, suggesting the presence of severe irreversible carbon formation.

Larimi and co-workers [235] investigated the influence of the $\mathrm{Ce} / \mathrm{Zr}$ ratio on the performance of a $\mathrm{Pt}_{0.05} \mathrm{Ce}_{\mathrm{x}} \mathrm{Zr}_{0.95-\mathrm{x}} \mathrm{O}_{2}$ catalyst for the aqueous-phase reforming of glycerol (GAPR), finding a dependence of the reactivity of the catalyst by the metal ratio, which influenced the Pt oxidation state, the active metal dispersion, the surface area, and the particle size. The catalyst showing the best results in term of activity $\left(\mathrm{Pt}_{0.05} \mathrm{Ce}_{0.475} \mathrm{Zr}_{0.475} \mathrm{O}_{2}\right)$ was subsequently tested for $50 \mathrm{~h}$ using TOS at $250{ }^{\circ} \mathrm{C}$ and 50 bar, during which no deactivation was detected. A comparison between monometallic Ir and bimetallic Ir-Ni and Ir-Co catalysts was evaluated by Espinosa-Moreno et al. [236], who found that IrNi bimetallic catalysts excelled, probably as a result of the high tendency of $\mathrm{Ni}$ to cleave to the $\mathrm{C}-\mathrm{C}$ bond. Moreover, the $\mathrm{IrNi} / \mathrm{La}_{2} \mathrm{O}_{3}$ sample exhibited improved resistance to deactivation, ascribable to the carbon species removal on Ni sites, which is promoted by the oxygen species formed upon La addition. Bimetallic $\mathrm{Ni}$ catalysts also showed less $\mathrm{CH}_{4}$ and $\mathrm{CO}$ selectivity, pointing out that the addition of $\mathrm{Ni}$ to Ir reduces the methanation reaction and increases the metal-support interactions, thus leading to higher $\mathrm{H}_{2}$ concentrations.

\subsection{The Role of the Support}

The role of the support is also fundamental in improving the stability of the adopted catalysts; the present paragraph discusses the benefits and drawbacks of the choices of various supports for bioglycerol reforming.

As a matter of fact, high dispersion and large surfaces are the mainly factors that enhance reactivity in glycerol reforming reactions nonetheless, support acidity and basicity properties also play key roles on the formation of coke deposits. Other authors $[237,238]$ employed Langmuir-Hinshelwood and Eley-Rideal kinetic models coupled with statistical discrimination and thermodynamic evaluation, and identified a molecular adsorption mechanism for glycerol and steam on both Brønsted acidic and basic sites on the catalysts. Thus, they pointed out the necessity of having acidic sites on the surface to improve the process efficiency. On the other hand, acid supports $\left(\mathrm{Al}_{2} \mathrm{O}_{3}\right)$ tend to improve dehydration, dehydrogenation, hydrogenolysis, and condensation reactions, which cause coke deposits, leading to rapid deactivation of catalysts [30]. Charisiou and co-authors, in order to evaluate the influence of the support on the glycerol steam reforming (GSR), performed an investigation on nickel catalysts ( $8 \mathrm{wt} . \%)$ supported on $\mathrm{Al}_{2} \mathrm{O}_{3}, \mathrm{ZrO}_{2}$, and $\mathrm{SiO}_{2}$. The results of the $20 \mathrm{~h}$ stability test at $600{ }^{\circ} \mathrm{C}$ pointed out the behavior of different catalysts related to the acidity or basicity of the three supports. In particular, the catalyst prepared on the acidic alumina $\left(\mathrm{Ni} / \mathrm{Al}_{2} \mathrm{O}_{3}\right)$ showed drastic deactivation, causing the blockage of the active sites by coke precursors formed on the acidic surface sites. Conversely, the more basic $\mathrm{Ni} / \mathrm{ZrO}_{2}$ catalyst appeared to be less affected by deactivation, which may be attributed to the stronger metal-support interactions observed during the TPR analysis, as well as to the capability of 
$\mathrm{ZrO}_{2}$ to enhance the water adsorption and activation. Lastly, the $\mathrm{Ni} / \mathrm{SiO}_{2}$ catalyst ensured the best outcomes in terms of both glycerol conversion and $\mathrm{H}_{2}$ selectivity, thus leading to the advantages gained from the neutral nature of the support, exploiting both acidic and basic surface sites. Moreover, in the characterization of the spent catalysts, $\mathrm{Ni} / \mathrm{Al}_{2} \mathrm{O}_{3}$ showed the lowest amount of deposited coke $(\sim 40 \%)$, while for the other two samples the value was almost equal or higher $(\sim 50 \%)$. On the other hand, the carbon degree of graphitization has also been estimated, which followed the order $\mathrm{Ni} / \mathrm{Al}_{2} \mathrm{O}_{3}$ $>\mathrm{Ni} / \mathrm{ZrO}{ }_{2}>\mathrm{Ni} / \mathrm{SiO}_{2}$, thus leading to the interconnection between the nature of the deposited coke and the deactivation catalysts [224]. The influence of the support towards Ni-based catalysts in the GSR has also studied by Zamzuri and co-authors [239] through the examination of $\mathrm{Ni} / \mathrm{Al}_{2} \mathrm{O}_{3}, \mathrm{Ni} / \mathrm{La}_{2} \mathrm{O}_{3}$, $\mathrm{Ni} / \mathrm{ZrO}_{2}, \mathrm{Ni} / \mathrm{SiO}_{2}$, and Ni/MgO. The TOS stability test carried out at $650{ }^{\circ} \mathrm{C}$ for $5 \mathrm{~h}$ showed that the catalysts' overall activity increased following the order $\mathrm{Ni} / \mathrm{Al}_{2} \mathrm{O}_{3}>\mathrm{Ni} / \mathrm{La}_{2} \mathrm{O}_{3}>\mathrm{Ni} / \mathrm{ZrO}_{2}>\mathrm{Ni} / \mathrm{MgO}>$ $\mathrm{Ni} / \mathrm{SiO}_{2}$. Conversely, while $\mathrm{Ni} / \mathrm{La}_{2} \mathrm{O}_{3}, \mathrm{Ni} / \mathrm{ZrO}_{2}$, and $\mathrm{Ni} / \mathrm{SiO}_{2}$ were found to be almost stable within the time-on-stream tests, $\mathrm{Ni} / \mathrm{Al}_{2} \mathrm{O}_{3}$ and $\mathrm{Ni} / \mathrm{MgO}$ showed decreased activity. Since $\mathrm{Al}_{2} \mathrm{O}_{3}$ has attracted major attention as a support for catalysts in GSR, by virtue of its high surface area and mechanical and chemical resistance under reaction conditions, numerous strategies have been investigated in order to limit the coke deposition, which is probably caused by the acidic properties of $\mathrm{Al}_{2} \mathrm{O}_{3}$. A comparison between Ni catalysts supported on mixed lanthana-alumina and Ni catalysts supported on commercial alumina pointed out that addition of La favored the dispersion of the active phase, increasing the basicity of the support and increasing the metal-support interactions. Moreover, after the stability tests, the comparison between the spent catalysts also showed the different nature of the carbon deposits on the catalysts surface. In fact, even though the amount of deposited carbon was approximately equal $\left(0.41 \mathrm{~g}_{\text {coke }} \cdot \mathrm{g}_{\text {catalyst }}{ }^{-1}\right.$ for $\mathrm{Ni} / \mathrm{Al}$ and $0.44 \mathrm{~g}_{\text {coke }} \cdot \mathrm{g}_{\text {catalyst }}{ }^{-1}$ for Ni/LaAl), TPO and Raman characterizations showed the presence of more graphitic carbon species on the $\mathrm{Ni} / \mathrm{Al}$ samples than $\mathrm{Ni} / \mathrm{LaAl}$, for which almost amorphous carbon deposits were detected. This result was in agreement with the trends of the stability tests, from which it was possible to highlight the good stability in the case of $\mathrm{Ni} / \mathrm{LaAl}$ and a drastic drop in the activity of $\mathrm{Ni} / \mathrm{Al}$ [221]. La-modified $\mathrm{Al}_{2} \mathrm{O}_{3}$ was also investigated by Sanchez et al. as a support for Ni catalysts in GSR reactions. The stability tests were performed on the bare supports and on the catalysts, involving $4 \mathrm{~h}$ time-on-stream tests for $\mathrm{Ni} / \mathrm{Al}_{2} \mathrm{O}_{3}$ and $\mathrm{Ni} / \mathrm{La}_{2} \mathrm{O}_{3}-\mathrm{Al}_{2} \mathrm{O}_{3}$ at $700{ }^{\circ} \mathrm{C}$ and WHSV $=35 \mathrm{~h}^{-1}$. The addition of La to the support enhanced the $\mathrm{H}_{2}$ production, giving a result that was close to that obtained with the Ni catalyst; moreover, while $\mathrm{Ni} / \mathrm{Al}_{2} \mathrm{O}_{3}$ showed a drop in the $\mathrm{H}_{2}$ production over time, $\mathrm{Ni} / \mathrm{La}_{2} \mathrm{O}_{3}-\mathrm{Al}_{2} \mathrm{O}_{3}$ gave an almost stable result after 90 min of reaction. The TGA analysis carried out on the spent catalysts also showed that the amount of coke deposited on $\mathrm{Ni} / \mathrm{Al}_{2} \mathrm{O}_{3}$ was almost twice that deposited on $\mathrm{Ni} / \mathrm{La}_{2} \mathrm{O}_{3}-\mathrm{Al}_{2} \mathrm{O}_{3}$. Moreover, the SEM analysis revealed that the surface of $\mathrm{Ni} / \mathrm{Al}_{2} \mathrm{O}_{3}$ was covered by carbon filaments, which could be the reason for the catalyst deactivation [30]. Additionally, modifications of the alumina support were investigated by Bobadilla et al., who prepared NiSn bimetallic catalysts supported on $\mathrm{Al}_{2} \mathrm{O}_{3}$, evaluating the influence of the addition of $\mathrm{Mg}$ and $\mathrm{Ce}$ on the support. NiSn/Al, NiSn/AlMg, NiSn/AlCe, and NiSn/AlMgCe were submitted to stability tests at $650{ }^{\circ} \mathrm{C}, \mathrm{P}=1 \mathrm{~atm}$, and with a water/glycerol molar ratio of 12 for $6 \mathrm{~h}$ TOS tests. The best results were obtained for the catalyst modified with both $\mathrm{CeO}_{2}$ and $\mathrm{MgO}$. In fact, the addition of these oxides resulted in a synergic effect that decreased the coke formation and favored the WGS reaction [240]. Furthermore, Charisiou and co-authors [241] performed a comparative analysis between $\mathrm{Ni} / \mathrm{CaO}-\mathrm{MgO}-\mathrm{Al}_{2} \mathrm{O}_{3}$ and $\mathrm{Ni} / \mathrm{Al}_{2} \mathrm{O}_{3}$ catalysts, which showed how the addition of $\mathrm{CaO}-\mathrm{MgO}$ led to smaller Ni particles, increased the basicity and the surface amount of the $\mathrm{Ni}^{0}$ phase, thus resulting in better GSR results. The activity and stability tests carried on the two catalysts showed a different distribution of products, as the modified support favored $\mathrm{H}_{2}$ and $\mathrm{CO}_{2}$ production (enhancement of the WGS reaction). Moreover, this proved that the deactivation can be prevented with the addition of $\mathrm{CaO}$ and $\mathrm{MgO}$ to the support. In addition, the modified support also led to a lower amount of coke being deposited on the catalyst's surface, altering its nature, which based on the Raman analysis appeared to be less graphitic than that deposited on the unmodified $\mathrm{Ni} / \mathrm{Al}_{2} \mathrm{O}_{3}$ catalyst. A study concerning the support roles for Pt-based catalysts in the GSR was carried out by 
de Rezende et al. [28]. Several layered double-hydroxides containing $\mathrm{Mg}$ and $\mathrm{Al}(\mathrm{Mg} / \mathrm{Al}$ ratios of 3 and 5) as supports were tested. Specifically, four catalysts were prepared, two containing hydrated layered supports, PtMg5Al-H and PtMg3Al-H; and two containing mixed calcined oxides, PtMg5Al-O and PtMg3Al-O. Subsequently, the catalysts were submitted to GSR time-on-stream stability tests at $600{ }^{\circ} \mathrm{C}$ for $250 \mathrm{~min}$, during which PtMg5Al-H showed a stable conversion rate of $\sim 85 \%$, while all the other catalysts exhibited losses in activity. Moreover, the authors presented a correlation between the amount of carbon deposited on the catalysts and the degree of deactivation, thus pointing out the minor contribution of carbonaceous materials derived from intermediate organic liquid compounds on the deactivation processes. This study is in contrast with what is usually found in the literature, as reaction intermediates adsorbed on the catalysts are generally considered responsible for deactivation of catalysts. An interesting study evaluated the effect of the support on Co-based catalysts adopting alumina, niobia, and $10 \mathrm{wt} . \%$ niobia/alumina. The three prepared catalysts containing $20 \mathrm{wt} . \% \mathrm{CoO}$ were tested under $30 \mathrm{~h}$ of GSR reaction at $500{ }^{\circ} \mathrm{C}$ with GHSV $=200,000 \mathrm{~h}^{-1}$. In the first $8 \mathrm{~h}$ of reactions, complete glycerol conversion was obtained for $\mathrm{CoNb}$, while the rate was $\sim 90 \%$ for $\mathrm{CoNbAl}$ and $\sim 80 \%$ for CoAl. Subsequently, after $24-26 \mathrm{~h}$, a strong deactivation trend was detected for all catalysts, especially for $\mathrm{CoNb}$. Indeed, from the analysis of the product distribution as a function of time, it was evaluated that even though the conversion was higher for $\mathrm{CoNb}$, the gas production was low, thus indicating the probability of coke formation during the process. The catalyst that showed the best stability during the reaction was CoAl, with a decrease observed only after $26 \mathrm{~h}$; these results were probably associated with the higher cobalt dispersion obtained for this catalyst. However, the catalyst supported by both $\mathrm{Nb}$ and $\mathrm{Al}$ presented the best values for $\mathrm{H}_{2}$ production during the first $8 \mathrm{~h}$ of reaction. On the contrary, CoAl showed reduced hydrogen formation and was also characterized by the lowest amount of deposited coke, thus suggesting a coke formation mechanism based on the hydrogenation reaction of $\mathrm{CO}$ and $\mathrm{CO}_{2}$. Conversely, looking at the $\mathrm{H}_{2}$ production results, the authors assumed that the coke formed on $\mathrm{CoNb}$ and $\mathrm{CoNb}$ catalysts was mainly caused by the $\mathrm{CO}$ disproportionation, thus excluding hydrogen. A further analysis of the nature of the formed carbon revealed more amorphous coke deposited on $\mathrm{CoNb}$ and $\mathrm{CoNbAl}$, while the deposits on the CoAl catalyst were predominantly graphitic [242]. The support effect on the stability of the catalysts was also investigated for glycerol dry reforming (GDR). In particular, a comparison between Ni catalysts supported on $\mathrm{CaO}$ and $\mathrm{ZrO}_{2}$ pointed out the differences in the two support species. With this purpose, several catalysts were prepared by wet impregnation on both $\mathrm{CaO}$ and $\mathrm{ZrO}_{2}$, increasing the amount of $\mathrm{Ni}(5 \%, 10 \%$ and $15 \%)$; moreover, the bare supports and the catalysts were also characterized by means of BET surface area determination tests, SEM analysis, XRD technique tests, and TGA and TPR analysis. Afterwards, the prepared catalysts were tested by the authors in stability experiments, which were carried out in a fixed-bed reactor at $700{ }^{\circ} \mathrm{C}$ and at atmospheric pressure over $3 \mathrm{~h}$ in time-on-streams. This resulted in better performances for the $15 \% \mathrm{Ni} / \mathrm{CaO}$ catalyst, characterized by a glycerol conversion rate of $30.52 \%$ and a hydrogen yield rate of $23.06 \%$. For the other tested catalysts, the performances decreased in the order of $10 \% \mathrm{Ni} / \mathrm{ZrO}_{2}>5 \% \mathrm{Ni} / \mathrm{CaO}>10 \% \mathrm{Ni} / \mathrm{CaO}>15 \% \mathrm{Ni} / \mathrm{ZrO}_{2}>5 \% \mathrm{Ni} /$ $\mathrm{ZrO}_{2}$. The better outcomes achieved for the $15 \% \mathrm{Ni} / \mathrm{CaO}$ were found to be in agreement with the characterization results, which proved better interactions between $\mathrm{Ni}$ and $\mathrm{CaO}$, better metal dispersion, and greater surface area results in comparison with $\mathrm{Ni} / \mathrm{ZrO}_{2}$, also resulting in smaller crystallite sizes for $\mathrm{NiO}$ species [243]. Lee et al. [244], through a comparison of $\mathrm{Ni}$-supported catalysts $\left(\mathrm{Ni} / \mathrm{LaAlO}_{3}\right.$, $\mathrm{Ni} / \mathrm{CeO}_{2}, \mathrm{Ni} / \mathrm{MgO}$, and $\mathrm{Ni} / \mathrm{MgAl}$ ) regarding glycerol aqueous-phase reforming (GAPR), highlighted the strong dependency of the glycerol conversion and hydrogen yield on the type of support and the $\mathrm{Ni}$ loading. The support influence was investigated by the authors on $15 \mathrm{wt} . \% \mathrm{Ni}$ catalysts supported on the four abovementioned species. In the activity tests at $250{ }^{\circ} \mathrm{C}$ and $20 \mathrm{bar}$, with LHSV $=5 \mathrm{~h}^{-1}$, the catalyst $15 \% \mathrm{Ni} / \mathrm{LaAlO}_{3}$ showed the best outcomes, with a glycerol conversion rate of $35.8 \%$ and a $\mathrm{H}_{2}$ selectivity rate of $67.2 \%$. Next, under the same conditions, four $\mathrm{LaAlO}_{3}$-supported catalysts with 5 , 10,15 , and $20 \mathrm{wt} . \% \mathrm{Ni}$ were tested, confirming that the best performances were obtained with the $15 \%$ Ni. $15 \% \mathrm{Ni} / \mathrm{LaAlO}_{3}$ product. The selectivity was also investigated with a $20 \mathrm{~h}$ TOS test, during which 
high $\mathrm{CO}_{2}$ and $\mathrm{H}_{2}$ yields were obtained, while low $\mathrm{CO}$ selectivity was achieved due to the WGS reaction. Moreover, the analysis of the spent catalysts revealed the presence of some agglomerated carbon particles on the surfaces of $\mathrm{Ni} / \mathrm{MgAl}, \mathrm{Ni} / \mathrm{CeO}_{2}$, and $\mathrm{Ni} / \mathrm{MgO}$. Conversely, the amount of deposited carbon was small and it was in a fibrous form in the case of the $\mathrm{Ni} / \mathrm{LaAlO}_{3}$ catalyst, thus highlighting the high resistance to coking of the catalyst, which was probably related to the migration of mobile oxygen from the support $\left(\mathrm{LaAlO}_{3}\right)$ to the metallic Ni particles [244]. In the study by Espinosa-Moreno and co-authors on Ir-based catalysts for $\mathrm{H}_{2}$ production through GAPR, a comparison was carried out between $\mathrm{La}_{2} \mathrm{O}_{3}$ and $\mathrm{CeO}_{2}$ as supports. The catalytic tests performed at $270{ }^{\circ} \mathrm{C}$ and 58 bar showed better values for $\mathrm{H}_{2}$ production with $\mathrm{La}_{2} \mathrm{O}_{3}$ catalysts compared to $\mathrm{CeO}_{2}$-supported catalysts due to the higher pore volume and metal-support interactions obtained using lantana [236]. As can be appreciated in Figure 19, comparing the performances of $\mathrm{IrNi} / \mathrm{La}_{2} \mathrm{O}_{3}$ and $\mathrm{IrNi} / \mathrm{CeO}_{2}$, much higher carbon-to-gas conversion rates were obtained when suing lantana as the support.

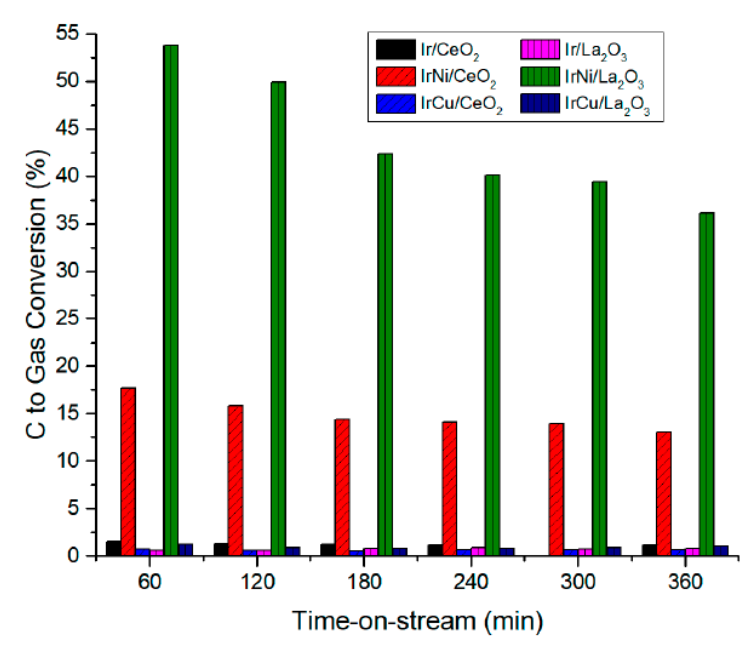

Figure 19. Carbon-to-gas conversion (\%) as a function of the time-on-stream (min) stability test carried out at $270{ }^{\circ} \mathrm{C}$ and 58 bar [236].

\subsection{The Effect of the Addition of Promoters}

In this paragraph, the effects of promoters on the stability of various catalysts for glycerol reforming is discussed. In fact, a further strategy to inhibit catalyst deactivation is the adoption of additives and promoters, in order to create specific surface centers, which are mainly acidic or basic, bimetallic, or redox sites [245]. The effect of the addition of promoters to $\mathrm{Ni} / \mathrm{Al}_{2} \mathrm{O}_{3}$ for the GSR has been widely studied in literature. Lima et al. investigated the consequences of the addition of $\mathrm{Mg}$, finding an increase in the Ni dispersion and in its resistance to sintering and a decrease of the catalysts' acidity, thus promoting the stability of the catalysts. The addition of $\mathrm{Mg}$ also resulted in a lower amount of deposited coke, which was more graphitic [246]. A supplementary investigation on the effect of the addition of $\mathrm{Mg}$ to $\mathrm{Ni} / \mathrm{Al}_{2} \mathrm{O}_{3}$ confirmed that its addition promotes the basicity of the catalyst and results in higher Ni dispersion, thus favoring the catalytic performance and lowering the carbon formation. Indeed, Dieuzeide et al. [247] pointed out that with an optimal loading of Mg of $3 \mathrm{wt} \%$, the amount of coke obtained was approximately half of the amount obtained without $\mathrm{Mg}$. In addition, correlations between the structure of the deposited carbon, the Ni particle size, and the Mg presence were evaluated, since it was previously observed that a decrease in the Ni particle size and an increase in the Mg loading resulted in an increase of the degree of graphitization of the formed coke. Demsash et al. [248] evaluated the effect of ceria-promoted Ni-alumina catalysts in GSR by varying the amounts of nickel and ceria $(5,10$, and $15 \mathrm{wt} . \% \mathrm{Ni}$, and 5 and $10 \mathrm{wt} . \% \mathrm{Ce})$. Among the prepared catalysts, $10 \mathrm{Ni} / \mathrm{Al}_{2} \mathrm{O}_{3} / 5 \mathrm{CeO}_{2}$ exhibited the best results in terms of activity and stability, with product distribution remaining almost stable over the $16 \mathrm{~h}$ TOS test at $650^{\circ} \mathrm{C}$. The Ce-promoted catalyst also showed the lowest coking activity, as a result of the inhibition effect of ceria to the formation of coke deposits; indeed, $\mathrm{CeO}_{2}$ promotes 
the hydration of the support. Carrero et al. [231] investigated the addition of $\mathrm{Cu}, \mathrm{Co}$, and $\mathrm{Cr}$ to a $\mathrm{Ni} / \mathrm{SBA}-15$ catalyst for GSR applications at $600{ }^{\circ} \mathrm{C}$, involving a steam/carbon ratio of 2 and a WHSV of $7.7 \mathrm{~h}^{-1}$ for a $5 \mathrm{~h}$ TOS test. During the stability tests, all the catalysts showed glycerol conversion rates above $85 \mathrm{~mol} \%$. In particular, glycerol conversion decreased following the order of Ni-Cr/SBA-15 > Ni-Co/SBA-15 > Ni/SBA-15 > Ni-Cu/SBA-15 along the reaction time, as can been seen in Figure 20.

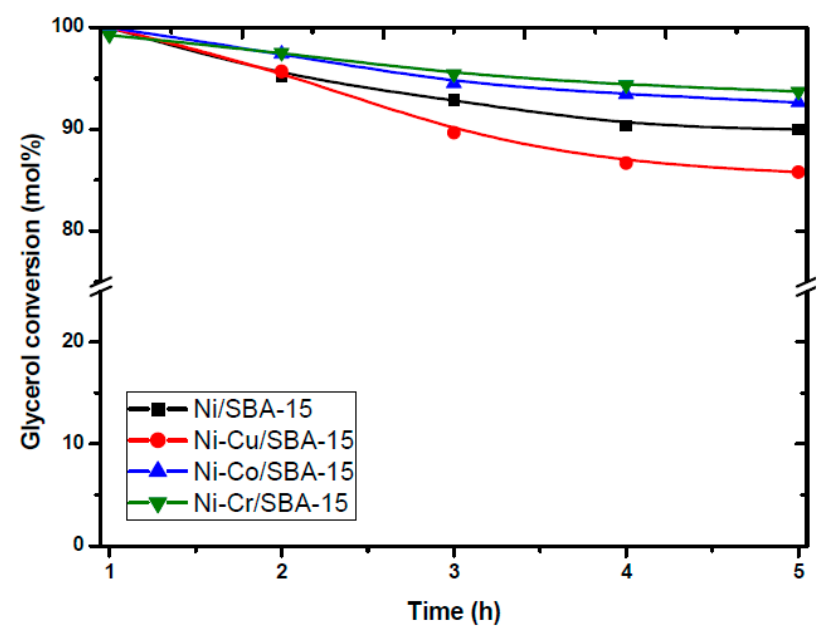

Figure 20. Conversion of glycerol over the $\mathrm{Ni}-(\mathrm{Cu}, \mathrm{Co}, \mathrm{Cr}) / \mathrm{SBA}-15$ catalysts $\left(\mathrm{T}=600{ }^{\circ} \mathrm{C}, \mathrm{P}=1 \mathrm{bar}\right.$, $\mathrm{WHSV}_{\text {glycerol }}=7.7 \mathrm{~h}^{-1}$, water $/$ glycerol $=6 \mathrm{~mol} / \mathrm{mol}$ ) [231].

Catalyst deactivation has been shown to be correlated with the amount of coke deposited, increasing in the order of Ni-Cr/SBA-15 $<$ Ni-Co/SBA-15 $<$ Ni/SBA-15 $<$ Ni-Cu/SBA-15. Focusing attention on the product distribution during the reaction with the Ni-Cu/SBA-15 samples, the catalyst characterized by the highest deactivation and largest amount of coke deposition also enhanced the formation of methane and carbon monoxide, while lower amounts of carbon dioxide and hydrogen were produced. Moreover, for the Ni-Cr/SBA-15 samples, the highest hydrogen concentrations were detected in the gas stream. Regarding Ni-Co/SBA-15, despite the high glycerol conversion values obtained, low $\mathrm{H}_{2}$ production was achieved - even lower than Ni/SBA-15, possibly due to the lower ability of Co than Ni to break the C-C bond. SEM images of the catalysts pointed out the presence of carbon nanofibers on Ni-Cu/SBA-15 and Ni-Co/SBA-15, while no formation of carbon nanofibers was detected by the SEM analysis on Ni-Cr/SBA-15. Subsequently, Ni-Cr/SBA-15 has been tested with a $60 \mathrm{~h}$ TOS protocol, which revealed good stability, with a glycerol conversion rate above $93 \%$ throughout the time period. Prior to investigating the promotion of Ni catalysts, the same authors evaluated the influence of additives on Co-catalysts in GSR. The study was focused on the comparison between Co/SBA-15 and promoted Co-M/SBA-15 with M/Zr, Ce, or La catalysts. The tests, which were carried out at 500 and $600^{\circ} \mathrm{C}$, with a water/glycerol ratio of 6 and a WHSV of $7.7 \mathrm{~h}^{-1}$, showed that the addition of promoters significantly improved the stability of $\mathrm{Co} / \mathrm{SBA}-15$, especially at $500{ }^{\circ} \mathrm{C}$, where the non-promoted catalyst suffered a drastic deactivation (from $98 \%$ to $75 \%$ ) in the first $2 \mathrm{~h}$. Among the promoted catalysts, $\mathrm{Co} / \mathrm{Ce} / \mathrm{SBA}-15$ ensured the best results, with a glycerol conversion rate of $\sim 100 \%$ during the $5 \mathrm{~h}$ time-on-stream test; moreover, despite the higher activity of this catalyst, the amount of coke deposited on its surface was lower compared to that observed for Co/SBA-15 $\left(0.025 \mathrm{~g}_{\text {coke }} \cdot \mathrm{g}_{\text {cat }} \cdot \mathrm{h}^{-1}\right.$ for Co/Ce/SBA-15 and $0.028 \mathrm{~g}_{\text {coke }} \cdot \mathrm{g}_{\mathrm{cat}} \cdot \mathrm{h}^{-1}$ for Co/SBA-15). The products distribution analysis also pointed out that the use of $\mathrm{Co} / \mathrm{Ce} / \mathrm{SBA}-15$ led to higher $\mathrm{CO}_{2}$ and $\mathrm{H}_{2}$ concentrations, while the $\mathrm{CO}$ formation was partially suppressed, highlighting the tendency of ceria to improve the oxygen mobility and water reactivity, enhancing the water-gas shift reaction. On the other hand, the addition of La and $\mathrm{Zr}$ resulted in lower hydrogen production; furthermore, the presence of ethylene was detected on $\mathrm{Co} / \mathrm{Zr} / \mathrm{SBA}-15$, possibly caused by the enhancement of the dehydration reactions on the zirconium acid sites. $\mathrm{Co} / \mathrm{Ce} / \mathrm{SBA}-15$ was then tested with a $50 \mathrm{~h}$ TOS test, during which high stability was reached 
(glycerol conversion rate of $\sim 100 \%$ ). However, the amount produced hydrogen decreased, while the methane concentration increased. Moreover, the amount of coke was found to be higher and the authors suggested the possibility of a secondary reaction, such as $\mathrm{C}+2 \mathrm{H}_{2} \leftrightarrow \mathrm{CH}_{4}$ [249]. The advantages gained by the addition of $\mathrm{Mg}$ to $\mathrm{Ni}$ catalysts were verified by Veiga and co-workers, who studied glycerol steam reforming with nickel supported by activated carbon. During stability tests at $650{ }^{\circ} \mathrm{C}$, Mg-promoted catalysts, among other promoters $\left(\mathrm{MgO}, \mathrm{La}_{2} \mathrm{O}_{3}, \mathrm{Y}_{2} \mathrm{O}_{3}\right)$, showed higher initial conversion and lower deactivation rates as a result of the capability of $\mathrm{Mg}$ to enhance the steam adsorption and stabilize $\mathrm{Ni}$ against sintering [250]. Other strategies used to improve the stability of catalysts for glycerol steam reforming involved the development of new types of catalysts and their subsequent doping with additives. Nickel, as a promoter for $\mathrm{Fe} / \mathrm{Mg}$-containing metallurgical waste, was prepared via solid-state impregnation of $\mathrm{Ni}$ into the structure of the metallurgical residue. Its stability was evaluated at $580^{\circ} \mathrm{C}$ and $1 \mathrm{~atm}$ with a $48 \mathrm{~h}$ of TOS test. The developed catalyst exhibited good stability, with a glycerol conversion rate of $\sim 90 \%$ and a hydrogen yield rate of $\sim 80 \%$; moreover, the amount of coke formation was low $\left(2.7 \mathrm{mg}_{\text {coke }} \mathrm{g}_{\mathrm{cat}}{ }^{-1} \mathrm{~h}^{-1}\right)$ and its nature was filamentous. This study also evidenced the ability of $\mathrm{Mg}$ to activate steam and promote the water-gas shift reaction [251]. An easily reducible $\mathrm{NiAl}_{2} \mathrm{O}_{4}$ spinel was developed using a novel method from a Ni-Al mixed-metal alkoxide, which was tested for use in GSR and was shown to have a highly porous structure and surface area. Moreover, the effect of the addition of $10 \mathrm{wt} . \% \mathrm{CeO}_{2}$ the catalyst stability was evaluated. The TOS tests performed at $630^{\circ} \mathrm{C}$ and $1 \mathrm{~atm}$ for $16 \mathrm{~h}$ showed the high potential of the catalyst, characterized by low coke formation $\left(0.0004 \mathrm{~g}_{\text {coke }} \mathrm{g}_{\text {cat }}{ }^{-1} \mathrm{~h}^{-1}\right)$. Indeed, the addition of ceria diminished the coke deposits and favored their gasification. Additionally, the formation of a well-dispersed $\mathrm{CeAlO}_{3}$ phase hindered the growth of filamentous carbon [245]. The role of $\mathrm{CeO}_{2}$ as a promoter was also studied by Dobosz et al. [252], who evaluated its addition to a calcium hydroxyapatite (HAp)-supported cobalt catalyst. During the TOS stability test, which was carried out at $800^{\circ} \mathrm{C}$ for $6 \mathrm{~h}$, the catalyst doped with ceria (10Co-Ce/Hap) was stable than the $10 \mathrm{Co} / \mathrm{Hap}$ catalyst. In fact, even if it a decrease in the hydrogen selectivity was observed, this effect was slower than the trend observed for the undoped catalyst. Ramesh et al. focused their attention on the influence of copper on perovskite catalysts for GSR, comparing a perovskite catalyst with two copper decorated perovskites $\left(\mathrm{LaNi}_{0.9} \mathrm{Cu}_{0.1} \mathrm{O}_{3}\right.$ and $\mathrm{LaNi}_{0.5} \mathrm{Cu}_{0.5} \mathrm{O}_{3}$ ). Comparing their activity, better results were obtained for $\mathrm{LaNi}_{0.9} \mathrm{Cu}_{0.1} \mathrm{O}_{3}$, which had a glycerol conversion rate of $73 \%$ and a hydrogen selectivity rate of $67 \%$. The stability of the $0.1 \%$-copper-decorated perovskite was confirmed by tests carried out at $650{ }^{\circ} \mathrm{C}, \mathrm{S} / \mathrm{C}=3$, and LHSV $=10,000 \mathrm{~h}^{-1}$, during which the catalyst exhibited an almost constant product distribution over the $24 \mathrm{~h}$ TOS test. The characterization of the spent catalysts showed the presence of small amounts of graphitic carbon in the perovskites without copper (detected by TGA analysis, in which two oxidation peaks were observed at 550 and $600^{\circ} \mathrm{C}$ ). Conversely, the addition of copper resulted in only one oxidation peak, suggesting the presence of only amorphous carbon on the surface of the spent catalyst [33]. The $\mathrm{Ni} / \mathrm{Al}_{2} \mathrm{O}_{3}$ catalyst and the improvements obtained with the addition of promoters were also studied in the development of the glycerol dry reforming (GDR) process. Harun and co-authors evaluated the effect of the Ag promotion via the preparation and testing of $\alpha$-alumina-supported catalysts containing $15 \% \mathrm{Ni}$; in particular, four catalysts with $\mathrm{Ag}$ loading rates of $0 \mathrm{wt} . \%, 1 \mathrm{wt} . \%, 3 \mathrm{wt} . \%$, and $5 \mathrm{wt} . \%$ were tested at $700{ }^{\circ} \mathrm{C}$ for $3 \mathrm{~h}$, with a glycerol/carbon dioxide feed ratio of 1:1. The results showed that even if similar trends were shown by all of the catalysts (increase of the glycerol conversion in the first $0.5 \mathrm{~h}$ followed by a decrease after $1 \mathrm{~h}$ and a final stabilization), among the investigated catalysts, $\mathrm{Ag}(3)-\mathrm{Ni} / \mathrm{Al}_{2} \mathrm{O}_{3}$ gave the best glycerol conversion result $(33.5 \%)$. Hence, this catalyst was tested with a $72 \mathrm{~h}$ stability test at $800^{\circ} \mathrm{C}$, during which the glycerol conversion firstly decreased from the $46 \%$ to the $33 \%$ after $10 \mathrm{~h}$, and then remained almost stable for the next $60 \mathrm{~h}$. After $10 \mathrm{~h}$ of reaction, $\mathrm{H}_{2}$ and $\mathrm{CO}$ concentrations increased, while $\mathrm{CH}_{4}$ decreased; the authors suggested that coke gasification by water may have been responsible. TGA analysis performed on the spent catalyst highlighted the presence of low- and high-temperature oxidation peaks, suggesting the presence of both amorphous and graphitic carbon deposits, as was further confirmed by the SEM 
images, in which it was possible to appreciate the presence of encapsulated solid carbon deposits and filamentous (whisker-like) carbon deposits [31]. The addition of lanthanum to Ni-based catalysts was also investigated in the GDR. A 3wt.\% La-promoted $\mathrm{Ni} / \mathrm{Al}_{2} \mathrm{O}_{3}$ in comparison with the unpromoted catalyst led to better metal dispersion, as evaluated by the increase in the specific surface area and the decrease of the crystallite size (La-promoted catalyst: BET $=96 \mathrm{~m}^{2} \mathrm{~g}^{-1}$, crystallite size $=9.1 \mathrm{~nm}$; unpromoted catalyst: BET $=85 \mathrm{~m}^{2} \mathrm{~g}^{-1}$, crystallite size $=12.8 \mathrm{~nm}$ ). The catalysts stability was tested with a 72 -h time-on-stream test at $750{ }^{\circ} \mathrm{C}$ and $1 \mathrm{~atm}$ with WHSV $=3.6 \cdot 10^{-4} \mathrm{~mL} \mathrm{~g}^{-1} \mathrm{~h}^{-1}$, during which no severe deactivation was encountered [253]. Regarding the aqueous-phase reforming of glycerol (GAPR), Reynoso et al. compared two Pt/CoAl ${ }_{2} \mathrm{O}_{4}$ catalysts (Pt loadings of $0.3 \mathrm{wt} . \%$ and $1 \mathrm{wt} . \%$ ) and monometallic Pt/alumina and $\mathrm{Co} /$ alumina in $100 \mathrm{~h}$ time-on-stream experiments. The results of the tests, which were performed at $260^{\circ} \mathrm{C}$ and 50 bar with WHSV $=0.68 \mathrm{~h}^{-1}$, pointed out that while for the bimetallic catalysts the glycerol conversion was high (above $99 \%$ ) and stable during time-on-stream testing, the monometallic catalysts suffered from deactivation. Similar outcomes were also obtained in terms of the conversion of carbon to gas, which was almost stable at $95 \%$ for the bimetallic catalysts, while CoAl and PtAl showed decreases of 36\% and 30\%, respectively. Raman spectroscopy and temperature-programmed hydrogenation $(\mathrm{TPH})$ were used to characterize the spent catalysts. from the Raman spectra, the presence of ordered graphite-like structures on the monometallic catalysts was evaluated, while no carbonaceous deposits were encountered on the bimetallic formulations. Through the TPH analysis, the presence of a low temperature peak $\left(\mathrm{T}=200^{\circ} \mathrm{C}\right.$, ascribable to the hydrogenation of the most amorphous carbon) was detected on the Pt-containing samples, suggesting that the hydrogenation of carbon deposits could happen in the proximity of the well-dispersed PT centers as a consequence of the spillover effect. However, the CoAl catalyst showed a higher amount of deposited carbon $\left(13.5 \mu_{\mathrm{mol}} \mathrm{C}_{\mathrm{cat}}{ }^{-1}\right)$, while for Pt-containing samples the values were much lower $\left(1.2-1.9 \mu \mathrm{mol}_{\mathrm{C}} \cdot \mathrm{g}_{\mathrm{cat}}{ }^{-1}\right)$ [254]. Furthermore, Pendem et al. [255] investigated the addition of potassium to hydrotalcite (Pt-KHT) catalysts for GAPR, finding that the K promotion increased the basicity of the catalyst and improved the hydrogen production. The results of the stability test carried out at $250{ }^{\circ} \mathrm{C}$ showed a hydrogen selectivity of $67.4 \%$ after $3 \mathrm{~h}$ of reaction.

Table 3 provides the values for thee carbon formation rate obtained from the glycerol steam reforming stability tests performed in the various considered studies. An analysis of the tendency to form coke pointed out that both the active phase and the support play key roles in the final amount of deposited carbon. Among the metals used for active phases, Ni showed better stability; indeed, all the catalytic formulations based on $\mathrm{Ni}$ showed lower amounts of carbonaceous deposits. In particular, the best carbon formation rates were seen for the $10 \mathrm{Ni} / \mathrm{Al}_{2} \mathrm{O}_{3}$ and $10 \mathrm{Ni} / \mathrm{Al}_{2} \mathrm{O}_{3} / 5 \mathrm{CeO}_{2}$ catalysts tested by Demshash et al. (0.00067 and $0.000424 \mathrm{~g}_{\text {coke }} \cdot \mathrm{g}_{\text {catalyst }}{ }^{-1} \cdot \mathrm{g}_{\text {carbon,fed }}{ }^{-1} \cdot \mathrm{h}^{-1}$, respectively) [248]. Moreover, the comparison between these two catalysts also highlighted that the support modification obtained using $\mathrm{CeO}_{2}$ can lead to a further performance increase for the catalysts. However, the eventual use of promoters in the preparation of catalysts is also of fundamental importance. Comparing the performances of the catalysts prepared by Carrero et al. [231,249], it is possible to observe that for SBA-15, the catalyst prepared using $\mathrm{Ni}$ as the active phase was characterized by high rates of carbon formation; conversely, the addition of $\mathrm{Co}$ and $\mathrm{Cr}$ resulted in an improvement of the obtained results. Indeed, from the investigation of the stability tests performed on Ni-Co/SBA-15 and Co/SBA-15 (stability tests were carried out at $600{ }^{\circ} \mathrm{C}$ and WHSV $=7 \mathrm{~h}^{-1}$ ), it seems that the Ni did not affect the formation of coke, as the carbon formation rate values for the two catalysts were equal. In addition, among all the catalysts tested by the authors, the lowest carbon formation rates were obtained with a catalyst based on $\mathrm{Ni}\left(\mathrm{Ni}-\mathrm{Cr} / \mathrm{SBA}-15\right.$ carbon formation rate $=3.009 \mathrm{~g}_{\text {coke }} \cdot \mathrm{g}_{\text {catalyst }}{ }^{-1} \cdot \mathrm{g}_{\text {carbon,fed }}{ }^{-1} \cdot \mathrm{h}^{-1}$ ), thus confirming the better results obtained for Ni catalysts for glycerol steam reforming. 
Table 3. Carbon formation rate for various catalysts used for glycerol steam reforming.

\begin{tabular}{|c|c|c|c|c|c|c|}
\hline Catalyst $^{\mathrm{a}}$ & Operative Conditions ${ }^{b}$ & $\mathrm{~T}\left({ }^{\circ} \mathrm{C}\right)$ & $\mathrm{WHSV}^{\mathrm{c}}\left(\mathrm{h}^{-1}\right)$ & X Glycerol (\%) & $\begin{array}{l}\text { Carbon Formation Rate } \\
\text { d (Multiplied for 1000) }\end{array}$ & Ref. \\
\hline \multicolumn{7}{|c|}{ Glycerol steam reforming } \\
\hline $\begin{array}{l}8 \mathrm{Ni} / \mathrm{Al}_{2} \mathrm{O}_{3} \\
8 \mathrm{Ni} / 4 \mathrm{La}_{2} \mathrm{O}_{3}-\mathrm{Al}_{2} \mathrm{O}_{3}\end{array}$ & $\begin{array}{l}\mathrm{m}_{\text {cat }}=200 \mathrm{mg} \\
31 \text { v.v. } \% \mathrm{C}_{3} \mathrm{H}_{8} \mathrm{O}_{3} \text { and } \mathrm{H}_{2} \mathrm{O}\left(63 \% \mathrm{H}_{2} \mathrm{O}, 7 \%\right. \\
\left.\mathrm{C}_{3} \mathrm{H}_{8} \mathrm{O}_{3} \text { and } 30 \% \mathrm{He}\right) \\
\text { TOS }=4 \mathrm{~h}\end{array}$ & 700 & $\begin{array}{l}\text { GHSV }= \\
50,000 \mathrm{~mL} \\
\mathrm{~g}^{-1} \mathrm{~h}^{-1}\end{array}$ & $\begin{array}{l}\sim 75 \\
\sim 80 \\
\text { After } 4 \mathrm{~h}\end{array}$ & $\begin{array}{l}0.141 \\
0.152\end{array}$ & [221] \\
\hline $\mathrm{Rh} /$ alumina & $\begin{array}{l}0.1 \mathrm{~mL} \min ^{-1} \text { of aqueous glycerol, } \mathrm{P}=4.5 \mathrm{bar} \\
\mathrm{m}_{\text {cat }}=800 \mathrm{mg} \\
\text { TOS }=13 \mathrm{~h}\end{array}$ & 400 & 7.8 & $\begin{array}{l}\sim 92 \\
\text { After } 13 \mathrm{~h}\end{array}$ & 0.045 & [227] \\
\hline $\begin{array}{l}14.5 \mathrm{Ni} / \mathrm{SBA}-15 \\
14.5 \mathrm{Ni}-4 \mathrm{Co} / \mathrm{SBA}-15 \\
14.3 \mathrm{Ni}-3.6 \mathrm{Cr} / \mathrm{SBA}-15 \\
15 \mathrm{Ni}-4 \mathrm{Cu} / \mathrm{SBA}-15\end{array}$ & $\begin{array}{l}\mathrm{S} / \mathrm{C}=2 \\
\text { Water } / \text { glycerol }=6 \mathrm{~mol} / \mathrm{mol} \\
\mathrm{m}_{\text {cat }}=300 \mathrm{mg} \\
\text { TOS }=5 \mathrm{~h}\end{array}$ & 600 & 7.7 & $\begin{array}{l}\sim 92 \\
\sim 94 \\
\sim 95 \\
\sim 88 \\
\text { After } 5 \mathrm{~h}\end{array}$ & $\begin{array}{l}27.879 \\
5.092 \\
3.009 \\
51.157\end{array}$ & [231] \\
\hline $\begin{array}{l}8 \mathrm{Ni} / \mathrm{Al}_{2} \mathrm{O}_{3} \\
8 \mathrm{Ni} / \mathrm{CaO}-\mathrm{MgO}-\mathrm{Al}_{2} \mathrm{O}_{3}\end{array}$ & $\begin{array}{l}\mathrm{m}_{\text {cat }}=200 \mathrm{mg} \\
31 \text { v.v. } \% \mathrm{C}_{3} \mathrm{H}_{8} \mathrm{O}_{3} \text { and } \mathrm{H}_{2} \mathrm{O}\left(63 \% \mathrm{H}_{2} \mathrm{O}, 7 \%\right. \\
\left.\mathrm{C}_{3} \mathrm{H}_{8} \mathrm{O}_{3} \text { and } 30 \% \mathrm{He}\right) \\
\text { TOS }=20 \mathrm{~h}\end{array}$ & 600 & $\begin{array}{l}\text { GHSV }= \\
50,000 \mathrm{~mL} \\
\mathrm{~g}^{-1} \mathrm{~h}^{-1}\end{array}$ & $\begin{array}{l}\sim 70 \\
\sim 80 \\
\text { After } 20 \mathrm{~h}\end{array}$ & $\begin{array}{l}0.057 \\
0.048\end{array}$ & [241] \\
\hline $\begin{array}{l}10 \mathrm{Ni} / \mathrm{Al}_{2} \mathrm{O}_{3} \\
10 \mathrm{Ni} / \mathrm{Al}_{2} \mathrm{O}_{3} / 5 \mathrm{CeO}_{2}\end{array}$ & $\begin{array}{l}\mathrm{m}_{\text {cat }}=1 \mathrm{~g} \\
30 \mathrm{wt} . \% \text { glycerol feed } \\
\text { TOS }=16 \mathrm{~h}\end{array}$ & 650 & 12 & - & $\begin{array}{l}0.00067 \\
0.000424\end{array}$ & [248] \\
\hline $\begin{array}{l}\text { 7Co/SBA-15 } \\
\text { 7Co-8.5Zr/SBA-15 } \\
\text { 7Co-8.5Ce/SBA-15 } \\
\text { 7Co-8.5La/SBA-15 }\end{array}$ & $\begin{array}{l}\mathrm{S} / \mathrm{C}=2 \\
\text { Water } / \text { glycerol }=6 \mathrm{~mol} / \mathrm{mol} \\
\mathrm{m}_{\text {cat }}=300 \mathrm{mg} \\
\text { TOS }=5 \mathrm{~h}\end{array}$ & 600 & 7.7 & $\begin{array}{l}\sim 75 \\
>90 \\
>90 \\
>90 \\
\text { After } 5 \mathrm{~h}\end{array}$ & $\begin{array}{l}5.092 \\
5.555 \\
5.555 \\
4.629\end{array}$ & [249] \\
\hline $12.5 \mathrm{Ni}-\mathrm{UGS}$ & $\begin{array}{l}\mathrm{m}_{\text {cat }}=500 \mathrm{mg} \\
\mathrm{S} / \mathrm{C}=3 \\
\text { Water } / \text { glycerol }=9 \\
(\text { Water+glycerol }) / \mathrm{Ar}=1: 4 \\
\text { TOS }=48 \mathrm{~h}\end{array}$ & 580 & $\begin{array}{l}\text { GHSV }=20600 \\
\mathrm{~cm}^{3} \mathrm{~g}_{\mathrm{cat}}{ }^{-1} \mathrm{~h}^{-1}\end{array}$ & $\begin{array}{l}90 \\
\text { After } 48 \mathrm{~h}\end{array}$ & 0.17 & [251] \\
\hline
\end{tabular}

Note: ${ }^{a}$ The metal or oxides loadings are intended for the weight of the catalyst; ${ }^{\mathrm{b}}$ refers to the glycerol mass flow rate; ${ }^{\mathrm{c}} \mathrm{g}_{\text {coke }} \cdot \mathrm{g}_{\text {catalyst }}{ }^{-1} \cdot \mathrm{g}_{\text {carbon,fed }}{ }^{-1} \cdot \mathrm{h}^{-1}$.

\section{Other Bioalcohol Reforming}

In recent years, hydrogen production through reforming processes has been widely studied. In addition to the most investigated biosources, other bioalcohols have been explored as models for hydroxyl-bearing oxygenates. Indeed, research towards the reforming processes of model compounds is a powerful tool that can be used to approach the more complex implementation of bio-oil for $\mathrm{H}_{2}$ production [256]. The paucity of available literature concerning reforming of butanol $\left(\mathrm{C}_{4} \mathrm{H}_{9} \mathrm{OH}\right)$ and propanol $\left(\mathrm{C}_{3} \mathrm{H}_{7} \mathrm{OH}\right)$, which are higher molecular weight alcohols and minor constituents of bio-oil in comparison with methanol or ethanol, makes this an interesting topic. Indeed, as reported in Figure 21, numerous advantages are gained through the use of butanol as a biohydrogen source $[257,258]$. Along with the other alcohols, reforming of butanol and propanol are processes in which the use of catalysts plays a key role in reactivity regarding the complete conversion, hydrogen yield, and stability. Indeed, different catalysts may induce different reaction pathways; therefore, the selection of a proper catalytic formulation is of prime importance in order to reduce the promotion of undesired by-products and to inhibit coke formation. The mechanisms that lead to coke formation in the reforming processes of the two investigated alcohols are different. Butanol reforming proceeds through numerous pathways; direct reforming and the formation of 1-butene, butyraldehyde, and coke deposits are mainly linked to butyraldehyde rather than 1-butene [259,260]. Instead, regarding the coke formation in the reforming process of propanol, the dehydration and dehydrogenation reactions lead to the formation of propene and propanal, which can subsequently decompose to $\mathrm{CO}$ and ethane or condense to form heavier compounds, leading to catalyst deactivation [256]. 


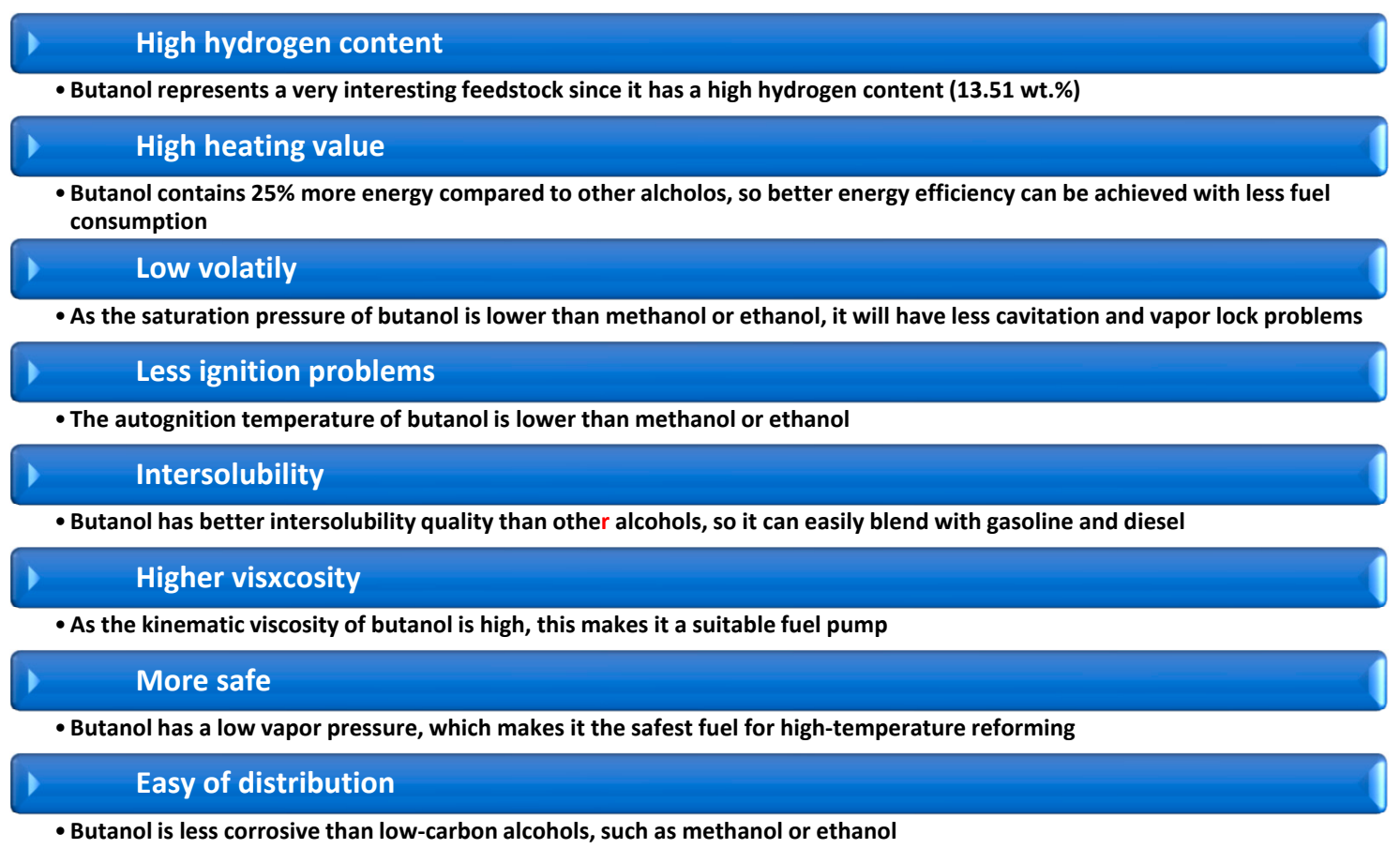

Figure 21. Advantages of using butanol [259].

The metal phase ability to activate the alcohol, the role of the support in the dispersion of the active phase and the eventual addition of promoters are crucial aspects to be taken into account in order to disadvantage the formation of coke, thus promoting catalytic stability [259].

\subsection{The Influence of the Active Phase}

This section focuses on the roles of active species selection in catalytic performance for butanol reforming; the stability of nickel-, ruthenium-, and platinum-based catalysts is discussed below.

The activity of nickel, as the most-used metal for reforming catalysts, has also been investigated in the steam reforming of butanol. Dhanala et al. [261] performed a comparative study of steam reforming (SR) and oxidative steam reforming (OSRB) of isobutanol on $\mathrm{Ni} / \gamma-\mathrm{Al}_{2} \mathrm{O}_{3}$ catalysts with different nickel loadings. Stability tests were carried out by the authors on the $30 \mathrm{NiAl}$ sample for the OSRB at $600{ }^{\circ} \mathrm{C}$ with WHSV $=7.6 \mathrm{~h}^{-1}$ for $12 \mathrm{~h}$ of time-on-stream testing, during which $100 \%$ carbon conversion to gaseous products persisted over time. The products distributions after the first $2 \mathrm{~h}$ of testing reached steady-state values, with a $\mathrm{H}_{2}$ yield rate of $\sim 60 \%$, confirming the stability of the tested catalyst. A further investigation on the spent catalysts showed the presence of complex criss-crossed carbon nanofiber networks on $\mathrm{Ni} / \gamma-\mathrm{Al}_{2} \mathrm{O}_{3}$ catalysts for both $\mathrm{SR}$ and OSRB, probably caused by the decomposition of carbonaceous compounds. The authors also tested catalysts with different Ni loadings (in particular $30 \mathrm{NiAl}$ and $20 \mathrm{NiAl}$ ) and the $\mathrm{XRD}$ analysis revealed that $30 \mathrm{NiAl}$ has a larger average crystallite size than 20NiAl. Moreover, the further characterization of the two spent catalysts pointed out a correlation between the extent of carbon deposits and the nickel crystallite sizes, while the carbon nanofiber networks over $30 \mathrm{NiAl}$ were found to be denser and bigger than $20 \mathrm{NiAl}$. In addition, the $\mathrm{O}_{2}$ addition to the common steam reforming led to less and smaller carbon nanofibers for the OSRB compared to SR. An investigation of Ni catalysts with various particle sizes $(3.6-8.8 \mathrm{~nm})$ was also carried out by Wang et al. [262] through the preparation and testing of mesoporous MgO-supported $\mathrm{Ni}$ catalysts for the butanol steam reforming (BSR). The different nickel particle sizes were achieved by the addition of a specific amount of nickel precursor. The as-prepared catalysts with different Ni loadings were denoted as $\mathrm{Ni}_{\mathrm{x}} \mathrm{O} / \mathrm{MgO}$, with $\mathrm{x}=0.04,0.08,0.12,0.15$, and 0.20 . From the activity tests, $\mathrm{Ni}_{0.12} \mathrm{O} / \mathrm{MgO}$ (Ni size of $5.62 \mathrm{~nm}$, as assessed by TEM analysis) showed better BSR results; thus, the catalyst 
was also submitted to a stability test for $20 \mathrm{~h}$ at $450{ }^{\circ} \mathrm{C}\left(\mathrm{S} / \mathrm{C}=20\right.$, liquid flow rate $\left.=5.5 \mathrm{~mL} \cdot \mathrm{h}^{-1}\right)$. During the first $10 \mathrm{~h}$ of reaction, butanol conversion declined from $95.2 \%$ to $92.1 \%$ and the $\mathrm{H}_{2}$ selectivity declined from $68.1 \%$ to $64.9 \%$. Then, in the following $10 \mathrm{~h}$, their values remained almost unchanged; moreover, the tests on the spent catalyst showed no severe coke deposition. A comparison between the activity of $\mathrm{Ni}$ and $\mathrm{Co}$ was carried out by Yadav and co-authors through the investigation of two multiwalled carbon-nanotube-supported catalysts. From the activity tests, Ni/CNT showed higher butanol conversion and hydrogen yield values for all the investigated temperatures $(500,450,400$, and $350{ }^{\circ} \mathrm{C}$ ); consequently, the catalyst was tested with $20 \mathrm{~h}$ of time-on-stream testing at $500{ }^{\circ} \mathrm{C}$ $\left(\mathrm{W} / \mathrm{F}_{\mathrm{A} 0}=4.2 \mathrm{~g} \mathrm{~h} \cdot \mathrm{mol}^{-1}\right)$. Only slight decreases in results were observed (butanol conversion decreased from $63.6 \%$ to $59.6 \%$ and $\mathrm{H}_{2}$ yield decreased from $0.63 \mathrm{~mol} / \mathrm{mol}$ to $0.57 \mathrm{~mol} / \mathrm{mol}$ ) [263]. A comprehensive study on the deactivation mechanism of a $0.5 \mathrm{wt} . \% \mathrm{Rh} / \mathrm{ZrO}_{2}$ catalyst involved in steam reforming and autothermal steam reforming (ATRB) of butanol was performed by Harju et al. [264]. Butanol conversion on the catalyst and the bare support was investigated by the authors for both processes at 500,600 , and $700{ }^{\circ} \mathrm{C}\left(\mathrm{S} / \mathrm{C}\right.$ molar ratio of 4 and $\mathrm{O}_{2} / \mathrm{C}$ molar ratio of 0.1$)$. The results showed the highest performance at $700^{\circ} \mathrm{C}$, with an initial complete conversion for both SR and ATR on the $\mathrm{Rh} / \mathrm{ZrO}_{2}$ catalyst and the bare support. However, while the conversion of the catalyst remained almost constant for $23 \mathrm{~h}$, butanol conversion with $\mathrm{ZrO}_{2}$ collapsed within $15 \mathrm{~min}$. The authors suggested that the deactivation of $\mathrm{Rh} / \mathrm{ZrO}_{2}$ was mainly caused by the coke deposits on and near the Rh nanoparticles as a result of butyraldehyde and condensation product formation. Moreover, the deactivation of the catalyst follows a different route depending on the operative temperature; while at $700{ }^{\circ} \mathrm{C}$ the formation of coke precursors is mainly caused by gas-phase reactions, at lower temperatures the formation of coke deposits takes place mostly through reactions on the catalysts' surfaces. Furthermore, Harju et al. [265] performed a study on the same type of catalyst $\left(\mathrm{Rh} / \mathrm{ZrO}_{2}\right)$ used in the aqueous-phase reforming of n-butanol. Their attention was focused on the effect of the variation of the support particle sizes. The $\mathrm{ZrO}_{2}$ support was crushed and sieved in order to obtain three catalysts with particle sizes in the range of $40-60,60-100$, and $250-420 \mu \mathrm{m}$. The stability tests, carried out at $220{ }^{\circ} \mathrm{C}$ and 35 bar with LHSV $=150 \mathrm{~h}^{-1}$ for $4 \mathrm{~h}$ TOS, pointed out that the catalyst deactivation was faster for large support particles, due to the high concentrations of butyraldehyde inside the catalyst particles, which favored the formation of deposits caused by aldol condensation reactions. However, the catalysts with smaller support particle sizes (4-60 $\mu \mathrm{m}$ and $60-100 \mu \mathrm{m})$ also showed decreases in the butanol conversion, albeit with lower values. Regarding the selectivity towards gaseous products, the values were high and almost constant for $40-60-\mu \mathrm{m}$ and $60-100-\mu \mathrm{m} \mathrm{Rh} / \mathrm{ZrO}_{2}$ catalysts (from $99 \%$ to $97 \%$ in $2.5 \mathrm{~h}$ ), whereas for the catalyst with the larger particle size this dropped off severely over time. Moreover, the elemental analysis of the spent catalyst revealed that the formation of coke deposits increased as the particle sizes of the catalysts increased. Yadav et al. [266] compared the activity and stability of two noble metal catalysts, $\mathrm{Pt} / \mathrm{Al}_{2} \mathrm{O}_{3}$ and $\mathrm{Pd} / \mathrm{Al}_{2} \mathrm{O}_{3}$, for butanol steam reforming. The 20 - $\mathrm{h}$ time-on-stream investigations conducted at $500{ }^{\circ} \mathrm{C}$ exhibited a decrease from $82.5 \%$ to $74.1 \%$ for butanol conversion with $\mathrm{Pt} / \mathrm{Al}$, while for the $\mathrm{Pd} / \mathrm{Al}$ catalyst the conversion decreased from $80.5 \%$ to $74.1 \%$. The $\mathrm{H}_{2}$ yield decreased from 0.37 to $0.28 \mathrm{~mol} / \mathrm{mol}$ for $\mathrm{Pt} / \mathrm{Al}$ and from 0.3 to $0.24 \mathrm{~mol} / \mathrm{mol}$ for the $\mathrm{PdAl}$ catalyst, thus pointing out the good stability of both noble-metal-based catalysts. Wang et al. [256] performed a study on n-propanol steam reforming with ruthenium and ruthenium-nickel bimetallic catalysts supported on ceria-alumina oxides, analyzing the influence of the variation of the loading of nickel, loading of ceria, and the calcination of the ruthenium precursor. The catalysts were denoted as AxCyN3Rc or AxCyN3Rnc, where "nc" was used if the ruthenium precursor not calcined and " $c$ " was used if it was calcined; moreover, a stood for the alumina carrier, $\mathrm{x}$ was the wt.\% loading of the ceria, and $\mathrm{y}$ was the weight percent loading of nickel. In this section, the contributions of the calcination of $\mathrm{Ru}$ and $\mathrm{Ni}$ loading will be discussed, while the effect of the addition of ceria will be discussed in the following section. The investigation of the calcination of the Ru precursor pointed out that poor ruthenium dispersion is achieved after the calcination of the precursor salt, worsening the steam reforming results. On the other hand, from the tests carried out on catalysts with different Ni loading values, it was seen 
that the increase of $\mathrm{Ni}$ from the $2.5 \%$ to $10 \%$ resulted in a better n-propanol SR activity due to the capability of $\mathrm{Ni}$ to activate the n-propanol molecules. Moreover, from the comparison between the catalysts with and without $\mathrm{Ni}$, a lower $\mathrm{H}_{2}$ formation rate and $\mathrm{CO}$ selectivity were found in the absence of $\mathrm{Ni}$, while $\mathrm{CH}_{4}$ was higher, suggesting that $\mathrm{Ru}$ is less active than $\mathrm{Ni}$ in the conversion of methane.

\subsection{The Role of the Support}

Various supports were selected for butanol reforming. This section describes the effect of the support choice on catalyst stability for butanol reforming.

Due to its high surface area, alumina has been widely adopted as a support for reforming catalysts; however, it has also been documented that the acidic nature of such a support may result in an enhancement of coke deposits, mainly caused by dehydration reactions [259]. Bikzarra et al. [267] investigated the effect of $\mathrm{Al}_{2} \mathrm{O}_{3}$ modifications by $\mathrm{CeO}_{2}, \mathrm{La}_{2} \mathrm{O}_{3}$, and $\mathrm{MgO}$ for Ni-based catalysts, since their basicity could moderate the acid properties of alumina. Moreover, $\mathrm{CeO}_{2}$ and $\mathrm{La}_{2} \mathrm{O}_{3}$ were also adopted to improve the metal dispersion and prevent sintering, while $\mathrm{MgO}$ improved the catalysts' strength and enhanced the steam adsorption. Hence, five catalysts were prepared $\left(\mathrm{Ni} / \mathrm{Al}_{2} \mathrm{O}_{3}\right.$, $\mathrm{Ni} / \mathrm{CeO}_{2}-\mathrm{Al}_{2} \mathrm{O}_{3}, \mathrm{Ni} / \mathrm{La}_{2} \mathrm{O}_{3}-\mathrm{Al}_{2} \mathrm{O}_{3}, \mathrm{Ni} / \mathrm{MgO}-\mathrm{Al}_{2} \mathrm{O}_{3}$ ) and tested in the n-butanol SR at three temperatures $\left(600,700\right.$, and $800{ }^{\circ} \mathrm{C}$ ), with a $\mathrm{S} / \mathrm{C}$ ratio of 5 . Among all the catalysts, $\mathrm{Ni} / \mathrm{CeO}_{2}-\mathrm{Al}_{2} \mathrm{O}_{3}$ showed the highest performance for all the investigated temperatures, reaching equilibrium hydrogen yields at 700 and $800{ }^{\circ} \mathrm{C}$, while $\mathrm{Ni} / \mathrm{MgO}-\mathrm{Al}_{2} \mathrm{O}_{3}$ exhibited the lowest hydrogen yield in all the performed tests. The adoption of $\mathrm{Ni} / \mathrm{La}_{2} \mathrm{O}_{3}-\mathrm{Al}_{2} \mathrm{O}_{3}$ resulted in experimental results that were much lower than those predicted by thermodynamic equilibrium. Additionally, the $\mathrm{CeO}_{2}$-supported catalysts also led to high $\mathrm{CO}_{2}$ selectivity values being obtained, suggesting the enhancement of the WGS reaction. On the other hand, reduced $\mathrm{CO}_{2}$ selectivity values were obtained with the adoption of $\mathrm{Ni} / \mathrm{MgO}-\mathrm{Al}_{2} \mathrm{O}_{3}$, along with high $\mathrm{C}_{2}, \mathrm{C}_{3}$, and $\mathrm{C}_{4}$ selectivity. Unfortunately, both $\mathrm{CeO}_{2}$ - and $\mathrm{MgO}$-supported catalysts showed deactivation; for $\mathrm{Ni} / \mathrm{CeO}_{2}-\mathrm{Al}_{2} \mathrm{O}_{3}$, decreases in the $\mathrm{H}_{2}$ yield rate and $\mathrm{CO}_{2}$ selectivity were observed by the authors. XPS analysis on the spent catalysts showed different carbon species for investigated samples, covering $62 \%$ to $93 \%$ of the total area. Lobo and co-authors [268] evaluated the support modification effects for the aqueous steam reforming of 1-propanol. Three Pt/alumina catalysts were prepared through atomic layer deposition, obtaining $~ 1-\mathrm{nm}$ layer of $\mathrm{Al}_{2} \mathrm{O}_{3}, \mathrm{TiO}_{2}$, or $\mathrm{CeO}_{2}(\mathrm{Pt}-\mathrm{Al}, \mathrm{Pt}-\mathrm{Ti}$, $\mathrm{Pt}-\mathrm{Ce}$ ), which was tested at $230-260^{\circ} \mathrm{C}$ and $69 \mathrm{bar}$ in the presence of liquid water. All the catalysts demonstrated good activity for 1-propanol conversion; the results decreased in the order of Pt-Ti $>\mathrm{Pt}-\mathrm{Al}$ $>\mathrm{Pt}-\mathrm{Ce}$. The authors suggested that the $\mathrm{TiO}_{2}$ coating enhanced the rate of the Pt clusters, while the presence of $\mathrm{CeO}_{2}$ had the opposite effect. Moreover, the characterization of catalysts showed that the coating of $\mathrm{Al}_{2} \mathrm{O}_{3}$ with both $\mathrm{TiO}_{2}$ and $\mathrm{CeO}_{2}$ led to a better Pt dispersion than that observed on the bare alumina, and since $\mathrm{Pt}-\mathrm{Al}$ performed better than $\mathrm{Pt}-\mathrm{Ce}$, this suggested that the dispersion of the $\mathrm{Pt}$ particles was not the most critical aspect in determining the catalytic activity. Li et al. [269] investigated the impacts of the acidic sites on the coke formation in the steam reforming of 1-propanol through the comparison of $\mathrm{Ni} / \mathrm{Al}_{2} \mathrm{O}_{3}$ and $\mathrm{Ni} / \mathrm{SiO}_{2}$; indeed, while on $\mathrm{Ni} / \mathrm{Al}_{2} \mathrm{O}_{3}$ the presence of both Lewis and Brønsted acidic sites was observed, on $\mathrm{Ni} / \mathrm{SiO}_{2}$ only Lewis acidic sites were detected by the authors. The 4-h time-on-stream stability tests performed at $600^{\circ} \mathrm{C}$ with a S/C ratio of 1.5 and a liquid flow rate of $0.12 \mathrm{~mL} \cdot \mathrm{min}^{-1}$ showed that the 1-propanol conversion was high in both catalysts $\left(\sim 100 \%\right.$ on $\mathrm{Ni} / \mathrm{Al}_{2} \mathrm{O}_{3}$ and $\sim 98 \%$ on $\left.\mathrm{Ni} / \mathrm{SiO}_{2}\right)$; however, the product distribution differed depending on the adopted support. For $\mathrm{Ni} / \mathrm{Al}_{2} \mathrm{O}_{3}$, the yields of $\mathrm{H}_{2}$ and $\mathrm{CO}_{2}$ were only 40 and $30 \%$, respectively, and there were significant amounts of $\mathrm{CH}_{4}$ and $\mathrm{CO}$. Additionally, for $\mathrm{Ni} / \mathrm{SiO}_{2}$, the methane formation was suppressed, resulting in increases of $\mathrm{H}_{2}, \mathrm{CO}_{2}$, and $\mathrm{CO}$ yields. The increased activity of $\mathrm{Ni} / \mathrm{SiO}_{2}$ compared to $\mathrm{Ni} / \mathrm{Al}_{2} \mathrm{O}_{3}$ could be attributed to the presence of less-basic sites or the absence of Brønsted acidic sites on the silica-supported catalyst. Moreover, neither catalyst showed signs of deactivation over the time period. The TEM analysis carried out on the spent catalysts highlighted the presence of amorphous coke and carbon nanotubes on both the samples; however, the amounts and the characteristics of the deposits differed depending on the support. Indeed, $\mathrm{Ni} / \mathrm{Al}_{2} \mathrm{O}_{3}$ displayed more amorphous coke deposits, 
while coke deposits were mostly carbon-nanotube-shaped on $\mathrm{Ni} / \mathrm{SiO}_{2}$. Moreover, the diameter and length of the carbon nanotubes were higher on $\mathrm{Ni} / \mathrm{SiO}_{2}$ compared to $\mathrm{Ni} / \mathrm{Al}_{2} \mathrm{O}_{3}$. The $\mathrm{Ni} / \mathrm{SiO}_{2}$ catalyst was found to promote the formation of carbon nanotubes; in fact, nanofiber-shaped carbon deposits were also detected on its surface. On the other hand, finer carbon nanotubes that were mostly hollow were observed for the $\mathrm{Ni} / \mathrm{SiO}_{2}$ sample, while the thicker ones were mainly solid. The reason for this result could be the different growth mechanisms of carbon nanotubes at different growth stages; in the early growth stage, coke was mainly deposited from the inside, while in the latter stages of growth, coke was deposited from the outside, thus increasing the diameter of the carbon nanotubes.

\subsection{The Effect of the Addition of Promoters}

In this section, the influence of the addition of promoters on the stability of the catalysts for butanol reforming is discussed. In particular, the addition of noble metals to reforming catalysts is a valuable feature that improves their coke resistance and stability. Indeed, despite their high cost, the addition of small percentages of noble metals (e.g., Pt, Pd, and $\mathrm{Ru}$ ) could result in an enhancement of the metal dispersion and reducibility; moreover, they also possess high reforming activity, due to the enhancement of the steam adsorption on the catalysts' surfaces.

A study concerning the $\mathrm{Pt}$, $\mathrm{Pd}$, and $\mathrm{Ru}$ doping of Ni-Cu catalysts supported on a La-Mg mixed-metal oxide for butanol SR pointed out the benefits of the addition of noble metals, which resulted in the absence of coke deposits, thus increasing the stability of the catalysts. In particular, the stability of the catalysts, which was tested at $500{ }^{\circ} \mathrm{C}$ and $1 \mathrm{~atm}$ with GHSV $=3120 \mathrm{~h}^{-1}$ for $30 \mathrm{~h}$ TOS, showed the better performance of the Pt-promoted catalyst, characterized by improved butanol conversion and hydrogen yield. Subsequently, in order to test the long-term stability of the investigated catalytic formulations, up to 10 cycles were carried out, during which the stability rates of the catalysts were in the following sequence: $\mathrm{Ru}>\mathrm{Pt}>\mathrm{Pd}$. In fact, the Ru-promoted catalyst showed better stability, despite producing lower $\mathrm{H}_{2}$ concentrations [270]. Furthermore, Sharma et al. [271] observed that promotion of $\mathrm{Ru}$ on $\mathrm{Ni}$ xerogel catalysts for the autothermal reforming of isobutanol resulted in improved hydrogen production and reduced coke formation. Indeed, the catalyst tested for $25 \mathrm{~h}$ TOS at $700{ }^{\circ} \mathrm{C}$ with $\mathrm{SV}=217,000 \mathrm{~h}^{-1}, \mathrm{H}_{2} \mathrm{O} / \mathrm{C}=2$, and $\mathrm{O} / \mathrm{C}=0.1$ showed a decrease in hydrogen yield from 1.53 to 1.4 , showing a slow decrease of the reforming extent. Moreover, on the catalysts' surfaces, very low carbon deposits were detected by the authors. Lei et al. [272] evaluated the advantages of the $\mathrm{ZnO}$ promotion on the performance of $\mathrm{Pt} / \mathrm{Al}_{2} \mathrm{O}_{3}$ in the aqueous-phase reforming of 1-propanol. An improvement in the sintering resistance of the $\mathrm{Pt}$ nanoparticles was observed upon addition of $\mathrm{Zn}$. In particular, three catalysts $\left(\mathrm{Pt} / \mathrm{ZnO} / \mathrm{Al}_{2} \mathrm{O}_{3}, \mathrm{ZnO} / \mathrm{Pt} / \mathrm{Al}_{2} \mathrm{O}_{3}\right.$, and $\mathrm{Pt} / \mathrm{Al}_{2} \mathrm{O}_{3}$ ) were prepared and tested for APR at $250{ }^{\circ} \mathrm{C}$ and 64 bar; the hydrogen selectivity decreased in the order of $\mathrm{ZnO} / \mathrm{Pt} / \mathrm{Al}_{2} \mathrm{O}_{3}>$ $\mathrm{Pt} / \mathrm{ZnO} / \mathrm{Al}_{2} \mathrm{O}_{3}>\mathrm{Pt} / \mathrm{Al}_{2} \mathrm{O}_{3}$. Indeed, $\mathrm{ZnO} / \mathrm{Pt} / \mathrm{Al}_{2} \mathrm{O}_{3}$ showed a $\mathrm{H}_{2}$ formation rate of $50.5 \%$. Moreover, both $\mathrm{ZnO}$-promoted catalysts exhibited greater stability under APR conditions.

\section{Conclusions}

Bioalcohols reforming is a very active research area for clean hydrogen production. During the last five years, the issue of catalyst deactivation has been widely investigated for ethanol steam reforming and oxidative reforming, while only a few studies are available for dry reforming and aqueous-phase reforming. The strategies for minimizing carbon deposition and particle sintering involve the optimization of the dispersion of active species and the improvement of metal-support interactions. In this regard, numerous catalytic formulations have been proposed (mainly based on $\mathrm{Ni}, \mathrm{Co}$ and $\mathrm{Pt}$ as the active phases), including bimetallic catalysts and samples containing additives, both of which were prepared using different routes and employing various salt precursors. The addition of promoters was also investigated as a valuable strategy to reduce the coke selectivity; at that end, different criteria have been proposed and the authors have studied the effects of promoter selection, promoter loading, preparation method, acidic-basic properties, as well as structural properties of the support. The operative conditions (temperature, space velocity, feeding composition, and ethanol 
concentration in the reactant stream) also affect the amounts of carbon deposits on the catalysts' surfaces; the lowest carbon formation rates (of the order of $10^{-6}-10^{-7} \mathrm{~g}_{\text {coke }} \cdot \mathrm{g}_{\text {catalyst }}{ }^{-1} \cdot \mathrm{g}_{\text {carbon,fed }}{ }^{-1} \cdot \mathrm{h}^{-1}$ ) were recorded for noble-metal-based and promoted catalysts. In particular, when ESR was performed over Ir- and Rh-based catalysts, the CFR value was among the lowest reported in the present review. Very low carbon formation rates were also measured in the presence of $\mathrm{Pd}$, as well as over bimetallic $\mathrm{Rh}-\mathrm{Ni}$ catalysts. Regarding the tests performed in the presence of oxygen, the highest stability was assured over the $\mathrm{Pt}-\mathrm{Ni} / \mathrm{CeO}_{2}-\mathrm{SiO}_{2}$ catalysts, as well as over Ru-based perovskites containing $\mathrm{La}$ as the promoter. During dry reforming of ethanol, the choice of ceria and zirconia as catalytic supports instead of alumina reduced the extent of the catalyst deactivation.

MSR is a very attractive alternative for hydrogen production due to the very low tendency for coke formation. Most of the published work on this topic has been focused on $\mathrm{Cu}$-based catalytic systems; the low costs of these materials make them particularly attractive for industrial applications. More sophisticated catalytic formulations, including noble-metal-based catalysts, could provide highly efficient and stable systems, with improved performance in terms of resistance towards deactivation. However, few articles have been published on these catalysts, meaning it is currently hard to establish the real potential of these materials. Although there is high potential for the $\mathrm{O}_{2}$-assisted process in terms of enhanced hydrogen productivity and the possibility to tune the methanol/oxygen ratio in the power generation, such systems do not seem to provide a valuable alternative to the MSR in terms of reducing the carbon formation rate. The use of alternative reactor configurations is very intriguing; membrane reactor studies have demonstrated the competitiveness of these systems, both in terms of hydrogen production and operating costs.

Bioglycerol reforming processes represent a promising route to improve the economic feasibility of the biodiesel industry. The catalytic transformation of bioglycerol into hydrogen is mainly limited by the undesired formation of coke deposits on the catalysts' surfaces, thus affecting the catalysts' stability, making this an unfeasible industrial process. Therefore, many research studies have been devoted to the deep understanding of the deactivation mechanisms and the possible ways to avoid this problem. In this regard, feasible modifications of Ni-based catalysts have been reported as promising methods to improve the hydrogen production. Moreover, further studies have been performed on the support modifications devoted to improve the basicity of catalysts (e.g., the addition of more basic oxides to high surface area supports, such as $\mathrm{Al}_{2} \mathrm{O}_{3}$ ) and on the effects resulting from the addition of promoters.

Among all the catalysts presented in this review, Ni-based catalytic formulations have shown better stability, being characterized by lower carbon formation rates, with reduced amounts of carbon deposits shown by $10 \mathrm{Ni} / \mathrm{Al}_{2} \mathrm{O}_{3}$ and $10 \mathrm{Ni} / \mathrm{Al}_{2} \mathrm{O}_{3} / 5 \mathrm{CeO}_{2}$. Moreover, analysis on the influences of supports and promoters on the stability of catalysts has shown that both of these aspects contribute to reducing the amount of carbon formed. Particular attention has been given to the modification of supports that include more basic compounds (e.g., $10 \mathrm{Ni} / \mathrm{Al}_{2} \mathrm{O}_{3} / 5 \mathrm{CeO}_{2}$ presented fewer carbon deposits than $10 \mathrm{Ni} / \mathrm{Al}_{2} \mathrm{O}_{3}$ ), as well as the use of metals as promoters (e.g., $\mathrm{Cr}, \mathrm{La}, \mathrm{Ce}$ ). Reforming processes for other bioalcohols have also been investigated in this review, as powerful tools for approaching the more complex implementation of bio-oil in the field of $\mathrm{H}_{2}$ production. In particular, butanol and propanol reforming processes have been analyzed, focusing on the influences of the active phase, supports, and eventual promoters on the stability of the catalysts and the coke formation. Indeed, for both bioalcohols, coke formation represents the main threat in the development process, and several actions can be taken to improve the stability of the catalysts.

Author Contributions: All authors have read and agreed to the published version of the manuscript. Conceptualization, V.P. and C.R.; methodology, M.M.; formal analysis, M.C. and M.M.; investigation, C.R. and M.M.; resources, V.P. and M.C. data curation, C.R.; writing-review and editing, C.R., M.C. and M.M.; visualization, V.P.; supervision, V.P.

Funding: This work has received funding from the European Union's Horizon 2020 research and innovation programme under the Marie Skłodowska-Curie grant agreement No 734561.

Conflicts of Interest: The authors declare no conflict of interest. 
Abbreviations

\begin{tabular}{|c|c|}
\hline APR & Aqueous-phase reforming \\
\hline APRE & Aqueous-phase reforming of ethanol \\
\hline ASRM & Autothermal steam reforming of methanol \\
\hline ATR & Autothermal reforming \\
\hline BET & Brunauer-Emmett-Teller surface area measurements \\
\hline BSR & Butanol steam reforming \\
\hline CCR & Carbon capture and recycling \\
\hline CFD & Computational fluid dynamics \\
\hline CFR & Carbon formation rate \\
\hline $\mathrm{CNF}$ & Carbon nanofibers \\
\hline CNT & Carbon nanotubes \\
\hline DFT & Discrete Fourier transform \\
\hline DRIFT & Diffuse reflectance infrared Fourier transform spectroscopy \\
\hline DSC & Differential scanning calorimeter \\
\hline EDR & Ethanol dry reforming \\
\hline EDS & Energy-dispersive $\mathrm{X}$-ray spectrometry \\
\hline EDX & Energy-dispersive $X$-ray analysis \\
\hline GAPR & Aqueous-phase reforming of glycerol \\
\hline GDR & Glycerol dry reforming \\
\hline GHSV & Gas hourly space velocity \\
\hline GSR & Glycerol steam reforming \\
\hline LHSV & Liquid hourly space velocity \\
\hline MSR & Methanol steam reforming \\
\hline MMT & Montmorillonite \\
\hline OSRE & Oxidative steam reforming of ethanol \\
\hline OSRM & Oxidative steam reforming of methanol \\
\hline OSRB & Oxidative steam reforming of butanol \\
\hline PEM & Polymer electrolyte membrane \\
\hline $\mathrm{PO}$ & Partial oxidation \\
\hline SEM & Scanning electron microscopy \\
\hline TEM & Transmission electron microscopy \\
\hline TGA & Thermogravimetric analysis \\
\hline TOF & Turnover frequencies \\
\hline TOS & Time-on-stream \\
\hline TPD & Temperature-programmed desorption \\
\hline $\mathrm{TPH}$ & Temperature-programmed hydrogenation \\
\hline TPO & Temperature-programmed oxidation \\
\hline TPR & Temperature-programmed reduction \\
\hline WGS & Water-gas shift \\
\hline WHSV & Weight hourly space velocity \\
\hline 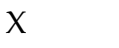 & Alcohol conversion \\
\hline XPS & X-ray photoelectron spectroscopy \\
\hline XRD & $X$-ray diffraction \\
\hline
\end{tabular}

\section{References}

1. Susmozas, A.; Iribarren, D.; Dufour, J. Assessing the life-cycle performance of hydrogen production via biofuel reforming in Europe. Resources 2015, 4, 398-411. [CrossRef]

2. Al-Maamary, H.M.S.; Kazem, H.A.; Chaichan, M.T. The impact of oil price fluctuations on common renewable energies in GCC countries. Renew. Sustain. Energy Rev. 2017, 75, 989-1007. [CrossRef]

3. Calles, J.A.; Carrero, A.; Vizcaíno, A.J.; García-Moreno, L.; Megía, P.J. Steam reforming of model Bio-Oil aqueous fraction using $\mathrm{Ni}-(\mathrm{Cu}, \mathrm{Co}, \mathrm{Cr}) / \mathrm{SBA}-15$ catalysts. Int. J. Mol. Sci. 2019, 20, 512. [CrossRef] [PubMed] 
4. Colmenares, J.C.; Colmenares Quintero, R.F.; Pieta, I.S. Catalytic dry reforming for biomass-based fuels processing: Progress and future perspectives. Energy Technol. 2016, 4, 881-890. [CrossRef]

5. Lisý, M.; Lisá, H.; Jecha, D.; Baláš, M.; Križan, P. Characteristic properties of alternative biomass fuels. Energies 2020, 13, 1448. [CrossRef]

6. Palma, V.; Barba, D.; Meloni, E.; Ruocco, C.; Martino, M. Chapter 2-Membrane reactors for $\mathrm{H}_{2}$ and energy production. In Current Trends and Future Developments on (Bio-) Membranes; Basile, A., Napporn, T.W., Eds.; Elsevier: Amsterdam, The Netherlands, 2020; pp. 33-56. [CrossRef]

7. Alique, D.; Bruni, G.; Sanz, R.; Calles, J.A.; Tosti, S. Ultra-Pure hydrogen via co-valorization of olive mill wastewater and bioethanol in pd-membrane reactors. Processes 2020, 8, 219. [CrossRef]

8. Frusteri, F.; Bonura, G. 5-Hydrogen production by reforming of bio-alcohols. In Compendium of Hydrogen Energy; Subramani, V., Basile, A., Veziroğlu, T.N., Eds.; Woodhead Publishing: Oxford, UK, 2015; pp. 109-136.

9. Melikoglu, M.; Singh, V.; Leu, S.Y.; Webb, C.; Lin, C.S.K. Biochemical production of bioalcohols. In Handbook of Biofuels Production, 2nd ed.; Luque, R., Lin, C.S.K., Wilson, K., Clark, J., Eds.; Woodhead Publishing: Oxford, UK, 2016; pp. 237-258.

10. Datta, A.; Hossain, A.; Roy, S. An overview on biofuels and their advantages and disadvantages. Asian J. Chem. 2019, 31, 1851-1858. [CrossRef]

11. Ail, S.S.; Dasappa, S. Biomass to liquid transportation fuel via Fischer Tropsch synthesis-Technology review and current scenario. Renew. Sustain. Energy Rev. 2016, 58, 267-286. [CrossRef]

12. Behera, S.; Singh, R.; Arora, R.; Sharma, N.K.; Shukla, M.; Kumar, S. Scope of algae as third generation biofuels. Front. Bioeng. Biotechnol. 2015, 2. [CrossRef]

13. Seretis, A.; Tsiakaras, P. Crude bio-glycerol aqueous phase reforming and hydrogenolysis over commercial $\mathrm{SiO}_{2} \mathrm{Al}_{2} \mathrm{O}_{3}$ nickel catalyst. Renew. Energy 2016, 97, 373-379. [CrossRef]

14. Coronado, C.J.R. Glycerol: Production, consumption, prices, characterization and new trends in combustion. Renew. Sustain. Energy Rev. 2013, 27, 475-493. [CrossRef]

15. Liu, Z.; Peng, W.; Motahari-Nezhad, M.; Shahraki, S.; Beheshti, M. Circulating fluidized bed gasification of biomass for flexible end-use of syngas: A micro and nano scale study for production of bio-methanol. J. Clean. Prod. 2016, 129, 249-255. [CrossRef]

16. Iaquaniello, G.; Centi, G.; Salladini, A.; Palo, E.; Perathoner, S.; Spadaccini, L. Waste-to-methanol: Process and economics assessment. Bioresour. Technol. 2017, 243, 611-619. [CrossRef]

17. Anitha, M.; Kamarudin, S.K.; Shamsul, N.S.; Kofli, N.T. Determination of bio-methanol as intermediate product of anaerobic co-digestion in animal and agriculture wastes. Int. J. Hydrogen Energy 2015, 40, 11791-11799. [CrossRef]

18. Bonfim-Rocha, L.; Gimenes, M.L.; Bernardo de Faria, S.H.; Silva, R.O.; Esteller, L.J. Multi-objective design of a new sustainable scenario for bio-methanol production in Brazil. J. Clean. Prod. 2018, 187, 1043-1056. [CrossRef]

19. Hartley, U.W.; Amornraksa, S.; Kim-Lohsoontorn, P.; Laosiripojana, N. Thermodynamic analysis and experimental study of hydrogen production from oxidative reforming of n-butanol. Chem. Eng. J. 2015, 278, 2-12. [CrossRef]

20. Palma, V.; Ruocco, C.; Meloni, E.; Ricca, A. Highly active and stable Pt-Ni/CeO $2-\mathrm{SiO}_{2}$ catalysts for ethanol reforming. J. Clean. Prod. 2017, 166, 263-272. [CrossRef]

21. Bepari, S.; Kuila, D. Steam reforming of methanol, ethanol and glycerol over nickel-based catalysts-A review. Int. J. Hydrogen Energy 2019. [CrossRef]

22. Montero, C.; Remiro, A.; Valle, B.; Oar-Arteta, L.; Bilbao, J.; Gayubo, A.G. Origin and nature of coke in ethanol steam reforming and its role in deactivation of $\mathrm{Ni} / \mathrm{La}_{2} \mathrm{O}_{3}-\alpha \mathrm{Al}_{2} \mathrm{O}_{3}$ catalyst. Ind. Eng. Chem. Res. 2019, 58, 14736-14751. [CrossRef]

23. Palma, V.; Ruocco, C.; Meloni, E.; Ricca, A. Influence of Catalytic Formulation and Operative Conditions on Coke Deposition over $\mathrm{CeO}_{2}-\mathrm{SiO}_{2}$ Based Catalysts for Ethanol Reforming. Energies 2017, 10, 1030. [CrossRef]

24. Horng, R.-F.; Lai, M.-P.; Chiu, W.-C.; Huang, W.-C. Thermodynamic analysis of syngas production and carbon formation on oxidative steam reforming of butanol. Int. J. Hydrogen Energy 2016, 41, 889-896. [CrossRef]

25. Valle, B.; Aramburu, B.; Olazar, M.; Bilbao, J.; Gayubo, A.G. Steam reforming of raw bio-oil over $\mathrm{Ni} / \mathrm{La}_{2} \mathrm{O}_{3}-\alpha \mathrm{Al}_{2} \mathrm{O}_{3}$ : Influence of temperature on product yields and catalyst deactivation. Fuel 2018, 216, 463-474. [CrossRef] 
26. Coll, R.; Salvadó, J.; Farriol, X.; Montane, D. Steam reforming model compounds of biomass gasification tars: Conversion at different operating conditions and tendency towards coke formation. Fuel Process. Technol. 2001, 74, 19-31. [CrossRef]

27. Larmier, K.; Chizallet, C.; Cadran, N.; Maury, S.; Abboud, J.; Lamic-Humblot, A.-F.; Marceau, E.; Lauron-Pernot, H. Mechanistic investigation of isopropanol conversion on alumina catalysts: Location of active sites for alkene/ether production. ACS Catal. 2015, 5, 4423-4437. [CrossRef]

28. De Rezende, S.M.; Franchini, C.A.; Dieuzeide, M.L.; De Farias, A.M.D.; Amadeo, N.; Fraga, M. Glycerol steam reforming over layered double hydroxide-supported Pt catalysts. Chem. Eng. J. 2015, 272, 108-118. [CrossRef]

29. Ochoa, A.; Aramburu, B.; Valle, B.; Resasco, D.E.; Bilbao, J.; Gayubo, A.G.; Castaño, P. Role of oxygenates and effect of operating conditions in the deactivation of a Ni supported catalyst during the steam reforming of bio-oil. Green Chem. 2017, 19, 4315-4333. [CrossRef]

30. Sánchez, N.; Encinar, J.M.; Nogales, S.; González, J.F. Lanthanum Effect on $\mathrm{Ni} / \mathrm{Al}_{2} \mathrm{O}_{3}$ as a Catalyst Applied in Steam Reforming of Glycerol for Hydrogen Production. Processes 2019, 7, 449. [CrossRef]

31. Harun, N.; Abidin, S.Z.; Osazuwa, O.; Taufiq-Yap, Y.H.; Azizan, M.T. Hydrogen production from glycerol dry reforming over Ag-promoted $\mathrm{Ni} / \mathrm{Al}_{2} \mathrm{O}_{3}$. Int. J. Hydrogen Energy 2019, 44, 213-225. [CrossRef]

32. Gharahshiran, V.S.; Yousefpour, M.; Amini, V. A comparative study of zirconia and yttria promoted mesoporous carbon-nickel-cobalt catalysts in steam reforming of ethanol for hydrogen production. Mol. Catal. 2020, 484, 110767. [CrossRef]

33. Ramesh, S.; Yang, E.-H.; Jung, J.-S.; Moon, D.J. Copper decorated perovskite an efficient catalyst for low temperature hydrogen production by steam reforming of glycerol. Int. J. Hydrogen Energy 2015, 40, 11428-11435. [CrossRef]

34. Shao, J.; Zeng, G.; Li, Y. Effect of Zn substitution to a $\mathrm{LaNiO}_{3-\delta}$ perovskite structured catalyst in ethanol steam reforming. Int. J. Hydrogen Energy 2017, 42, 17362-17375. [CrossRef]

35. Sun, C.; Zheng, Z.; Wang, S.; Li, X.; Wu, X.; An, X.; Xie, X. Yolk-shell structured Pt-CeO $@_{2} \mathrm{Ni}^{-S i O} \mathrm{O}_{2}$ as an efficient catalyst for enhanced hydrogen production from ethanol steam reforming. Ceram. Int. 2018, 44, 1438-1442. [CrossRef]

36. He, S.; Mei, Z.; Liu, N.; Zhang, L.; Lu, J.; Li, X.; Wang, J.; He, D.; Luo, Y. Ni/SBA-15 catalysts for hydrogen production by ethanol steam reforming: Effect of nickel precursor. Int. J. Hydrogen Energy 2017, 42, 14429-14438. [CrossRef]

37. Ruocco, C.; Palma, V.; Ricca, A. Hydrogen production by oxidative reforming of ethanol in a fluidized bed reactor using a Pt Ni/CeO${ }_{2} \mathrm{SiO}_{2}$ catalyst. Int. J. Hydrogen Energy 2019, 44, 12661-12670. [CrossRef]

38. Wang, F.; Zhang, L.; Deng, J.; Zhang, J.; Han, B.; Wang, Y.; Li, Z.; Yu, H.; Cai, W.; Deng, Z. Embedded Ni catalysts in $\mathrm{Ni}-\mathrm{O}-\mathrm{Ce}$ solid solution for stable hydrogen production from ethanol steam reforming reaction. Fuel Process. Technol. 2019, 193, 94-101. [CrossRef]

39. Ricca, A.; Palma, V.; Martino, M.; Meloni, E. Innovative catalyst design for methane steam reforming intensification. Fuel 2017, 198, 175-182. [CrossRef]

40. Palma, V.; Ruocco, C.; Castaldo, F.; Ricca, A.; Boettge, D. Ethanol steam reforming over bimetallic coated ceramic foams: Effect of reactor configuration and catalytic support. Int. J. Hydrogen Energy 2015, 40, 12650-12662. [CrossRef]

41. Koc, S.; Avci, A.K. Reforming of glycerol to hydrogen over Ni-based catalysts in a microchannel reactor. Fuel Process. Technol. 2017, 156, 357-365. [CrossRef]

42. Montero, C.; Ochoa, A.; Castaño, P.; Bilbao, J.; Gayubo, A.G. Monitoring Ni 0 and coke evolution during the deactivation of a Ni/La $\mathrm{O}_{3}-\alpha \mathrm{Al}_{2} \mathrm{O}_{3}$ catalyst in ethanol steam reforming in a fluidized bed. J. Catal. 2015, 331, 181-192. [CrossRef]

43. Mondal, T.; Pant, K.K.; Dalai, A.K. Catalytic oxidative steam reforming of bio-ethanol for hydrogen production over Rh promoted $\mathrm{Ni} / \mathrm{CeO}_{2}-\mathrm{ZrO}_{2}$ catalyst. Int. J. Hydrogen Energy 2015, 40, 2529-2544. [CrossRef]

44. Li, M.-R.; Wang, G.-C. The mechanism of ethanol steam reforming on the $\mathrm{Co}^{0}$ and $\mathrm{Co}^{2+}$ sites: A DFT study. J. Catal. 2018, 365, 391-404. [CrossRef]

45. Grewal, T.P.K.; Roy, S. Modeling the effect of coke deposition in a heat integrated ethanol reformer. Int. J. Hydrogen Energy 2016, 41, 19863-19880. [CrossRef]

46. Argyle, M.D.; Bartholomew, C.H. Heterogeneous catalyst deactivation and regeneration: A review. Catalysts 2015, 5, 145-269. [CrossRef] 
47. Trevisanut, C.; Mari, M.; Millet, J.-M.M.; Cavani, F. Chemical-loop reforming of ethanol over metal ferrites: An analysis of structural features affecting reactivity. Int. J. Hydrogen Energy 2015, 40, 5264-5271. [CrossRef]

48. Sharma, Y.C.; Kumar, A.; Prasad, R.; Upadhyay, S.N. Ethanol steam reforming for hydrogen production: Latest and effective catalyst modification strategies to minimize carbonaceous deactivation. Renew. Sustain. Energy Rev. 2017, 74, 89-103. [CrossRef]

49. Li, D.; Li, X.; Gong, J. Catalytic reforming of oxygenates: State of the art and future prospects. Chem. Rev. 2016, 116, 11529-11653. [CrossRef] [PubMed]

50. Lazar, M.D.; Senila, L.; Dan, M.; Mihet, M. Chapter 10-Crude bioethanol reforming process: The advantage of a biosource exploitation. In Ethanol; Basile, A., Iulianelli, A., Dalena, F., Veziroğlu, T.N., Eds.; Elsevier: Amsterdam, The Netherlands, 2019; pp. 257-288.

51. Liu, Z.; Duchoň, T.; Wang, H.; Peterson, E.W.; Zhou, Y.; Luo, S.; Zhou, J.; Matolin, V.; Stacchiola, D.J.; Rodríguez, J.A.; et al. Mechanistic Insights of Ethanol Steam Reforming over Ni-CeOx(111): The Importance of Hydroxyl Groups for Suppressing Coke Formation. J. Phys. Chem. C 2015, 119, 18248-18256. [CrossRef]

52. Gonçalves, A.A.S.; Faustino, P.B.; Assaf, J.M.; Jaroniec, M. One-Pot Synthesis of Mesoporous Ni-Ti-Al Ternary Oxides: Highly Active and Selective Catalysts for Steam Reforming of Ethanol. ACS Appl. Mater. Interfaces 2017, 9, 6079-6092. [CrossRef]

53. Osorio-Vargas, P.; Flores-González, N.A.; Navarro, R.M.; Fierro, J.L.; Campos, C.H.; Reyes, P. Improved stability of $\mathrm{Ni} / \mathrm{Al} 2 \mathrm{O} 3$ catalysts by effect of promoters $\left(\mathrm{La}_{2} \mathrm{O}_{3}, \mathrm{CeO}_{2}\right)$ for ethanol steam-reforming reaction. Catal. Today 2016, 259, 27-38. [CrossRef]

54. Jo, S.W.; Kwak, B.S.; Kim, K.M.; Do, J.Y.; Park, N.-K.; Lee, T.J.; Lee, S.-T.; Kang, M. Reasonable harmony of $\mathrm{Ni}$ and $\mathrm{Mn}$ in core@shell-structured $\mathrm{NiMn@SiO} 2$ catalysts prepared for hydrogen production from ethanol steam reforming. Chem. Eng. J. 2016, 288, 858-868. [CrossRef]

55. Chen, M.; Wang, C.; Wang, Y.; Tang, Z.; Yang, Z.; Zhang, H.; Wang, J. Hydrogen production from ethanol steam reforming: Effect of Ce content on catalytic performance of Co/Sepiolite catalyst. Fuel 2019, 247, 344-355. [CrossRef]

56. Passos, A.R.; Martins, L.; Pulcinelli, S.H.; Santilli, C.; Briois, V. Correlation of Sol-Gel Alumina-Supported Cobalt Catalyst Processing to Cobalt Speciation, Ethanol Steam Reforming Activity, and Stability. Chem CatChem 2017, 9, 3918-3929. [CrossRef]

57. Spallina, V.; Matturro, G.; Ruocco, C.; Meloni, E.; Palma, V.; Fernandez, E.; Melendez, J.; Tanaka, A.P.; Sole, J.V.; Annaland, M.V.S.; et al. Direct route from ethanol to pure hydrogen through autothermal reforming in a membrane reactor: Experimental demonstration, reactor modelling and design. Energy 2018, 143, 666-681. [CrossRef]

58. Muñoz, M.; Moreno, S.; Molina, R. Oxidative steam reforming of ethanol (OSRE) over stable NiCo-MgAl catalysts by microwave or sonication assisted coprecipitation. Int. J. Hydrogen Energy 2017, 42, 12284-12294. [CrossRef]

59. Passos, A.R.; Pulcinelli, S.H.; Santilli, C.V.; Briois, V. Operando monitoring of metal sites and coke evolution during non-oxidative and oxidative ethanol steam reforming over $\mathrm{Ni}$ and $\mathrm{NiCu}$ ex-hydrotalcite catalysts. Catal. Today 2019, 336, 122-130. [CrossRef]

60. Palma, V.; Ruocco, C.; Meloni, E.; Ricca, A. Oxidative steam reforming of ethanol on mesoporous silica supported $\mathrm{PtNi} / \mathrm{CeO}_{2}$ catalysts. Int. J. Hydrogen Energy 2017, 42, 1598-1608. [CrossRef]

61. Palma, V.; Ruocco, C.; Meloni, E.; Ricca, A. Oxidative reforming of ethanol over $\mathrm{CeO}_{2}-\mathrm{SiO}_{2}$ based catalysts in a fluidized bed reactor. Chem. Eng. Process. Process. Intensif. 2018, 124, 319-327. [CrossRef]

62. Yu, J.; Odriozola, J.; Reina, T.R. Dry reforming of ethanol and glycerol: Mini-review. Catalsts 2019, 9, 1015. [CrossRef]

63. Zhao, S.; Cai, W.; Li, Y.; Yu, H.; Zhang, S.; Cui, L. Syngas production from ethanol dry reforming over $\mathrm{Rh} / \mathrm{CeO}_{2}$ catalyst. J. Saudi Chem. Soc. 2018, 22, 58-65. [CrossRef]

64. Nozawa, T.; Yoshida, A.; Hikichi, S.; Naito, S. Effects of Re addition upon aqueous phase reforming of ethanol over $\mathrm{TiO}_{2}$ supported $\mathrm{Rh}$ and Ir catalysts. Int. J. Hydrogen Energy 2015, 40, 4129-4140. [CrossRef]

65. Xiong, H.; DeLaRiva, A.; Datye, A.K.; Wang, Y. Low-temperature aqueous-phase reforming of ethanol on bimetallic PdZn catalysts. Catal. Sci. Technol. 2015, 5, 254-263. [CrossRef]

66. Zhao, Z.; Zhang, L.; Tan, Q.; Yang, F.; Faria, J.; Resasco, D.E. Synergistic bimetallic Ru-Pt catalysts for the low-temperature aqueous phase reforming of ethanol. AIChE J. 2018, 65, 151-160. [CrossRef] 
67. Gogoi, P.; Nagpure, A.S.; Kandasamy, P.; Satyanarayana, C.V.V.; Raja, T.; Kandasamy, P.; Thirumalaiswamy, R. Insights into the catalytic activity of $\mathrm{Ru} / \mathrm{NaY}$ catalysts for efficient $\mathrm{H}_{2}$ production through aqueous phase reforming. Sustain. Energy Fuels 2020, 4, 678-690. [CrossRef]

68. Mulewa, W.; Tahir, M.; Amin, N.A.S. MMT-supported Ni/TiO 2 nanocomposite for low temperature ethanol steam reforming toward hydrogen production. Chem. Eng. J. 2017, 326, 956-969. [CrossRef]

69. Nejat, T.; Jalalinezhad, P.; Hormozi, F.; Bahrami, Z. Hydrogen production from steam reforming of ethanol over Ni-Co bimetallic catalysts and MCM-41 as support. J. Taiwan Inst. Chem. Eng. 2019, 97, $216-226$. [CrossRef]

70. Di Michele, A.; Dell'Angelo, A.; Tripodi, A.; Bahadori, E.; Sànchez, F.; Motta, D.; Dimitratos, N.; Rossetti, I.; Ramis, G.; Sanchez, F. Steam reforming of ethanol over Ni/MgAl2O4 catalysts. Int. J. Hydrogen Energy 2019, 44, 952-964. [CrossRef]

71. Carvalho, F.L.; Asencios, Y.J.O.; Bellido, J.D.; Assaf, J.M. Bio-ethanol steam reforming for hydrogen production over $\mathrm{Co}_{3} \mathrm{O}_{4} / \mathrm{CeO}_{2}$ catalysts synthesized by one-step polymerization method. Fuel Process. Technol. 2016, 142, 182-191. [CrossRef]

72. Konsolakis, M.; Ioakimidis, Z.; Kraia, T.; Marnellos, G.E. Hydrogen Production by Ethanol Steam Reforming (ESR) over $\mathrm{CeO}_{2}$ Supported Transition Metal (Fe, $\mathrm{Co}, \mathrm{Ni}, \mathrm{Cu}$ ) Catalysts: Insight into the Structure-Activity Relationship. Catalsts 2016, 6, 39. [CrossRef]

73. Greluk, M.; Słowik, G.; Rotko, M.; Machocki, A. Steam reforming and oxidative steam reforming of ethanol over PtKCo/CeO 2 catalyst. Fuel 2016, 183, 518-530. [CrossRef]

74. Riani, P.; Garbarino, G.; Canepa, F.; Busca, G. Cobalt nanoparticles mechanically deposited on $\alpha-\mathrm{Al}_{2} \mathrm{O}_{3}$ : A competitive catalyst for the production of hydrogen through ethanol steam reforming. J. Chem. Technol. Biotechnol. 2019, 94, 538-546. [CrossRef]

75. Mhadmhan, S.; Natewong, P.; Prasongthum, N.; Samart, C.; Reubroycharoen, P. Investigation of Ni/SiO 2 fiber catalysts prepared by different methods on hydrogen production from ethanol steam reforming. Catalysts 2018, 8, 319. [CrossRef]

76. Rodrigues, T.S.; De Moura, A.B.; Silva, F.; Candido, E.G.; Da Silva, A.G.; De Oliveira, D.C.; Quiroz, J.; Camargo, P.H.; Bergamaschi, V.S.; Ferreira, J.C.; et al. Ni supported $\mathrm{Ce}_{0.9} \mathrm{Sm}_{0.1} \mathrm{O}_{2-\delta}$ nanowires: An efficient catalyst for ethanol steam reforming for hydrogen production. Fuel 2019, 237, 1244-1253. [CrossRef]

77. Roy, B.; Leclerc, C. Study of preparation method and oxidization/reduction effect on the performance of nickel-cerium oxide catalysts for aqueous-phase reforming of ethanol. J. Power Sources 2015, 299, 114-124. [CrossRef]

78. Sohn, H.; Ozkan, U.S. Cobalt-Based Catalysts for Ethanol Steam Reforming: An Overview. Energy Fuels 2016, 30, 5309-5322. [CrossRef]

79. Yoshida, H.; Yamaoka, R.; Arai, M. Stable Hydrogen Production from Ethanol through Steam Reforming Reaction over Nickel-Containing Smectite-Derived Catalyst. Int. J. Mol. Sci. 2014, 16, 350-362. [CrossRef]

80. Ogo, S.; Sekine, Y. Recent progress in ethanol steam reforming using non-noble transition metal catalysts: A review. Fuel Process. Technol. 2020, 199, 106238. [CrossRef]

81. Hou, T.; Yu, B.; Zhang, S.; Xu, T.; Wang, D.; Cai, W. Hydrogen production from ethanol steam reforming over $\mathrm{Rh} / \mathrm{CeO} 2$ catalyst. Catal. Commun. 2015, 58, 137-140. [CrossRef]

82. Hou, T.; Lei, Y.; Zhang, S.; Zhang, J.; Cai, W. Ethanol dry reforming for syngas production over Ir/CeO 2 catalyst. J. Rare Earths 2015, 33, 42-45. [CrossRef]

83. Moraes, T.S.; Neto, R.C.R.; Ribeiro, M.; Mattos, L.V.; Kourtelesis, M.; Ladas, S.; Verykios, X.; Noronha, F.B. The study of the performance of $\mathrm{PtNi} / \mathrm{CeO}_{2}$-nanocube catalysts for low temperature steam reforming of ethanol. Catal. Today 2015, 242, 35-49. [CrossRef]

84. Moraes, T.S.; Neto, R.C.R.; Ribeiro, M.; Mattos, L.V.; Kourtelesis, M.; Ladas, S.; Verykios, X.; Noronha, F.B. Ethanol conversion at low temperature over $\mathrm{CeO}_{2}$-Supported Ni-based catalysts. Effect of Pt addition to $\mathrm{Ni}$ catalyst. Appl. Catal. B Environ. 2016, 181, 754-768. [CrossRef]

85. Cifuentes, B.; Valero, M.F.; Conesa, J.A.; Cobo, M. Hydrogen Production by Steam Reforming of Ethanol on Rh-Pt Catalysts: Influence of $\mathrm{CeO}_{2}, \mathrm{ZrO}_{2}$, and $\mathrm{La}_{2} \mathrm{O}_{3}$ as Supports. Catalsts 2015, 5, 1872-1896. [CrossRef]

86. Palma, V.; Ruocco, C.; Meloni, E.; Ricca, A. Renewable hydrogen from ethanol reforming over $\mathrm{CeO}_{2}-\mathrm{SiO}_{2}$ based catalysts. Catalsts 2017, 7, 226. [CrossRef] 
87. Campos, C.H.; Pecchi, G.; Fierro, J.L.G.; Osorio-Vargas, P. Enhanced bimetallic Rh-Ni supported catalysts on alumina doped with mixed lanthanum-cerium oxides for ethanol steam reforming. Mol. Catal. 2019, 469, 87-97. [CrossRef]

88. Sanchez, N.; Ruiz, R.; Cifuentes, B.; Cobo, M. Hydrogen from glucose: A combined study of glucose fermentation, bioethanol purification, and catalytic steam reforming. Int. J. Hydrogen Energy 2016, 41, 5640-5651. [CrossRef]

89. Bilal, M.; Jackson, S.D. Ethanol steam reforming over $\mathrm{Pt} / \mathrm{Al}_{2} \mathrm{O}_{3}$ and $\mathrm{Rh} / \mathrm{Al}_{2} \mathrm{O}_{3}$ catalysts: The effect of impurities on selectivity and catalyst deactivation. Appl. Catal. A Gen. 2017, 529, 98-107. [CrossRef]

90. Iulianelli, A.; Palma, V.; Bagnato, G.; Ruocco, C.; Huang, Y.; Veziroglu, N.T.; Basile, A. From bioethanol exploitation to high grade hydrogen generation: Steam reforming promoted by a Co-Pt catalyst in a Pd-based membrane reactor. Renew. Energy 2018, 119, 834-843. [CrossRef]

91. Nichele, V.; Signoretto, M.; Pinna, F.; Ghedini, E.; Compagnoni, M.; Rossetti, I.; Cruciani, G.; Di Michele, A. Bimetallic $\mathrm{Ni}-\mathrm{Cu}$ catalysts for the low-temperature ethanol steam reforming: Importance of metal-support interactions. Catal. Lett. 2014, 145, 549-558. [CrossRef]

92. Rodriguez-Gomez, A.; Caballero, A. Bimetallic Ni-Co/SBA-15 catalysts for reforming of ethanol: How cobalt modifies the nickel metal phase and product distribution. Mol. Catal. 2018, 449, 122-130. [CrossRef]

93. Chen, L.-C.; Cheng, H.; Chiang, C.-W.; Lin, S.D. Sustainable hydrogen production by ethanol steam reforming using a partially reduced copper-nickel oxide catalyst. ChemSusChem 2015, 8, 1787-1793. [CrossRef]

94. Braga, A.H.; Ribeiro, M.; Noronha, F.B.; Galante, D.; Bueno, J.M.C.; Santos, J.B.O. Effects of Co addition to supported Ni catalysts on hydrogen production from oxidative steam reforming of ethanol. Energy Fuels 2018, 32, 12814-12825. [CrossRef]

95. Baruah, R.; Dixit, M.; Parejiya, A.; Basarkar, P.; Bhargav, A.; Sharma, S. Oxidative steam reforming of ethanol on rhodium catalyst-I: Spatially resolved steady-state experiments and microkinetic modeling. Int. J. Hydrogen Energy 2017, 42, 10184-10198. [CrossRef]

96. Weng, S.-F.; Hsieh, H.-C.; Lee, C.-S. Hydrogen production from oxidative steam reforming of ethanol on nickel-substituted pyrochlore phase catalysts. Int. J. Hydrogen Energy 2017, 42, 2849-2860. [CrossRef]

97. Hsieh, H.-C.; Chang, Y.-C.; Tsai, P.-W.; Lin, Y.-Y.; Chuang, Y.-C.; Sheu, H.-S.; Lee, C.-S. Metal substituted pyrochlore phase $\mathrm{Li}_{x} \mathrm{La}_{2-\mathrm{x}} \mathrm{Ce}_{1.8} \mathrm{Ru}_{0.2} \mathrm{O}_{7-\delta}(\mathrm{x}=0.0-0.6)$ as an effective catalyst for oxidative and auto-thermal steam reforming of ethanol. Catal. Sci. Technol. 2019, 9, 1406-1419. [CrossRef]

98. Cao, D.; Zeng, F.; Zhao, Z.; Cai, W.; Li, Y.; Yu, H.; Zhang, S.; Qu, F. Cu based catalysts for syngas production from ethanol dry reforming: Effect of oxide supports. Fuel 2018, 219, 406-416. [CrossRef]

99. Cao, N.; Cai, W.; Li, Y.; Li, C.; Yu, H.; Zhang, S.; Qu, F. Syngas Production from Ethanol Dry Reforming over $\mathrm{Cu} / \mathrm{Ce}_{0.8} \mathrm{Zr}_{0.2} \mathrm{O}_{2}$ Catalyst. Catal. Lett. 2017, 147, 2929-2939. [CrossRef]

100. Chen, Q.; Cai, W.; Liu, Y.; Zhang, S.; Li, Y.; Huang, D.; Wang, T.; Li, Y. Synthesis of Cu-Ce ${ }_{0.8} \mathrm{Zr}_{0.2} \mathrm{O}_{2}$ catalyst by ball milling for $\mathrm{CO}_{2}$ reforming of ethanol. J. Saudi Chem. Soc. 2019, 23, 111-117. [CrossRef]

101. Dang, C.; Wu, S.; Yang, G.; Cao, Y.; Wang, H.; Peng, F.; Yu, H. Syngas production by dry reforming of the mixture of glycerol and ethanol with $\mathrm{CaCO}_{3}$. J. Energy Chem. 2020, 43, 90-97. [CrossRef]

102. Da Costa-Serra, J.F.; Chica, A. Catalysts based on Co-Birnessite and Co-Todorokite for the efficient production of hydrogen by ethanol steam reforming. Int. J. Hydrogen Energy 2018, 43, 16859-16865. [CrossRef]

103. Wei, Y.; Cai, W.; Deng, S.; Li, Z.; Yu, H.; Zhang, S.; Yu, Z.; Cui, L.; Qu, F. Efficient syngas production via dry reforming of renewable ethanol over Ni/KIT-6 nanocatalysts. Renew. Energy 2020, 145, 1507-1516. [CrossRef]

104. Chai, R.; Li, Y.; Zhang, Q.; Zhao, G.; Liu, Y.; Lu, Y. Monolithic Ni-MO $/$ Ni-foam (M = Al, Zr or Y) catalysts with enhanced heat/mass transfer for energy-efficient catalytic oxy-methane reforming. Catal. Commun. 2015, 70, 1-5. [CrossRef]

105. Moraes, T.S.; Borges, L.E.P.; Farrauto, R.; Noronha, F.B. Steam reforming of ethanol on $\mathrm{Rh} / \mathrm{SiCeO}_{2}$ washcoated monolith catalyst: Stable catalyst performance. Int. J. Hydrogen Energy 2018, 43, 115-126. [CrossRef]

106. Gaudillere, C.; González, J.J.; Chica, A.; Serra, J.M. YSZ monoliths promoted with Co as catalysts for the production of $\mathrm{H}_{2}$ by steam reforming of ethanol. Appl. Catal. A Gen. 2017, 538, 165-173. [CrossRef]

107. Palma, V.; Ruocco, C.; Ricca, A. Ceramic foams coated with $\mathrm{PtNi} / \mathrm{CeO}_{2} \mathrm{ZrO}_{2}$ for bioethanol steam reforming. Int. J. Hydrogen Energy 2016, 41, 11526-11536. [CrossRef]

108. Turczyniak, S.; Greluk, M.; Słowik, G.; Gac, W.; Zafeiratos, S.; Machocki, A. Surface state and catalytic performance of ceria-supported cobalt catalysts in the steam reforming of ethanol. ChemCatChem 2017, 9, 782-797. [CrossRef] 
109. Greluk, M.; Rybak, P.; Słowik, G.; Rotko, M.; Machocki, A. Comparative study on steam and oxidative steam reforming of ethanol over $2 \mathrm{KCo} / \mathrm{ZrO}_{2}$ catalyst. Catal. Today 2015, 242, 50-59. [CrossRef]

110. Greluk, M.; Rotko, M.; Turczyniak-Surdacka, S. Enhanced catalytic performance of $\mathrm{La}_{2} \mathrm{O}_{3}$ promoted $\mathrm{Co} / \mathrm{CeO} 2$ and $\mathrm{Ni} / \mathrm{CeO}_{2}$ catalysts for effective hydrogen production by ethanol steam reforming. Renew. Energy 2020, 155, 378-395. [CrossRef]

111. Cerdá-Moreno, C.; Da Costa-Serra, J.F.; Chica, A. Co and La supported on Zn-Hydrotalcite-derived material as efficient catalyst for ethanol steam reforming. Int. J. Hydrogen Energy 2019, 44, 12685-12692. [CrossRef]

112. Kim, D.; Kwak, B.S.; Park, N.-K.; Han, G.B.; Kang, M. Dynamic hydrogen production from ethanol steam-reforming reaction on $\mathrm{Ni}_{\mathrm{x}} \mathrm{Mo}_{\mathrm{y}} / \mathrm{SBA}-15$ catalytic system. Int. J. Energy Res. 2015, 39, $279-292$. [CrossRef]

113. Kwak, B.S.; Lee, G.; Park, S.-M.; Kang, M. Effect of MnOx in the catalytic stabilization of $\mathrm{Co}_{2} \mathrm{MnO}_{4}$ spinel during the ethanol steam reforming reaction. Appl. Catal. A Gen. 2015, 503, 165-175. [CrossRef]

114. Liu, Z.; Xu, W.; Yao, S.; Johnson-Peck, A.C.; Zhao, F.; Michorczyk, P.; Kubacka, A.; Stach, E.A.; Fernández-García, M.; Senanayake, S.D.; et al. Superior performance of Ni-W-Ce mixed-metal oxide catalysts for ethanol steam reforming: Synergistic effects of W- and Ni-dopants. J. Catal. 2015, 321, 90-99. [CrossRef]

115. Li, D.; Zeng, L.; Li, X.; Wang, X.; Ma, H.; Assabumrungrat, S.; Gong, J. Ceria-promoted Ni/SBA-15 catalysts for ethanol steam reforming with enhanced activity and resistance to deactivation. Appl. Catal. B Environ. 2015, 176, 532-541. [CrossRef]

116. Du, Y.-L.; Wu, X.; Cheng, Q.; Huang, Y.-L.; Huang, W. Development of Ni-Based Catalysts Derived from Hydrotalcite-Like Compounds Precursors for Synthesis Gas Production via Methane or Ethanol Reforming. Catalysts 2017, 7, 70. [CrossRef]

117. Marinho, A.L.A.; Rabelo-Neto, R.C.; Noronha, F.B.; Mattos, L.V. Steam reforming of ethanol over Ni-based catalysts obtained from $\mathrm{LaNiO}_{3}$ and $\mathrm{LaNiO}_{3} / \mathrm{CeSiO}_{2}$ perovskite-type oxides for the production of hydrogen. Appl. Catal. A Gen. 2016, 520, 53-64. [CrossRef]

118. Dan, M.; Senila, L.; Roman, M.; Mihet, M.; Lazar, M.D. From wood wastes to hydrogen-Preparation and catalytic steam reforming of crude bio-ethanol obtained from fir wood. Renew. Energy 2015, 74, 27-36. [CrossRef]

119. He, S.; He, S.; Zhang, L.; Li, X.; Wang, J.; He, D.; Lu, J.; Luo, Y. Hydrogen production by ethanol steam reforming over Ni/SBA-15 mesoporous catalysts: Effect of Au addition. Catal. Today 2015, 258, 162-168. [CrossRef]

120. Mondal, T.; Pant, K.K.; Dalai, A.K. Oxidative and non-oxidative steam reforming of crude bio-ethanol for hydrogen production over $\mathrm{Rh}$ promoted $\mathrm{Ni} / \mathrm{CeO}_{2}-\mathrm{ZrO}_{2}$ catalyst. Appl. Catal. A Gen. 2015, 499, $19-31$. [CrossRef]

121. Bahari, M.B.; Phuc, N.H.H.; Abdullah, B.; Alenazey, F.; Vo, D.-V.N. Ethanol dry reforming for syngas production over Ce-promoted $\mathrm{Ni} / \mathrm{Al}_{2} \mathrm{O}_{3}$ catalyst. J. Environ. Chem. Eng. 2016, 4, 4830-4838. [CrossRef]

122. Bahari, M.B.; Phuc, N.H.H.; Alenazey, F.; Vu, K.B.; Ainirazali, N.; Vo, D.-V.N. Catalytic performance of $\mathrm{La}-\mathrm{Ni} / \mathrm{Al}_{2} \mathrm{O}_{3}$ catalyst for $\mathrm{CO}_{2}$ reforming of ethanol. Catal. Today 2017, 291, 67-75. [CrossRef]

123. Fayaz, F.; Danh, H.T.; Nguyen-Huy, C.; Vu, K.B.; Abdullah, B.; Vo, D.-V.N. Promotional Effect of Ce-dopant on $\mathrm{Al}_{2} \mathrm{O}_{3}$-supported Co Catalysts for Syngas Production via $\mathrm{CO}_{2}$ Reforming of Ethanol. Procedia Eng. 2016, 148, 646-653. [CrossRef]

124. Fayaz, F.; Bach, L.-G.; Bahari, M.B.; Nguyen, D.T.; Vu, K.B.; Kanthasamy, R.; Samart, C.; Nguyen-Huy, C.; Vo, D.-V.N. Stability evaluation of ethanol dry reforming on Lanthania-doped cobalt-based catalysts for hydrogen-rich syngas generation. Int. J. Energy Res. 2018, 43, 405-416. [CrossRef]

125. Shafiqah, M.-N.N.; Nguyen, T.D.; Jun, L.N.; Bahari, M.B.; Phuong, P.T.; Abdullah, B.; Vo, D.-V.N. Production of Syngas from Ethanol $\mathrm{CO}_{2}$ Reforming on La-Doped Cu/Al2O3: Impact of Promoter Loading; AIP Publishing LLC: Melville, NY, USA, 2019; p. 020011.

126. Słowik, G.; Greluk, M.; Rotko, M.; Machocki, A. Evolution of the structure of unpromoted and potassium-promoted ceria-supported nickel catalysts in the steam reforming of ethanol. Appl. Catal. B Environ. 2018, 221, 490-509. [CrossRef]

127. Cifuentes, B.; Hernández, M.; Monsalve, S.; Cobo, M. Hydrogen production by steam reforming of ethanol on a $\mathrm{RhPt} / \mathrm{CeO}_{2} / \mathrm{SiO}_{2}$ catalyst: Synergistic effect of the $\mathrm{Si}$ :Ce ratio on the catalyst performance. Appl. Catal. A Gen. 2016, 523, 283-293. [CrossRef] 
128. Wang, F.; Zhang, L.; Zhu, J.; Han, B.; Zhao, L.; Yu, H.; Deng, Z.; Shi, W. Study on different $\mathrm{CeO}_{2}$ structure stability during ethanol steam reforming reaction over $\mathrm{Ir} / \mathrm{CeO}_{2}$ nanocatalysts. Appl. Catal. A Gen. 2018, 564, 226-233. [CrossRef]

129. Osorio-Vargas, P.; Campos, C.H.; Navarro, R.M.; Fierro, J.L.; Reyes, P. Rh/ $\mathrm{Al}_{2} \mathrm{O}_{3}-\mathrm{La}_{2} \mathrm{O}_{3}$ catalysts promoted with $\mathrm{CeO}_{2}$ for ethanol steam reforming reaction. J. Mol. Catal. A Chem. 2015, 407, 169-181. [CrossRef]

130. Gunduz, S.; Doğu, T. Hydrogen by steam reforming of ethanol over Co-Mg incorporated novel mesoporous alumina catalysts in tubular and microwave reactors. Appl. Catal. B Environ. 2015, 168, 497-508. [CrossRef]

131. Zhao, L.; Han, T.; Wang, H.; Zhang, L.; Liu, Y. Ni-Co alloy catalyst from $\mathrm{LaNi}_{1-x} \mathrm{Co}_{\mathrm{x}} \mathrm{O}_{3}$ perovskite supported on zirconia for steam reforming of ethanol. Appl. Catal. B Environ. 2016, 187, 19-29. [CrossRef]

132. Bepari, S.; Basu, S.; Pradhan, N.C.; Dalai, A.K. Steam reforming of ethanol over cerium-promoted Ni-Mg-Al hydrotalcite catalysts. Catal. Today 2017, 291, 47-57. [CrossRef]

133. Prasongthum, N.; Xiao, R.; Zhang, H.; Tsubaki, N.; Natewong, P.; Reubroycharoen, P. Highly active and stable Ni supported on $\mathrm{CNTs}_{-} \mathrm{SiO}_{2}$ fiber catalysts for steam reforming of ethanol. Fuel Process. Technol. 2017, 160, 185-195. [CrossRef]

134. Dai, R.; Zheng, Z.; Sun, C.; Li, X.; Wang, S.; Wu, X.; An, X.; Xie, X. Pt nanoparticles encapsulated in a hollow zeolite microreactor as a highly active and stable catalyst for low-temperature ethanol steam reforming. Fuel 2018, 214, 88-97. [CrossRef]

135. Dobosz, J.; Małecka, M.; Zawadzki, M. Hydrogen generation via ethanol steam reforming over Co/HAp catalysts. J. Energy Inst. 2018, 91, 411-423. [CrossRef]

136. Chen, M.; Wang, Y.; Yang, Z.; Liang, T.; Liu, S.; Zhou, Z.; Li, X. Effect of Mg-modified mesoporous $\mathrm{Ni}$ /Attapulgite catalysts on catalytic performance and resistance to carbon deposition for ethanol steam reforming. Fuel 2018, 220, 32-46. [CrossRef]

137. Xiao, Z.; Li, Y.; Hou, F.; Wu, C.; Pan, L.; Zou, J.; Wang, L.; Zhang, X.; Liu, G.; Li, G. Engineering oxygen vacancies and nickel dispersion on $\mathrm{CeO}_{2}$ by Pr doping for highly stable ethanol steam reforming. Appl. Catal. B Environ. 2019, 258, 117940. [CrossRef]

138. Lee, J.H.; Do, J.Y.; Park, N.-K.; Ryu, H.-J.; Seo, M.W.; Kang, M. Hydrogen production on $\mathrm{Pd}_{0.01} \mathrm{Zn}_{0.29} \mathrm{Mg}_{0.7} \mathrm{Al}_{2} \mathrm{O}_{4}$ spinel catalyst by low temperature ethanol steam reforming reaction. J. Energy Inst. 2019, 92, 1064-1076. [CrossRef]

139. Yang, P.; Li, N.; Teng, J.; Wu, J.; Ma, H. Effect of template on catalytic performance of $\mathrm{La}_{0.7} \mathrm{Ce}_{0.3} \mathrm{Ni}_{0.7} \mathrm{Fe}_{0.3} \mathrm{O}_{3}$ for ethanol steam reforming reaction. J. Rare Earths 2019, 37, 594-601. [CrossRef]

140. Dai, R.; Zheng, Z.; Yan, W.; Lian, C.; Wu, X.; An, X.; Xie, X. Dragon fruit-like Pt-Cu@mSiO 2 nanocomposite as an efficient catalyst for low-temperature ethanol steam reforming. Chem. Eng. J. 2020, 379, 122299. [CrossRef]

141. Zhurka, M.D.; Lemonidou, A.A.; Kechagiopoulos, P.N. Elucidation of metal and support effects during ethanol steam reforming over $\mathrm{Ni}$ and $\mathrm{Rh}$ based catalysts supported on $\left(\mathrm{CeO}_{2}\right)-\mathrm{ZrO}_{2}-\mathrm{La}_{2} \mathrm{O}_{3}$. Catal. Today 2020. [CrossRef]

142. Morales, M.; Segarra, M. Steam reforming and oxidative steam reforming of ethanol over $\mathrm{La}_{0.6} \mathrm{Sr}_{0.4} \mathrm{CoO}_{3}-$ perovskite as catalyst precursor for hydrogen production. Appl. Catal. A Gen. 2015, 502, 305-311. [CrossRef]

143. Fang, W.; Pirez, C.; Paul, S.; Jiménez-Ruiz, M.; Jobic, H.; Dumeignil, F.; Jalowiecki-Duhamel, L. Advanced functionalized $\mathrm{Mg}_{2} \mathrm{AlNiXHZOY}$ nano-oxyhydrides ex-hydrotalcites for hydrogen production from oxidative steam reforming of ethanol. Int. J. Hydrogen Energy 2016, 41, 15443-15452. [CrossRef]

144. Muñoz, M.; Moreno, S.; Molina, R. Promoter effect of Ce and Pr on the catalytic stability of the Ni-Co system for the oxidative steam reforming of ethanol. Appl. Catal. A Gen. 2016, 526, 84-94. [CrossRef]

145. Hsieh, H.-C.; Tsai, P.-W.; Chang, Y.-C.; Weng, S.-F.; Sheu, H.-S.; Chuang, Y.-C.; Lee, C.-S. Oxidative steam reforming of ethanol over $\mathrm{M}_{\mathrm{x}} \mathrm{La}_{2-\mathrm{x}} \mathrm{Ce}_{1.8} \mathrm{Ru}_{0.2} \mathrm{O}_{7-\delta}(\mathrm{M}=\mathrm{Mg}$, Ca) catalysts: Effect of alkaline earth metal substitution and support on stability and activity. RSC Adv. 2019, 9, 39932-39944. [CrossRef]

146. Bej, B.; Bepari, S.; Pradhan, N.C.; Neogi, S. Production of hydrogen by dry reforming of ethanol over alumina supported nano- $\mathrm{NiO} / \mathrm{SiO}_{2}$ catalyst. Catal. Today 2017, 291, 58-66. [CrossRef]

147. Samsudeen, K.; Ahmed, A.F.; Yahya, M.; Ahmed, A.; Anis, F. Effect of Calcination Temperature on Hydrogen Production via Ethanol Dry Reforming Over Ni/ $\mathrm{Al}_{2} \mathrm{O}_{3}$ Catalyst. Int. J. Res. Sci. 2018, 4, 5-9. [CrossRef]

148. Usman, M.; Daud, W.M.A.W. Recent advances in the methanol synthesis via methane reforming processes. RSC Adv. 2015, 5, 21945-21972. [CrossRef] 
149. Kothandaraman, J.; Kar, S.; Goeppert, A.; Sen, R.; Prakash, G.K.S. Advances in Homogeneous Catalysis for Low Temperature Methanol Reforming in the Context of the Methanol Economy. Top. Catal. 2018, 61, 542-559. [CrossRef]

150. Lee, H.; Jung, I.; Roh, G.; Na, Y.; Kang, H. Comparative Analysis of On-Board Methane and Methanol Reforming Systems Combined with HT-PEM Fuel Cell and $\mathrm{CO}_{2}$ Capture/Liquefaction System for Hydrogen Fueled Ship Application. Energies 2020, 13, 224. [CrossRef]

151. Araya, S.S.; Liso, V.; Cui, X.; Li, N.; Zhu, J.; Sahlin, S.L.; Jensen, S.; Nielsen, M.; Kær, S. A Review of The Methanol Economy: The Fuel Cell Route. Energies 2020, 13, 596. [CrossRef]

152. Iulianelli, A.; Ghasemzadeh, K.; Basile, A. Progress in Methanol Steam Reforming Modelling via Membrane Reactors Technology. Membranes 2018, 8, 65. [CrossRef]

153. Palma, V.; Ruocco, C.; Martino, M.; Meloni, E.; Ricca, A. Bimetallic supported catalysts for hydrocarbons and alcohols reforming reactions. In Hydrogen Production, Separation and Purification for Energy; Institution of Engineering and Technology: London, UK, 2017; pp. 39-70.

154. Xu, X.; Shuai, K.; Xu, B. Review on copper and palladium based catalysts for methanol steam reforming to produce hydrogen. Catalysts 2017, 7, 183. [CrossRef]

155. Iulianelli, A.; Ribeirinha, P.; Mendes, A.; Basile, A. Methanol steam reforming for hydrogen generation via conventional and membrane reactors: A review. Renew. Sustain. Energy Rev. 2014, 29, 355-368. [CrossRef]

156. Tonelli, F.; Gorriz, O.; Tarditi, A.M.; Cornaglia, L.; Arrúa, L.; Abello, M.C. Activity and stability of a CuO/CeO 2 catalyst for methanol steam reforming. Int. J. Hydrogen Energy 2015, 40, 13379-13387. [CrossRef]

157. Das, D.; Llorca, J.; Domínguez, M.; Colussi, S.; Trovarelli, A.; Gayen, A. Methanol steam reforming behavior of copper impregnated over $\mathrm{CeO}_{2}-\mathrm{ZrO}_{2}$ derived from a surfactant assisted coprecipitation route. Int. J. Hydrogen Energy 2015, 40, 10463-10479. [CrossRef]

158. Deshmane, V.G.; Abrokwah, R.Y.; Kuila, D. Synthesis of stable Cu-MCM-41 nanocatalysts for $\mathrm{H}_{2}$ production with high selectivity via steam reforming of methanol. Int. J. Hydrogen Energy 2015, 40, 10439-10452. [CrossRef]

159. Xu, T.; Zou, J.; Tao, W.; Zhang, S.; Cui, L.; Zeng, F.; Wang, D.; Cai, W. Co-nanocasting synthesis of Cu based composite oxide and its promoted catalytic activity for methanol steam reforming. Fuel 2016, 183, 238-244. [CrossRef]

160. Thattarathody, R.; Sheintuch, M. Kinetics and dynamics of methanol steam reforming on $\mathrm{CuO} / \mathrm{ZnO} / \mathrm{alumina}$ catalyst. Appl. Catal. A Gen. 2017, 540,47-56. [CrossRef]

161. Bagherzadeh, S.B.; Haghighi, M. Plasma-enhanced comparative hydrothermal and coprecipitation preparation of $\mathrm{CuO} / \mathrm{ZnO} / \mathrm{Al}_{2} \mathrm{O}_{3}$ nanocatalyst used in hydrogen production via methanol steam reforming. Energy Convers. Manag. 2017, 142, 452-465. [CrossRef]

162. Ajamein, H.; Haghighi, M.; Alaei, S. The role of various fuels on microwave-enhanced combustion synthesis of $\mathrm{CuO} / \mathrm{ZnO} / \mathrm{Al}_{2} \mathrm{O}_{3}$ nanocatalyst used in hydrogen production via methanol steam reforming. Energy Convers. Manag. 2017, 137, 61-73. [CrossRef]

163. Abrokwah, R.Y.; Deshmane, V.G.; Kuila, D. Comparative performance of M-MCM-41 (M: Cu, Co, Ni, Pd, Zn and Sn) catalysts for steam reforming of methanol. J. Mol. Catal. A Chem. 2016, 425, 10-20. [CrossRef]

164. Papadopoulou, E.; Ioannides, T. Methanol Reforming over Cobalt Catalysts Prepared from Fumarate Precursors: TPD Investigation. Catalysts 2016, 6, 33. [CrossRef]

165. Li, J.; Mei, X.; Zhang, L.; Yu, Z.; Liu, Q.; Wei, T.; Wu, W.; Dong, D.; Xu, L.; Hu, X. A comparative study of catalytic behaviors of $\mathrm{Mn}, \mathrm{Fe}, \mathrm{Co}, \mathrm{Ni}, \mathrm{Cu}$ and $\mathrm{Zn}$-Based catalysts in steam reforming of methanol, acetic acid and acetone. Int. J. Hydrogen Energy 2020, 45, 3815-3832. [CrossRef]

166. Maiti, S.; Llorca, J.; Dominguez, M.; Colussi, S.; Trovarelli, A.; Priolkar, K.R.; Aquilanti, G.; Gayen, A. Combustion synthesized copper-ion substituted $\mathrm{FeAl}_{2} \mathrm{O}_{4}\left(\mathrm{Cu}_{0.1} \mathrm{Fe}_{0.9} \mathrm{Al}_{2} \mathrm{O}_{4}\right)$ : A superior catalyst for methanol steam reforming compared to its impregnated analogue. J. Power Sources 2016, 304, 319-331. [CrossRef]

167. Qing, S.-J.; Hou, X.-N.; Liu, Y.-J.; Wang, L.; Li, L.-D.; Gao, Z.-X. Catalytic performance of Cu-Ni-Al spinel for methanol steam reforming to hydrogen. J. Fuel Chem. Technol. 2018, 46, 1210-1217. [CrossRef]

168. Luo, X.; Hong, Y.; Wang, F.; Hao, S.; Pang, C.H.; Lester, E.H.; Wu, T. Development of nano $\mathrm{Ni}_{\mathrm{x}} \mathrm{Mg}_{\mathrm{y}} \mathrm{O}$ solid solutions with outstanding anti-carbon deposition capability for the steam reforming of methanol. Appl. Catal. B Environ. 2016, 194, 84-97. [CrossRef] 
169. Zeng, Z.; Liu, G.; Geng, J.; Jing, D.; Hong, X.; Guo, L. A high-performance PdZn alloy catalyst obtained from metal-organic framework for methanol steam reforming hydrogen production. Int. J. Hydrogen Energy 2019, 44, 24387-24397. [CrossRef]

170. Claudio-Piedras, A.; Ramírez-Zamora, R.M.; Alcántar-Vázquez, B.C.; Gutiérrez-Martínez, A.; Mondragón-Galicia, G.; Morales-Anzures, F.; Pérez-Hernández, R.; Modragón-Galicia, G. One dimensional $\mathrm{Pt} / \mathrm{CeO}_{2}-\mathrm{NR}$ catalysts for hydrogen production by steam reforming of methanol: Effect of Pt precursor. Catal. Today 2019. [CrossRef]

171. Barrios, C.; Bosco, M.V.; Baltanás, M.A.; Bonivardi, A.L. Hydrogen production by methanol steam reforming: Catalytic performance of supported-Pd on zinc-cerium oxides' nanocomposites. Appl. Catal. B Environ. 2015, 179, 262-275. [CrossRef]

172. Ajamein, H.; Haghighi, M.; Shokrani, R.; Abdollahifar, M. On the solution combustion synthesis of copper based nanocatalysts for steam methanol reforming: Effect of precursor, ultrasound irradiation and urea/nitrate ratio. J. Mol. Catal. A Chem. 2016, 421, 222-234. [CrossRef]

173. Lin, L.; Zhou, W.; Gao, R.; Yao, S.; Zhang, X.; Xu, W.; Zheng, S.; Jiang, Z.; Yu, Q.; Li, Y.-W.; et al. Low-temperature hydrogen production from water and methanol using $\mathrm{Pt} / \alpha-\mathrm{MoC}$ catalysts. Nature 2017, 544, 80-83. [CrossRef]

174. Cai, F.; Ibrahim, J.J.; Fu, Y.; Kong, W.; Zhang, J.; Sun, Y. Low-temperature hydrogen production from methanol steam reforming on Zn-modified Pt/MoC catalysts. Appl. Catal. B Environ. 2020, 264, 118500. [CrossRef]

175. Liu, X.; Men, Y.; Wang, J.; He, R.; Wang, Y. Remarkable support effect on the reactivity of $\mathrm{Pt} / \mathrm{In}_{2} \mathrm{O}_{3} / \mathrm{MO}_{\mathrm{x}}$ catalysts for methanol steam reforming. J. Power Sources 2017, 364, 341-350. [CrossRef]

176. Diaz-Perez, M.A.; Moya, J.; Serrano-Ruiz, J.C.; Faria, J. Interplay of support chemistry and reaction conditions on copper catalyzed methanol steam reforming. Ind. Eng. Chem. Res. 2018, 57, 15268-15279. [CrossRef] [PubMed]

177. Tahay, P.; Khani, Y.; Jabari, M.; Bahadoran, F.; Safari, N.; Zamanian, A. Synthesis of cubic and hexagonal $\mathrm{ZnTiO}_{3}$ as catalyst support in steam reforming of methanol: Study of physical and chemical properties of copper catalysts on the $\mathrm{H}_{2}$ and $\mathrm{CO}$ selectivity and coke formation. Int. J. Hydrogen Energy 2020, 45, 9484-9495. [CrossRef]

178. Talkhoncheh, S.K.; Minaei, S.; Ajamein, H.; Haghighi, M.; Abdollahifar, M. Synthesis of CuO/ZnO/ $\mathrm{Al}_{2} \mathrm{O}_{3}$ $/ \mathrm{ZrO}_{2} / \mathrm{CeO}_{2}$ nanocatalysts via homogeneous precipitation and combustion methods used in methanol steam reforming for fuel cell grade hydrogen production. RSC Adv. 2016, 6, 57199-57209. [CrossRef]

179. Taghizadeh, M.; Akhoundzadeh, H.; Rezayan, A.; Sadeghian, M. Excellent catalytic performance of 3D-mesoporous KIT-6 supported $\mathrm{Cu}$ and $\mathrm{Ce}$ nanoparticles in methanol steam reforming. Int. J. Hydrogen Energy 2018, 43, 10926-10937. [CrossRef]

180. Phongboonchoo, Y.; Thouchprasitchai, N.; Pongstabodee, S. Hydrogen production with a low carbon monoxide content via methanol steam reforming over $\mathrm{Cu}_{x} \mathrm{Ce}_{y} \mathrm{Mg}_{\mathrm{z}} / \mathrm{Al}_{2} \mathrm{O}_{3}$ catalysts: Optimization and stability. Int. J. Hydrogen Energy 2017, 42, 12220-12235. [CrossRef]

181. Hou, X.; Qing, S.; Liu, Y.; Li, L.; Gao, Z.; Qin, Y. Enhancing effect of MgO modification of Cu-Al spinel oxide catalyst for methanol steam reforming. Int. J. Hydrogen Energy 2020, 45, 477-489. [CrossRef]

182. Liu, X.; Toyir, J.; De La Piscina, P.R.; Homs, N. Hydrogen production from methanol steam reforming over $\mathrm{Al}_{2} \mathrm{O}_{3}$ - and $\mathrm{ZrO}_{2}$ - modified $\mathrm{CuOZnOGa} 2 \mathrm{O}_{3}$ catalysts. Int. J. Hydrogen Energy 2017, 42, 13704-13711. [CrossRef]

183. Mohtashami, Y.; Taghizadeh, M. Performance of the $\mathrm{ZrO} 2$ promoted $\mathrm{Cu} \mathrm{ZnO}$ catalyst supported on acetic acid-treated MCM-41 in methanol steam reforming. Int. J. Hydrogen Energy 2019, 44, 5725-5738. [CrossRef]

184. Lu, J.; Li, X.; He, S.; Han, C.; Wan, G.; Lei, Y.; Chen, R.; Liu, P.; Chen, K.; Zhang, L.; et al. Hydrogen production via methanol steam reforming over Ni-based catalysts: Influences of Lanthanum (La) addition and supports. Int. J. Hydrogen Energy 2017, 42, 3647-3657. [CrossRef]

185. Azenha, C.; Mateos-Pedrero, C.; Queirós, S.; Concepción, P.; Mendes, A. Innovative $\mathrm{ZrO}_{2}$-supported CuPd catalysts for the selective production of hydrogen from methanol steam reforming. Appl. Catal. B Environ. 2017, 203, 400-407. [CrossRef]

186. Liu, D.; Men, Y.; Wang, J.; Kolb, G.; Liu, X.; Wang, Y.; Sun, Q. Highly active and durable $\mathrm{Pt} / \mathrm{In}_{2} \mathrm{O}_{3} / \mathrm{Al}_{2} \mathrm{O}_{3}$ catalysts in methanol steam reforming. Int. J. Hydrogen Energy 2016, 41, 21990-21999. [CrossRef]

187. Martinelli, M.; Jacobs, G.; Graham, U.; Crocker, M. Methanol Steam Reforming: Na Doping of Pt/YSZ Provides Fine Tuning of Selectivity. Catalysts 2017, 7, 148. [CrossRef] 
188. Zhang, R.; Huang, C.; Zong, L.; Lu, K.; Wang, X.; Cai, J. Hydrogen Production from Methanol Steam Reforming over $\mathrm{TiO}_{2}$ and $\mathrm{CeO}_{2}$ Pillared Clay Supported Au Catalysts. Appl. Sci. 2018, 8, 176. [CrossRef]

189. Lytkina, A.A.; Orekhova, N.V.; Ermilova, M.; Yaroslavtsev, A.B. The influence of the support composition and structure $\left(\mathrm{M}_{X} \mathrm{Zr}_{1-\mathrm{X}} \mathrm{O}_{2-\delta}\right)$ of bimetallic catalysts on the activity in methanol steam reforming. Int. J. Hydrogen Energy 2018, 43, 198-207. [CrossRef]

190. Lu, P.-J.; Cai, F.-F.; Zhang, J.; Liu, Y.; Sun, Y.-H. Hydrogen production from methanol steam reforming over B-modified CuZnAlO catalysts. J. Fuel Chem. Technol. 2019, 47, 791-798. [CrossRef]

191. Maiti, S.; Das, D.; Pal, K.; Llorca, J.; Soler, L.; Colussi, S.; Trovarelli, A.; Priolkar, K.R.; Sarode, P.; Asakura, K.; et al. Methanol steam reforming behavior of sol-gel synthesized nanodimensional $\mathrm{Cu}_{\mathrm{x}} \mathrm{Fe}_{1-\mathrm{x}} \mathrm{Al}_{2} \mathrm{O}_{4}$ hercynites. Appl. Catal. A Gen. 2019, 570, 73-83. [CrossRef]

192. Song, Q.; Men, Y.; Wang, J.; Liu, S.; Chai, S.; An, W.; Wang, K.; Li, Y.; Tang, Y. Methanol steam reforming for hydrogen production over ternary composite ZnyCe1Zr9Ox catalysts. Int. J. Hydrogen Energy 2020, 45, 9592-9602. [CrossRef]

193. Mateos-Pedrero, C.; Silva, H.; Tanaka, D.P.; Liguori, S.; Iulianelli, A.; Basile, A.; Mendes, A. CuO/ZnO catalysts for methanol steam reforming: The role of the support polarity ratio and surface area. Appl. Catal. B Environ. 2015, 174, 67-76. [CrossRef]

194. Kim, S.; Yun, S.-W.; Lee, B.; Heo, J.; Kim, K.; Kim, Y.-T.; Lim, H. Steam reforming of methanol for ultra-pure $\mathrm{H}_{2}$ production in a membrane reactor: Techno-economic analysis. Int. J. Hydrogen Energy 2019, 44, 2330-2339. [CrossRef]

195. Köpfle, N.; Mayr, L.; Schmidmair, D.; Bernardi, J.; Knop-Gericke, A.; Hävecker, M.; Klötzer, B.; Penner, S. A Comparative Discussion of the Catalytic Activity and $\mathrm{CO}_{2}$-Selectivity of $\mathrm{Cu}-\mathrm{Zr}$ and Pd-Zr (Intermetallic) Compounds in Methanol Steam Reforming. Catalysts 2017, 7, 53. [CrossRef]

196. Zhou, W.; Ke, Y.; Pei, P.; Yu, W.; Chu, X.; Li, S.; Yang, K. Hydrogen production from cylindrical methanol steam reforming microreactor with porous $\mathrm{Cu}-\mathrm{Al}$ fiber sintered felt. Int. J. Hydrogen Energy 2018, 43, 3643-3654. [CrossRef]

197. Ke, Y.; Zhou, W.; Chu, X.; Yuan, D.; Wan, S.; Yu, W.; Liu, Y. Porous copper fiber sintered felts with surface microchannels for methanol steam reforming microreactor for hydrogen production. Int. J. Hydrogen Energy 2019, 44, 5755-5765. [CrossRef]

198. Tajrishi, O.Z.; Taghizadeh, M.; Kiadehi, A.D. Methanol steam reforming in a microchannel reactor by Zn-, Ce- and Zr- modified mesoporous Cu/SBA-15 nanocatalyst. Int. J. Hydrogen Energy 2018, 43, 14103-14120. [CrossRef]

199. Liu, Y.; Zhou, W.; Lin, Y.; Chen, L.; Chu, X.; Zheng, T.; Wan, S.; Lin, J. Novel copper foam with ordered hole arrays as catalyst support for methanol steam reforming microreactor. Appl. Energy 2019, 246, 24-37. [CrossRef]

200. Sarafraz, M.; Safaei, M.R.; Goodarzi, M.; Arjomandi, M. Reforming of methanol with steam in a micro-reactor with $\mathrm{Cu}-\mathrm{SiO}_{2}$ porous catalyst. Int. J. Hydrogen Energy 2019, 44, 19628-19639. [CrossRef]

201. Shanmugam, V.; Neuberg, S.; Zapf, R.; Pennemann, H.; Kolb, G. Hydrogen production over highly active Pt based catalyst coatings by steam reforming of methanol: Effect of support and co-support. Int. J. Hydrogen Energy 2020, 45, 1658-1670. [CrossRef]

202. Zhuang, X.; Xia, X.; Xu, X.; Li, L. Experimental investigation on hydrogen production by methanol steam reforming in a novel multichannel micro packed bed reformer. Int. J. Hydrogen Energy 2020, 45, 11024-11034. [CrossRef]

203. Zhu, J.; Araya, S.S.; Cui, X.; Sahlin, S.L.; Kær, S.K. Modeling and design of a multi-tubular packed-bed reactor for methanol steam reforming over a $\mathrm{Cu} / \mathrm{ZnO} / \mathrm{Al}_{2} \mathrm{O}_{3}$ catalyst. Energies 2020, 13, 610. [CrossRef]

204. Ke, C.; Lin, Z. Density functional theory based micro-and macro-kinetic studies of Ni-catalyzed methanol steam reforming. Catalysts 2020, 10, 349. [CrossRef]

205. Wang, G.; Wang, F.; Chen, B. Performance study on methanol steam reforming rib micro-reactor with waste heat recovery. Energies 2020, 13, 1564. [CrossRef]

206. Udani, P.P.C.; Gunawardana, P.V.D.S.; Lee, H.C.; Kim, D.H. Steam reforming and oxidative steam reforming of methanol over $\mathrm{CuO}-\mathrm{CeO}_{2}$ catalysts. Int. J. Hydrogen Energy 2009, 34, 7648-7655. [CrossRef]

207. Kim, J.H.; Jang, Y.S.; Kim, D.H. Multiple steady states in the oxidative steam reforming of methanol. Chem. Eng. J. 2018, 338, 752-763. [CrossRef] 
208. Turco, M.; Bagnasco, G.; Costantino, U.; Marmottini, F.; Montanari, T.; Ramis, G.; Busca, G. Production of hydrogen from oxidative steam reforming of methanol: I. Preparation and characterization of $\mathrm{Cu} / \mathrm{ZnO} / \mathrm{Al}_{2} \mathrm{O}_{3}$ catalysts from a hydrotalcite-like LDH precursor. J. Catal. 2004, 228, 43-55. [CrossRef]

209. Pojanavaraphan, C.; Satitthai, U.; Luengnaruemitchai, A.; Gulari, E. Activity and stability of $\mathrm{Au} / \mathrm{CeO}_{2}-\mathrm{Fe}_{2} \mathrm{O}_{3}$ catalysts for the hydrogen production via oxidative steam reforming of methanol. J. Ind. Eng. Chem. 2015, 22, 41-52. [CrossRef]

210. Pérez-Hernández, R.; Gutiérrez-Martínez, A.; Espinosa-Pesqueira, M.; Estanislao, M.L.; Palacios, J. Effect of the bimetallic $\mathrm{Ni} / \mathrm{Cu}$ loading on the $\mathrm{ZrO}_{2}$ support for $\mathrm{H}_{2}$ production in the autothermal steam reforming of methanol. Catal. Today 2015, 250, 166-172. [CrossRef]

211. Mierczynski, P.; Vasilev, K.; Mierczynska, A.; Maniukiewicz, W.; Ciesielski, R.; Rogowski, J.; Szynkowska, I.M.; Trifonov, A.Y.; Dubkov, S.V.; Gromov, D.G. The effect of gold on modern bimetallic Au-Cu/MWCNT catalysts for the oxy-steam reforming of methanol. Catal. Sci. Technol. 2016, 6, 4168-4183. [CrossRef]

212. Jampa, S.; Jamieson, A.M.; Chaisuwan, T.; Luengnaruemitchai, A.; Wongkasemjit, S. Achievement of hydrogen production from autothermal steam reforming of methanol over $\mathrm{Cu}$-loaded mesoporous $\mathrm{CeO} 2$ and $\mathrm{Cu}$-loaded mesoporous $\mathrm{CeO}_{2}-\mathrm{ZrO}_{2}$ catalysts. Int. J. Hydrogen Energy 2017, 42, 15073-15084. [CrossRef]

213. Pu, Y.-C.; Li, S.-R.; Yan, S.; Huang, X.; Wang, D.; Ye, Y.-Y.; Liu, Y.-Q. An improved Cu/ZnO catalyst promoted by $\mathrm{Sc}_{2} \mathrm{O}_{3}$ for hydrogen production from methanol reforming. Fuel 2019, 241, 607-615. [CrossRef]

214. Adeniyi, A.G.; Ighalo, J.O. A review of steam reforming of glycerol. Chem. Pap. 2019, 73, $2619-2635$. [CrossRef]

215. Roslan, N.A.; Abidin, S.Z.; Ideris, A.; Vo, D.-V.N. A review on glycerol reforming processes over Ni-based catalyst for hydrogen and syngas productions. Int. J. Hydrogen Energy 2019. [CrossRef]

216. Bulutoglu, P.S.; Say, Z.; Bac, S.; Ozensoy, E.; Avci, A.K. Dry reforming of glycerol over Rh-based ceria and zirconia catalysts: New insights on catalyst activity and stability. Appl. Catal. A Gen. 2018, 564, 157-171. [CrossRef]

217. Bagnato, G.; Iulianelli, A.; Sanna, A.; Basile, A. Glycerol Production and Transformation: A Critical Review with Particular Emphasis on Glycerol Reforming Reaction for Producing Hydrogen in Conventional and Membrane Reactors. Membranes 2017, 7, 17. [CrossRef]

218. Silva, J.; Soria, M.A.; Madeira, L.M. Challenges and strategies for optimization of glycerol steam reforming process. Renew. Sustain. Energy Rev. 2015, 42, 1187-1213. [CrossRef]

219. Schwengber, C.A.; Alves, H.J.; Schaffner, R.A.; Silva, F.A.; Sequinel, R.; Bach, V.R.; Ferracin, R.J. Overview of glycerol reforming for hydrogen production. Renew. Sustain. Energy Rev. 2016, 58, 259-266. [CrossRef]

220. Seadira, T.; Sadanandam, G.; Ntho, T.A.; Lu, X.; Masuku, C.M.; Scurrell, M. Hydrogen production from glycerol reforming: Conventional and green production. Rev. Chem. Eng. 2018, 34, 695-726. [CrossRef]

221. Charisiou, N.; Siakavelas, G.; Papageridis, K.; Baklavaridis, A.; Tzounis, L.; Polychronopoulou, K.; Goula, M. Hydrogen production via the glycerol steam reforming reaction over nickel supported on alumina and lanthana-alumina catalysts. Int. J. Hydrogen Energy 2017, 42, 13039-13060. [CrossRef]

222. Gallegos-Suárez, E.; Guerrero-Ruiz, A.; Rodríguez-Ramos, I. Efficient hydrogen production from glycerol by steam reforming with carbon supported ruthenium catalysts. Carbon 2016, 96, 578-587. [CrossRef]

223. Papageridis, K.; Siakavelas, G.; Charisiou, N.D.; Avraam, D.; Tzounis, L.; Kousi, K.; Goula, M. Comparative study of $\mathrm{Ni}, \mathrm{Co}, \mathrm{Cu}$ supported on $\gamma$-alumina catalysts for hydrogen production via the glycerol steam reforming reaction. Fuel Process. Technol. 2016, 152, 156-175. [CrossRef]

224. Charisiou, N.D.; Papageridis, K.; Siakavelas, G.; Tzounis, L.; Kousi, K.; Baker, M.A.; Hinder, S.J.; Sebastian, V.; Polychronopoulou, K.; Goula, M. Glycerol Steam Reforming for Hydrogen Production over Nickel Supported on Alumina, Zirconia and Silica Catalysts. Top. Catal. 2017, 60, 1226-1250. [CrossRef]

225. Charisiou, N.; Siakavelas, G.; Tzounis, L.; Dou, B.; Sebastian, V.; Hinder, S.; Baker, M.; Polychronopoulou, K.; Goula, M. Ni/ $\mathrm{Y}_{2} \mathrm{O}_{3}-\mathrm{ZrO}_{2}$ catalyst for hydrogen production through the glycerol steam reforming reaction. Int. J. Hydrogen Energy 2020, 45, 10442-10460. [CrossRef]

226. Senseni, A.Z.; Rezaei, M.; Meshkani, F. Glycerol steam reforming over noble metal nanocatalysts. Chem. Eng. Res. Des. 2017, 123, 360-366. [CrossRef]

227. Silva, J.; Ribeiro, L.; Órfão, J.; Soria, M.A.; Madeira, L.M. Low temperature glycerol steam reforming over a Rh-based catalyst combined with oxidative regeneration. Int. J. Hydrogen Energy 2019, 44, 2461-2473. [CrossRef] 
228. Jiang, B.; Zhang, C.; Wang, K.; Dou, B.; Song, Y.; Chen, H.; Xu, Y. Highly dispersed Ni/montmorillonite catalyst for glycerol steam reforming: Effect of Ni loading and calcination temperature. Appl. Therm. Eng. 2016, 109, 99-108. [CrossRef]

229. Bepari, S.; Pradhan, N.C.; Dalai, A.K. Selective production of hydrogen by steam reforming of glycerol over Ni/Fly ash catalyst. Catal. Today 2017, 291, 36-46. [CrossRef]

230. Wang, Y.; Chen, M.; Yang, Z.; Liang, T.; Liu, S.; Zhou, Z.; Li, X. Bimetallic Ni-M (M = Co, Cu and Zn) supported on attapulgite as catalysts for hydrogen production from glycerol steam reforming. Appl. Catal. A Gen. 2018, 550, 214-227. [CrossRef]

231. Carrero, A.; Calles, J.; García-Moreno, L.; Vizcaíno, A. Production of Renewable Hydrogen from Glycerol Steam Reforming over Bimetallic Ni-(Cu,Co,Cr) Catalysts Supported on SBA-15 Silica. Catalysts 2017, 7, 55. [CrossRef]

232. Wang, R.; Liu, S.; Liu, S.; Li, X.; Zhang, Y.; Xie, C.; Zhou, S.; Qiu, Y.; Luo, S.; Jing, F.; et al. Glycerol steam reforming for hydrogen production over bimetallic MNi/CNTs ( $\mathrm{M} \mathrm{Co}, \mathrm{Cu}$ and Fe) catalysts. Catal. Today 2019. [CrossRef]

233. Tavanarad, M.; Meshkani, F.; Rezaei, M. Production of syngas via glycerol dry reforming on Ni catalysts supported on mesoporous nanocrystalline $\mathrm{Al}_{2} \mathrm{O}_{3}$. J. CO2 Util. 2018, 24, 298-305. [CrossRef]

234. Bac, S.; Say, Z.; Koçak, Y.; Ercan, K.E.; Harfouche, M.; Ozensoy, E.; Avci, A.K. Exceptionally active and stable catalysts for $\mathrm{CO}_{2}$ reforming of glycerol to syngas. Appl. Catal. B Environ. 2019, 256, 117808. [CrossRef]

235. Larimi, A.; Kazemeini, M.; Khorasheh, F. Aqueous phase reforming of glycerol using highly active and stable $\mathrm{Pt}_{0.05} \mathrm{Ce}_{\mathrm{x}} \mathrm{Zr}_{0.95-\mathrm{x}} \mathrm{O}_{2}$ ternary solid solution catalysts. Appl. Catal. A Gen. 2016, 523, 230-240. [CrossRef]

236. Espinosa-Moreno, F.; Balla, P.; Shen, W.; Chavarría-Hernández, J.C.; Ruiz-Gómez, M.; Tlecuitl-Beristain, S. Ir-Based Bimetallic Catalysts for Hydrogen Production through Glycerol Aqueous-Phase Reforming. Catalysts 2018, 8, 613. [CrossRef]

237. Kousi, K.; Chourdakis, N.; Matralis, H.; Kontarides, D.; Papadopoulou, C.; Verykios, X. Glycerol steam reforming over modified Ni-based catalysts. Appl. Catal. A Gen. 2016, 518, 129-141. [CrossRef]

238. Cheng, C.-K.; Foo, S.Y.; Adesina, A.A. Glycerol Steam Reforming over Bimetallic Co-Ni/Al $\mathrm{O}_{3}$. Ind. Eng. Chem. Res. 2010, 49, 10804-10817. [CrossRef]

239. Zamzuri, N.H.; Mat, R.; Amin, N.A.S.; Talebian-Kiakalaieh, A. Hydrogen production from catalytic steam reforming of glycerol over various supported nickel catalysts. Int. J. Hydrogen Energy 2017, 42, 9087-9098. [CrossRef]

240. Bobadilla, L.; Penkova, A.; Alvarez, A.; Domínguez, M.; Romero-Sarria, F.; Centeno, M.A.; Odriozola, J.; Leal, M.I.D. Glycerol steam reforming on bimetallic $\mathrm{NiSn} / \mathrm{CeO}_{2}-\mathrm{MgO}-\mathrm{Al}_{2} \mathrm{O}_{3}$ catalysts: Influence of the support, reaction parameters and deactivation/regeneration processes. Appl. Catal. A Gen. 2015, 492, 38-47. [CrossRef]

241. Charisiou, N.; Papageridis, K.; Tzounis, L.; Sebastian, V.; Hinder, S.; Baker, M.; Alketbi, M.; Polychronopoulou, K.; Goula, M. Ni supported on $\mathrm{CaO}-\mathrm{MgO}-\mathrm{Al}_{2} \mathrm{O}_{3}$ as a highly selective and stable catalyst for $\mathrm{H}_{2}$ production via the glycerol steam reforming reaction. Int. J. Hydrogen Energy 2019, 44, 256-273. [CrossRef]

242. Menezes, J.P.D.S.; Duarte, K.R.; Manfro, R.L.; Souza, M.M.V.M. Effect of niobia addition on cobalt catalysts supported on alumina for glycerol steam reforming. Renew. Energy 2020, 148, 864-875. [CrossRef]

243. Arif, N.N.M.; Vo, D.-V.N.; Azizan, M.T.; Abidin, S.Z. Carbon Dioxide Dry Reforming of Glycerol for Hydrogen Production using $\mathrm{Ni} / \mathrm{ZrO}_{2}$ and $\mathrm{Ni} / \mathrm{CaO}$ as Catalysts. Bull. Chem. React. Eng. Catal. 2016, 11, 200. [CrossRef]

244. Lee, H.-J.; Shin, G.S.; Kim, Y.-C. Characterization of supported Ni catalysts for aqueous-phase reforming of glycerol. Korean J. Chem. Eng. 2015, 32, 1267-1272. [CrossRef]

245. Yancheshmeh, M.S.; Sahraei, O.A.; Aissaoui, M.; Iliuta, M.C. A novel synthesis of $\mathrm{NiAl}_{2} \mathrm{O}_{4}$ spinel from a Ni-Al mixed-metal alkoxide as a highly efficient catalyst for hydrogen production by glycerol steam reforming. Appl. Catal. B Environ. 2020, 265, 118535. [CrossRef]

246. Lima, D.S.; Calgaro, C.O.; Perez-Lopez, O.W. Hydrogen production by glycerol steam reforming over Ni based catalysts prepared by different methods. Biomass Bioenergy 2019, 130, 105358. [CrossRef]

247. Dieuzeide, M.; Laborde, M.; Amadeo, N.; Cannilla, C.; Bonura, G.; Frusteri, F. Hydrogen production by glycerol steam reforming: How $\mathrm{Mg}$ doping affects the catalytic behaviour of $\mathrm{Ni} / \mathrm{Al}_{2} \mathrm{O}_{3}$ catalysts. Int. J. Hydrogen Energy 2016, 41, 157-166. [CrossRef] 
248. Demsash, H.; Mohan, R. Steam reforming of glycerol to hydrogen over ceria promoted nickel-alumina catalysts. Int. J. Hydrogen Energy 2016, 41, 22732-22742. [CrossRef]

249. Carrero, A.; Vizcaíno, A.; Calles, J.; García-Moreno, L. Hydrogen production through glycerol steam reforming using Co catalysts supported on SBA-15 doped with Zr, Ce and La. J. Energy Chem. 2017, 26, 42-48. [CrossRef]

250. Veiga, S.; Bussi, J. Steam reforming of crude glycerol over nickel supported on activated carbon. Energy Convers. Manag. 2017, 141, 79-84. [CrossRef]

251. Sahraei, O.A.Z.; Larachi, F.; Abatzoglou, N.; Iliuta, M. Hydrogen production by glycerol steam reforming catalyzed by Ni-promoted Fe/Mg-bearing metallurgical wastes. Appl. Catal. B Environ. 2017, 219, 183-193. [CrossRef]

252. Dobosz, J.; Cichy, M.; Zawadzki, M.; Borowiecki, T. Glycerol steam reforming over calcium hydroxyapatite supported cobalt and cobalt-cerium catalysts. J. Energy Chem. 2018, 27, 404-412. [CrossRef]

253. Siew, K.W.; Lee, H.C.; Gimbun, J.; Chin, S.Y.; Khan, M.R.; Taufiq-Yap, Y.H.; Cheng, C.-K. Syngas production from glycerol-dry $\left(\mathrm{CO}_{2}\right)$ reforming over La-promoted $\mathrm{Ni} / \mathrm{Al}_{2} \mathrm{O}_{3}$ catalyst. Renew. Energy 2015, 74, 441-447. [CrossRef]

254. Reynoso, A.; Iriarte-Velasco, U.; Gutiérrez-Ortiz, M.A.; Ayastuy, J. Highly stable $\mathrm{Pt} / \mathrm{CoAl}_{2} \mathrm{O}_{4}$ catalysts in Aqueous-Phase Reforming of glycerol. Catal. Today 2020. [CrossRef]

255. Pendem, C.; Sarkar, B.; Siddiqui, N.; Konathala, L.N.S.K.; Baskar, C.; Bal, R. K-Promoted Pt-Hydrotalcite Catalyst for Production of $\mathrm{H}_{2}$ by Aqueous Phase Reforming of Glycerol. ACS Sustain. Chem. Eng. 2017, 6, 2122-2131. [CrossRef]

256. Wang, M.; Au, C.T.; Lai, S.Y. H2 production from catalytic steam reforming of n-propanol over ruthenium and ruthenium-nickel bimetallic catalysts supported on ceria-alumina oxides with different ceria loadings. Int. J. Hydrogen Energy 2015, 40, 13926-13935. [CrossRef]

257. Patel, R.; Patel, S. Process development for bio-butanol steam reforming for PEMFC application. Int. J. Eng. Technol. 2018, 7, 110-112. [CrossRef]

258. Patel, R.; Patel, S. Effect of operating conditions on hydrogen production in butanol reforming: A review. Int. Conf. Multidiscip. Res. Pract. 2015, 145-150.

259. Patel, R.; Patel, S. Renewable hydrogen production from butanol: A review. Clean Energy 2017, 1, 90-101. [CrossRef]

260. Harju, H.; Lehtonen, J.; Lefferts, L. Steam reforming of $\mathrm{n}$-butanol over $\mathrm{Rh} / \mathrm{ZrO} \mathrm{C}_{2}$ catalyst: Role of 1-butene and butyraldehyde. Appl. Catal. B Environ. 2016, 182, 33-46. [CrossRef]

261. Dhanala, V.; Maity, S.K.; Shee, D. Oxidative steam reforming of isobutanol over $\mathrm{Ni} / \gamma-\mathrm{Al}_{2} \mathrm{O}_{3}$ catalysts: A comparison with thermodynamic equilibrium analysis. J. Ind. Eng. Chem. 2015, 27, 153-163. [CrossRef]

262. Wang, Y.; Yang, X.; Wang, Y. Catalytic performance of mesoporous MgO supported Ni catalyst in steam reforming of model compounds of biomass fermentation for hydrogen production. Int. J. Hydrogen Energy 2016, 41, 17846-17857. [CrossRef]

263. Yadav, A.K.; Vaidya, P.D. Renewable hydrogen production by steam reforming of butanol over multiwalled carbon nanotube-supported catalysts. Int. J. Hydrogen Energy 2019, 44, 30014-30023. [CrossRef]

264. Harju, H.; Lehtonen, J.; Lefferts, L. Steam- and autothermal-reforming of n-butanol over $\mathrm{Rh} / \mathrm{ZrO}_{2}$ catalyst. Catal. Today 2015, 244, 47-57. [CrossRef]

265. Harju, H.; Pipitone, G.; Lefferts, L. Influence of the catalyst particle size on the aqueous phase reforming of n-butanol over $\mathrm{Rh} / \mathrm{ZrO}_{2}$. Front. Chem. 2020, 8, 17. [CrossRef]

266. Yadav, A.K.; Vaidya, P.D. A study on the efficacy of noble metal catalysts for butanol steam reforming. Int. J. Hydrogen Energy 2019, 44, 25575-25588. [CrossRef]

267. Bizkarra, K.; Barrio, V.; Yartu, A.; Requies, J.M.; Arias, P.L.; Cambra, J.F. Hydrogen production from n-butanol over alumina and modified alumina nickel catalysts. Int. J. Hydrogen Energy 2015, 40, 5272-5280. [CrossRef]

268. Lobo, R.; Marshall, C.L.; Dietrich, P.J.; Ribeiro, F.H.; Akatay, C.; Stach, E.A.; Mane, A.; Lei, Y.; Elam, J.; Miller, J.T. Understanding the chemistry of $\mathrm{H}_{2}$ production for 1-propanol reforming: Pathway and support modification effects. ACS Catal. 2012, 2, 2316-2326. [CrossRef]

269. Li, Y.; Zhang, L.; Zhang, Z.; Liu, Q.; Zhang, S.; Liu, Q.; Hu, G.; Wang, Y.; Hu, X. Steam reforming of the alcohols with varied structures: Impacts of acidic sites of Ni catalysts on coking. Appl. Catal. A Gen. 2019, 584, 117162. [CrossRef] 
270. Shejale, A.D.; Yadav, G.D. Noble metal promoted $\mathrm{Ni}-\mathrm{Cu} / \mathrm{La}_{2} \mathrm{O}_{3}-\mathrm{MgO}$ catalyst for renewable and enhanced hydrogen production via steam reforming of bio-based n-butanol: Effect of promotion with $\mathrm{Pt}, \mathrm{Ru}$ and $\mathrm{Pd}$ on catalytic activity and selectivity. Clean Technol. Environ. Policy 2019, 21, 1323-1339. [CrossRef]

271. Sharma, M.P.; Akyurtlu, J.F.; Akyurtlu, A. Autothermal reforming of isobutanol over promoted nickel xerogel catalysts for hydrogen production. Int. J. Hydrogen Energy 2015, 40, 13368-13378. [CrossRef]

272. Lei, Y.; Lee, S.; Low, K.-B.; Marshall, C.L.; Elam, J.W. Combining Electronic and Geometric Effects of ZnO-Promoted Pt Nanocatalysts for Aqueous Phase Reforming of 1-Propanol. ACS Catal. 2016, 6, 3457-3460. [CrossRef]

(C) 2020 by the authors. Licensee MDPI, Basel, Switzerland. This article is an open access article distributed under the terms and conditions of the Creative Commons Attribution (CC BY) license (http://creativecommons.org/licenses/by/4.0/). 